\title{
On the Grammar and Semantics of Sentence Accents
}



ON THE GRAMMAR AND SEMANTICS OF SENTENCE ACCENTS 



\section{On the Grammar and Semantics of Sentence Accents}

\section{PROEFSCHRIFT}

ter verkrijging van de graad van doctor in de letteren aan de Katholieke Universiteit te Nijmegen, op gezag van de Rector Magnificus Prof. Dr. J.H.G.I. Giesbers, volgens besluit van het College van Dekanen in het openbaar te verdedigen op maandag 25 juni 1984 des namiddags te 2.00 uur precies

door

CAROLUS HENRICUS MARIA GUSSENHOVEN geboren te Amsterdam 
Promotores: Prof. dr. F.G.A.M. Aarts

Prof. dr. W.H. Vieregge

ISBN 9067650226

1984 Forıs Publıcatıons - Dordrecht

No part of this publication may be reproduced or transmitted in any form or by any means, electronic or mechanical, including photocopy, recording, or any information storage and retrieval system, without permission from the copynght owner

Printed in the Netherlands by ICG Prntıng, Dordrecht 


\section{Contents}

Preface $\ldots \ldots \ldots \ldots \ldots \ldots \ldots \ldots \ldots \ldots \ldots \ldots \ldots \ldots \ldots \ldots$, vii

Introduction $\ldots \ldots \ldots \ldots \ldots \ldots \ldots \ldots \ldots \ldots \ldots \ldots \ldots \ldots \ldots, 1$

1. Focus, mode and the nucleus $\ldots \ldots \ldots \ldots \ldots \ldots \ldots \ldots \ldots \ldots, 11$

2. From focus to sentence accent: A rule for the assignment of sentence accents in Dutch ............................. 63

3. The intonation of 'George and Mildred': Post-nuclear generalisations 93

4. Testing the reality of focus domains $\ldots \ldots \ldots \ldots \ldots \ldots \ldots \ldots \ldots 151$

5. Idiomaticity in sentence accent location in English and Dutch $\ldots 177$

6. A semantic analysis of the nuclear tones of English $\ldots \ldots \ldots \ldots 193$

7. A three-dimensional scaling of nine English tones $\ldots \ldots \ldots \ldots \ldots 267$

8. Stress shift and the nucleus $\ldots \ldots \ldots \ldots \ldots \ldots \ldots \ldots \ldots \ldots \ldots, 291$

9. Stress shift in Dutch as a rhetorical device $\ldots \ldots \ldots \ldots \ldots \ldots . \ldots 33$

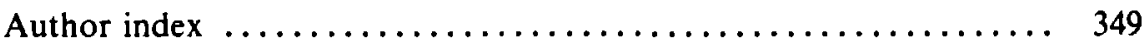

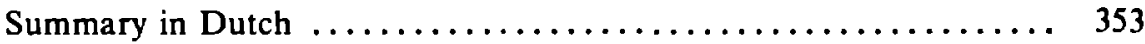

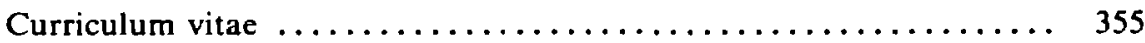



The present volume could not have been produced without a two-year grant from the Research Pool of the University of Nijmegen and without the excellent services of Hans Verhulst, who took over my teaching duties during the period covered by the grant. I thank the staff of the Department of Linguistics of the University of Edmburgh, above all Gill Brown, for providing me with everything a research student can want during the first year of the project: an office, laboratory faclities, access to courses, guidance, and such light leaching duties as make even someone whose research does not progress feel tolerably useful. I thank Bob ladd for the stumulating coffee-room conversations during the 1981 PILEI Linguistic Institute at Cornel, and for the encouragement and help he has given me ever since. I thank all my colleagues at the Instituut Engels-Amerikaans for their support and help in various ways, and for treading soltly on my teaching duties when the grant had run out, as well as those in the inversity of $N i$ megen who kindly offered their expert help when I called on them I thank Theo van den Heuvel and Frans van der Heijden for their patience with my problems to get the text-editing program to do what I wanted it to do, and the student assistints lneke Brus, Margo van Eyck, Cis van Heertum and Annemoon van Hest for thejr help at varlous stages of the work.

Most of the articles in this volume appeared or will appear elsewhere: the first in Journal of Linguistics 1983, pp 377-417, the third in Intonation in Discourse, a volume edited by $C$. Johns-Lewis (London, Croom Helm, 1984), the fourth in Language and Speech 1983, pp 61-80, the seventh in Journal of Semantics 1983, pp 186-204, and the elghth in Linguisties 1983, pp 303-339. The second is a translation of a Dutch article that appeared in GLOT 1983, pp 131-155, while the sixth was distribuled by the Indiana Lniversity Linguistics Club in 1983. The ninth article will also appear in Linguistics These articles are here published in their original form Only minor editorial changes have been made, while references have been updated I thank all those involved for permission to publish copyright material here. 'The tifth article was written specially for this volume. 



\section{Introduction}

The nine papers collected in this volume are concerned with three central issues in the prosody of English and Dutch The first is that of the location of sentence accents, the second that of their realisation, and the third that of stress shift

In the case of the first two issues, the subject is approached in the awareness that (1) Intonational data should be seen as autonomous in the sense that dependence on segmental linguistic structure (syntax/lexis and segmental phonology) should have no place in the description, and (2) the descriptive task is not defined by the complex of situational and textual factors that must be assumed to account for the occurrence of intonational phenomena in utterances, but by the relation between linguistic options and surface forms By linguistic option 1 mean any semantic contrast that is encoded in linguistic form (where linguistic form naturally includes prosodic form)

Of these two points of departure, the first is primarly inspired by the bankruptcy of syntax-dependent descriptions of intonation, by now widely recognised (cf Cutler \& Isard 1980), and most forcefully expressed in Bolinger (1972) This is not to deny that there are many occasions on which statements can be made that couple the occurrence of a form in the segmental system with one in the prosodic system, either probabulistically or absolutely For example, subjects and objects are more likely to be accented than predicates $\mathrm{m}$ both Dutch and English Or, English tag questıons never have a fall-rise tone Or, If a main clause/relative clause combination has a downstepped contour, a relative pronoun who/which can always be replaced with that ( 1 e the relative clause is always restrictive) However, I belseve that such apparent 'dependencres' should be seen as interactions between syntax and prosody On the one hand, the two systems are sometumes umpinged upon by the same linguistic options On the other, conditions may obtain so as to motivate speakers to simultaneously employ two different options, one in the segmental component and the other in the prosodic component, causing partıcular prosodic and segmental surface facts frequently to go hand in hand It remains the case, however, that what should be accounted for is what effects linguistic options have on surface 
forms. Any interactions should then proceed from such an account as a matter of course.

The second point of departure was chosen in the realisation that prosodic structure is in fact rule-governed, comparable, indeed, to the way the segmental surface structure is. Sentence accents are where they are and their realisation is what it is because the linguistic options that are expressed in such aspects of surface form were addressed the way they were. Clearly, Schmerling (1976) was referring to a theory that accounts for the motivation for employing particular linguistic options, when she observed that no current theory is up to the task of clarifying why speakers may on occasion accent man in This is the man I was telling you about and on other occasions telling, for a linguistic theory can easily be constructed: one that says that in one case 'the man' is [+focus] and in the other 'was telling about'. The triviality of the relation between abstract option and concrete surface form in this particular case should not deceive us. In other cases the relation appears to be a lot less trivial (in the case of the difference between an 'eventive sentence' and a 'contingency sentence', say). Yet, again, we achieve no more than stating a relation between abstract options and surface forms, i.e. a statement of linguistic structure.

In dealing with the three issues mentioned at the beginning of this introduction, a variety of research methods has been used. Like many researchers, linguistic researchers can go in for two things: devising theories (i.e. linguistic descriptions) and testing them. With respect to the first activity, it can be observed that it is some time since linguists believed that inductive methods could be developed for discovering the structure of language. The notion went out of fashion with the demise in the late fifties of the discovery procedures for setting up phoneme systems proposed by American structuralist and Prague School linguists. In practice, exploratory research - which includes inventory-oriented description, exploratory investigations carried out with the help of instrumental procedures, as well as cogitation - is what the modern researcher takes recourse to. Clearly, choice of methodology is a non-issue here. The only thing that counts is the resultant theory and the way it stands up to the facts of life. In particular, there can be no argument that an experimental approach is in any way inherently preferable to what some might refer to as 'armchair linguistics'. Of course, this latter activity is not without its problems. As Schils has 1t, it creates a situation where 'the selfsame person is of ten the source of both theory and data', with the result that devising the theory becomes entangled with testing it: inspection of the data for the purpose of getting ideas 
about them may no longer be distinguishable from testing the ideas against the data (1983 10) Although this might in practice mean no more than that the progress of science can be very fast indeed, there is of course a genume danger here, which is that of bulding one's theory on 'streamlined' (or possibly even partly imaginary) data I have tried to guard against this potential methodological degeneration by seeing to it that most of the examples on which the arguments centre are real-hfe utterances In addition, the theoretical treatment is backed up by an exhaustive analysis of a 14,000-word corpus While we may thus hope to have bult our description on fact rather than on fancy, the second activity, that of testing the description, remains te be exercised Opinions may differ as to what constitutes a valid test in the case of linguistic descriptions Some prefer to apply theory-internal principles like evaluation measures, in combination with a demonstration of the theory's explanatory power, others may feel that in addition experimental evidence needs to be provided that corroborates the concepts and structures postulated Whle the cholce between these two approaches will in general be determined by the nature of the descriptive task, in the area of prosodic research, where intuitions about linguistic structure seem less accessible and where as a result erroneous opinion may more easily masquerade as insight, it would seem prudent to take the second approach For this reason, I have opted to resort to the methodology of the behavioural sciences at a number of points at which non-trivial, testable hypotheses could be formulated These concern, furst, a prediction made by the model for sentence accent assignment, second, the structure of the nuclear-tone paradigm, and, third, the rule of Rhetorical Retraction, a Dutch stress shift rule which was hypothesised to be sensitive to speech style The first two experinents, in particular, show that conventional behavioural methodology can be fruitfully applied to issues of linguistic theory In addition, we have been able to apply this methodology in a very simple way to shed light on an issue about which considerable confusion existed in the introspective literature, that of the question of the 'nucleus' or 'tonic' of intonation contours It is in this sense that this volume provides an integration of different methods of linguistic research ${ }^{1}$

In the first two papers, Focus, mode and the nucleus and From focus to sentence accent. A rule for the assignment of sentence accents in Dutch, the linguistic options that underlie the occurrence and location of sentence accents are presented In addition to the traditional concept of 'newness' or 'focus', the options [ \pm eventive] and [ \pm definitional] are identified, leading to the three sentence types 'eventıve sentence', 'contlngency sentence' and 'definitional sentence' These data alone would be sufficient to demonstrate the untenablity 
of the proposition that prosodic structure can be derived from syntactic structure, since the former is unambiguously seen to depend on linguistic options in their own right, which only in some cases have an effect on syntactic surface forms As is shown in these papers, the relevant data in both English and Dutch can be accounted for by a very sumple rule (the Sentence Accent Assignment Rule, or SAAR), together with the constraint on focus domain formation in the case of [-eventive] sentences The rule thus very elegantly explains the fact that neither speakers of English nor speakers of Dutch experience any problems in assigning sentence accents in the sentences covered by the rule when speaking each other's languages A further option, [ \pm counterassertive], which in the literature had been shown to be relevant for the surface forms of a number of languages, appears to be of crucial importance for the position of sentence accents in polarity-focus sentences in English and Dutch These data, together with the data discussed in the fifth paper, Idiomaticity in sentence accent location in English and Dutch, leave no doubt that accent-assignment is indeed rule-governed Here, equivalent specifications of the linguistic options concerned lead to different accent locations in the two languages Therefore, any theory of accent assignment which couches the significance of sentence accents in terms of the salience of the words they occur on must founder in the face of these data

The rule-governed nature of sentence accent assignment is highlighted in a different way in the fourth paper, Testing the reality of focus domains, in which a prediction made by SAAR is put to the test Since SAAR puts no condition on the order of the constituents in a focus domain, it predicts that a single accent is present (on the second Argument) in both He kissed Mary and its Dutch equivalent $\mathrm{Hij}$ heeft Marietje gekust, if only the subject is kept outside the focus Equally, it predicts that both sentences could also figure in contexts in which also the Predicate is left outside the focus ( 1 e where Mary/Marietje has a contrastive accent, in pre-theoretical parlance) While this prediction is readly testable by means of a thought experiment in the case of Dutch (where the Predicate comes after the Argument), in the case of English this is not so easy, because the accent on the Argument makes it difficult to establish the prosodic status of the word before it, as testified by the disagreement in the literature on this point The results of the context-switching experiment show quite clearly that SAAR passes this test, and that therefore discussions about how sentences like He kissed Mary are pronounced differently depending on whether the new information is Mary or kissed Vary, appear to lack a factual basis There is another important consequence, and that is that the members of pairs 
like I kissed Mary and I kissed no one have different prosodic surface forms, if everything except the subject is included in the focus. This is because a non-lexical Argument like no one fails to form a focus-domain with a Predicate, and both kissed and no one are assigned an accent. This finding is particularly relevant at a time when a new type of syntax-derived prosodic structure, this time at the phonological phrase level, is being proposed, as in Selkirk (1980). The experiment demonstrates yet again the point made above: sentence accents are assigned by rule, but it is not syntactic structure that those rules take as input.

One of the constituents that SAAR refers to is the Condition. More so than the other two semantic constituents (Argument and Predicate), Conditions seem uncomfortably gelatinous when attempts are made to capture them in a definition. In general, they express the conditions under which the semantic function of the Predicate holds good for its Argument(s). The problem is that not all conditions count as Conditions for the purposes of SAAR: there are many that remain unaccented even when introduced for the first time. In the third paper, The intonation of 'George and Mildred': post-nuclear generalisations, an attempt is made to categorise such statutorily [-focus] expressions on the basis of corpus data. This analysis, which confirms to a large extent the findings of Firbas (1979), makes it clear that such expressions largely refer to what might be called the default parameters of any conversational setting: time, place, the relation between speaker and hearer, and certain relations holding within texts. In addition to contributing to a clearer definition of the constituents SAAR refers to, the analysis has yielded two important by-products. First, it renders it extremely implausible that there exists in English a compound fall-plus-rise tone, that curiously resistant strain of linguistic unit in the British tradition of intonation analysis, as the postulation of such tones, which are claimed to mark two syllables as accented, prevents the generalisations concerned from being made. Second, it makes it possible to refute Bing's (1979) claim that there are separate tonal paradigms serving two kinds of domain, with one kind of domain being served by accent-lending tones and the other by boundary tones. This refutation is based mainly on the consideration that the restrictions that would have to be stated on permissible sequences of tones from different paradigms would be precisely those that are captured by a single-tone/single-domain analysis.

The autonomous approach to intonational data and the concomitant requirement that these data should be described as forming part of the structure of language 
rather than in terms of the extra-linguistic circumstances that cause them to be there, is carried through in the analysis of the manifestations of sentence accents, i.e. the analysis of the melodic patterns that are encountered in sentence accent positions. While the conventionality of the relationship between linguistic options and surface forms has already become clear in the area of the location of sentence accents, it is - in view of the confusing array of approaches to the problem of the meaning of intonation contours - these melodic patterns that provide the more challenging testing-ground for our approach. The position has been graphically phrased by Ladd (1980: 144): '[ . .] neither writers like Pike and Liberman, nor critics of the abstract meaning approach, have ever really considered what seems to me to be the simplest hypothesis: that intonational meaning is like segmental meaning' (emphasis Ladd's). What this means is that the things sentence accents are made of are morphemes, and that since morphemes have a phonological form as well as a meaning, the task at hand is to define those forms and describe those meanings.

The important contributions in the sixth paper, A semantic analysis of the nuclear tones of English, are, first, the demonstration that a consistent relation between linguistic form and meaning exists in the case of nuclear tones as it does in the case of segmental morphemes, and, second, that the semantic framework is parallelled by a formal framework such that there is a straightforward relationship between semantic complexity and linguistic complexity. The plausibility of the analysis rests on two noteworthy features. One is its simplicity. While simplicity in linguistic description may on occasion raise justifiable doubts when the data described are complex, I have often had the reverse sensation when reading descriptions of intonation. In comparison with syntax, intonation appears to be a push-over in language acquisition (Crystal 1975), and we should expect this relative ease to be reflected in the structure of the data. The second feature is the predictive character of the analysis. While other analyses have confined themselves to listing the most frequently observed nuclear tones and imposing (part-)structure on them, our analysis postulates cross-cutting parameters, with the result that on the one hand tones that were treated as 'the same' in the literature could be revealed to consist of demonstrably different linguistic constructs, and on the other hand tones have been 'discovered' that may be extremely rare, but are nevertheless perfectly decodable by the native speaker. Clearly, this latter point provides strong evidence that the analysis captures the language user's competence. 
In view of the premisses of the theory of autosegmental phonology, it is not surprising that this theory can be successfully applied to intonation. By lodging the analysis in an autosegmental framework, I belıeve that a contribution has also been made to phonological theory.

In the seventh paper, A three-dimensional scaling of nine English tones, an attempt is made to provide experimental evidence for the analysis of nuclear tones If, as the analysis predicts, nuclear tones are in fact organised like cells in a matrıx, then that structure should be derivable from suitably elicited informant reactions to the tones. In the experiment, the arrangement of nine tones was put to the test, representing the incidences of three tonal modifications with three tone categories Although in broad terms, the hypothetical structure and the obtained structure turned out to be suggestively sumlar, there were certain unexpected differences It can be maintained, however, that the results confirm our analysis, since the deviations can be explained as an artefact of the phonetic simularity of certain (linguistically non-simular) tones. The difficulty with the experiment would appear to have been that it did not succeed in tapping the judges' knowledge of the semantic attributes of the tones to the complete exclusion of their appreciation of the phonetic attributes, causing a 'phonetic' artefact to be present in the scores

Stress shift is dealt with in two papers, number 8 , Stress shift and the nucleus, and number 9 , Stress shift in Dutch as a rhetorical device Both are manly about Dutch In the former paper, it is shown that Dutch has four stress shift rules that operate above the word level One of these, Non-nuclear Retraction, is of particular interest for the subject of sentence accents, by vurtue of the fact that (a) it is obligatory and (b) its domain spans a unit that would appear to be identical with the tone group of British descriptions As a result, the application of the rule in any of the words that are subject to it, serves as an unambiguous indication that that particular word does not carry the last accent of the tone group, and, conversely, non-application can unambiguously be taken to signal that the word does carry the last accent of the tone group In other words, the rule reveals what is the nucleus of the tone group This feature of Non-nuclear Retraction has been exploited in two ways First, it is established that what 't Hart \& Coller (1975) analyse as a non-accent-lending rise (the ' 2 ') is indeed non-accent-lending By showing how this pitch movement corresponds to the rise element of both the sumple fall-rise and the complex fall-plus-rise of British English intonation analyses, and argung that the intonational grammars of the two languages are very sumlar indeed, further 
support is provided for the position that there are no bi-nuclear tones in Eng Lsh Second, it is demonstrated that Currie's (1980, 1981) approach to establishing the nature of the tonic (our 'nucleus') by experimental means is misguided To counter her claun that valıd conclusions can be based on listeners' judgements on the presence or otherwise of theoretical constructs, an experiment was run to show that listeners' recognition of the tonic can be utterly erratıc, whle at the same time those listeners behave in a perfectly predictable and regular fashion when the task offered to them draws on their tacit knowledge of what that construct is intencled to capture More concretely, whle these listeners were not able to say what the nucleus was in a set of utterances presented to them, they appeared to be foolproof when application of Non-nuclear Retraction was elicited from them In more general terms, the experment demonstrates that 'analysis-by-vote' is not a viable tool of linguistic research

The ninth paper explores another of the four Dutch stress shift rules, Rhetorical Retraction The rule is of some interest because of its variable nature Just as variable segmental phonological rules are frequently exploited by speakers to signal extra-Inguistic information (most notably about their social affllations), so variable prosodic rules may be used for this purpose It is shown that the application of the rule is more frequent as the rhetoricity of the style is greater The effect would seem to tie in with the phenomenon of variable preposition placement in English (discussed in the fifth paper in this volume), and it seems not unreasonable to suggest that innovation in accentual patterns is somehow felt to rub off on the message This would explain Osselton's comment on the public nature of speech with 'preposition stressing' (cf Doodkorte \& Zandvoort 1962), and suggests that 'rhetoricity' is perhaps too specific a label to cover the pragmatic significance of Rhetorical Retraction in Dutch 


\section{Note}

1. I thank Erik Schils for his comments on an earlier draft of this paragraph.

\section{References}

Bing, J.M. (1979). Aspects of English prosody. Bloomington (Indiana): IULC.

Bolinger, D. (1972). 'Accent is predictable (if you're a mind-reader)'. LanEuage 48, 633-44.

Crystal, D. (1975). 'Non-segmental phonology and language acquisition'. In D. Crystal, The English tone of voice. London: Arnold. 125-58.

Currie, K.L. (1980). 'An initial "search for tonics"'. Language and Speech 23, 329-50.

Currie, K.L. (1981). 'Further experiments in the "search for tonics"'. Language and Speech 24, 1-28.

Cutler, A. \& S.D. Isard (1980). 'The production of prosody'. In B. Butterworth (ed), Language Production. Volume 1: Speech and talk. London: Academic Press. 245-69.

Doodkorte, A.C.J. \& R.W. Zandvoort (1962). 'On the stressing of prepositions'. English Studies 43, 93-101.

Firbas, J. (1979). 'Post-intonation-centre prosodic shade in the modern English clause'. In S. Greenbaum, G. Leech \& J. Svartvik (eds), Studies in English linguistics for Randolph Quirk. London: Longman. 125-33.

Hart, J. 't \& R. Collier (1975). 'Integrating different levels of intonation analysis'. Journal of Phonetics 3, 235-55.

Ladd, D.R. (1980). The structure of intonational meaning: Evidence from English. Bloomington: Indıana University Press.

Schils, E.D.J. (1983). Cohesion in the sentence: Its use in evaluating grammars. Dissertation Nijmegen.

Schmerling, S.F. (1976). Aspects of English sentence stress. Austin \& London: University of Texas Press.

Selkirk, E.O. (1980). 'On prosodic structure and its relation to syntactic structure'. Bloomington (Indiana): IULC. 



\section{Focus, mode and the nucleus}

Introduction

This article argues for the hypothesis that the location of the nucleus of the intonation contour is rule-governed The term 'nucleus' is taken to refer to what has elsewhere been discussed as the 'nuclear syllable' (Crystal 1969), 'tonic' (Halliday 1967a), 'sentence stress' (Schmerling 1976), '[1 stress]' (Chomsky \& Halle 1968), and 'Designated Terminal Element' (Liberman \& Prince 1977) (Ignoring certain differences of analysis, such as that between double-nucleus and single-nucleus interpretation of some contours) Drawing on the facts of English and Dutch, it does so by attempting to identify the linguistic options avalable to speakers that are relevant to the location of the nucleus The main argument hinges on the assumption that the chief functions of the location of the nucleus are (1) to signal the focus distribution of the sentence and (2) to signal whether the sentence is or is not meant as a counter-assertion, with the proviso that in many instances the location of the nucleus allows of more than one interpretation of one or both variables Section 1 devotes some discussion to the problem of predictablity, whle the concepts of 'focus' and 'normal stress' are explored in sections 2 to 4 Section 5 states the Sentence Accent Assignment Rule (SAAR), giving llustrations of its application In section 6, special attention is devoted to the pragmatic effects of SAAR in subject + predicate sentences Section 7 attempts to give a fuller def 1 nition of the constituents the rule refers to and puts a general condition on its application Section 8 introduces the variable mode, whle section 9 defines the problem of the location of the nucleus in sentences with minimal focus and introduces another accent assignment rule (PFR) A summary in the form of a set of propositions concludes the article I should like to point out that most of the examples in this article are attested, it is only the more pedestrian ones that have been made up for the purpose of llustrating certain points 


\subsection{PREDICTABILITY VS FREE CHOICE}

Linguistic theories usually contain sets of elements, and rules that operate on those elements to form well-formed sentences. ' When linguists require such theories to have predictive power, they usually mean that, given a choice from a set or sets of elements, the rules will generate a sentence, or a number of sentences, that look like $X$ rather than $Y .^{2}$ If $X$ is well-formed and $Y$ is ill-formed, the theory is fine; if either is not the case, it is not. This would seem a fairly uncontroversial, if simplified, interpretation of what linguistic theories are about. It is not, however, the interpretation that linguists dealing with intonation, or more particularly with the position of the nucleus, have typically adopted. Before roughly 1976, when discussions like those in Schmerling (1976) and Ladd (1980) began appearing, there were basically two kinds of linguists, as described below.

1. Those who held that, given a syntactically well-formed sentence, the position of the nucleus ought to follow from the lexico-syntactic choices that the speaker has made. (Invariably, allowance was made for semantic factors to account for what is known as 'contrastive stress'.) Chomsky \& Halle's Nuclear Stress Rule (1968) and the subsequent contributions to Language by those taking part in the debate about Bresnan's modification of the way the NSR ought to apply (Bresnan 1971, 1972, Lakoff 1972, Berman \& Szamosi 1972) fall in this category. Also Chafe's discussion of 'old' versus 'new' information in sentence-types (Chafe 1970) can be seen as belonging to this category in that the emphasis is laid on predicting the new-old distribution on the basis of syntactic structure. It is clear that this position does not correspond to the interpretation that was sketched above of what linguistic theories are like. Rather, those holding this view expected that, given a choice from sets of elements in one component of the linguistic system (syntax and lexis, or 'transitivity' in Halliday's term (1967b)), It was possible to predict the final result as produced by another component (phonology, in our case intonational phonology). To make the same point perhaps over-emphatically: it is rather as if phonologists were to try and predict the lexico-syntactic content of a sentence on the basis of a given intonation contour.

2. Those who held that human beings are endowed with a free will and enjoy In many societies - freedom of speech, and that therefore the position of the nucleus cannot be predicted. The nucleus is seen as a 'highlighter' of particular 
lexical elements and since speakers are perfectly free to highlight word A rather than word $B$ or word $C$, it is futile to go on trying to find rules that will predict which one they will choose. This is the view that Bolinger adopted (1972) and that Schmerling borrowed to account for a sizeable, recalcitrant part of her data. To give an example, Schmerling (1976: 67) pointed out that the difference between

(1) This is the MAN I was telling you about

and

(2) This is the man I was TELLIng you about

could not possibly be accounted for by any conceivable linguistic theory. Without wanting to argue about the validity of the observations made by Bolinger and Schmerling, it must be said that, this view, too, is incompatible with the above sketch of what linguistlc theories are supposed to be doing for us. In this vlew, the unexpressed demand that is put on the power of a theory is that, instead of predicting what a speaker's sentence will look like once he has made his choices from the sets of elements available to him, it will predict which cholces the speaker will make. Even in varlationist theory, which goes a long way towards predicting what speakers wlll do in what circumstances, such a demand would be unheard of. It is tantamount to wanting to predict what people are going to say.

The purpose of this article, then, is to identify the formal linguistic options available to speakers that are relevant to nucleus placement, and thereby define the boundary-line between this part of the linguistic system and pragmatics. That is, we do not pretend to be able to do more than predict the position of the nucleus given a choice [rom sets of linguistic primes. The reason for the choice is seen as falling outside the scope of the article proper, although it is not suggested that that choice is impervious to explanatory theories. Indeed, the question will be touched on at various points in the discussion below. It should be realised, however, that theories accounting for speakers' choices cannot be of the same 'mechanical' type as theories that take speakers' choices as their input. Rather, these will be probabilistic in nature, and be based on the fact that human beings are not only endowed with a free will, but are also reasonable. Thus, given the sentence in (3) 
the location of the nucleus on policeman will have to be accounted for in terms of some (underlying) linguistic structure which determines this position. A Bolingerian objection of the type 'the speaker could also have put the nucleus on up' is therefore as valid as saying that the speaker could also have used a passive construction, or a lexically specified subject, or assault instead of beat up, or copper instead of policeman, or whatever. Just as the latter 'objections' do not generally count as relevant linguistic arguments, so the former objection, which incidentally represents an emendation that affects the semantics of the sentence rather more drastically than any of the lexico-syntactic ones, should be seen as Irrelevant to the point at issue.

\subsection{Focus}

The first concept we will postulate is that of focus. Focus is seen as a binary variable which obligatorily marks all or part of a sentence as [+focus], 1.e. no sentence can be entirely [-focus]. In the relevant examples, [+focus] is usually symbolised as underscoring, although more explicit symbolisations will also be introduced. The concept of focus has been discussed in the literature as focus (Chomsky 1969, Jackendoff 1972, Quirk et al. 1972, Dik 1978, Ladd 1980), comment (Bloomfield 1933, Kraak 1970, Schmerling 1976), rheme (Prague School), new (information) (Halliday 1967b, Chafe 1970, 1976), while their counterparts are called, respectively, presupposition (Chomsky 1969, Jackendoff 1972, Quirk et al. 1972) or deaccenting (Jackendoff 1972, Ladd 1980), topic, theme and given (Halliday 1967b) or old (information) (Chafe 1970, 1976). The definitions that these various terms are given are not the same, however, and may refer to such varied things as the intonation contours of utterances, preceding elements in discourse, thematic organisation, and the communicative intentions of the speaker. (For analyses of some of these concepts see Allerton 1978, Prince 1979.)

We will here leave 'focus' semantically undefined, but nevertheless assume that it exists as a formal category available in speakers' grammars. It is important to keep the concept of focus, as a linguistic prime, distinct from, on the one hand, the reason or reasons why speakers mark part or all of their sentences as [+fo- 
cus\}, and on the other, what such a choice implies for the phonetic/syntactic realisation of those sentences. ${ }^{3}$ It is the latter relationship that this article is trying to come to grips with. It should be carefully noted that the relationship is not the other way around: we do not define focus on the basis of the position of the nucleus. Indeed, for all we know, a given [-focus] - [+focus] structure may well require the nucleus to fall outside the material marked [+focus]. It is also important to see that every sentence is marked for focus. We should not resort to a classification of sentences into e.g. 'topic-comment sentences' and 'news sentences', the way Schmerling (1976) does:

$$
\begin{aligned}
& \text { Truman DIED (topic-comment sentence) } \\
& \text { JOHNson died (news sentence) }
\end{aligned}
$$

since this can only lead to circularity in the description. If we carry this method to its logical extreme, we will end up with as many sentence types as there are intonation contours to be explained, and we could start all over again.

A third point to note is that focus marks semantic material, not syntactic constituents or words. Because there is, in general, a rather close relationship between semantic structure and lexico-syntactic structure, making it possible to associate semantic constituents with lexical or syntactic ones, our notational device of underscoring does not normally run into difficulties, certainly not in case of the three major semantic constituents recognised in this article: Arguments, Predicates and Conditions. Thus, Arguments (e.g. John, Mary) and Predicates (e.g. kissed) invariably correspond to some lexical material, and if any of these are [+focus], underlining is clearly unproblematic. This also goes for Conditions that are put on propositions (e.g. on Sunday as a condition on the proposition John kissed Mary), and any modifiers (e.g. silly John, beautiful Mary, last Sunday). If any of the above elements is incremented (e.g. John or Bill, kissed and fondled, on Sunday or Saturday), then one or both terms, or the relation between them, could be [+focus] (John AND Mary, etc.), and underlined. In many cases, however, the focus cannot be associated with any particular word. Trivially, this may happen when a speaker utters (6) in reply to Is this Beverley a bachelor?

(6) Well, this Beverley is a SPINster. YES.

which reply does not have the full semantic representation of spinster in focus, but only its component FEMALE. (The yes, of course, is added to confirm the 
rest of the representation.) Such focus-markings are particularly relevant in the case of predicates, where the verb phrase breaks down into the elements polarity, tense, aspect, voice, and lexical item. Consider the following example: ${ }^{4}$

(7) A (Tour guide in Canada): I want you all to speak FRENCH now B (Tourist) : I hadn't realised we were IN Quebec

In B's reaction, the [+focus] material is not realise plus the positive polarity of the embedded sentence. Note that even if we can associate the focus with a particular word, this does not necessarily mean that the nucleus goes to it. In (8), the element in focus includes certain special aspects, but the nucleus goes to to.

(B) But you do accept that there are certain specjal aspects TO this case?

It should also be observed that certain words do not themselves take part in the focus distribution (if we can exclude from consideration utterances in which such words are talked about, such as some of the ones that follow), but rather add to the meaning of the material that is [+focus]. Examples of such focus-governing morphemes are also, even, only, purely, etc. They tend to have a syntax of their own, and most of them are obligatorily assigned an accent by the accent assignment rules. (This particular rule is not stated explicitly here.) An exception is even, which is never assigned an accent: compare John/ALso vs Also/JOHN with JOHN even vs Even JOHN, where in the former case two accents are assigned, and in the letter only one. In terms of focus distribution such morphemes had best be regarded as governing the focus, a la Jackendoff (1972). Diagrammatically, the structures of (9) and (10) could therefore be represented as (11) and (12) respectively. (Note that the appended lllocution-marker please normally falls outside the focus.) ${ }^{3}$

(9) JOHN's on the dole even

(10) (Shall I bring John and Mary?) John ONLY, please 


$$
\begin{aligned}
& \text { [ } x \text { is on the dole] [x= John] } \\
& \uparrow \uparrow \\
& {[\text {-focus }]\left[\begin{array}{c}
+ \text { focus } \\
\text { even }
\end{array}\right]} \\
& \text { [you bring } x] \quad[x=\text { John }] \text { (please) } \\
& \uparrow \\
& {\left[\begin{array}{l}
\text { tocus } \\
\text { only }
\end{array}\right]}
\end{aligned}
$$

A final point to be made, already hinted at above, is that there is an upper limit to the amount of material to be put in a focus. By contrast, the tone group, like the sentence, has no upper limit, in linguistic terms. In (13) for example, there is a focus boundary within a tone group:

\section{Strikes have been reported/in Gdansk}

Accent assignment rules apply as often as there are focl in the tone group. In section 5 the concept of focus domains will be dealt with.

Briefly, then, in the model proposed here, all sentences are obligatorlly marked for focus. Accent assignment rules, taking the [+focus] material as their input, assign accents in a purely mechanical way. If there are more than one [+focus] stretches in a tone group, the assignment rules apply to all these stretches individually, with the last of these accents so assigned being the nucleus. In addition, as will be seen in section 6 , the rules are sensitive to a feature mode, which is a binary variable specifying whether the sentence is meant as a counterassertion or not.

\subsection{THE 'MEANING' OF [+FOCUS]}

While no attempt is made to define the semantic difference between [+focus] and [-focus] in any formal way, something ought to be said about what semantic material can be marked [+focus]. In order to account for intonational data, linguistic communication had best be seen as the manipulation by speakers of certain semantic material with respect to a discourse background, which could crudely be thought of as a set of propositions that speakers assume is shared by their 
hearers. The first, from now on called the Variable, is what speakers obligatorily assign [+focus] to, while, in addition, [-focus] may be assigned to the Background. The term 'Variable' has only its semantic blandness to recommend itself. A more meaningful formulation might be that [+focus] marks the speaker's declared contribution to the conversation, while [-focus] constitutes his cognitive starting point. In this sense, the contribution causes a 'Background update', which term expresses the fact that after it, the Background has been modified. This formulation lays no claim on the predictability or otherwise of either the [+focus] or the [-focus] material.

The number of different manipulations of the Variable with respect to the Background that speakers can choose from is limited. It is suggested that these manipulations are signalled by the particular nuclear tone used to realise the nucleus. It is these manipulations, then, that are proposed as the meanings of the nuclear tones. These tones are thus seen to form an intonational lexicon (Liberman 1975, Ladd 1980), a paradigm of mutually exclusive units, each of which has a consistent meaning which is independent of whatever other semantic material goes into the construction of sentences. While the choice of any one tone always implies an addition to the semantics of the lexico-syntactic material in the sentence, the eventual semantic effect is always integrative with that material. To quote Liberman (cited in Ladd 1978):

The meanings [of words in ideophonic systems] are extremely abstract properties, which pick out classes of situations related in some intuitively reasonable, but highly metaphorical way: the general 'meaning' seems hopelessly vague and difficult to pin down, yet the application to a particular usage Is vivid, effectlve, and of ten very exact. (Liberman 1975: 142)

While I neither subscribe to Liberman's idea that these meanings are attached to holistic intonation contours, nor to his comparison of these meanings to 'ideophones', the sentiment expressed seems appropriate enough. This article is not about the meanings of nuclear tones. Yet, I should here like to give three examples of such tones, not just in order to illustrate what their role is, but mainly to demonstrate that the choice of nuclear tone may have an influence on our intuition about where the nucleus should be located in sentences presented in written form, as in this and many other articles. Three tones will be illustrated with the house is on fire as the Variable, to which no material from the Background is added. In section 5 it will be shown that this focus distribution re- 
quires the nucleus to be put on house. It should perhaps be noted that this same nucleus placement would result if only the house was the Variable and be on fire belonged to the Background (as it is likely to do in a conversation about fires); this latter focus distribution is nowhere intended below.

1. One type of manipulation available to the speaker is adding the Variable to the Background, which will require him to use the nuclear tone fall. The corresponding sentence is

(14) The 'HOUSE is on fire

Its meaning could be paraphrased as 'I want you to know that from now on I consider the house is on fire to be part of our Background'. The speaker may of course have any number of reasons for employing this option: the sentence could serve as a warning, or it could be meant to signal to the hearer that the speaker has just made an inference. We will call this manipulation $\mathrm{V}$-addition. It is of some interest to note that readers of isolated example sentences generally assume that this is the manipulation intended by the writer.

2. A second type of manipulation is the selection of a Variable from the Background, which would require the speaker to use nuclear tone fall-rise. The corresponding sentence is

(15) The ${ }^{`}$ HOUSE is on fire

(The notation is British: the phonetic realisation of the fall-rise is a pitch-drop on house, and a pitch-rise on fire, with is on low in pitch, cf e.g. O'Connor \& Arnold (1973: 13).) The meaning can be paraphrased as 'I want you to take note of the fact that the house is on fire is part of our Background'. The pragmatic effects of this manipulation can be quite varied. It could be a reminder to the hearer that this Variable is in fact part of the Background (as an answer to, for example, a masochist's complaint that There are hardly any major personal tragedies these days!), or an expression of surprise over the fact that it should be. Again, just why the speaker chose to employ the semantic option he did employ is up to the hearer to determine on the basis of the pragmatics of the speech situation. We will call this option V-selection. It should be noted that while speakers must associate [-focus] with the Background and [+focus] with the Vari- 
able, there is no reason why the Variable could not be a subset of the Background, as it is in $\mathrm{V}$-selection.

3. A third type of manipulation open to speakers is to leave it up to the hearer to determine whether it is relevant for the Variable to be part of the Background or to be added to the Background, which will require him to use the nuclear tone rise. The corresponding sentence is

(16) The 'HOUSE is on fire

Its meaning can be paraphrased as 'I will leave it up to you to determine whether we should establish this Variable as belng part of the Background'. The interpretative possibilities are, as always, multiple. It could be a straightforward request for information, requiring the hearer to either confirm or deny that this Variable is part of the Background, it could represent a tentative guess as to whether it is, or it could, again, signal surprise, but unlike the $\mathrm{V}$-selection sentence above, at the same time carry the implication of a strong appeal to the hearer for confirmation. We will call this option $\mathbf{V}$-relevance testing.

It may be noted that ' $\mathrm{V}$-addition' and 'V-selection' would appear to correspond to what Brazil has called 'proclaiming' and 'referring' respectively (Brazil 1975, Brazll, Coulthard \& Johns 1980), while the distinction between 'V-addition' and 'V-relevance testing' might be seen as a more specific characterisation of what Cruttenden (1981) calls 'closed' and 'open'. Note, however, that Cruttenden and Brazll group the fall-rise and the rise together.

These hypotheses concerning the meanings of these nuclear tones of English of course require testing against a large body of data. They are given here, however, not only to put the descriptive model in its proper perspective, but also to llustrate how the choice of nuclear tone may interfere with our intuitions as to where the nucleus should naturally come, as it would seem to do in some of the examples used by Berman \& Szamosi (1972) to argue against Bresnan's proposal that the NSR could be salvaged by having it apply to deep structure representations (Bresnan 1971). They claim that (17), for instance, represents a 'non-normal' nucleus placement: 
and that the normal position for the nucleus is on dormant. It is suggested that the oddity of (17) is caused by the combination of choices - assumed by the reader on the basis of the representation of the sentence in (17) - from the intonational lexicon as well as from the possible focus distributions. These choices are: the Variable is the volcanoes are dormant and the manipulation is $V$-addition. Since in the reader's Background volcanoes are dormant by way of reference point, these choices lead to a non-interpretable discourse context (unless the reader is to assume that the intended speaker was making a point of stating the obvious).

The sentence can be made acceptable in two ways: either we change the manipulation or the focus distribution. With a fall-rise tone, the utterance could suitably be taken as a reminder, and the oddity of the nucleus location on volcaroes would disappear (cf A: Nothing's RIGHT on this island, there's nothing we can attract TOURists with. B: (with shrug of shoulders) The vol ${ }^{\circ}$ CANoes are dormant). Alternatively, we could change the focus distribution, and leave the volcanoes in the Background: the hearer can now assume that he ought to be able to identify the referent of the volcanoes, presumably a set of volcanoes that was not prevlously dormant because the predication, the Variable added to the Background, is that they are. This focus distribution of course requires the nucleus to fall on dormant, the reading that Berman \& Szamosi designate as 'normal'. There is, perhaps trivially, a third way in which we could alter the speaker's choices so as to make the sentence acceptable: If we change dormant into erupting, the full-focus interpretation combined with the speech act V-addition would no longer clash with the Background. In (18), Berman \& Szamosi consider the nucleus placement on volcanoes to be 'normal':

\section{The volCANoes are erupting}

Thus, we may establish a felicity condition on V-addition, viz. that the added Variable must not already be part of the Background. It will be clear that in a discussion of the mechanics of nucleus assignment, it is important to factor out the effects of the choice from the intonational lexicon as well as of Background on the focus distribution of the sentence."

The terms used in this section can be summarised as follows: 
Background

Variable

Focus

Intonational lexicon

Nucleus body of knowledge about the world operated upon by speakers and hearers which they assume to be mutually shared,

semantic material to which speakers apply one of a number of manipulations with respect to the Background,

linguistic category, specifying the size of the Var1able, set of tones signalling ('realısing') the particular manıpulation chosen, location of the tone in the sentence, the chief means of signalling ('realısing') the focus marking

\subsection{ON 'NORMAL STRESS'}

From the above analysis it wll be clear that what people have called 'normal stress' may be a more complex phenomenon than is sometumes thought What happens when a reader is presented with a written sentence and is asked to pronounce it - or simply does so sulently for himself - is that, assuming the manipulation $V$-addition, he first puts a focus/non-focus interpretation on the semantic material represented by that sentence, and then the position of the nucleus follows as a mechanical consequence of that cholce People's natural tendency when dealing with this somewhat unnatural task is to give the producer of that sentence the benefit of the doubt and assign as much of it as is reasonable to the Variable What is reasonable here not only depends on the semantic material itself, but also on the reader's world For example, when someone is called upon to read out (19)

(19) He said the princess had laughed'

he may either imagine hinself to be a citizen of a country ruled by a king whose daughter was afflicted with the inablity to laugh, in which case he will be able to assign [+focus] to the entire embedded clause, or he may assume that in this world princesses are just as likely to laugh as not to laugh, in which case he will not look upon the whole of the embedded sentence as the Variable The next best interpretation is that reference is made to one of those princesses who had 
somehow already been identified, and that the point made is that she had laughed, and not not laughed, which could also have been the case. In the first interpretation we get (20), in the second (21). 7

He said the prinCESS had laughed!

He said the princess had LAUGHED!

What this means is that the concept of normal stress cannot reasonably be part of a linguistic theory of accent assignment, as it necessarily involves a prior interpretation of semantic material as either Background or Variable. The best one could do is to provide an explanation of why a particular accent assignment is called 'normal': the answer is that it is that position that results from the widest reasonable interpretation of the semantic material as the Variable with speech act V-addition.

'Normal stress' has been characterised, implicitly by Chomsky (1969) and explicitly by Hohle (1979) and Ladd (1980), as that nucleus placement that results from the interpretation of the entire sentence as [+focus]. Hohle says that the nucleus placement that allows for the largest possible number of focus/non-focus interpretations is normal, while Ladd states that the nucleus placement that results from an interpretation of the sentence as one with 'unmarked focus' or 'focus unspecified' is normal. (From this discussion it is clear that this is conceptually the same thing as our 'with nothing marked [-focus]', cf also Halliday 1967b.) Both definitions of course amount to the same thing, by virtue of the fact that it is natural for larger things to comprise smaller ones rather than the other way around. This can be illustrated by (22), which is a paraphrase of the example given by Hohle:
What's happened?
Papa has given Tommy a GUN
What's Papa done?
Papa has given Tommy a GUN
What happened to Tommy? Papa has given Tommy a GUN
What's Papa done to Tommy? Papa has given Tommy a GUN
What's Papa given Tommy? Papa has given Tommy a GUN

All other nucleus placements allow for fewer focus interpretations. (The same point arises from Chomsky's discussion of the focus interpretations of the noun phrase an ex-convict in a red SHIRT (Chomsky 1969)). Of the two definitions Ladd's would seem to be the more straightforward. The point that arises from Hohle's discussion is that we are dealing with five different intonational struc- 
tures in the right-hand column of (22). Indeed, since every [+focus] Argument will be assigned an accent - as will be argued below - we are in fact dealing with four phonetically different surface structures, only the last two being truly homophonous.

From our discussion so far it will be clear that neither definition of 'normal stress' will cover all instances of what has been called 'normal stress' in the literature. Many sentences are excluded from having full focus interpretation because their semantic material is too obviously part of the Background. Also, sentences that Include a focus governer cannot be given a full [+focus] interpretation either. In the literature, the designation 'normal' for the accent in such sentences depends crucially on the fact that there is only one focus/non-focus interpretation possible, viz. the one marked by the lexical focus indicator. We can illustrate this with (23).

\section{John would like to go there himSELF}

When in English we wish to focus on the meaning 'not an NP other than the NP speclfied', we produce (my/your etc.) self, -ves as a matter of course, because that is the way our syntax works. And since we specifically produce it when we wish to express that meaning, it can only occur with [+focus] for that NP, and [-focus] for the rest of the material, which is therefore also the obligatory interpretation. ' (The same point is made by Ladd (1980: 76) with respect to the focus adjunct even. Cf also Schmerling (1976: 49).)

The important point is, however, that the notion 'normal stress' has no role to play in our theory, simply because we cannot make it do anything to account for the data. The only thing a characterisation of the concept can do for us is to account for people's intuitions about what is the most likely ('normal') place in which they will put the nucleus in isolated 'sentences' that are presented to them. I believe that the formulation I gave earlier in this section does precisely that.

Like Schmerling (1974), we are therefore forced to reject the notion of 'normal stress' as a meaningful concept, but for a different reason. Schmerling rejected It because she came upon too many sentences in which different nucleus placements seemed equally 'normal' (cf examples (1) and (2)) and which therefore could not be explained by resorting to a concept of 'normal stress'. Part of the 
point in this article is that such different positions can be accounted for, but that it is not 'normal stress' that will do this for us.

\subsection{ACCENT ASSIGNMENT RULES}

Without wanting to prejudge the question of whether all languages always require that the same (or equivalent) semantic material be marked [+focus] If speakers' communicative intentions are the same, it may be hypothesised that Variable, Background and focus are universal concepts. What is clearly not universal are the ways in which languages realise focus. This could - theoretically - be done with the help of focus-morphemes, to be placed, say, at the beginning and end of the [+focus] material, or by means of word order, by placing the [+focus] material at the end or the beginning of the sentence. An example taken from Edwards (1979) lllustrates the effect of word order in Haida, an Amerindian language. In this language, elements are placed 'in sentence-initial position (...) because of the speaker's intention to place before the audience that information which has the most communicative Importance.' Thus, (24) means FRED killed the woman and (25) means The WOMan killed Fred:

$$
\begin{aligned}
& \text { (24) Fred nang Jaades tiigan } \\
& \text { Fred the woman killed } \\
& \text { (25) Nang jaades Fred tiigan } \\
& \text { The woman Fred killed }
\end{aligned}
$$

Interestingly, the hearer is supposed to be aware of the deceased state of the woman in (24) and of Fred in (25), because the same sentences could also be used to mean The woman killed FRED and Fred killed the WOMan, respectively. If we wanted to disambiguate the subject-object relation, that is, if we wanted to express the equivalent of the English sentence The woman killed FRED with full focus interpretation, the Haida speaker would have to resort to a 'topicalisation' morpheme after the sentence-initial element, which would then be taken as the object:

Fred uu nang jaades tiigan

(a sentence that by Haida intuitions would be anything but 'normal'!) 
Languages like English and Dutch sometimes make use of word order or other syntactic devices to aid their focus marking (e.g. clefting, topicalisation, passivisation'), but most importantly they employ accent for this purpose. They have, in other words, accent assignment rules that take focus distributions as their input. Again, there is no reason why these accent assignment rules should be the same in the two languages. The first rule to be presented here, called simply the Sentence Accent Assignment Rule, or SAAR, is common to both languages, but the second, the Polarity Focus Rule, or PFR (more properly an extension of SAAR), points up a number of differences. It is this second rule, in particular, that makes it clear that the relation between the location of the nucleus and the semantics of the sentence can be very indirect, and cannot always reasonably be accounted for in terms of the communicative importance of the word the nucleus happens to be found on. SAAR attempts to capture in a more insightful way the observation that Schmerling (1976: 82) made when she formulated her Principle II, which says:

The verb receives lower stress that the subject and the direct object, if there is one; in other words, predicates receive lower stress that their arguments, irrespective of their linear position in surface structure.

Apart from the unfortunate appeal to degrees of stress in a stress assignment rule, the mistake Schmerling made is that she intended her Principle to apply to what she called 'news sentences', i.e. to sentences that consist of [+focus] material only (e.g. (27)). What she failed to realise is that it applied to [+focus] material, full stop. Trivially, this becomes clear when we want to account for the location of the nucleus in B's reply in (28), where her is [-focus]:

(27) (Have you heard?) JOHNson's died

(28) A: And what has SHE come to us for?

B: Her HUSband beats her

It will be clear that the nuclei in both (27) and (28) should be accounted for by one and the same principle. Non-trivially, the unwarranted distinction between 'news sentences' and sentences containing [-focus] material can lead to serious errors of analysis. By restricting Principle II to the class of 'news sentences', Schmerling finds herself in the position of having to trump up additional principles to account for other data, such as the other member of her well-known minimal pair JOHNson died - Truman DIED. As will be recalled, her examples are authentic. The first was used by her husband to inform her of the sudden 
death of President Johnson, while the second was uttered a few weeks earlier: 'one morning I came downstairs to breakfast, and my mother, who had gotten up earlier and listened to the news, announced to me

(29) Truman died (=Truman DIED)' (Schmerling 1976: 41)

Schmerling accounts for the nucleus placement in (29) by postulating two principles. After correctly arguing that Truman is topic, or [-focus] in our terms, she first introduces a principle that assigns an accent to both the topic (Truman) and the comment (died), and then postulates a principle that designates the last of a number of accents ('equal' stresses for Schmerling) as the nucleus. In other words, she assigns an accent to [-focus] material. It is easy to see that this cannot be right. If we paraphrase (29), admittedly somewhat clumsily, as

The disease KILLED Truman

we get the nucleus on killed, despite the fact that the topic comes last. (It should be clear that the disease in (30) is [-focus]: the Background for both (29) and (30) is 'Truman is (dangerously) ill'). By extending the application of Principle II to [+focus] material as such, we not only account for sentences like (28), but also for sentences like (29) and (30): in them, there is only one constituent that is [+focus], and not surprisingly, it is given the nucleus (Gussenhoven 1978).

There is a further problem with Principle II. Phrased the way it is, it puts no condition on the linear adjacency of the Argument and the Predicate. Consider, however, the following two 'news sentences':

Our DOG's disappeared

Our dog's mysteriously disapPEARED

It would appear that if the speaker wishes to treat mysteriously as [+focus], he must, by that very choice, give disappeared an accent. What this suggests is that if an Argument and a Predicate are to merge into a structure that can be marked [+focus] by just the accent on the Argument, no other [+focus] constituents must be inserted between them. It is clearly not the case that the information status of disappeared in (31) differs from that in (32): both instances count as equally new. It is rather that because of the interposition of the [+fo- 
cus] Condition, the [+focus] status of disappeared can no longer be served by the accent on dog

These facts suggest that SAAR operates over focus domains A focus domain can be defined as one or more constituents whose [+focus] status can be signalled by a single accent We will therefore formulate SAAR in terms of (1) a domain assignment rule, and (2) a rule assigning an accent to every domain formed In (33), A, P and C stand for Argument, Predicate and Condition, respectively, whle $X$ and $Y$ stand for any of these Underlining symbolises [+focus], absence of underlining [-focus] Square brackets are used to mark off focus domains, and the asterisk indicates a sentence accent

SAAR
a Domain assignment
$\underline{P}(X) \underline{A} \rightarrow[P(X) A]$$$
\underline{A}(X) \underline{P} \rightarrow[A(X) P]
$$$$
\underline{\mathrm{Y}} \rightarrow[\mathrm{Y}]
$$
b Accent assignment []$\rightarrow\left[{ }^{*}\right]$ In $\mathrm{AP} / \mathrm{PA}$, accent $\mathrm{A}$

Some examples of the operation of SAAR are given in (34) ${ }^{10},{ }^{12}$ Note that any [-focus] material has been included in the nearest focus domain, but is not, of course, accented The last assigned accent (the nucleus) corresponds to capitalisation in other examples

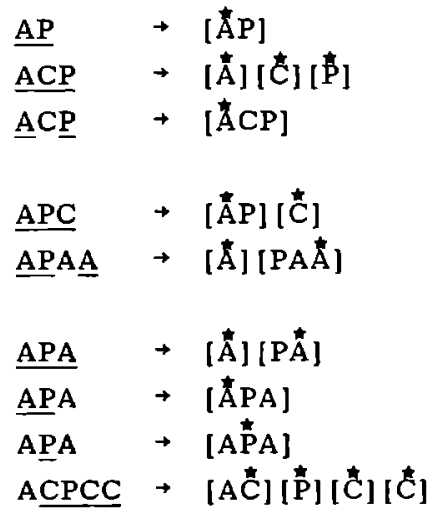

Our dồg's disappeared

Our dög's mystếriously disappêtared (Talkıng about mysterıes) Our dög's mysteriously disappeared Jẳne's had an accldent in Lö́ndon (Any news about Jane?) Jớhn's promised Jane a bikke Jö̀nn beats Märy' Her hutsband beats her He beats her Truman was quijetly bứried in Indepềndence in 1972

Observe that the interposition of [-focus] constituents (corresponding to (X) in (33)) do not prevent AP/PA focus domans from being formed, as in $(34 \mathrm{c}, e)$ 
There is an important condition that must be put on the A in SAAR. As a 'news sentence', (36) is not well-formed (compare (35)):

(35) The PRISoners have escaped!

(36) *EVerybody has escaped!

Similarly, (37) is ill-formed (as a 'news sentence' again, of course: if has esceped is [-focus], as in an echo question, it is entirely well-formed).

$$
\text { "WHO's escaped? }
$$

If (36) and (37) are to be all [+focus], they must have an accent on the Predicate, in addition to one on the Argument. AP domain formation would thus appear to be ruled out in cases where the $A$ is elther a quantifier or an interrogative pronoun. These Arguments require a focus domain to themselves. Observe how this rule accounts for the fact that (38) en (39) translate into Dutch the way they do:

$$
\begin{aligned}
& \text { I've seen JOHN } \rightarrow \text { Ik heb JAN gezien } \\
& \text { I've seen NO one } \rightarrow \text { Ik heb nlemand geZIEN }
\end{aligned}
$$

That is, in (38) seen John is one focus domain, but seen no one is (39) are two. Fuchs (1980), who discusses the accentuation of subject + predicate sentences in German, observes that if a nucleus on the predicate is to be possible, the subject must be 'lexically filled', i.e. must not be a pronoun. This may well be the correct generalisation, for it would seem that not only quantifiers (indefinite pronouns) and interrogative pronouns are excluded, but also personal pronouns. This may be clear from a comparison of the two replies to A's question in (40). Speaker B is here assumed to be A's sister, and Your sister and I refer to the speaker herself:
A: Why don't we go to Val d'Isere for our holiday?
B: Your SISter had an accident there (You insensitive thing!)
B: $*$ I had an accident there (nucleus on I)

Of course, in either case, the subject could be treated as [-focus], as the referent is clearly present in the background in her role as speaker:... $\mathrm{ACCl}$ dent there. The point is rather that it is possible to only accent Your sister, but not - unless an emotional style is presupposed which need not be assumed in 
the former example - to only accent I. With Fuchs, I will therefore assume that the A must be lexically filled. Note that this formulation includes headless A's like three in Three died.

\subsection{TOPICALISATION}

It has often been claimed that subject accentuation in subject + predicate sentences should be accounted for in terms of predictability: 'The point is [...] that given the subject and given the situation, the predicate follows as a foregone conclusion' is the formulation in Quirk et al. (1972: 941, Note b). It is for this reason that many of the examples above have semantically rather 'weighty' predicates, like die and have an accident. It should also be observed that the semantic content of the subject and the predicate may be reversible. This fact in itself makes it difficult to maintain that the position of the nucleus is not -at least partly - structurally determined. In (41) the notion 'tear' is apparently equally predictable from 'trousers' as 'trousers' is from 'tear' in (42). Then why are the nuclei where they are?

(42) There's a TEAR in your trousers

Nevertheless, postulating a rule for the assignment of sentence accents, even when the input is defined in terms of focus distributions over semantic constituents rather than in terms of syntactic structure, is a hazardous undertaking in the light of the lessons Bollnger gave, notably in Bolinger (1972). For example, it could be argued that in spite of the 'given' status of Doris in (43), it is given an unmistakable accent, or that despite the fact that in B's reply in (44) a [+focus] Argument and a [+focus] Predicate are adjacent, the predicate is nevertheless assigned the nucleus.

(43) A: What about DORis? Couldn't SHE do anything about it?

B: ‘Doris had LEFT! (That's the whole point!)

(44) A: But why didn't you simply drive OFF?

B: My 'tyres had been SLASHED! (How could I?)

Sentence accents, it could be argued, are placed on words that the speaker considers sufficiently important for them to have accents: Doris is too important to be left unaccented, and the fact that $B^{\prime}$ 's tyres were so brutally slashed in- 
duces him to accent the Predicate expressing that act. There is, however, a more insightful explanation. Note, first, that the syntactic rule of topicalisation cannot be applied without first assigning an accent to the element to be topicalised:

Preposing him requires accenting him. There is, in other words, an intonational topicalisation rule that must apply before syntactic topicalision can apply. The reverse, however, is not true:

(46) I hate ${ }^{\vee}$ HIM

Also, intonational topicalisation can apply to constituents that syntactic topicalisation cannot apply to, or better, applies to vacuously, because the constituent concerned already is in sentence-initial position. It is suggested that this is what has taken place in (43) and (44): the Arguments Doris and My tyres have been intonationally topicalised. The rule could be formulated as follows:

$$
\left.\begin{array}{rl}
\text { INTONATIONAL TOPICALISATION } & \mathrm{x} \\
\underline{\mathrm{x}}
\end{array}\right] \rightarrow[\underline{\mathrm{x}}]
$$

That is, it applies to constituents irrespective of their focus marking, and has two effects: the constituent is marked [+focus] and forms a focus domain by itself. The superiority of this formulation is evident when we consider the non-topicalised versions of (43) and (44):

(48) Doris had LEFT!

(49) My TYRES had been slashed!

where had left and all of (49) are [+focus]. Observe that as in the case of (32), the nucleus on the Predicate in (44) is parasytic: in either case, the focus boundary between the Predicate and the Argument prevent the formation of an AP focus domain. 


\subsection{INTERPRETATIVE EFFECTS OF SAAR}

Before an attempt is made to refine the statement made in (33) in terms of general semantic constraints on its application and in terms of more precise definitions of the constituents it refers to, some discussion will be devoted to the semantic effects that may result from the assignment of full focus to subject + predicate sentences (nucleus on subject) as compared to the assignment of [+focus] to the predicate only (nucleus on predicate). The fact that the discussion is restricted to examples in the literature dealing with sentences that consist of a single Argument (the subject) and a Predicate, should not be taken to imply that the rule is not applicable in cases where the Argument has an object-function, as is illustrated by

(50) They're detaining SUSpects again

The irrelevance of linear position here is aptly demonstrated by translating the sentence into a language in which the same rule is operative, but in which the lexical verb is positioned after the object, such as Dutch.

Ze zijn weer verDACHten aan het vasthouden

Schmerling (1976: 84) and Oakeshott-Taylor (1981) use German to make the same point. In fact, from this point onward, this expository method will be used here as well, the assumption being that SAAR is a rule of Dutch as much as it is a rule of English (cf also (38) en (39)).

1. The first pair of sentences is provided by Kraak (1970), who discusses the position of the nucleus in terms of topic and comment. He observes that

(52) Your EYES are red (= Your eyes are red)

(53) Your eyes are BLUE (= Your eyes are blue)

differ in that redness of the first pair of eyes would be taken to be of a temporary kind, but the blueness of the other pair of permanent type. Because he considers both sentences to be entirely 'comment' (i.e. [+focus]), Kraak has to resort to the semantic feature [inherent property] of the colour to account for the difference in nuclear position. Of course, in (53) Your eyes is [-focus], and it is that because it is part of the Background 
for people to have, inherently, blue eyes. (Of course, in addition to a number of other colours, like brown, grey, green, etc.) If we want to put a full [+focus] interpretation on this sentence, we would have to resort to a world where this is not the case:

(54) Adam (upon first seelng Eve): Your EYES are blue! Eve: PARdon?

Adam: Your EYES! They're BLUE! I LOVE blue!

2. A second example is the interesting minimal pair provided by Oakeshott-Taylor (1981):

(55) A: Can't we eat yet?

B: No, mother's still COOKing (= mother's still cooking)

(56) A: Can't we eat yet?

B: No, MOTHer's still cooking (= mother's still cooking)

The different interpretations that these sentences will be given are, as Oakeshott-Taylor observes, that in (55) the referent of mother will be assumed to be the agentive subject of the transitive verb cook, while that in (56) would be taken as the passive subject of the intransitive verb cook, 1.e. would be assumed to be the intended victim of cannibalism. The analyst's temptation is, again, to try and incorporate this semantic effect in a linguistic theory of accent assignment, either by giving different prosodic statuses to transitive and intransitive verbs, or by hypothesising that passive and agentive subjects must be treated differently. The correct answer, I would suggest, is that the sentences have different focus-distributions (as indicated) and that the hearer's interpretative strategles are triggered accordingly; in (56) he knows, by SAAR, that mother is [-focus], 1.e. part of the Background, in which the referent has presumably just finished cooking, but would certainly not be in a cooking-pot. The predicate can suitably be interpreted as 'is still preparing the meal'. In (56), however, the hearer knows that mother must be [+focus], and is forced to construct a Background in which mother cannot be taken for granted as the subject of still cooking. He can only do so by assuming that she is one of a set of objects that could still be cooking, and therefore, if the hearer considers it less likely that the readiness of the meal is contingent upon the completion of the simultaneous cooking activities by a number of people than upon the simul- 
taneous readiness of a number of ingredients, he will assume that mother is an ingredient The different interpretations are therefore an effect of our knowledge of the world Indeed, in the household of Van Gogh's potato-eaters, we would not only expect (55), but also (58), because in either case there are no other referents in the Background that could be related to the predicates concerned

(57) (A Can't we eat yet') B No, mother's stull COOKing

(58) (A Can't we eat yet?) B No, the potatoes are stull COOKing

3 A third set of examples can be found in Allerton \& Cruttenden (1979), who take Schmerling to task for formulating her Principle II (here SAAR), because for every one of Schmerling's examples of subject intransitive verb sentences that has the nucleus on the subject, they can think of one that has the nucleus on the verb

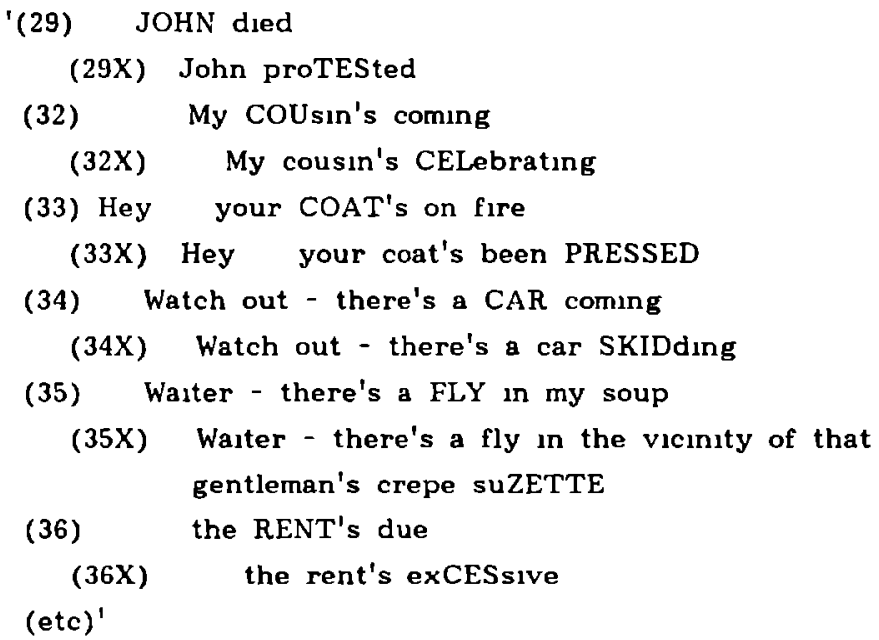

(Allerton \& Cruttenden 1979)

They observe that all of Schmerling's examples concern verbs that fall semantically in one of three categories (1) 'empty' verbs (e g The SUV's shining, (2) verbs of (dis)appearance (e g The DOG's escaped), (3) verbs denoting a misfortune (e g The CAR broke down) Schmerling should perhaps be taken to task for some of the things she said in her the- 
sis, but certainly not for the formulation of her Principle II. What Allerton \& Cruttenden have done is to identify the sort of verb that is likely to figure in sentences that are entirely [+focus]. And indeed, an analysis of the news bulletin along these lines will probably give just these results. The semantic material contained in their examples here given as (59) can all very easily be interpreted as [+focus], because they are so clearly not part of the Background, and can therefore be seen as the added Variable. The readings in the $X$-examples would seem to depend on the (subconscious) creation of Backgrounds in which the referents of the subjects were already present, and would therefore be excluded from the focus in the sentences concerned. It is not difficult to think of contexts in which the alternative readings are forced, however: A: Why didn't the plan go through THIS time? B: JOHN protested; A: What are you going to BRIStol for? B: My COUSin's celebrating; A: JEEVES, consider yourself SACKED: nothing has been SEEN to. B: Your COAT's been pressed, etc. The 'error' here comes from 'concentrating on the commonplace' (Bolinger 1972). Allerton \& Cruttenden have fallen into the trap of taking the most likely Background for each of these sentences and assuming that the subsequent reading, which is of course 'normal' in the light of our knowledge of the world, is also 'normal' in a linguistic sense.

By our discussion of these examples we intended to stress the importance of distinguishing between the semantic contribution of the speaker's linguistic choices from the paradigms available to him and the pragmatic implications that these choices may have in any given situation. It would seem difficult to give a generalisation of the circumstances in which speakers will choose one focus distribution in preference to another, however. Perhaps the best generalisation is that the subject in subject+predicate sentences is included in the focus if, given the discourse and the situation, the hearer is not expected to be able to rely in any way on the predicate in identifying the referent of that subject. The hearer's (assumed) ability to identify the referent is of course closely related to the degree of 'newness' of that referent. Yet, it does not appear to be possible to give a perfect predictive formula for the speaker's focus distribution which is based on degrees of 'newness'. Prince (1979) proposes a categorisation of the degrees of 'newness' attached to NP's occurring in discourse. These categories are:

1. New a. Brand-new

a newly created entity ( $\underline{\text { A Mrs Delaney) }}$ 
b. Brand-new, anchored a newly created entity, linked to some other entity already in the 'discourse model' (our 'Background') (A neighbour of mine)

c. Unused an entity known to the hearer, but not yet placed in the 'discourse model' (Mrs Delaney)

2. Given a. Inferable entity inferable from entities already in the 'discourse model' (The neighbour (in the context of adjoining premises))

b. Evoked entity present in the 'discourse model' either by virtue of any of the above (The poor soul (referring to Mrs Delaney)) or by virtue of being situationally present (me)

When we run these degrees of 'newness' through a predicate-frame that has a reasonable degree of newsvalue (NP has killed -self), the likelihood of inclusion in the focus would appear to be definable only for the extremes of the scale. Around the centre, focus marking does not seem very predictable from the degree of 'newness'.

Brand-new:

You know what? A Mrs Delaney's just killed herself.

Brand-new, anchored: You know what? A neighbour of mine's

Unused:

Inferable:

Evoked: just killed herself.

You know what? Mrs Delaney's just killed herself.

I know what the ruckus next door was all about. The neighbour's just killed herself. You know Mrs Delaney, my neighbour? The poor soul's just killed herself. very likely

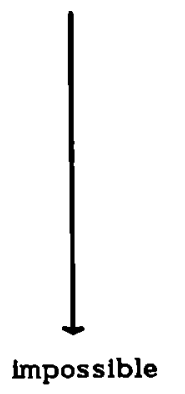

As stressed by Halliday (1967b: 211), what would be considered [+focus] in any situation is 'in the last resort what the speaker chooses to present as new, and predictions from the discourse have only a high probabllity of being fulfilled'. Ultimately, we cannot base generalisations about focus-choice on the degree of 'newness' of the material in question, since such generalisations must somehow include the speaker's intentions with regard to the interpretative strategies he knows will be employed by his hearer. Thus, in the example illustrating the category 'Inferable', the choice (again) would not so much seem to depend on how 
inferable 'neighbour' is from 'next door', as on whether the speaker wishes to create the impression that Mrs Delaney is the only neighbour, or perhaps the only neighbour worth thinklng of (exclusion from focus), or is one of a set of neighbours who might possibly have killed themselves (inclusion in focus).

\subsection{SOME REFINEMENTS}

In this section, some refinements to SAAR are introduced. They are of three kinds. First, some discussion is devoted to certain correspondences between the semantic constituents and particular syntactic constituents that seem worth noting. Second, it is demonstrated that focus domain formation can be culturally - more generally, pragmatically - determined. Third, a general semantic constraint is put on the AP (PA) domain formation part of SAAR.

\subsection{SOME SEMANTIC-SYNTACTIC CORRESPONDENCES}

$A, P$ and $C$ are semantic constituents. Because of their stable one-to-one relationships with syntactic constituents, $A$ and $C$ can be fairly easlly identified. $A$ 's are subjects and objects, and $C$ 's are all adverbials except (1) those that are part of the $P$ (see below), and (2) those that are typically treated as [-focus], such as still, again, generally, if you like. (For a specification of the latter group, see e.g. Firbas 1980).

The specification of the $P$ is more problematic. The first thing to notice is that adverbials with predicate status function as Predicates (cf There's a FLY in my soup). Such adverbial predicates may be premodified, as in There's DIRT on Uncle Jack's trousers, where neither Uncle Jack nor trousers need be [-focus] (unlike Uncle Jack in The TROUSers of Uncle Jack are dirty or trousers in Uncle JACK's trousers are dirty). The same goes for expressions like have a hollday, have an accident, come a cropper, or even have one's head chopped off, as in Bolinger's (1978) example What happened today? - Marie AntoiNETTE just had her head chopped off. It should be noted that in many such cases, there are single-verb paraphrases (to vacation, to fall, (be) guillotine(d)) or single-word equivalents in other languages (Du verongelukken 'have an accident'). 
The syntactic composition of predicates can be of a less expected sort, though, as the following three cases llustrate

1. Adverbs of proper functioning. This is a class of adverbs that is incorporated with the verb into a single Predicate As it happens, the verb receives the accent, a fact which should of course be accounted for by rules which specify the position of the accent within Predicates, and within Arguments, for that matter The adverbs concerned are called adverbs of 'proper functioning', because they denote the degree to which the action or state expressed by the verb is properly the case These adverbs come after the verb in English, but in embedded sentences and in all sentences with complex verb phrases - before the verb in Dutch, so that in this case it is English that demonstrates the difference between this type of adverb and other adverbs more consistently Compare (60) and (61)
A What are you using my PEN for?
B Because it WRITES well (Adverb of 'proper functioning') Omdat hij goed SCHRIJFT because it well writes
A (ditto)
B Because it writes/ beẳutıfully Omdat hij mot/ schrîft

Sumlarly, to SIT well (with inanumate subject, like chaur), to HEAR properly, to SEE poorly, to CUT right Observe that these Predicates readily fuse with Arguments into single focus domains, as in

\section{This KNIFE doesn't cut right}

Adverbs of proper functioning should be distinguished from evaluative adverbs, which are treated like ordinary Conditıons A physician might say that patient so-and-so sleeps wêll, whlle a toy mender might say of a doll that it now slekeps right again If we choose to wish a guest good night by using the words I hope you'll sleep well, we wll probably not treat well as an adverb of proper functioning the guest might think that the house was haunted or that he was supposed to have a gulty conscience In the morning things are different Did you SLEEP well? can be a perfectly straightforward, polite question Indeed, an evaluative well would now be slightly odd, as it suggests a degree of personal interest that may be too high for comfort Adverbs of proper functioning would 
appear to constitute a semantic paradigm ranging from not to its opposite, and the fact that not, too, is unaccented may not be unrelated.

2. Adjectival object complements. Adjectival objects complements, like open in (63) also call for special comment.

He left the DOOR open

Here, an adjectival object complement is placed after an Argument (door), and does not get assigned an accent. It is suggested that this is because it is part of the Predicate. Within the Predicate, however, it is the object complement rather than the verb that is accented, as in (64), where the door is [-focus]:

A: (slams door)

B: I wish you'd left the door OPEN

Ik wou dat je de deur had OPen gelaten

I wish that you the door had open left

Stuctures like to paint GREEN, to make HAPpy (cf It'll make your FATHer happy), to scrape BARE (Hey! The front DOOR's been scraped bare!) etc., are therefore prosodically on a par with phrasal verbs like to bring IN (cf to bring the PRAM in), to leave beHIND. ${ }^{2}$

3. Destination adjuncts. Special provision must also be made for destination adjuncts. Observe, first, that a combination of a verb of motion and a destination adjunct forms a single focus domain: in (65) the [+focus] status of cycled to town can be signalled by the single accent on town. In (66), by contrast, the duration adjunct for hours does not so fuse with the verb, and both consituents require a focus domain to themselves $(\underline{P C} \rightarrow[\vec{P}][\vec{C}])$ : Interestingly, there is a concomitant syntactic difference in Dutch. The perfective auxiliary is zijn ('be') if the adverbial denotes destination, but hebben ('have') if it does not (e.g. Lodewyckx 1944: 63).

(65) He has cycled to TOWN

Hij is naar de STAD gefietst

he has to the town cycled

(66) He has cycled for HOURS

Hij heeft uren geFIETST

he has hours cycled 
It does not, however, appear to be the case that constituents like cycle to town readily function as Predicates that can fuse with Arguments into single focus domains. Thus,

The KING has fled to Spain!

may not seem an acceptable 'news sentence', unless it is the case that Spain is the only ellgible country for kings, or this particular king, to flee to, and to Spain is [-focus]. The solution here would appear to be that this C, like A's, merges with Predicates into a single focus domain, and that once such merging has taken place we cannot then regard the result as a $P$ that can merge with yet another constituent. That is, if we symbolise a merging $\mathrm{C}$ as $\mathrm{Cm}$, then $\mathrm{APCm}$ is treated like $\underline{A P A}, 1 . e .[A][P C m]$. In the next section some other cases of $\mathrm{Cm}$ will be discussed.

\subsection{CULTURAL CONSIDERATIONS}

Bolinger (1972) observes that (68) (one of many similar examples he gives) demonstrates that speakers - in this case the speaker is assumed to be the Boston strangler on the prowl - will put the nucleus on whichever word needs highlighting, and that such preferences simply cannot be accounted for in a grammar. While it is agreed that the determination of the choice between (68) and (69) is beyond the power of linguistic theories in a strict sense, the nature of the options must nevertheless be defined in terms of linguistic concepts available in some such theory.

Where can I find a girl to STRANGle?

Where can I find a GIRL to strangle?

For example, it is in the framework presented here not meaningful to say that a speaker may put the nucleus either on girl or on strangle, depending on which concept is uppermost in his mind. Instead, the option must be said te be between merging a girl and to strangle into a single focus domain (nucleus on girl), or to keep them in separate focus domains (nucleus on strangle). Of course, within certain limits, speakers are free to break their information up over separate information carrying units, If they feel that this contributes to the success of their communication. If the speaker of (68) is the Boston strangler, it must have been spoken fairly early on in his deplorable career. The 
speaker of (69), however, no longer saw the need to encode the Argument and the Predicate as two different information units, presumably because he had combined them sufficiently frequently in this particular relationship in life which fact he took his hearer to be aware of. Observe that this analysis makes explicit that there is another sentence that has the nucleus on strangle that is phonetically different from (68): a sentence having only to strangle in focus ('I know where I can find girls to SHOOT, but...'): the nucleus locations are the same, but the sentences differ with respect to the pre-nuclear accent on girl.

We must, in other words, recognise that domain formation can be culturally (pragmatically) determined. The merging of Predicates and Conditions, in particular, would appear to be sensitive to considerations of cultural normalcy. Consider (70) and (71), and compare them with their Dutch translations:

(70) (A: Is your husband in? B:) He's gone fishing with his SON Hij is met zijn zoontje VISSen

(71) (A: Is your husband in? B:) He's out playing with his SON $H i j$ is met zijn ZOONtje an ' $t$ spelen

As will be clear, gone fishing and with his son quite naturally constitute seperate focus domains, but, equally naturally, be out playing and with his son are merged. (A nucleus location on spelen in the Dutch sentence in (71) would be odd, and might imply that the husband was behaving childishly.)" ${ }^{1}$ Here, we should also mention the combinations live/work in $X$, which are normally merged foci, although generally only destination adjuncts merge like this. Compare (72) and (73):

A: How did you come to speak such excellent German?

B: I lived in AUStria for a while

Ik heb een tijdje in OOStenrijk gewoond

I have a while in Austria lived

(73) A: (ditto)

B: I taught in AUStria for a while

Ik heb een tijdje in Oostenrijk LESgegeven

Clearly, although there are strong syntactic correlates, focus is essentially a semantic concept. 


\subsection{EVENTIVE AND NON-EVENTIVE SENTENCES}

In his discussion of information focus, Halliday (1970:38) at one point refers to the man in the London underground who uttered (74) for what was intended as (75), and 'was worried because he had no dog':

DOGS must be carried

$$
\text { Dogs must be CARRied }
$$

Halliday observes that the speaker of (74) 'treated dogs as 'new", the implication being that in (75) Dogs is 'given'. While the semantic difference between the members of this minimal pair is interestingly clear-cut, it is difficult to accept Halliday's analysis. It is, to begin with, not clear how Dogs can be 'given', i.e. [-focus]: it is not the case that there are necessarily dogs in the context, nor, indeed, could the transport corporation which first introduced the rule, have used (74) to proclaim it. Secondly, (75) is a member of another minimal pair: one between it and a lexically identical sentence in which dogs is unaccented (low-pitched). Perhaps pair (76)-(77) provides a better illustration here:

(76) Peōple will be shŏ́t

(77) People will be shŏt

Note that (77) can be used to try and convince someone who has just acquired a new gun that it would be unwise to try it out in a busy street. People here refers to entities clearly available in the background (a busy street), and can be [-focus]. But (77) cannot be used if the intended meaning is: 'Should there be people, they will be shot', which would require (76). Clearly, (75) and (77) are sentences in which both the Argument and the Predicate have an accent. It is suggested, that is, that they are both entirely [+focus] (as are (74) and (76)), and that the domain formation part of SAAR has failed to apply. The constraint that must be put on the application of the rule is that the proposition expressed in the sentence should directly refer to an event. Observe that the A's in (75) and (77) do not necessarily exist: they have a conditional status, as the paraphrase of (76) above suggests ('If there is an A of this sort, then...'). Eventive sentences, by contrast, express propositions that say that something was (1s, will be, might have been, was not, etc) an event, without the conditional hedging present in (75) and (76). 
'Eventive' is thus a semantic feature that marks entire sentences. Interestingly - and reassuringly - it is not only intonational aspects of surface forms that are sensitive to it. ${ }^{14}$ In Dutch, there is a rule of er ('there') -inversion that applies to indefinite subjects of intransitive verbs (e.g. Paardekooper 1963: 34). However, er-inversion is blocked, if the sentence is non-eventive. The only interpretation of the Dutch sentence in (79) is the one given; the translation of the more expected (78) cannot have er-inversion.

(78) Thiểves will be prốsecuted

Diềven zullen worden vervölgd

(79) THIEVES will be prosecuted (Come and see it: tickets $\$ 25$ !)

Er zullen DIEVen worden vervolgd

The distinction between 'conditional' and 'non-conditional' Arguments need not be confined to subjects, incidentally. Compare $(B 0)$, a non-eventlve regulation, with (81), a possible caption under a picture showing squatters being evicted from their squat:

(80) The Sheriff's Officer turns squatters OUT

(81) The Sheriff's Officer turns SQUATters out

The examples given so far might suggest that the different nucleus locations should be given an alternative explanation: all non-eventive sentences appear to have 'generic' Arguments, and vice versa. There are two reasons why the feature [eventive] cannot be replaced with the existing feature [generic]. One is simply that both 'eventive' and 'non-eventive' sentences can have generic as well as non-generic Arguments. First, observe that there is no reason why the non-generic Lord Coolan cannot be given the same 'conditional' interpretation as the generic thieves of (78): ('Should Lord Coolan enter these premises... ') :

\section{Lord Cöolan will be prösecuted}

Conversely, a scientist who was lucky enough to have had the last dodo under his care, could, upon the demise of that dodo, have announced this event by using either (83) or (84), where (84) is an eventive sentence with a generic Argument. 
It is suggested that the undoubted correlation between non-generic Arguments and eventive sentences has a pragmatic explanation: the occasions on which we can report on events affecting whole classes of entities are few and far between.

The second reason why an appeal to genericity does not work is that sentences with conditional Arguments constitute only one type of non-eventive sentence. There is another type, which, because it is non-eventive, similarly fails to tolerate AP domain formation: the class of 'definitional' sentences. (The former type could be referred to as 'contingency sentences'.) Compare (85) and (86):

(85) Milk is ANimal

(86) The MILK's in the sun

(85) defines an entity in the Background. Sentence (86), by contrast, can be used to actually update the Background in a historical sense: 'Please look upon the fret that the milk is in the sun as an eventive (historical) development of our Background', the implication presumably being 'Please do something about it'. Again, both sentences are entirely [+focus] ('news sentences', if this term is preferred); only, (86) is marked [teventive] and (85) is not.

This, surely, is the real explanation for the fact that a sentence like My sister-in-law is a Swede is odd with just an accent on the subject, and not, as Schmerling (1976: 95) and Fuchs (1980) claim, that predicates with indefinite nouns denoting permanent properties should be treated differently from other predicates. It is simply that such nouns typically figure in definitional sentences. Significantly, eventive readings of such sentences can, at a pinch, be forced. By the side of (87) we can imagine the eventive (88), without having to resort to a context in which spy can be [-focus]:

Mata-Hari was a SPY

(8B) (Have you heard?) The First SECretary is a spy!

(89) Beverley is a MAN

(90) (Have you heard about the dope tests?) Pavla CherKoVa is a man!

It would appear that if there is a semantic condition that must be put on the well-formedness of AP/PA domain formation, it is that the sentence should be eventive, and not that the predicate should not be a noun, or, for that matter, that it should express one of the three meanings identified by Allerton \& Cruttenden (1979) (although with two of them - misfortune and (dis)appearance - 
they were probably groping for the more general characterisation). Moreover, the feature [eventive] has been shown to be relevant outside the context of nucleus placement for the Dutch rule of er-inversion.

\subsection{MODE}

The application of SAAR presupposes that there is at least one major [+focus] semantic constituent in the sentence ( $A, P$ or $C$ ): the rule does not, as it stands, provide for sentences in which less than those constituents is in focus, such as sentences in which only the polarity is [+focus]. Before we can discuss the position of the nucleus in sentences with polarity focus, however, a distinction must be introduced which is of direct relevance to the issue of nucleus location. Consider the following examples:

(91) The house ISn't on fire

(92) (Stop squirting WATer all over the house. I TOLD you) The house isn't $O N$ fire

It is important to note that both in (91) and in (92) the semantic material that is treated as [-focus] is the house is on fire, and the semantic material treated as [+focus] is the negative polarity. In both sentences the speaker intends to 'refer to' the house be on fire (which the addressee apparently takes to be the case) as Background, i.e. [-focus], and add to it (equally emphatically, as far as we can tell) the Variable that this material is not in fact part of the Background. The semantic difference between them is that in (91) the speaker tries to prevent the addressee from adding an incorrect Variable to the Background, while in (92) the speaker is concerned to 'debug' his addressee's Background. Taking their lead from Watters (1979), Dik et al (1980) use the term 'counterassertive' and 'counterpresuppositional' in a discussion of focus types for sentences like (91) and (92) respectively. The 'counterassertive' sentence (or the V-rejection, to use our own earlier term, Gussenhoven 1981) would appear to be formally distinct from the corresponding non-counterassertive sentence in quite a number of languages. Thus, Dutch maintains the distinction between polarity-focus sentences with and without $V$-rejection, by placing the nucleus in the former type on wel (affirmative particle) or niet ('not'), but on the main verb in 
the latter: taking the house be on fire to be [-focus], the counterassertive sentence is (93), and the corresponding non-counterassertive one is (94):

Het huis staat WEL in brand

The house stands affirmative particle in fire

Het huis STAAT in brand

The corresponding negatives are, respectively:

(95) Het huis staat NIET in brand $(=(91))$

(96) Het huis STAAT niet in brand $(=(92))$

The situation in English is more complex than in Dutch and, moreover, would seem to allow for more than one nucleus location for certain focus/mode markings, but this should not be allowed to confuse the issue: the point is that the distinction is relevant to the problem of nucleus location. It should also be noted that there may be other than intonational means available in other languages to mark counterassertion, as indeed there are other means to mark focus distribution per se. Neither is the formal distinction necessarily restricted to sentences with polarity focus. Efik exemplifies both points rather nicely. In this language (the data are T.L. Cook's and are reported in De Jong (1980)), $V$-rejection sentences are distinct from other sentences, irrespective of focus distribution, through reduplication of the verb stem. Thus, both (97) and (98) have Etim In focus and have [-focus] for the rest of the sentence, and both therefore translate as ETIM bult that house. However, (97) is a rejection of the hearer's statement that someone else built that house, while (98) could be the answer to the question Who built that house?. (The focus on Etim itself is marked by the combination of the verbal prefix kj and high tone for the verb buśb.)

$$
\text { é-tim jó-kj́-bj-bj́b ú-fjk ó-kò }
$$

Etim past+prefix $+V-$ rejection+build house that

$$
\text { é-tìn j-kj-bjb ú-fjk ó-kb }
$$

Etim past+prefix+build house that

In order to emphasize the fact that counterassertion may occur independently of both focus distribution and the choice from the intonational lexicon (section 3 ), we will introduce the variable mode, which has two values, [+counterassertive] and [-counterassertive]. Below, mode is only specified when its value is 
[+counterassertive]; when nothing is specified the unmarked value is always assumed. It is suggested that counterassertion is the only relevant factor involved In discussions about 'contrastive stress' in English as well as in Dutch, and that all other claims about 'contrastive stress' can be reduced to instances of narrow focus (mode [-counterassertive]) or to the application of intonational topicalisation. (For a discussion of the vacuity of the traditional notion of contrastive stress, see Bolinger (1961), and for an attempt at constraining the notion, Taglicht (1982)).

Outside the class of polarity-focus sentences, mode is relevant in English and Dutch in so far as the focus domain in [+counterassertive] sentences is in some cases split up and confined to separate elements, if these are felt to be individually different from the elements they are substituted for. Compare (99) with (100):

A: What's that about MARy you said?

B: Oh, JOHN's fallen in love with her ([-counterass])

(100) A: INteresting. So Bill's gone off MARy, has he?

B: NO. I said John's/ fallen in LOVE with her ([+counterass])

Possibly, too, mode can be invoked to account for the oddity of the focus distribution in affirmative answers to yes/no questions. Observe, first, that answers to WH-questions have the focus on the requested bit of information, which is what one would expect (e.g. Dik 1980: 213):

(101) A: Who was born in Paris in 194SIX?

B: JOHN (was born in Paris in 1946)

Analogously, one would expect answers to yes/no questions to have polarity focus. This is true for short-form replies (Yes it IS, No it ISn't) and for negative answers (Was he the GARDener? No, he WASn't the gardener). But the more neutral focus distribution in lexically fully specified versions of affirmative answers have the same focus distribution as the question:
A: Is he the GARDener?
B: YES, he's the GARDener 
Odder still, a focus boundary tends to be inserted between Arguments and Predicates. In (103), the focus includes the volcanoes are dormant, and the nucleus therefore goes to the Argument in the question. In the answer, a focus boundary is inserted between the volcanoes and are dormant, and the nucleus therefore goes to dormant, leaving volcanoes with a prenuclear accent, which situation would seem to parallel that of $(100)$.

\section{A: Are the volCANoes dormant? \\ B: Yes, the volcanoes/ are DORmant}

Are we pushing the analysis too far if we say that the full focus in $B$ 's answer is [+counterassertive]? What this would mean is that the questioner, in asking the question, presents the focused material in it as a tentative addition to the Background, to be corrected by the hearer as appropriate. If the answer is yes, the hearer behaves as if he is to correct an empty slot, the absence of a proposition as it were, and marks his sentence with full focus and switches to mode [+counterassertive]. If the answer is no, he behaves as if the proposition in the question had in fact been added to the Background, and replies with a polarity-focus sentence, again, of course, with mode [+counterassertive], as is illustrated in (104).

A: Is the HOUSE on fire?

$B$ : No, the house ISn't on fire *No, the house isn't ON fire

If mode is indeed the feature involved here, then the term 'counterassertion' would clearly be too restrictive in meaning, and the more neutral ' $V$-rejection' should be preferred. Whether or not this analysis is correct, the relevance of mode to nucleus location in polarity-focus sentences has been clearly demonstrated.

In sections 5,7 and 8 , the following concepts have been added to the model:

Focus domain:

Eventive:

Mode: structure which can be marked [+focus] by means of a single operation of SAAR;

feature specifying whether a sentence is presented as a historical development or otherwise; variable specifying whether the sentence is counterassertive or otherwise. 


\subsection{MINIMAL FOCUS AND THE POLARITY FOCUS RULE (PFR)}

By minimal focus we mean any focus distribution that has less than the elements specified in the structural description of SAAR in its focus. An important sub-class of minimal focus is polarity focus, discussed above. However, minimal focus may also arise when part of an argument or predicate is [+focus]. It is minimal-focus sentences in general that make it clear that Bolinger's 'highlighting' hypothesis is untenable. In such sentences, there is often so little in the way of words that is marked [+focus], that the resultant nucleus locations are scattered all over the place: the nucleus is desperately looking for semantically empty little words it can go to, and - not surprisingly - it is here that even closely related languages like Dutch and English part company. The examples (105) - (111) below are provided with Dutch translations for comparison: the focus distribution is either marked by underscoring or given separately.

(105) A: J.R., I'm SOber. I don't DRINK. I wonna go HOME

$B$ : The only reason you're so CALM is that you don't get anything TO drink

is dat je niks te drinken KRIJGT

is that you nothing to drink get

(106) Now if we want to find a solution TO this problem

Maar als we een OPlossing voor dit probleem willen vinden

but if we a solution to this problem want-to find

(107) A(soccer fan): I want you to sprinkle my ashes all over the PITCH

B: Well, you know spectators aren't really allowed ONto the pitch

Je weet dat toeschouwers eigenlijk niet op het veld worden

TOEgelaten

You know that spectators really not on the pitch are allowed

(108) And a careful watch is belng kept on the river TWEED in case it bursts ITS banks

voor het geval dat DIE buiten zijn oevers treedt

in case that that-one outside its banks bursts

(109) They used either the $y$ or the THORN. But here they started using the tH, instead of either y OR thorn (focus on coordination)

in plaats van of wel de $y$-GREQUE, ofwel de THORN

in place of either the $y$ or the thorn

(110) She never GREETS you, and she doesn't look very HAPpy when she DOES say hello 
ALS ze je een keer gedag zegt

when she you of-a-time hello says

(111) A: What OTHer artistes have been in your car?

B: Patty Grey was never IN my car (polarity focus)

PG IS nooit in mijn auto geweest

PG has never in my car been

What this set of examples should make clear is that it is necessary to take the notion of the location of the nucleus as the realisation of focus distribution seriously. Clearly, the placements are rule-governed: there could be no explanation for the fact that they are on different elements in Dutch if they were not. It is stressed that if in the Dutch translations the nucleus is placed on the word corresponding to the word that has the nucleus in English, the result is frequently a well-formed sentence, but always one with a different spectfication for focus and/or mode. Thus, if the Dutch version of (107) is pronounced with the nucleus on op, a sentence results that actually has op in focus. As such, it could figure in a text in which the speaker's next utterance might be When hovering OVer It, they must keep well clear of grass blade TOPS. The English sentence is simply ambiguous between these two focus readings. Similarly, Patty Grey is noolt IN mijn auto geweest is well-formed only if the speaker intends to imply that she HAS been underneath it, or on top of it: his starting point is explicitly 'PG had some spatial relationship to my car' (nooit is focus governing), and his added Variable is 'But it was not an inside-relationship'. If the English speaker of (111), by contrast, were later te be confronted with forensic reports about PG's fingerprints on the roof of his car, he cannot then say that 'I never sald she might not have been on top of it' without deliberate duplicity. The English sentence is, again, ambiguous, this time between a reading with polarity focus and a reading with focus for in. The formulation of the extension to SAAR (this time for English and Dutch separately) will have to distinguish between cases in which nucleus placement seems variable, as it does when in a longer Predicate at least a verb is under focus (e.g. (105), (107)), or in a longer Argument at least a noun (e.g. (106)), and cases in which such placement is obligatory, as it of ten is when polarity is under focus, or some grammatical binding element, as in (109), (110), and (111). Ideally, the extension would specify the factors that favour the location of the nucleus on element $x$ rather than $y$ in the case of varlable nucleus placement. The formulation of this extension is felt to be outside the scope of this article, however, and we will here confine ourselves to a statement of nucleus placements in polarity focus sentences. Table 1 attempts to capture the facts for both English and Dutch. 
Table 1 Nucleus locations in English and Dutch polarity-focus (PF) sentences

\begin{tabular}{|l|l|l|l|}
\hline Mode & PF & English & Dutch \\
\hline -ca & + & $\begin{array}{l}\text { tucleus goes to the last verb } \\
\text { phrase element but one, or to } \\
\text { the rightmost preposition or } \\
\text { to-particle, if present }\end{array}$ & $\begin{array}{l}\text { Nucleus goes to the operator } \\
\text { in non-embedded sentences, } \\
\text { but to the comp-node in em- } \\
\text { bedded sentences }\end{array}$ \\
\hline+ & $\begin{array}{l}\text { as above, but the second dis- } \\
\text { junct is optional }\end{array}$ & $\begin{array}{l}\text { Nucleus goes to operator (un- } \\
\text { less not doesn't contract, } \\
\text { and it gets the nucleus) }\end{array}$ & $\begin{array}{l}\text { Nucleus goes to wel (affirm- } \\
\text { ative particle) }\end{array}$ \\
\hline
\end{tabular}

The nucleus locations in (105) to (110) wll here be left unaccounted for, as these would not seem to require essential additions to the model, and are therefore better treated in a more explicitly comparative framework

It will be clear that the words that are singled out to carry the nucleus in non-counterassertive sentences in English are conspicuous for their semantic emptiness I will label them 'nucleus carriers' or NCs Stll confining our attention to English non-counterassertive sentences, NCs are (1) the penultimate verb-phrase element (modal auxuliary, grammatical auxllary, lexical item), unless there is only one item, in which case that is the NC, (11) prepositions, and (iii) the verbal to-particle Note that when there is only a lexical item in the verb phrase, there is a strong pressure to insert do as an NC ('emphatic do') Negative non-counterassertive sentences show a clear preference for the rightmost NC, while in positive non-counterassertive sentences there appears to be a cholce between a verbal NC and a later one, if there is one In counterassertive sentences the nucleus always goes to the operator, unless not remains uncontracted and the nucleus goes to not We could formulate these facts as follows

(112) English PFR
a $\stackrel{N}{\star} \mathrm{C}(\mathrm{X})$
[- counterassertive]
b operator
[ counterassertive]

Condition if $S$ is negative, $X$ does not contain an NC 
In Dutch, the situation is marginally simpler: in non-counterassertive sentences the nucleus goes to the operator, unless the sentence is embedded, in which case it goes to the Chomskyan COMP-node, if appropriately filled: conjunctions, relative pronouns, comparative clause-introducers and the non-finite clause introducer orn (te) all qualify. In counterassertive sentences it goes to the polarity morphemes wel and niet. Thus, we may say:

Dutch: $\quad$ PFR
a. COMP, if $\mathbf{S}$ operator [-counterassertive]
b. polarity morphem
[ + counterassertive]
where $\mathbf{S}$ stands for 'embedded sentence'.

The following examples illustrate the above rules (cf also (7), (91) to (96), (110) and (111)). First, [-counterassertive] sentences:

(114) A: Why didn't you take the GARbage out?

$B$ : I TOOK the garbage out

Ik HEB de vuilnis buiten gezet

I have the garbage outside put

(115) A: I wish you LOVED me

B: But I DO love you

Maar ik HOU van je

But I love you

(116) A: Now that everything has been CLEANED, we can start putting things aWAY

B: ExCUSE me, not everything has BEEN cleaned

ParDON, niet alles IS schoongemakt

not everything has-been cleaned

(117) A: SIMple! We'll transplant a new KIDney!

B : In THIS hospital, no organs will BE transplanted!

ZULlen geen organen worden getransplanteerd

will no organs be transplanted

(118) A: I wish we were in FRANCE

B: We ARE in France/ We're IN France! 
We ZIJN in Frankrijk

We are in France

(119) A: Why haven't you started READing yet?

B: There are no books TO read

Er ZIJN geen boeken om te lezen

There are no books (for) to read

(120) A: Why aren't you looking at your PICtures?

B: I have no plctures to look AT

Ik HEB geen plaatjes om naar te kijken

I have no pictures for to(prep.) to(particle) listen

The following examples illustrate polarity focus in (non-counterassertive) embedded clauses, which in Dutch require the nucleus on the COMP-node:

(121) We can't bend backwards any further than we HAVE done

We kunnen u niet verder tegemoet komen DAN we dat al hebben gedaan

than we that already have done

(122) I didn't know we were IN Quebec

Ik wist niet DAT we in Quebec waren

I knew not that we in Quebec were

(123) I know most of the people that I DID see

Ik ken de meeste mensen DIE ik heb gezien

I know the most people who I have seen

(124) Our task is to SOLVE these problems and if you've got the means TO solve them...

en als je de middelen hebt $O M$ ze op te lossen

and if you the means have for them (prefix) to solve

(Note how in (124) the nuclei are on equivalent words, but that this similarlty is superficial: Dutch om is a COMP-filler, English to is an NC.) Nucleus locations in polarity-focus sentences that are counterassertive are considerably less complex. One example will suffice:

(125) A: DARling, we could never have MADE it!

B: Oh, but we COULD have!

Ach, we hadden het WEL kunnen halen

Oh, we had it affirmative particle can make 
Ambiguities, so it would seem on some reflection, are the rule rather than the exception Two cases are perhaps worth singling out In Dutch, a nucleus on a finite verb form may signal focus for the verb (by SAAR) or non-counterassertive polarity focus (by PFR) In English, a nucleus on an operator may signal either non-counterassertive or counterassertive polarity focus (both by PFR) In (126) - (128) these ambiguities are compared across the two languages Note that Dutch niet rewrites as geen if the sentence contains an indefinite object

(126) A Have you seen Brideshead ReVISited?

B I don't WATCH television

Ik KIJK geen televisie ('not' focus on verb)

(127) A Monk RUFus, it says in this report that you watch TElevision

B But I DON'T watch television, father ("WATCH) Maar ik KIJK geen televisie ('GEEN) (polarity, [-counterass])

(128) A Monk RUFus, you watch TElevision'

B NO, I DON'T watch television'

NEE, lk kıjk GEEN televisıel (polarıty, [+counterass])

A final remark on the role of not in focus assignment is made here Observe that not only occurs in the Variable in negative polarity-focus sentences (and may have the nucleus only when the mode is [+counterassertive] and does not contract) Elsewhere, not is focus-governing, like even, also etc, but it may also occur in the [-focus] material (cf Jackendoff 1972) The three possiblities are lllustrated in (129), (130) and (131) below

(129) (The SHED may be on fire, but) the `HOUSE isn't on fire

$$
\begin{array}{ll}
\text { [ } x \text { is on fire] } & {[x=\text { the house }]} \\
\uparrow & {\left[\begin{array}{l}
\uparrow \\
\text { +focus } \\
\text { not } \\
\text { SELECTIS }]
\end{array}\right]}
\end{array}
$$

(130) (A The HOUSE is on fire B NO,) the house 'ISn't on fire

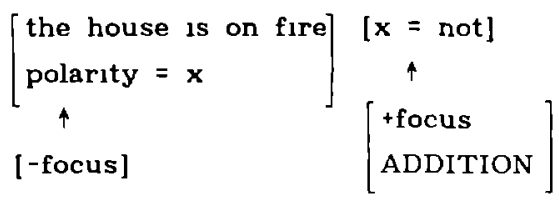


(131) (A: LUCKily, the HOUSE wasn't on fire. B: More reassuring STILL, ) the house 'ISn't on fire (Put that BLOW torch out!)

$\left[\begin{array}{l}\text { the house be not on fire } \\ \text { tense }=x\end{array}\right]$
$\uparrow$
$[$-focus $]$$\quad \begin{gathered}{[x=\text { present }]} \\ \uparrow \\ {\left[\begin{array}{l}\text { +focus } \\ \text { ADDITION }\end{array}\right]}\end{gathered}$

The obvious advantage of taking not as focus-governing is that there is no semantic reason for postulating a feature 'scope' for not, the scope of not being identical with the focus of the sentence. It may perhaps be noted that not is sometimes invoked to account for differences of interpretation that it really cannot be held responsible for. An example is the difference between epistemic and deontic interpretations of English modal auxiliaries. As Lyons (1981: 133) says, He may not come can mean either 'It is possible that he will not come' or 'He is not permitted to come', with not associating differentially with the (paraphrase of) the modal. In our interpretation of not, both sentences have the same representation, however:

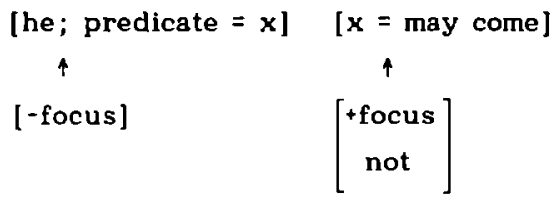

Note that although logically the status of not may seem different in the two interpretations, there is no reason for postulating different lingulstic structures for them, any more than for the difference between the two interpretations of he may come, except of course in so far as there are two auxiliaries may, one indicating permission and the other indicating possibility. There is, in other words, a crucial distinction between, on the one hand, differences of the type exemplified by ALL the men didn't go (either all [+focus] and not [-focus]: 'None of the men went'; or all [+focus] and not focus-governing: 'Not all the men went'), or by John didn't kill his brother (for instance, either John [+focus] or brother [+focus], and not focus-governing in either case), and on the other hand, the difference between the two interpretations of he may not come: in the former case we are dealing with paradigmatic choices available in the linguistic system affecting the status of not, in the latter case we are not. ${ }^{15}$ 


\subsection{SUMMARY}

1. On the level of the sentence, the nucleus, more generally accent, is seen as the major realisation of the universal concepts of focus and mode in languages like Dutch and English.

2. While it is possible to define the concept of 'normal stress' in terms of the model, the concept has no role to play in the mechanics of accent assignment.

3. Focus is not co-extensive with the tone group: while the material in a single focus domain need not be contiguous (provided no alien [+focus] constituents are interposed), there may be more than one [+focus] focus domain in the same tone group, in which case the Sentence Accent Assignment Rule applies to each one of them.

4. For an Argument and a Predicate to be able to form a single focus domain, the Argument must be lexically filled and the sentence must be eventive.

5. Mode is relevant to accent assignment independently of focus distribution. A concept of 'contrastive stress' has no role to play in the model.

6. The Polarity Focus Rule demonstrates that two closely related languages may differ in the way they realise focus and mode. 


\section{Notes}

1. An earlier version of sections 1 to 4 was presented at the Tenth PILEI Symposium (Cornell University, 1 August 1981) and the Edinburgh Linguistics Circle (4 November 1981), while the distinction between mode and focus (then called 'range') was the subject of a paper presented at the Second Conference on the Teaching of Spoken English (Leeds University, 7 August 1979). I should like to thank Ton Broeders, Gill Brown, Jim Hurford, Bob Ladd, Toni Rietveld, Felix Vieregge and an anonymous reviewer for Journal of Linguistics for their comments on earlier drafts. To Bob Ladd I am more generally indebted for encouraging me to pursue the approach taken here.

2. The term 'sentence' is used in its ordinary sense of 'well-formed surface structure' (or fragment of it), which of course includes the sentence accent(s). The term 'ambiguity' then naturally refers to the existence of more than one possible specification for the features to which the presence of sentence accents is sensitive, like [focus].

3. The same point is made by Ladd (1980: 98) when he says that the operation of a deaccenting rule he postulates 'should not be confused with the reasons for which the speaker chooses to operate the rule in the first place'.

4. I am freely paraphrasing an example which was brought to my attention by Ton Broeders. It occurred in the British television serial Dad's Army, when a member of the Home Guard, who for some undisclosed military reason had been ordered to speak French, justified his obvious non-compliance with the order by saying But we're not IN France.

5. Please belongs to a group of expressions that can be appended to sentences without attracting the nucleus. Among them are vocatives (Crystal 1975: 25, Bing 1979: 25) and general time indicators like for a while, tomorrow (Brown 1977: 89). Bing calls them 'Class O expressions'.

6. For 'manipulation' some such term as 'intonational speech act' might seem appropriate. The term is unfortunate, as it would suggest a similarity to 'speech acts' (Searle 1969), which essentially refer to speakers' intentions (or hearers' conclusions), whereas 'manipulations' constitute a linguistic paradigm, like tense or mood.

7. For expository reasons, I exclude from consideration non-interpretative readings, referred to by Brazil, Coulthard \& Johns (1980) as 'reading what it says'. People in fact frequently read out isolated sentences almost on a word-by-word basis, without constructing any Background at all.

8. The focus governer should be distinguished from the viewpoint adjunct (Quirk et al 1972: 429) meaning 'as far as NP is concerned'. It is syntactically distinct from the focus governer in that it can only be used to refer to subjects. Thus, I wouldn't like to go there mySELF is ambiguous between mySELF meaning 'personally' (as in London is a fine place, but ...) and mySELF meaning 'no one other than $\mathrm{me}^{t}$ (as in Not only wouldn't my wife like to go there, but ...). Secondly, it may need pointing out that the focuser should be kept distinct from the reflexive pronoun, which has the same phonemic make-up and is part of the predicate, occurring in e.g. John KICKED himself. An interesting structure results when we produce a [+focus] reflexive and insert the focus governer, in which case the reflexive is deleted in English, as in John kicked himSELF (= John kicked himself himSELF). Note that this sentence is ambiguous in three ways: the focus 
governer may have John in focus (Was it Bull who John kicked? No _), it may have the reflexive in focus (Was it Blll who kıcked John? lo ), or it may have John in focus without there being a reflexive pronoun (Did Blll kıck? No ) For the distinction between the reflexive and the focus governer, see van der Leek (1980)

9 Clark \& Clark (1977) cite evidence that passive sentences with the nucleus on the by-agent are less likely to be given full focus interpretations than active sentences with the nucleus on the object

10 Note that [AP] and [AP] give the same surface form Aghem, a Grassfields Bantu language, distinguishes these structures by placing the argument in final position if the predicate is [+focus] By contrast, this language makes no formal distinction between [AP] and [AP] in the case of subject + intransitive verb sentences (Watters 1979 145)

11 As far as the assignment of sentence accents is concerned, there is thus no reason to postulate any form of metrical structure as proposed by Liberman \& Prince (1977), a linguistic device enlısted by Ladd (1980 87, 1981a) to account for the nucleus location in B's reply in $A$ Has John read Slaughterhouse Five? B John doesn't READ books Ladd assumes that here the focus is 'broad', and that there is a deaccenting rule that switches the 'strong' and 'weak' round associated with books and read respectively Quite apart from the fact that the postulation of full focus plus a deaccenting rule plus a metrical tree amounts to an unnecessary burdening of the mechanics of accent assignment, and the fact that such a description relies on the idea that there is some form of 'normal' accentuation ('broad focus'), the ploy doesn't work as Ladd himself points out (personal communication), there would be no accounting for a sentence like He TOOK the garbage out, unless the garbage out is taken to be a constituent by the side of took I have included his example as (114) It is pointed out that the Slaughterhouse example corresponds to (126)

12 It is, however, the semantics rather than syntactic structure that provides the stronger link For one thing, unlike adverbs of 'proper functioning', an object complement can, for whatever reasons, be assigned to a separate focus domain, as in

(1) They left the first team/GASPing'

For another, if the object complement denotes a degree of 'proper functioning', it may behave just like the adverb

(2) If it doesn't do what you WANT it to do, you've probably spelt the comMAND word wrong

but with a [-focus] Argument

(3) BeLIEVE me If you get a result bigger than ONE or smaller than MINus one, you've DONE it wrong'

13. I owe the example to Ton Broeders It is interesting to note that the original of (71) was $\mathrm{H}_{1}$ is met zijn zoontje fietsen ('He's gone cycling with his son') As cycling with one's son is a fairly everyday activity for a father to go in for in the Netherlands, the Dutch sentence naturally has a single focus domain The English translation, however, provoked some protest from native speakers, who seemed to require an accent on cycling, in the same way as they would put one on fishing By the same token, (70) may be more llustrative of the point at issue if fishing is replaced with hunting These cultural differences would seem to support the the analysis offered

14 I thank Pieter Nieuwint for drawing my attention to this fact 
15 A syntactic correlate between focus-governing not and not as part of the [-focus] material can be observed when we add a focus governing adjunct like also Note that He didn't hll John is ambiguous between
(1) [he hlled $x] \quad[x=\underset{\uparrow}{J}$ John] and (2) [he didn't kلll $x]$ [x $=$ John] [-focus $] \quad\left[\begin{array}{l}+ \text { focus } \\ \text { not }\end{array}\right]$ [-focus] [+focus]

In (1), the fact that 'he' kulled someone is part of the Background, and the variable is that this is not true for John In (2), the fact that 'he' didn't kll someone is part of the Background, and the variable is that this is true for John When we add a focus-governing addittve adjunct, we get not too in (1), but not either in (2) he didn't kll John/ TOO' versus he didn't kll John /EITHer' Cf also Ladd's 'inside NEG' and 'outside NEG' (1981b)

\section{References}

Allerton, D J (1978) 'The notion "Givenness" and its relations to presupposition and theme', Lingua 44 133-168

Allerton, D J \& Cruttenden, A (1979) 'Three reasons for accenting a definite subject' Journal of Linguistics $15 \quad 49-53$

Berman, A \& Szamosi, M (1972) 'Observations on sentential stress' Language 48 304-325

Bıng, J M (1979) Aspects of English prosody Bloomington IULC

Bing, J M (1980) 'The given/new distinction and the unmarked stress pattern' NELS XI 13-21

Bloomfield, L (1933) Language New York Holt

Bolinger, D (1958) 'A theory of pitch accent in English' Word 14 109-149

Bolinger, D (1961) 'Contrastive accent and contrastive stress' Language 37 83-96 Reprinted in D Bolınger (I Abe \& $T$ Kanekiyo eds) Forms of English Accent, morpheme, order Tokyo Hokuou (1965) 101-117

Bolinger, D (1972) 'Accent is predictable (If you're a mind-reader)' Language $48 \quad 633-644$

Bolınger, D (1978) Review of Schmerling (1976) American Journal of Computational Linguistics

Brazil, D (1975) Discourse intonation vol 1 Birmingham University Department of English

Brazl, D , Coulthard, M \& Johns, C (1980) Discourse intonation and language teaching London Longman

Bresnan, J (1971) 'Sentence stress and syntactic transformations' Language $47 \quad 257-281$

Bresnan, J (1972) 'Stress and syntax a reply' Language 48 326-342

Brown, G (1977) Listening to spoken English London Longman 
Brown, G , Currie, K L \& Kenworthy, J (1980). Questions of intonation London Croom Helm

Chafe, W L. (1970). Meaning and the Structure of Language. Chicago. Chicago University Press

Chafe, W.L (1976). 'Givenness, contrastiveness, definiteness, subjects, toplcs, and points of view'. In L1, C (ed), Subject and toplc. London' Academic Press. 25-56.

Chomsky, N. (1969). Deep structure, surface structure, and semantic interpretation. IULC. Reprinted in Chomsky, $N$ (1972) Studies on semantics in generative grammar. The Hague: Mouton

Chomsky, N \& Halle, M. (1968). The Sound pattern of English. New York: Harper \& Row.

Clark, H.H, \& Clark, E.V. (1977) Psychology and language New York: Harcourt Brace Jovanovich.

Cruttenden, A. (1981). 'Falls and rises' meanings and universals'. Journal of Linguisties 17 77-91.

Crystal, D (1969). Prosodic systems and intonation in English. Cambridge: Cambridge University Press.

Crystal, D (1975) The English tone of volce London Arnold

Dik, S. (1978). Functional grammar. Amsterdam North Holland

Dik, S. (1980) Perspectives on functional grammar London. Academic Press.

Dik, S. et al (1980) 'On the typology of focus phenomena' Leids Taalkundig Bulletin GLOT 3 41-74.

Edwards, E A. (1979) 'Topic marking in Haida' International Journal of American Linguistics 45. 149-156

Firbas, J. (1979). 'Post-intonation-centre prosodic shade in the modern English clause'. In Greenbaum, S, Leech, G \& Svartvik, J. (eds), Studies In English linguistics for Randolph Quirk London Longman 125-133.

Fuchs, A. (1980) 'Accented subjects in 'all-new' utterances'. In G. Brettschneider \& C Lehmann (edd) Wege zur Universalienforschung sprachwissenschaftliche Beitrage zum 60 Geburtstag von Hansjakob Seler. Tubingen Narr. 449-461.

Gussenhoven, C (1978). Review of Schmerlıng (1976). Dutch Quarterly Review 8 233-240.

Gussenhoven, C. (1981) 'Nucleus, focus and mode'. Paper given at the Xth PILEI Symposium held at Cornell University (1 August), Ithaca (NY).

Halliday, M A K (1967a) Intonation and grammar in British English The Hague: Mouton.

Halliday, M.A.K. (1967b). 'Notes on transitivity and theme in Englısh, part 2'. Journal of Linguistics 3 199-244. 
Hohle, T.N. (1979). 'Normalbetonung' und 'Normale Wortstellung': eine pragmatische Explikation'. Leuvense Bijdragen 68. 385-437.

Jackendoff, R.S. (1972). Semantic interpretation in generative grammar. Cambridge, Mass: MIT Press.

Jong, J. de (1980), 'On the treatment of focus in functiongl grammar'. Leids Taalkundig Bulletín GLOT 3. 89-115.

Kraak, A. (1970) . 'Zinsaccent en syntaxis'. Studia Neerlandica 4. 41-62.

Ladd, D.R. (1978). 'Stylized intonation'. Language 54. 517-540.

Ladd, D.R. (1980). The structure of intonational meaning: evidence from English. Bloomington: Indiana University Press.

Ladd, D.R. (1981a) 'Rhythm and sentence stress in a modified Liberman-Prince theory'. Paper given at the Phonology Colloqulum held at Cornell University (24 July), Ithaca (NY).

Ladd, D.R. (1981b) 'A first look at the semantics and pragmatics of negative questions and tag questions.' Papers from the seventeenth regional meeting of the Chicago Linguistic Society. 164-171.

Lakoff, G. (1972). 'The global nature of the Nuclear Stress Rule'. Language 48. $285-303$.

Leek, F.C. van der (1980). 'Reflexive or non-reflexive'. Dutch Quarterly Review 10. 124-146.

Liberman, M. (1975). The intonational system of English. MIT Dissertation.

Liberman, M. \& Prince, A. (1977). 'On stress and linguistic rhythm'. Linguistic Inquiry 8. 249-336.

Lodewyckx, A. (1944). A handbook of Dutch. Melbourne: Melbourne Universlty Press.

Lyons, J. (1981). Language, meaning and context. London: Fontana.

Oakeshott-Taylor, J. (1981). '/Nót to stress/ or tó stress/3 On the location of "Tonic Prominence" in English'. Linguistic Agency University of Trier paper Series $A$, no. 86 .

O'Connor, J.D. \& Arnold, G.F. (1973). Intonation of colloquial English, 2nd edition. London: Longman.

Paardekooper, P.C. (1963). Beknopte ABN-syntaxis. Den Bosch: Malmberg .

Prince, E.F. (1979). 'Toward a taxonomy of the Given/New distinction'. To appear In Cole, P. (ed), Radical pragmatics. London: Academic Press.

Quirk, R., Greenbaum, S., Leech, G. \& Svartvik, J. (1972). A grammar of contemporary English. London: Longman.

Schmerling, S.F. (1974). 'A re-examination of normal stress'. Language 50. 66-73.

Schmerling, S.F. (1976). Aspects of English sentence stress. Austin: Texas University Press. 
Searle, J.R. (1969). Speech acts. Cambridge: Cambridge University Press.

Taglicht, J. (1982). 'Intonation and the assessment of information'. Journal of Linguistics 18. 213-230.

Watters, J.R. (1979). 'Focus in Aghem'. In Hyman, L.M. (ed), Aghem grammatical structure. Southern California Occasional Papers in Linguistics 7. 137-197. 


\section{From focus to sentence accent: A rule for the assignment of sentence accents in Dutch}

\subsection{INTRODUCTION}

In the past two decades, the problem of how the assignment of sentence accents is to be described has been approached in a number of ways. ${ }^{2}$ In the transformational-generative tradition the possibility of a syntactic solution has been investigated (Chomsky \& Halle 1968: 17-24, Bresnan 1971, 1972, Lakoff 1972). These efforts were always made in the realisation that a successful description (which, incidentally, has never been produced) would only account for part of the data, viz. the part that, on the basis of largely implicit criteria, was characterised as representing 'normal (unmarked) sentence accentuation'. The remaining data, the instances of 'contrastive sentence accentuation', led a somewhat shadowy existence in the theory. These sentence accents we not so much generated - as was the case for normal sentence accents - but were assigned interpretive status; if they were there, then rules of interpretation would see to it that the language user would be able to derive the appropriate focus interpretations (Chomsky 1972).

Bolinger (1972) has correctly pointed out that this syntactic approach ignores the fact that the position of the sentence accent is determined by speakers ${ }^{\prime}$ intentions, which are altogether unpredictable from syntactic structure. Moreover, as particularly Schmerling (1974, 1976) emphasised, the distinction between 'normal' and 'contrastive' accents cannot always be made in practice.

A possible conclusion to be drawn from these observations is that there is no point in continuing the search for rules that control the assignment of sentence accents. Such defeatism, however, would be decidedly unwelcome to an increasingly popular area of linguistic research. As is well-known, there is a growing interest in the development of automatic speech generators, which - in their least ambitious form - should be able to convert written text into spoken language. It will be clear that such an instrument will have to meet not only segmental demands (which should not pose a major problem to it), but also prosodic 
demands. Thanks to the descripion by 't Hart \& Collier (1975), Collier \& 't Hart (1978), the generation of Dutch intonation patterns does not have to present insuperable difficulties, but the complex problem of which of the well-formed intonation patterns can best appear in which positions has remained. The question where those patterns should appear is the same as the question of the position of the sentence accent - assuming that certain combinations of movements are interpreted as the 'tones' of the British descriptions, or the 'melodies' of autosegmental phonology. Rightly, therefore, the conclusion suggested by Bolinger (1972) has not been drawn, and research has been started in the Netherlands among other places - into the problem of sentence accent placement in an as yet probabilistic framework (Nooteboom, Kruyt \& Terken 1981, Nooteboom \& Terken 1982). That ls, the aim in that type of research is to discover the factors that determine the accentuation behaviour of speakers through the observation of statistical regularities in the behaviour of subjects in experimental situations, the eventual objective being the replacement of the probabilistic rules by deterministic ones.

This development has led to a shift of discipline In the research into sentence accent assignment. The research has been lifted out of a langur se-theoretical framework and been transferred to an area of applied linguistics. Although it will not be assumed here that it is mainly syntactic factors that determine the position of the sentence accent, the approach taken in this article is more akin to that of the syntacticians. Thus, there will be no attempt here to explain speakers' behaviour in any way. We will start simply from the assumption that speakers can make certain linguistic (systemic) choices. The goal is to generate surface structures of sentences on the basis of these specified choices. The terms 'account for' and 'explain', therefore, will not be used in this article in the sense of 'giving a justification of the motives that led the speaker to make certain choices', but in the sense of 'accounting for the surface structure of sentences in terms of the options postulated', where 'surface structure' mainly stands for sentence accents. The rules to be discussed below are rules of the language, not rules of language use.

The discussion is mainly restricted to a single sentence accent assignment rule, simply referred to as SAAR, and as such to those structures that rank as input for that rule. This does not imply that input structures to which SAAR does not apply have a separate status on the basis of which they can be left out of consideration, comparable to the treatment given by syntacticians to 'contrastive sentence accents'. Sentence accents that SAAR does not account for are left un- 
discussed simply because the intention here is not so much to explain all the data, but, through the formulation of SAAR, to place the problem of sentence accent assignment in a somewhat more orthodox theoretical framework than it seems to have got itself into at present.

In the next section the most important linguistic option relevant to our problem, focus, will be introduced. In section 3, SAAR will be formulated as a focus-sensitive rule. SAAR does two things: it divides the focussed material into domains and then assigns an accent to each domain. After a discussion of some implications of the rule and of some instances of focus assignment that lead to apparent counterexamples to the domain assignment rule, a tripartite division of the sentences of Dutch will be made in section 5. It will be argued that in two of the three sentence categories the domain assignment rule does not apply. Moreover, it will be shown that it is necessary to keep these two sentence types separate, since in certain circumstances they have different surface structures. Finally, section 6 will attempt to provide a somewhit more complete description of the constituents SAAR refers to than has been given in the preceding sections.

\subsection{FOCUS}

The most important option realised by sentence accents is focus. Of each sentence or sentence fragment at least part of the semantic material must be marked [+focus]. If not all the material is thus marked, the rest remains [-focus]. In other words, sentences that are entirely [-focus] do not exist. It is important to reallse that [ $₫$ focus] is a linguistic option, just like, for example, [ \pm passive], and that as such it is also a semantic choice. It is difficult to define the meaning of focus, although perhaps no more so than it is to describe the meaning of syntactic options like [ \pm perfect] or [ \pm passive]. Perhaps the best formulation is that the speaker presents the linguistic material in focus as his 'contribution' to the conversation and the material which he leaves out of focus as his 'starting point', i.e. information that the hearer already knows or should know about. In this sense, [tfocus] material is 'new' and [-focus] material is 'old' or 'given' (Halliday 1967, Chafe 1970). However, the disadvantage of these terms is that they are apt to give rise to misconceptions, or rather, alternative interpretations (cf Brown 1983). One might for instance expect that what is marked 'new' 
is actually 'new' in the sense of 'unpredictable', and that what is 'old/given' is 'predictable', and subsequently investigate whether this is in fact the case. This activity is useful to the extent that it will lead to the elimination of that misconception, but less useful insofar as the interpretation it seeks to test ultimately implies the reduction of an important semantic choice on the part of the speaker to something redundant, to something like second marking of the plural in De Karpaten liggen in Oost-Europa ('The Carpathian Mountains are in Eastern Europe'), or to something that concerns only the phonetic shape of the sentence, comparable to the fact that the Dutch vowel / $\mathrm{j} /$ is long before a homosyilabic $/ r /$, as in bier ('beer'). (Cf also Keijsper 1982, who argues that sentences - marked with sentence accents - should be regarded as independent linguistic objects.)

Even if one is convinced that focus is a 'systemic' choice, it can still be hard to realise - since it is generally not at all expressed in writing - what is focus in a given utterance or what can be frcus in a given sentence, also where the context is known. This paper will only deal with relatively clear cases of focus distribution. Yet, it may be useful to know that there are methods that make it easler for us to see what exactly is [+focus] in a given instance.

An entirely [+focus] sentence can be used by a speaker who, until the moment of speaking, was not yet involved in a conversation with the hearer about the subject-matter expressed in it. This sentence type is also known as 'news sentence' (Schmerling 1976). Suppose we wonder whether sentence (1) is entirely [+focus]. ( $H$ here indicates a sentence accent. The notation is taken from autosegmental phonology, where the symbol may be used to mark the association position of a 'melody'.)

(1) Uw Everhemd is gestreken
Your shirt has-been ironed

We might then realise that it is possible for $B$ to knock at $A$ 's door, upon $A$ 's "Come in!" to enter, and use (1), knowing that A was unaware that B would that day be engaged in the troning of shirts. B's starting point is nil and he utters a 'news sentence'. Suppose, now, that we ask the same question with respect to $B$ 's utterance in (2):

(2) A: Is er nog nieuws?

Is there any news? 
B: Oom Wanja is gisteren in het zitekenhuis opgenomen Uncle Wanja has-been yesterday to the hospital admitted

and imagine that we are sitting outside in a pavement cafe, B walks up to us and uses the sentence. Notice that now the sentence is possible only if A and B have common background knowledge (and are mutually aware of this) to the effect that Uncle Wanja is ill and may have to go to hospital. In other words, there is background knowledge 'Uncle Wanja is ill', Uncle Wanja is [-focus], and the sentence is not a 'news sentence'. For it to be a 'news sentence' we must imagine that $A$ had no idea that there was a sick Uncle Wanja who could be used as a starting point for a contribution about the consequences of his illness. In this case we would get:

A: Is er nog nieuws?

B: Oom Wănja is gisteren in het ziekenhuis opgenomen

A : Wăt zeg je ? Wat is er met hem aan de hând?

Good heavens! What's the matter with him?

In order to determine more easily what is [-focus], it is often helpful to let the utterance (or sentence) be preceded by the context 'Talking of $X^{\prime}$ or 'Now that we are on the subject of $X^{\prime}$, where $X$ can naturally be $[$-focus] in the sentence concerned (cf (1)-(3)). If, for instance, one wished to determine whether in (4), in addition to Jan, stukslaan ('break') is [-focus], one could place (4) in

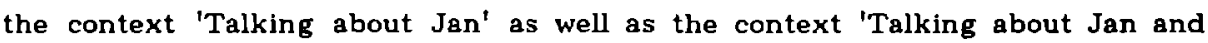
breaking', and observe that the sentence is well-formed in both contexts, which renders it ambiguous between a reading with just Jan [-focus] and a reading with Jan kan stukslaan [-focus].

(4) Jan kan met een ếi een biếrflesje stukslaan John can with an egg a beer-bottle break

However, if we place (4) in the context 'Now that we're on the subject of what Jan can do with eggs', it appears that the sentence accent on el in (4) can easily be (some would say 'should be') left out.

There is another ploy that can help us to recognize what is [+focus]. There is a group of words that are not marked for focus. The function of these words is rather to add a meaning to [+focus] material. An example of such a focus-governing word is zelfs ('even'). As [+focus] linguistic material is also the 
linguistic material that lies inside the scope of focus-governing morphemes, addition of such a morpheme may help to show the focus distribution of that material. Often we have a better intuition for what lies inside the scope of a word like zelfs than for what is [+focus] material. Note that here we can only consider utterances, i.e. sentences used in a particular context. If, for example, one wished to determine, by means of adding zelfs to sentence (5), whether it is ambiguous between a 'news sentence' and a sentence with just de bever [+focus], and one placed zelfs at the beginning:

(5) De bềver is ontsnapt

The beaver has escaped

(6) Zelfs de betver is ontsnapt

Even the beaver has escaped

then It will be clear (see (6)) that zelfs can only refer to de bever, and not to de bever is ontsnapt. Yet, without zelfs, de bever is ontsnapt is ambiguous. In order to show the other focus distribution as well, we would have to place zelfs between is and ontsnapt:

( $\left.{ }^{7}\right)$ Álles gaat föut! Het dakk lekt en de bèver is zelfs ontsnapt! Everything goes wrong! The roof leaks and the beaver has even escaped!

(B) We moeten betere slöten hebben. De zểbra's zijn er vandoor, en de bểver is zelfs ontsnapt

We must better locks get. The zebras are gone, and the beaver has even escaped

In (7) de bever is ontsnapt is [+focus], whereas in (8) only de bever is 1+focus]. This example, incidentally, illustrates that ambiguous sentences may sometimes be dlsambiguated by syntactic means. With zelfs at the beginning of the sentence only the leftmost constituent can be [+focus], without zelfs, de bever is ontsnapt is ambiguous. ${ }^{2}$ This shows that even a purely syntactic description of surface structures cannot ignore focus distribution with impunity, and that it is not just sentence accents that are sensitive to it. ${ }^{3}$ 


\subsection{SAAR}

For the purposes of SAAR it is necessary to distinguish three sentence constituents:

1. Arguments: Constituents that function as subject or object;

2. Predicates: Constituents that function as syntactic predicates;

3. Conditions: Constituents that function as adverbial adjuncts.

Although these constituents are here defined in syntactic terms, they are not syntactic constituents, but semantic ones. However, since in the examples to be discussed, there is, approximately, a one-to-one correspondence between these semantic constituents and the syntactic ones indicated, further definition of them can be postponed (see section 6).

In SAAR the constituents are indicated by the symbols $A, P$, and $C$; the variables $X$ and $Y$ may stand for any of these. SAAR assumes that at least one of these three constituents is [+focus]: in (9) underlining indicates [+focus] and absence of underlining [-focus]. SAAR works in two stages. Flrst the [+focus] language material is divided into focus domains (indicated by square brackets) and subsequently each focus domain is assigned an accent. Thus, a focus domain may be defined as a structure that can be marked [+focus] with a single sentence accent." Note that if an Argument and a Predicate occur in the same focus domain, the accent is assigned to the Argument.

(9) SAAR

$\begin{array}{ll}\text { a. Domain assignment: } & \underline{\mathrm{P}}(\mathrm{X}) \underline{\mathrm{A}} \rightarrow[\mathrm{P}(\mathrm{X}) \mathrm{A}] \\ \text { (ordered) } & \underline{\mathrm{A}}(\mathrm{X}) \underline{\mathrm{P}} \rightarrow[\mathrm{A}(\mathrm{X}) \mathrm{P}] \\ & \underline{\underline{Y}} \rightarrow[Y] \\ \text { b. Accent assignment: } & {[] \quad \rightarrow[*] . \text { In }[\mathrm{AP} / \mathrm{PA}], \text { accent } A .}\end{array}$

In other words, SAAR assigns a focus domain to each [+focus] constituent, except to an Argument and Predicate (optionally separated by a [-focus] constituent), which share a focus domain. Subsequently each domain is assigned an accent. Before illustrating the rule, we need to put a restriction on the kind of language use it applies to. The restriction concerns language mode: SAAR only 
applies to normal conversational style. Reading style, such as $A^{\prime}$ 's utterance in (10), is excluded.

(10) A (news reader): ...en bij de Amerikaanse Ambassade zijn ălle rưten íngegooid...

at the American Embassy have-been all windows smashed

B: Wat?

Pardon?

C: Oڤ̆, bij de Amerikăanse Ambassắde zijn ălle rửiten ingegooid

It will be clear that $A^{\prime}$ 's utterance is the result of a specialised type of language use: reading out written texts. As such, it falls outside the scope of our investigation. 'C's utterance, however, is an instance of 'normal conversational style' and falls inside 1t. This comment also applies to example sentences in linguistic essays. A written sentence like Yvonne slaapt ('Yvonne is asleep') will probably be pronounced as Yvŏnne slakapt, a surface structure we are not interested in. We do have to explain, however, why the sentence accents in (11) and (12) are where they are.

(11) Stîl! Yvönne slaapt!

Quiet. Yvonne sleeps

(12) A: Watar zijn de kinderen?

(Where are the children?)

B: Jắn is bij de bứren en Yvổnne släapt

John is with the neighbours and Yvonne sleeps

Below are some examples of focus distributions SAAR applies to:
(13a) $\underline{\mathrm{A} P} \rightarrow[\stackrel{\sharp}{A}] \mathrm{P}$
(Has anyone resigned?)
De voorzitter is afgetreden
The chairman has resigned

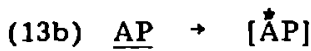
(What's new?)
(13c) $\underline{\mathrm{ACP}} \rightarrow[\stackrel{\mathbb{A}}{\rightarrow}][\stackrel{\vec{C}}{\mathrm{C}}][\stackrel{\vec{P}}{\mathrm{P}}]$
De vöorzitter is afgetreden
De voorzitter is inderhäast
ăf getreden
The chairman has hurriedly resigned
(13d) $\mathrm{A} \underline{\mathrm{P}} \rightarrow \mathrm{A}[\stackrel{\vec{P}}{ }]$
(Why can't the chairman do that?)
De voorzitter is ăfgetreden 
To the left of the arrows examples of focus distributions are given, to the right is the output of SAAR, followed by an example sentence. The following comments are made:

1. (13a) and (13b) yield identical surface structures. This is in agreement with the remarks made earlier for (4) and (5). In (13a) the Argument is assigned its own domain, in (13b) it shares a domain with the Predicate.

2. In (13c) the accent on afgetreden is parasytic; the information status of this Predicate" has not changed relative to (13b): they are both equally 'new'. The explanation for the accent on afgetreden is that the focus domain it shared with de voorzitter in (13b) has been broken up by the 1+focus] Condition inderhaast. If afgetreden in (13c) remains unaccented, it can only be interpreted as [-focus]. Examples such as these (cf also De televisie is nu Echt stutk 'The television has now definitely gone on the blink' versus De televisie is stuk, De dö́i was alläng ingetreden 'The thaw had long since set in' versus De doboi was ingetreden, etc.) show that the concept of focus domain is indispensable. It is impossible to explain the difference in accentuation of the Predicates in (13b) and (13c) on the basis of their focus markings alone. Rules that relate the accentuation of a constituent directly to its focus marking, as suggested for English by Schmerling (1976: 84), Bing (1979: 126) and Ladd (1980: 85), break down in the face of this kind of data (and other data, see below), simply because a rule that gives priority to the accentuation of NPs over the accentuation of VPs will fail to assign an accent to the Predicate in both (13b) and (13c).

3. SAAR, in its present formulation, is unable to generate the surface structure De vơtorzitter is alfgetreden. For this structure to be generated it is necessary for AP domain assignment to be blocked. Section 4 will deal with this problem in more detail.

Further to 2 above, note that also a change in word order may prevent the creation of an AP/PA domain. Examples (14a) and (14b) are 'news sentences'. In (14b) AP domain assignment is allowed, in (14a) it is not, because of the interposition of the Condition in Marseille.

(14a) (Heb je 't al gehơord?) Yvốnne is in Marsểille gearrestë́erd (Have you heard?) Yvonne has-been in Marseille arrested (14b) (Heb je 't al gehoord?) Yvồnne is gearresteerd in Marsềille 
SAAR not only explains the difference in the number of accents in (14a) and (14b), it also accounts for the fact that when Yvonne is [-focus] (and is replaced by the pronoun ze for convenience), the number of accents is equal again (two) (cf (15a) and (15b)).

(15a) (Wat is er met Yvonne?) Ze is in Marsềlle gearrestéerd (What is the matter with Yvonne?) She has been in Marseille arrested (15b) (Wat is er met Yvonne?) Ze is gearrestêterd in Marsêtlle

If we let the $C$ in Marseille correspond to the $X$ in SAAR, and it is kept outside the focus (as in (16)), AP domain assignment is allowed, even though this Condition is placed between an Argument and a Predicate. The accent may here be realised as $1 \mathrm{E}$ (or a 'half-fall') (cf Collier \& 't Hart 1978 for this terminology).

(16) (Waarom laat je het niet via Marseille lopen?) Yvổnne is in Marseille gearresteerd

(Why don't you ship it in through Marseilles?) Yvonne has-been in Marseilles arrested

In (9) PA domain assignment precedes AP domain assignment. The rest it is that in APA sentences that are entirely [+focus] the prosodic break will be placed after the first Argument, as in (17):

(17) (Wat is dat voor lawaai?) [Jăn] [slaat zijn vrouw]

(What is that noise?) John beats his wife

Of course, if the second Argument is [-focus], AP domain assignment regularly takes place despite the presence of the object, as in (18):

(18) (Waarom is Yvonne hier?) D'r mẳn slaat 'r

(Why is Yvonne here?) Her husband beats her

Whenever the input structure of SAAR is assumed to contain a [+focus] Argument, this Argument is always intended to have at least the 'head', or the lowest $\mathrm{N}$-node, in focus. In an entirely [+focus] input like Mijn oudste oom is overleden ('My eldest uncle has died') AP domain assignment takes place, and accent assignment to the Argument mijn oudste oom gives a well-formed surface structure. However, if we make oom [-focus], an accent on just oudste will not 
do: in this kind of structure there is not really a [+focus] Argument, and AP domain assignment therefore cannot take place.

(19) (Nu we het over mijn ooms hebben:) Ik hoor nêtt dat mijn oudste oom is overlểden $(* \ldots$ is overleden $)$

(Now that we are talking about my uncles) I heard just that my eldest uncle has died

Finally, it is necessary to mention here that in SAAR the Argument cannot be a pronoun. Each [+focus] pronoun is simply assigned its own focus domain, which it cannot share with any Predicate. Therefore (20) is well-formed, whereas (21) is not: in the latter example the Argument is an indefinite pronoun (such as everyone, both, many, etc.).

(20) (Wat is er aan de hand?) De gevằngenen zijn ontsnapt! (What is the matter?) The prisoners have escaped

(21) (Wat is er aan de hand?) *Iedereen is ontsnapt! (What is the matter?) Everyone has escaped

The well-formed version of (21) is, of course, tedereen is ontsnatpt!. (For an explanation of the accent shift in iedereen, see Gussenhoven, forthcoming.) Similarly, the Argument cannot be an interrogative pronoun, i.e. is ontsnapt in (22) must be [-focus].

(22) Wie is ontsnapt?

Who has escaped?

This restriction on the Argument also explains why Oom Wấnja Is daar verongelukt ('Uncle Wanja had an accident there') can be the answer to the question En weet iềmand iets over Amsterdăm? ('Does anyone know anything about A.?') but not $l k$ ben daar verongelukt ('I had an accident there'). In this connection, Fuchs (1980) argues that the subject in subject+predicate sentences must be lexically 'filled' for accentuation of just the subject to be possible. This may be a better generalisation, though it must be noted that Fuchs does not mention any examples of indefinite or interrogative pronouns. 


\subsection{OTHER STRUCTURES THAT BLOCK AP DOMAIN ASSIGNMENT}

AP domain assignment may be prevented by structural causes other than the interposition of a [+focus] constituent, viz topicalisation and independent permutation

\subsection{TOPICALISATION}

Topicalisation is generally regarded as a syntactic phenomenon the process of preposing a constituent, as in (23)

(23) Jan ken lk net

John know I not

However, topicalisation is first and foremost an intonational phenomenon Syntactic topicalisation cannot take place without prior application of intonational topicalisation First, note that in (24b) haar ('her') appears in its 'strong form' only it cannot, as in (24a), be pronounced as $/(d) e r /$, the obligatory form beung /har/

(24a) Ik ken haar ( $d^{\dagger} r$ ) niet

I know her not

(24b) Haar ('d'r) ken lk niet

Her know I not

Not only is the clitic form d'r disallowed in (24b), haar must also be assigned a sentence accent hence Haar kë̀n $1 \mathrm{k}$ niet is not well-formed (Of course it is possıble to give trivial counterexamples like Nee, ik zeı niet 'Haar mag ik niet', maar 'Haar kèn $1 \mathrm{k}$ nıet', where the speaker makes the words haar $1 \mathrm{k}$ niet [-focus] to indicate that these have already been coirectly understood by the hearer The speaker is concerned with the words themselves rather than their semantic content)

For the purposes of SAAR, however, the most important effect of intonational topicalisation is the assignment to the topicalised constituent of its own focus domain In other words, a topicalised Argument can no longer be merged with with a Predicate into a single focus domain Let us assume that in (25) heeft 
Yvonne gearresteerd is [+focus] and hij is [-focus] (e.g. with a preceding context 'Tell me something about him'):

(25) Om maar te beginnen: hij heeft Yvonne gearresteerd For a start: he has Yvonne arrested

If the speaker chooses to topicalise Yvonne, however, as in (26)

(26) On maar te beginnen: Yvŏnne heeft hij gearresteêrd

he is thereby forced to assign a sentence accent to the Predicate. (For the realisation of the sentence accent on Yvonne, see section 4.2.) Although hij is a [-focus] constituent corresponding with the bracketed $X$ in (9), AP domain assignment appears to be impossible. Clearly, the reason for this is that the Argument is topicalised. Intonational topicalisation can be formulated as follows:

(27) INTONATIONAL TOPICALISATION

$$
\left.\begin{array}{l}
\mathrm{X} \\
\underline{\mathrm{X}}
\end{array}\right] \rightarrow[\underline{\mathrm{X}}]
$$

That is to say, independent of its input focus marking, the constituent is marked [+focus] and is assigned its own focus domain. Rule (27) is applied before syntactic topicalisation. Notice that the latter rule does not apply - or rather, applies vacuously - to sentence-initial constituents, but that intonational topicalisation may nevertheless apply. If this is the case - and let us here restrict the discussion to Arguments, although topicalisation may also involve other constituents - the application of the rule is apparent in the surface structure either by the sentence accent on the topicalised Argument (which would otherwise have been [-focus]) or, somewhat paradoxically, by the sentence accent on the Predicate, with which the topicalised Argument would have shared a focus domain if it had not been topicalised. The first possibility appears in (28), the second in (29).

(28) (Kon Yvonne er niks tegen doen?) Yvŏ̀nne was gearrestee̋rd! (Dat was het 'm nou net)

(Couldn't Yvonne have prevented this?) Yvonne had-been arrested! (That's the whole point)

(29) (Waarom ben je niet weggereden?) Mijn bẳnden waren döorgesneden! (Wat wil je?) 
(Why didn't you drive off?) My tyres had-been slashed! (What do you expect?)

If we confine ourselves to explanations of the sort 'The word is important and therefore It gets a sentence accent' it is impossible to relate (28) and (29) to (30) and (31) respectively, which would fit equally well in the contexts given. In combination with SAAR, the introduction of the (optional) intonational topicalisation rule reveals In a straightforward manner the relationship between the two pairs of examples: in the first pair (27) has applied, in the second pair it has not.

(30) Yvonne was gearrestëerd!

(31) Mijn bắnden waren doorgesneden!

\subsection{INDEPENDENT PERMUTATION}

Sometimes speakers assign separate focus domains to Arguments and Predicates because they wish to permute these constituents independently of each other; both are different from the corresponding constituents in another sentence. Compare (32) with (33):

(32) (Wat een ellếnde!) De bềver is ontsnapt en het dẳk lekt en de gootsteen is verstopt...

(How exasperating!) The beaver has escaped and the roof leaks and the sink is blocked...

(33) (Wat een ellểnde!) De bềver is ontsndpt, het dẩk lểkt en de gờotsteen Is verstő̉pt!

In (32) the three calamities are presented as three integral events, whereas in (33) the impression is given that with each of the three Arguments a number of things could have been amiss, of which the ones mentioned happened to be actually the case. For this reason, independent permutation may lend a certain expressive force to the sentence, but it is not obligatory. If, however, the Arguments belong to a restricted set known to the hearer, then such independent permutation is obligatory. Thus, AP domain assignment is still possible in (34), but no longer in (35). 
(34) A: Wat is het toch stil in huis

(Isn't quiet in the house)

B: Tja, de televísie is stuk, Yvônne slaapt, Jấn is bij de buren...

Well, the television is broken-down, Yvonne sleeps, John is with the neighbours...

(35) A: Wäar zijn de kinderen?

(Where are the children?)

B : Yvönne släapt en Jắn is bij de büren

It is possible that sentences like (35) should also be classified as instances of topicalisation. We note, however, that the accents on Yvonne and Jan are preferably realised differently from those on Yvonne and mijn banden In (28) and (29) respectively (in Collier \& 't Hart's notation: 1, possibly 1B for Yvonne and Jan, and 1A4 for Yvonne and mijn banden), and that therefore it does not seem attractive to class these cases together.

\subsection{EVENTIVE SENTENCES, CONTINGENCY SENTENCES AND DEFINITIONAL SENTENCES}

In this section an important restriction is imposed on SAAR. For AP/PA domain assignment to take place in a sentence it must be marked [teventive]. The feature [eventive] is introduced here to be able to indicate whether or not a sentence refers to a historical event (past, present, future, or presumed). If this is not the case, AP/PA domain assignment is blocked. There are two kinds of non-eventive sentences. The sentence can be (1) a 'contingency sentence' or (2) a 'definitional sentence'. These two categories will be discussed in separate sections, where they are notationally distinguished by the introduction of the feature [definitional]. Thus, sentences that are both [-eventive] and [-definitional] are by definition contingency sentences.

\subsection{CONTINGENCY SENTENCES}

Compare the following sentences:

(36) De dirểktie geeft diêven ẳn 
The management reports thieves (verbal particle) ( 1 e to the police) (37)

De dirêktie geeft diéven aan

Notice that, although (36) wll typically be a written sentence and might as such fall outside our 'normal conversational style' when read aloud (The notice says_), this is not necessarily the case, witness a possible conversational utterance Mag lk U erop wijzen dat de dirěktıe dièven angeeft? 'May I point out to you that the management reports theves?' The important point here - assuming that dieven is [+focus] and the speaker is not facetiously implying that the hearer's behaviour gives cause to brand hun or her as a thief - is that a surface structure without a sentence accent on the Predicate is not well-formed If we compare (36) with (37), it turns out that the latter, but not the former, might be used as a caption for a cartoon in which an elegantly dressed gentleman hands over two apparent thieves to an officer at a police station This sentence is 'eventive', and requires domain formation of geeft dieven aan Other examples of the type represented by (36) are

(38) Kinderen moeten worden gedrăgen

Chlldren must be carried

(39) Höngerıgen zullen worden gevöed

Hungry (people) will be fed

(40) Een begrắfenssstoet heeft vơorrang

A funeral procession has right-of-way

Clearly, the Arguments in the non-eventive sentences have something in common they do not necessarly refer to existing referents, but may also refer to potential ones The Argument can always be paraphrased as 'If there is an Argument of this kind, then (Predicate)' Because the Argument is potential, the sentence it appears in cannot be eventive, the Argument retains its own focus domain and therefore the Predicate gets a sentence accent This category of sentences will be termed 'contingency sentences' We may at this point call attention to a syntactic correlate 6 It is well-known (Rijpma \& Schuringa 1963 234) that in Dutch er (there)-inversion must be applied if the subject is indef 1 nite and the verb passive or intransitive (There are other reasons for applying the rule, as well as exceptions to it, neither of which need concern us here) However, there is a condition that needs to be added to this formulation the sentence must be [+eventive] When (36) and (37) are passivised, the consequence for (37), but not for (36), is that er-inversion must be applied as well 
(41) Diểven worden aăngegeven

Thieves are reported

(42) Er worden diềven aangegeven

There are thieves reported

Perhaps superfluously, it is pointed out that the difference between the two types of sentence cannot be explained by an appeal to the syntactic feature [ \pm generic]. That this feature is not relevant here is shown on the one hand by the fact that a potential Argument does not have to be generic:

(43) Yvő̀nne wordt niêt töegelaten (Maar ze zal wel niet durven komen)

Yvonne is not admitted (But she won't dare to come anyway)

and on the other hand that a generic Argument can be used in an eventive sentence. Such sentences are rare, simply because we rarely have anything to say about events that concern whole classes of Arguments. But if we imagine that (44) was used by the biologist in charge of the last living dodo to announce the decease of that animal, she would have used a generic Argument in an eventive sentence:

(44) De dốdo is uitgestorven

The dodo is extinct

Moreover, the feature [generic] has no explanation to offer for the behaviour of non-eventive, definitional sentences (see section 5.2.).

It goes without saying that sentences which contain a potential Argument also have a potential Predicate: it is for this reason that these sentences are called 'contingency sentences' and not 'sentences with a potential Argument'. It would seem that the crucial point is not so much that the Argument potentially exists, but rather that it is potentially involved in the semantic function expressed by the Predicate. Indeed, it is possible for contingency sentences to have [-focus] Arguments, for instance because their referents are physically present (and both speaker and hearer are aware of this fact). Although in such sentences the Argument, because of its physical presence, is necessarily 'real', it can nevertheless be potentially involved in the semantic function of the Predicate. This raises the question to what extent contingency sentences that do not contain a [+focus] Argument can be distinguished from eventive sentences; after all, their non-eventive status cannot be formally apparent from the absence of AP/PA do- 
main assignment. Yet here, too, it appears that the distinction is reflected in the surface structure. When a contingency sentence is negated, the negative particle must be assigned a sentence accent, whereas this is not the case in eventive sentences. Let us suppose that the speaker and hearer of (45) sit down to dinner.

(45) En je böert niêt!

And you belch not!

By the use of a contingency sentence the speaker here indicates that he would prefer his companion to refrain from displaying the behaviour concerned. Note that the sentence implies that on this occasion the hearer has not as yet exhibited that behaviour: (45) is meant as a warning just in case. The speaker of (46), on the other hand, uses an eventive sentence. With it he or she indicates that an event that should have or could have occurred is not taking place. The speaker could be the director of a play in which at a particular point the hearer ought to exhibit the behaviour. During the rehearsals he might then interrupt the play by means of (46). Alternatively, it could be a bride's reply to her future husband's question why she has chosen him, of all people. Notice that these example-contexts also show that the distinction 'general-specific' (or 'inherent-temporary') is not relevant to our problem.

\section{(46) Je botert nlet!}

You belch not!

If we now return to (43) and change the marking [-eventive] into [+eventive], this results in the removal of two of the three sentence accents. In the eventive sentence AP domain assignment takes place and niet remains unaccented. If, in addition, Yvonne were to be replaced by an indefinite Argument, e.g. mannen ('men'), two further syntactic rules would have to be applied: first er-inversion and then, because of the resulting adjacency of niet and an indefinite NP, rewriting of niet to geen ('no') (see (47) and (48)).

(47) (Wat is er aan de hand?) Yvönne wordt niet toegelaten

(What is going on?) Yvonne is not admitted

(48) (Wat is er aan de hand?) Er worden geen mắnnen toegelaten

(What is golng on?) There are no men admitted 
These examples sufficiently illustrate the difference in surface structure between eventive sentences and contingency sentences. However, they do not sufficiently illustrate the semantic variety of these sentences. In the following paragraphs we will try and arrive at a more satisfactory semantic characterisation of 'contingency sentences'.

To begin with, it is not necessarily the case that the proposition in a negative contingency sentence concerns the non-occurrence of a future event, as in (45). The contingency may lie elsewhere, as in (49).

(49) (Yvonne had last van vrểselijke depre̋ssies.) Door haar hửwelijk verbếterde de situatie niết

(Yvonne suffered from terrible depressions.) By her marrlage improved the situation not

Here de situatle, just like je in (45), is [-focus]: the important noint is the accent on niet. In (49), Yvonne, her marriage, and the proposition are only too real. Yet, it is a contingency sentence, and it is that because the speaker presents 'improving' as a potential property of 'the situation'. He intends io say that the marrlage might have improved the situation, althorgh it is not the case that Yvonne got married especially for her depressions to disappear. If, in the opinion of the speaker, she had, then he could have used an eventive sentence, omitting the accent on niet. He might then have followed his statement up with I then suggested that she should make a trip round the world. I expect her to benefit more from that. In other words, although the Argument is in a real sense involved in the semantic function of the Predicate, the proposition is nevertheless presented by the speaker as potential. The formulation 'the proposition is presented by the speaker as potentlal' seems to cover all the examples discussed so far. Also (50), which clearly satisfies the earlier characterisations 'the Argument is potentially involved in the Predicate', and even 'the Argument has potential status', is covered by the revised formulation.

(50) Incidềnten zijn ứtgebleven

Incidents have remained-absent

If the characterisation 'the proposition is presented as potential' seems inapplcable in (50), this is caused by the negative meaning of uitblijven: the speaker intends to say that they might not have remained absent. (Cf the eventive varlant Incidênten zijn uitgebleven, a possible reason for the dismissal of an agent 
provocateur ) But the formulation really does not seem applicable to (51) Let us assume that the speaker is a hotel porter who suspects that the hearer does not know that at that moment he can no longer leave the bulding via the main exit

(51) De butitendeur is op slöt

The mann door is locked

Yet, (51), too, is a contingency sentence, but not because there exists a potential relationship between Argument and Predicate, or because the pioposition is presented as potential, but because the proposition is presented as one that is potentially relevant to the hearer's background knowledge An eventive sentence (with an accent on buitendeur only) would inmediately lead the hearer to wonder what the relevance of the statement was For this reason a contingency sentence may best be characterised as a sentence in which a proposition is presented as potential or is presented as potentially relevant

\subsection{DEFINITIONAL SENTENCES}

Compare the following two sentences

(52) Mĕllk is dièrlıjk

Muk is anumal

(53) De mĕlk staat in de zon

The mulk stands in the sun

Sentence (52) means 'Muk is not vegetable or mineral, but anumal' The sentence defines the Argument melk Sentence (53), on the other hand, is not meant to define de melk, but to indicate that it is involved in an event 'It wlll turn sour if you leave it there' Sentence (53) is eventive, (52) is definitional Like contingency sentences, definitıonal sentences, do not tolerate AP/PA domain assignment It is often argued that sentences in which the Predicate contains an indefinite noun (e g Yvonne is a Belgian) must always have a sentence accent on that noun, assuming it is [+focus] (Schmerling 1976, Fuchs 1980) The reason for this, of course, lies not so much in the indefiniteness of the noun, but rather in the fact that indefinite nouns typically occur in definitional sentences 
The question remains whether non-eventive sentences can be regarded as a single group for the purposes of sentence accent assignment. It appears that in this respect there are grounds for distinguishing definitional sentences from contingency sentences. Definitional sentences resemble contingency sentences in that they do not trigger AP domain assignment, but they resemble eventive sentences in that the negation remains unaccented, Compare the following sentences:

(54) Mănnen worden niểt tỏegelaten

Men are not admitted

(55) Mẳnnen worden niet tởegelaten

Let us assume that the management of a particular pub decides to admit only women to the premises. It may announce this by using (54), where mannen is a potential Argument ('If any men present themselves...'). However, sentence (55) does not have this meaning. Here, mannen is no longer a potential Argument, but a real one. This sentence is definitional and might be used to point out to a prospective male customer how matters stand. Of course the speaker could also - somewhat more formally - use (54) and quote, as it were, the regulation that applies to the situation in hand. By contrast, this regulation could never be quoted in the form of (55). (For the eventive variant of these sentences, see (48).)

The difference in the behaviour of the negation between definitional sentences and contingency sentences is phonetically clearer when niet occurs in sentence-final position. Suppose that a newly appointed employee of a restaurant must be informed that, unlike in the cafeteria where he used to work, vouchers are not accepted in the establishment concerned. In this context the person who breaks the new employee in could use (56a) or (56b) to point this out to him.

(56a) $ठ \mathrm{ja}$, en tegoëdbonnen gẻlden hier nièt Oh, and vouchers are-valid here not

(56b) $\delta \mathrm{ja}$, en in dit restaurằnt gêlden tegöedbonnen niêtt

(In reality he would probably say: '... worden hier niet geaccepteerd', i.e. '. . are not accepted here', but the intention here was to move niet into final position.) The meaning of (56a) and (56b) is, of course, 'If anyone tries to use vouchers...': tegoedbonnen has a potential status. If the speaker now omits 
the accent on nlet, the sentence becomes definitional and tegoedbonnen acquires reality status:

(57) $\varnothing$ ja, tegoèdbonnen gèlden hier niet

Oh, vouchers are-valid here not

The addressee will now be more Inclined to assume that his future customers will actually want to use vouchers. Similarly, a verb form like the subjunctive can readily be used in a contingency sentence. If we assume that the verb form in the typically definltional sentence Öma's klâkgen niet ('Grannies don't complain', the first line of a Dutch popular song) is changed from the indicative into the subjunctive mood, then we must interpret it as a contingency sentence, which results in niet being assigned a sentence accent:

Öma's klägen nitet (Of zil zullen zwaar worden gestraft!)

Grannies complain not (Or they will come to a sorry end!)

Notice that if a definitional sentence does not contain a [+focus] Argument, it becomes identical in form to an eventive sentence: AP domain assignment can no longer have a distinguishing function. Thus, the eventive sentence in (46) might also be interpreted as a definitional sentence, meaning 'This activity is non-existent', in which case je is Interpreted as 'people' (or 'one') and boert as 'ought to belch'. Note also that the 'general' interpretation of (46) is indeed eventive and not definitional. The bride might also have answered the groom's question with (59).

(59) Je ögen zijn blauw

Your eyes are blue

A definitional variant of (59), i.e. without AP domain assignment, is of course a possible answer to a blind person's question What do I look like?.

The examples in this section show very clearly that the assumption that sentence accents are straightforward indicators of the status of the word they occur on cannot be maintained. Thus, instead of altering the status of the negation, the accent on niet in (58), (56a) and (56b) changes the status of the proposition it negates and thereby the status of the Argument (which becomes potential). Also, discussions about the semantic implications of intonationless 'sentences' like De koning van Frankrijk is kaal (The King of France is bald) 
are inadequate if it is not clear whether we are dealing with an eventive sentence (De koning van Frẳnkrijk is kaal! Keizer Willhelm zal nu wel spóedig een inval wagen '... Emperor William will now probably launch an invasion'), a definitional sentence ('The person referred to is bald') or a sentence containing a potential Argument ('Should there be a person as indicated, then he is bald'). The latter two meanings result in the same surface structure (De koning van Frankrijk is kaal). Adding niet makes the difference apparent once again: De koning van Fränkrijk is niet käal. Hij moet in ons toneelstukje dus maar een ândere rol krijgen ('He will have to be given a different role in our our play') versus De konlng van Frănkrijk is nîtet kăbl. The latter sentence gets a vacuous interpretation inasmuch as we still do not know whether there is a King of France: we only know that if he exists, he is not bald.

\subsection{DEFINING PREDICATES AND CONDITIONS}

This last section will attempt to give a more precise definition of two of the three semantic constituents referred to by SAAR, Predicates and Conditions. Arguments are relatively unproblematic, since they always correspond to constituents that function as subjects or objects. Predicates, however, will have to be defined more broadly than is customary in syntax. Not only do complex structures like op vakantie gaan ('go on holiday'), longontsteking krijgen ('get pneumonia'), op je jas zitten ('be on your coat') (with klit ('burr'), vull ('dirt'), etc. as subject), in de stad zijn ('be in town') function as simple Predicates, the Predicate may also contain certain adverbs. Firstly, this is the case for adverbs that signify to what extent the semantic function denoted by the verb is in effect. Compare (60), which contains a 'real' C, and (61) (In both sentences the subject is [-focus]):

(60) De patient slaăpt slếcht

The patient sleeps badly

(61) Mijn man slakpt slecht

My husband sleeps badly

In (60) slecht is an evaluative adverb. It characterises the quality of the patient's sleeping, which the speaker may consider his reponsibility, as unsatisfactory. In (61), on the other hand, the speaker intends to say that the 
Predicate 'sleepıng' is only partially operational, as it were The speaker indıcates a point between presence and absence of 'sleeping' rather than a point on a scale from 'very unsatisfactory' to 'excellent', as is the case in (60) Other examples of adverbs of this kind occur in goed ziên, niet goed snijden, goed lǘsteren (but not uitstekend zien " "7 Ze lứstert scherp) When such Predicates occur with a [+focus] Argument AP domain assignment causes no problems

(62) (Waarom loop je toch zo te drentelen?) Dit mè̀s snıjd niet goed (What are you mooning about for like that?) This knife cuts not well

Note that within the Predicate (e g goed snijden) the verb is the acentable part

Secondly, it must be noted that object complements, like groen in (63)

(63) $\mathrm{H}_{1 \mathrm{j}}$ heeft de deur groen geschlderd

He has the door green painted

function as accentable elements within the Predicate (gron schilderen) Such a complex Predicate can form a focus domain together with a [+focus] Argument Hence, a syntactic structure like the one in (63) gets a surface structure with a sentence accent on deur If everything except hl] is [+focus] (e $g$ as answer to the question 'Has he done anything today?') Incidentally, such object complements behave syntactically and prosodically like separable suffixes of verbal compounds such as ôppakken ('pick up'), doorlezen ('read through'), binnenrıjen ('pull in (to ')', platsvinden ('take place') The decision whether this type of element is to be regarded as an 'independent' object complement or as part of the verb, and therefore whether the two are separated by a space in writing, seems arbitrary as far as the linguistic system is concerned and to depend on our intuition about whether the element functions as a semantic unit Compare

(64) $\mathrm{Er}$ is een vrouw gelukkig gemaakt

There has-been a women happy made

(65) Er heeft een öngeluk plaatsgevonden

There has an accident place-taken

Thirdly, special status must be given to locatıve adverbials that denote destination Unlike other Conditions, these adverbials are not assigned a separate fo- 
cus domain when they are combined with a verb denoting movement, they share a focus domain with the Predicate Within that domain the accent is assigned to the adverbial This explains the surface structures in (66) and (67), where the subjects are again [-focus]

(66) Hıj is naar Amếrıka gevaren He has to America salled

(67) Hı heeft in Amềrıka gevăren He has in America saled

Note that the distinction also has syntactic consequences in the case of intransitive verbs it determines the choice of the perfective auxllary (Rijpma \& Schurınga 1968 132) Other combinations of this type are naar de stẩd fietsen ('cycle to town'), in de riviêr duiken ('dive into the river'), de wêreld rond vliegen ('fly round the world') After the domain between the adverbial and the verb has been formed it is no longer possible to add a [+focus] Argument to it (see (68)) It would therefore seem appropriate to allow this PC focus domain to be constructed by the domain assignment rule of SAAR, in which ' $A$ ' would have to be replaced by 'A or a adverbıal of place denoting destination'

(68) (Waarom is er feest?) ?7Mijn văder is de wereld rond gevlogen (What's the party for') My father has the world round flown

Other Conditions may also behave in this way, provided that the resulting focus domain denotes a relatively common sort of activity in Bềlgie wonen ('live in Belgium'), in Düitsland werken ('work in Germany'), vŏor Rusland spıoneren ('spy for Russia'), but preferably not "'n Amêrıka varen ('saul in Amerıca'), "In Dứtsland uitrusten ('rest in Germany'), "voor een jốngen zıjn best doen ('do one's best for a boy')

A further remark to be made concerning Conditions is that adverbs denoting in a general sense the time-space orientation of a proposition statutorily remain [-focus] Examples are

(69) Is de pöst er al?

Is the post there yet?

(70) Is er nog wat te doen vandaag"

Is there stil anything to do today?

(71) $\mathrm{H}_{1 \mathrm{j}}$ heeft het er goked van genờmen in het leven 
He has it there well of taken in the life (1.e. He has done himself well in life)

(72) Wat een rốtzooi is het hier

What a mess is it here

Similarly, adverbials indicating discourse links are kept outside the focus:

(73) Dat is je tom toch?

That Is your uncle isn't it?

(74) Ze weet het niet zogenaand

She knows it not so-called (i.e. She pretends not to know)

(75) Dan schrijf je toch een briếf of zo?

Then write you (modal particle) a letter or something

For an analysis of such expressions in English, see Bing (1979: 21-52), Gussenhoven (in press).

\subsection{CONCLUSION}

The hope exists that this article has provided some answers to the question why speakers assign sentence accents to certain words. However, it does not pretend to have explalned all the data, even those that fall within our restrictions of language mode ('conversational style') and focus distribution (at least one Argument, Predicate or Condition [+focus]). The intention was rather to show that it will not do to regard sentence accents as markers of 'importance', 'newness', or whatever, of the words they occur on and that the prosodic component of language deserves as much attention as the component of lexis and syntax (the segmental component). As such, this paper is a plea for regarding the prosodic component as a system with specifiable options (the 'underlying structure'), a rule system (the 'grammar'), a phonology (the 'surface structure') and, of course, a phonetic component, quite along the lines one would envisage a treetment of the segmental component. In addition, the intention was to show, through the introduction of SAAR, INTONATIONAL TOPICALISATION and three sentence categories, that the relationship between underlying and surface structure is anything but trivial. Research into the nature of this component may yield information that is important also to those who study other aspects of language. 


\section{Notes}

1. This article aims to give an elaboration of certain aspects of sentence accent assignment which are discussed in 'Focus, mode and the nucleus' (Journal of Linguistics 19 (2), also this volume). These aspects mainly concern the three sentence categories distinguished in that article ('eventive sentences', 'contingency sentences' and 'definitional sentences'). A first version of the article was presented at the Linguistics Colloquium of the Katholieke Universiteit Nijmegen, on October 29, 1982. I have freely and gratefully drawn on comments on earlier versions made by Flor Aarts, Ton Broeders, Dick Klein, Bob Ladd, Jac Terken and an anonymous referee for GLOT. I thank Dwight Bolinger for his comments on the English version.

2. Bob Ladd (personal communication). Incidentally, it is sometimes claimed that sentences may be disambiguated by means of intonation. In such statements the term 'sentence' is used in the sense of '(conventional) written representation of a well-formed surface structure'. As will be clear, this representation remains wholly or partly unspecified as far as Intonational aspects are concerned. In this article, the term 'sentence' does not imply the restriction '(conventional) written representation of', and sentence accents therefore are included by it.

3. In a similar manner, the place of the adverbial appears to correlate with focus distribution (cf Verhagen 1979). The syntactic structure in (1) probably does not have just Oom Wanja is gestorven in focus (e.g. in the context 'Talking about Amsterdam...').

(1) Oom Wanja is gestorven in Amsterdam

Uncle Wanja has died in Amsterdam

The expected word order is obtained by placing in Amsterdam inside the Predicate (is in Amsterdam gestorven). The structure in (1) would be preferred if in Amsterdam, with or without other constituents, is [+focus], although possibly also with only is gestorven [+focus] (e.g. in the context 'Why should we celebrate the anniversary of Uncle Wanja's death in Amsterdam?'). The latter possibility suggests that word order may not be directly related to focus and that what is sometimes called 'communicative dynamism' is a factor which can be manipulated independently of focus distribution. (Cf also Allerton 1978 on the distinction between 'themeness' and 'givenness'.)

4. We here ignore the fact that many Arguments have more than one accentable syllable, like de oude man. In cases like these SAAR is assumed to assign an accent to all accentable syllables.

5. Jac Terken (personal communication) points out that work by Truus Kruyt shows that there is a high correlation between accentuation in reading style and accentuation in conversational style.

6. I thank Pieter Nieuwint for observing this fact.

\section{References}

Allerton, D.J. (1978). "The notion "givenness" and its relation to presupposition and theme'. Lingua 44, 133-68. 
Bing, J M (1979) Aspects of English prosody Indiana University Linguistics Club, Bloomington, Indiana

Bolinger, D L (1972) 'Accent is predictable (If you're a mind-reader)' Language $48,633-44$

Bresnan, J W (1971) 'Sentence stress and syntactic transformations' Language $47,257-81$

Bresnan, J W (1972) 'Stress and syntax a reply' Language 48, 326-42

Brown, G (1983) 'Prosodic structure and the Given/New distinction' In A Cutler \& D R Ladd (eds) Prosody Models and measurements Springer, Ber$\operatorname{lin} /$ Heidelberg 67-77

Chafe, W L (1970) Meaning and the structure of language University of Ch1cago Press, Chicago

Chomsky, $N$ (1972) 'Deep structure, surface structure, and semantic interpretation' In D D Steinberg \& L A Jakobovits (eds) Semantics An interdis cıplinary reader in phuosophy, linguistics and psychology Cambridge University Press, New York \& London

Chomsky N \& M Halle (1968) The sound pattern of English Harper \& Row, New York

Coller, R \& J 't Hart (1978) Cursus Nederlandse intonatie Wetenschappelijk Onderwijs Limburg, Diepenbeek Revised edition 1981, Acco, Leuven

Fuchs, A (1980) 'Accented subjects in "all-new" utterances' In is Brettschneider \& C Lehmann (edd), Wege zur Universalienforschung Sprachwissenschaftliche Beitrage zum 60 Geburtstag von Hansjakob Seler Gunter Narr, Tubingen 449-61

Gussenhoven, C (in press) "The intonation of "George and Muldred" post-nuclear generalisations' In C Johns-Lewis (ed) Intonation in discourse Croom Helm, London (Also this volume)

Gussenhoven, C (forthcoming) 'Stress shift and the nucleus' Linguistics (Also this volume)

Halliday, M A K (1976) 'Notes on transitivity and theme in English, Part 2' Journal of Linguistics 3,199-244

Hart, J 't \& $R$ Collier (1975) 'Integrating different levels of intonation analy sis' Journal of Phonetics 3, 235-55

Keısper, C E (1982) 'Over de relatıe tussen context en accentuatie' Forum der Letteren 23, 31-45

Ladd, D R (1980) The structure of intonational meaning evidence from English Indiana University Press, Bloomington, Indiana

Lakoff, G (1972) 'The global nature of the Nuclear Stress Rule' Language $48,285-303$ 
Nooteboom, S., T. Kruyt \& J. Terken (1981). 'What speakers and listeners do with pitch accents: some explorations'. In Th. Fretheim (ed) Nordic prosody II. Tapir, Trondheim. 9-32.

Nooteboom, S.G. \& J.M.B. Terken (1982). 'What makes people omit pitch accents: an experiment'. Phonetica 39, 317-36.

Rijpma, E. \& F.G. Schuringa (1968). Nederlandse spraakkunst (21st edition, ed $\mathrm{J}$. van Bakel). Wolters-Noordhoff, Groningen.

Schmerling, S.F. (1974). 'A re-examination of normal stress'. Language 50, 66-73.

Schmerling, S.F. (1976). Aspects of English sentence stress. University of Texas Press, Austin.

Verhagen, A. (1979). 'Fokusbepalingen en grammatikale theorie'. Spectator 8, 372-402. 



\section{The intonation of 'George and Mildred': Post-nuclear generalisations}

\subsection{INTRODUCTION}

\subsection{PRELIMINARY COMMENTS}

A general reference point for the treatment of English intonation as attempted in this article is the 'British' tradition of intonation contour analysis begun by Palmer (1922), an introduction to which is perhaps most readily avalable in J.D. O'Connor and G F. Arnold (1973) Intonation of Colloquial English (2nd edition, Longman) ${ }^{1}$. An important unit of analysis in this tradition is the intonation contour associated with the stretch of speech known as the 'tone group'. This contour is split into four parts: the nucleus, a one-syllable stretch with which the last major intonation movement is associated, the tail, which is the stretch following the nucleus, the head, which is the stretch preceding the nucleus counting from the first accented syllable onwards, and the prehead, any stretch preceding the head. The nucleus is the only obligatory element, tone groups being minumally one syllable long. In the following example, taken from O'Connor \& Arnold (1973. 13), I is the prehead, want to be absolutely the head, sure the nucleus, and about it the tall.

I went to be ebsolutely sere about it.

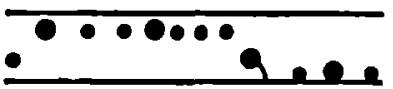

This article concentrates on the stretches of intonation contours formed by the nucleus and the tail In spite of the fact that this stretch is talked about as if consisting of two parts, the British tradition views it as a holistic 'bit' of the contour, each such bit providing an instance of a nuclear tone. Examples of nuclear tones are the fall, the rise, the fall-rise, the rise-fall, and the level tone. If there is no tal (and the stretch is only one syllable long), the nuclear tone wll run its full course on that syllable; if there is a tal, the nuclear tone 
will expand so as to cover the whole stretch. (Details of mapping vary from tone to tone. For instance, the fall is usually virtually completed on the nuclear syllable, while the rise may be literally stretched out from the nucleus to the last syllable of the tail.)

Observe that in the above there is no suggestion that the nucleus is necessarly the most prominent syllable of the tone group (where 'prominent' is used in some loose sense of 'subjectively most striking'), or that it is necessarily the syllable with which the largest pitch movement is associated. We can encourage a child who is just learning to write by saying Write it down! with a generally falling contour from beginning to end, causing the (high-pitched) write to be subjectively the most prominent syllable, and the syllable with which the largest pitch movement is associated (assuming it is already rather low in pitch). Yet, it is the auditorily less striking hump on down that we would perceive as marking the nuclear syllable, recognising it as a well-formed instance of the (low) fall. That is, the utterance would not be interpreted as an injunction to WRITE it down, as opposed to jot, clumsily note, press etc. it down.

The 'British' approach represented above (which we should now perhaps refer to as the 'consensus view' of intonation analysis, Ladd 1980) implies that quite long sections of contours may have to be seen as holistic units After all, there is no theoretical limit to the length of the tail. It also implies that pitch movements that are quite far apart may have to be seen as belonging to the same unit, the same nuclear tone. This will happen when a fall-rise is used, and there is a long tail. In this situation, the fall-element will be mapped onto the nuclear syllable, while the rise-element will be mapped onto the last syllable of the tail, irrespective of whether it is accentable. This situation is illustrated in (2), where true is the nucleus.

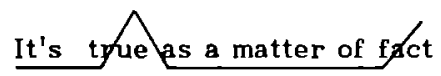

However, it is precisely with regard to the implication above that opinions differ in the literature. For the pattern in (2), for example, interpretations have been proposed in the literature that range from one nucleus, via a compound bi-nucleus or two nuclei, to a sequence of tones taken from different tonal paradigms, one nuclear and the other non-nuclear (for references see section 7 ). In this article the one-nucleus interpretation is defended against these alternative analyses. 


\subsection{THE AIMS OF THE INVESTIGATION}

Our aim in undertaking a corpus-based analysis of tals, of which this article is a report, was twofold

First, the analysis was intended to yield part of the answer to the question where speakers place their nucle If we know where these nucler are not placed, we also know at least part of the answer of where they are placed As such, the article is intended as a contribution to the discussion of the location of the sentence stress, or 'nucleus', in English

The second aim, whose attainment should in a sense precede that of the first, was to try and gather evidence concerning the identity of the nucleus and the domain over which the nuclear tone is assigned This evidence is extracted from the analysis by exploiting the circularity inherent in a classification of tals The circularity is, of course, that we are generalising over phenomena, in our case 'talls', that we are at least partly free to define as we please, in our case so as to maximise our ablity to generalıse Clearly, if of a number of possible interpretations of what should be considered 'tall', one admits of more powerful generalisations than the others, it will have to be preferred to them, other things being equal In particular, this line of argument is brought to bear on the interpretation of falling-rising intonation patterns of the type exemplified in (2) The question of the interpretation of pitch movernents in terms of nucleus and tal is of far-reaching importance It immediately affects one's definition of the nucledr tones, and as such essentially concerns the segmentation of utterances into the basic units of analysis Different interpretations will inevitably lead to different statements about the paradigmatic and syntagmatic properties of the intonational system, and with it, most probably, too, about the semantıcs of that system

Our procedure is as follows we will begin by assuming that one of the interpretations proposed in the literature is the correct one, and apply it We wull then evaluate the resultant description in terms of the extent to which the generalisations produced by it would have to be given up, If we were to adopt one of the other interpretations suggested in the literature Before doing so, however, we wll describe the corpus on which the investigation was based and characterise it by means of a few general statistics 


\subsection{THE CORPUS}

The corpus consists of four instalments of British television serials, together comprising some 14,000 words. ${ }^{2}$ Three of these, or 11,550 words, are instalments of the serial 'George \& Muldred'. These are Days of Beer and Rosie (DBR), Finders Keepers? (FK), and On the Second Day of Christmas (SC). A fourth instalment of 'George \& Mudred' could, for technical reasons, not be made available, and was replaced with one taken from 'Roath' $(R)$. The origin of the examples given below is indicated by the initials of the instalment concerned (see above), whlle examples that are made up for the purpose of exposition are followed by ["]. Only George (G) and Muldred (M) are specified as speakers of the examples. ' $O$ ' is used to indicate that the example was spoken by some other actor in the George \& Muldred data The language of both serials can be characterised as famlıar-style Standard English.

\subsection{MOTIVATION}

The motivation for choosing quasi-spontaneous rather than real spontaneous speech as the basis of our analysis is partly that the latter frequently contains 'mushy' material like false starts, repetitions and vocalısations of various sorts, towards which our analysis was not directed. In material of the kind represented in our corpus, by contrast, we can be sure that all utterances are intended to be well-formed, in that they may be expected to have made a closely-vetted pass through the fulter of the actors' linguistic competence As such, our material is the natural, direct spoken counterpart of written language, which has usually undergone a simular degree a monitoring on the part of the producer.

A second reason for choosing this corpus was that it was hoped that the significance of the intonational features to be studied was more clearly brought out in it than in other types of corpus, in so far as it may be expected that they are used to create particular 'comedy' effects, which might make it easier to determine just what their significance is. It may at this point be relevant to observe that, apart from punctuation marks, the scripts of the G\&M instalments contain no prosodic indications of any kind, and that the actors - George and Mudred more so than the others - frequently deviate from their text, and are clearly allowed to improvise on their script to a certain extent. The script of the Roath 
instalment, by contrast, occasionally contains capitalisations, suggesting particular prosodic 'readings'.

\subsection{TRANSCRIPTION}

The material was transcribed orthographically, with nuclear tones and tone group boundaries indicated. No systematic attempt was made to indicate pitch range, rhythm or any other features. The analysis was carried out by the author on an auditory basis. This was not out of a cavalier attitude towards instrumental registrations of periodicity, but because recognition of nuclear tones on the basis of periodicity tracings is still beyond the power of man or machine. The transcription was checked some eight months after it had first been done. Changes of opinion were few and far between, and most frequently concerned decisions about the inclusion of short introductory vocalisations like well, yeah, oh, which were often spoken rapidly and lacked an easily interpretable 'tone'. Another area of uncertainty was the division into tone groups. On a number of occasions, stretches that had been regarded as single tone groups with a pre-nuclear and a nuclear accent were re-analysed as two tone groups in the second analysis. Second thoughts about which was the nuclear syllable and which tone was used were rare in other instances. In a few cases more detailed information about general contour range or tone variants was noted. All counted, changes accounted for less than $5^{\circ}$ of the data, and did not concern the examples cited in this article.

The following tones were distinguished in the transcription: the fall ('), the rise $\left({ }^{\prime}\right)$, the fall-rise $\left({ }^{\vee}\right)$, the level tone $(-)$, the rise-fall $\left(^{\wedge}\right)$, and the stylised fall $\left(^{-}\right)$. As was said above, no distinction between high tones and low tones was made, although in some cases certain tone variants were noted. These refinements have been ignored in the representation of the examples in this paper.

The following comments should be made:

1. The fall-rise was considered a unitary tone, marking a single syllable as nuclear, also when the fall-element and the rise-element were quite far apart, as in

(3) G: I think Geor ${ }^{\sim}$ GINa would have been a better name [DBR] 
(4) G: Nothing to ${ }^{` D O}$ with you, in fact [DBR]

in which the rise-elements are on name and fact, respectively. It should be noted therefore, that what Crystal (1969, 1975), Crystal \& Davy (1969, 1975), Svartvik \& Quirk (1980) may regard as a compound (binuclear) fall-plus-rise, or what Brazil (1978), Brazil, Coulthard \& Johns (1980) may regard as a sequence of two tone groups, one with a fall and one with a rise, or what Bing (1979) may regard as a nuclear fall followed by a non-nuclear boundary tone, has here been analysed as a single tone group with a mono-nuclear fall-rise.

2. There is no rise-plus-fall in the analysis: sequences of such pitch movements are either instances of unitary rise-falls (as in most, if not all other analyses), as in

(5) O: For handing in my ^CREDit card [FK]

or as a sequence of two tone groups, one with a rise and one with a fall, as in

(6) O: As I was saying to 'ANN | oil and 'WATer | simply don't 'MIX [FK]

3. The stylised fall (Ladd, 1978), earlier also called the 'spoken chant' (Pike 1945: 71), or 'call contour' (e.g. Gibbon 1976: 276), as in

(7) $\mathrm{M}$ : = MORning George [FK]

occurred sufficiently frequently for it to be marked separately.

4. As was inplied earlier, the fact that these tone categories were distinguished in the analysis must not be taken to mean that it is proposed that 'English has six tones'. 
20 SOME STATISTICAL DATA

Bearing potential differences of analysis in mind, it may be interesting to compare some general statistical data with data obtained by other researchers Crystal (1969), for example, whlle noting that length of tone group is a stylistic variable, gives 5 as the mean number of words per tone group in his corpus In DBR it is 45 , to which the comment should perhaps be added that the number of one-syllable tone groups, such as vocatives or interjections like oh, yeah, right, etc, seems rather high in our material generally The incidence of nuclear-tone types, in particular, can only be compared across researchers with considerable caution, in view of the different treatments of 'compound tones' Table 1 gives the percentages obtamed by Davy (1968, cited in Crystal 1969 225) for conversational style and reading style separately, as well as the frequencies in the G\&M data The Davy data have been adjusted so as to make a comparison more meaningful the percentages for the fall-rise ( $\left.\begin{array}{llll}11 & 1 \text { and } & 7 & 4\end{array}\right)$ and the fall-plus-rise (5 5 and 5 1) have been added together, and those given for the rise-plus-fall ( 06 and 04 ) have been divided between the rise and the fall

Table 1 Proportions of nuclear tones in (a) reading style, (b) conversational style and (c) 'George and Mildred' The data for (a) and (b) are form Davy (1968)

\begin{tabular}{|c|c|c|c|c|c|c|c|}
\hline & 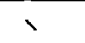 & $\checkmark$ & , & - & $\hat{\imath}$ & $=$ & \\
\hline Readıng & 505 & 166 & 249 & 55 & 21 & - & \\
\hline Conversation & 589 & 125 & 163 & 80 & 42 & - & \\
\hline G\&M & 618 & 187 & 153 & 33 & 04 & 04 & $\mathrm{~N}=2411$ \\
\hline
\end{tabular}

The proportions in the G\&M data are very stable Table 2 gives the percentages for the three instalments separately None of the differences are significant

Table 2 Proportions of nuclear tones in three instalments of 'George \& Mildred'

\begin{tabular}{|c|c|c|c|c|c|c|c|}
\hline & V & $\checkmark$ & , & - & n & $=$ & \\
\hline FK & 624 & 178 & 145 & 41 & 06 & 03 & $N=777$ \\
\hline DBR & 620 & 188 & 140 & 41 & 05 & 06 & $N=870$ \\
\hline $\mathrm{SC}$ & 613 & 192 & 176 & 17 & 01 & 01 & $N=764$ \\
\hline
\end{tabular}


It would appear that the shift observed by Davy from the rise in favour of the fall between reading and conversation is reflected in the G\&M data. The G\&M data is distinct from conversational style, it would seem, in that the incidence of fall-rises is higher, and those of rise-falls and level tones lower. I will refrain from ad-hoc explanations of these findings.

If we want to see if nuclear tone choice is exploited in any way to assist in creating particular effects in the material under investigation, it would obviously be better to look for patterns in the speech of individual characters. If we take George and Mildred separately, for example, it appears that in both instalments George uses significantly fewer falls than does Mildred, and uses significantly more fall-rises than does Mildred. The differences are even more striking if we count only those nuclei that occurred in situations in which the two actors are by themselves, without other actors either taking part in the conversation or being present as listeners. The figures are given in Table 3. The probability levels are based on $x^{2}$-tests for the frequencies obtained for the combined data.

Table 3. Proportions of nuclear tones for George and Mildred separately in mutual interaction in three instalments

\begin{tabular}{|c|c|c|c|c|c|c|c|c|}
\hline & & $y$ & $\checkmark$ & , & - & ค & $=$ & \\
\hline \multirow[t]{2}{*}{ FK } & George & 60.8 & 22.2 & 13.1 & 3.3 & 0.6 & - & $N=153$ \\
\hline & Mildred & 66.4 & 11.2 & 17.6 & 4.0 & - & - & $N=125$ \\
\hline \multirow[t]{2}{*}{$\mathrm{DB}$} & George & 50.6 & 30.3 & 14.8 & 3.7 & - & - & $N=162$ \\
\hline & Mildred & 75.0 & 13.0 & 10.3 & 1.7 & - & - & $N=116$ \\
\hline \multirow[t]{2}{*}{$\mathrm{SC}$} & George & 58.3 & 27.1 & 6.3 & 8.3 & - & - & $N=48$ \\
\hline & Mildred & 71.2 & 19.2 & 6.8 & 2.7 & - & - & $N=73$ \\
\hline & & $p<.01$ & $p<.01$ & n.s. & n.s. & n.s. & & \\
\hline
\end{tabular}

It is reasonable to assume that the observed frequency differences are related to the particular characters the two actors are supposed to portray, with Mildred being the more assertive of the two and George more of ten than not playing the 'hen-pecked' husband." It should be stressed that these data are in no way intended to serve as pointers towards any male-female distribution differences in actual speech. More probably, they are the result of the unconscious exploitation of the actors of social/sexual stereotypes. Correlations between nuclear tone-frequency profiles and social roles have not, as far as I know, been researched, although Crystal (1975: 85) notes that complex tones, i.e. 
fall-rise and rise-fall types, may be more frequent in a 'simpering' speaker than in other speakers. It may be further observed that, contrary to what is sometimes suggested, no evidence was found that the rise was more frequent in the speech of actors portraying non-assertive characters than in that of other actors.

\subsection{CLASSIFYING TAILS}

Ours is not the first attempt to see if any generalisations can be made with respect to what sort of material typically goes into post-nuclear stretches. Apart from numerous incidental observations, there are three more or less systematic listings of final non-nuclear items in English: Crystal (1975: 25-8), Bing (1979: ch2) and Firbas (1980). The classification offered below differs considerably from Crystal's. In part, these differences are due to differences of interpretation in the area of the nuclear tones themselves: 'compound tones' do not figure in the present analysis, but do in Crystal's. In other respects, the present analysis may be seen to be more complete than Crystal's, and to offer generalisations that go beyond it. Bing discusses linguistic expressions that fall in one of our categories. There are many similarities and some differences between her list and ours in that category. More important, there are theoretical differences between the two analyses that concern the intonational status of the linguistic expressions in it. It will be argued that Bing's proposal to reserve a special, separate domain for these expressions must be rejected. Our analysis agrees best with that given by Firbas (1980). Our main disagreement here concerns the status of post-nuclear predicates.

\subsection{THREE CATEGORIES OF TAIL}

A discussion of tails cannot be undertaken without some clarification of the theoretical status of the nucleus. It is assumed that the location of the nucleus is the major surface realisation of two binary variables, focus and mode. The variable 'mode', which specifies whether or not the focus of the sentence is meant as a counterassertion, is not relevant to our discussion here, and can therefore be ignored. Focus, however, is relevant. It is seen as a binary variable, obligatorily marking all or part of a sentence as [+focus] (to all intents and pur- 
poses equivalent to Halliday's 'new' (1967: 204)). If only part of a sentence is so marked the rest is said to be [-focus] (similarly equivalent to Halliday's 'giv$\left.e^{\prime}\right)$. Accent assignment rules take the sentence with its focus and mode markings as their input, and assign accents accordingly. The advantage of this approach is that it makes it possible to divorce the significance of the nucleus from the word it happens to be assigned to, and instead see the nucleus as manifesting focus on linguistic material including more than just the nuclear word (or, in rarer cases, not necessarily including the nuclear word itself). It thus rids us of explanations in terms of ill-defined notions of 'salience' or 'importance' of the words that are seen as potential candidates for the nucleus in a given utterance.

There is only one accent assignment rule we need consider here, which I refer to as the Sentence Accent Assignment Rule, or SAAR. For the purposes of SAAR, sentence constituents should be allocated to arguments (subject, objects), predicates and conditions (most adverbials). "SAAR operates over focus domains, that is, it assigns an accent to each [+focus] focus domain. A condition forms a focus domain by itself, but an argument and a predicate may fuse into a single focus domain: in it, SAAR assigns the accent to the argument. Thus, if in I met Jane in London everything except I is [+focus], two accents are assigned: one to Jane, the argument in the focus domain met Jane, and one to in London, a condition. If we alter the focus distribution so as to leave Jane [-focus], again two accents are assigned, one to met, which now forms a focus domain by itself, and one to in London, the condition. The last of these assigned sentence accents in a tone group is the nucleus.

Given the word order of English, the number of sentences that have the predicate in final position is statistically smaller than the number that have an argument in final position, and the all-pervasive operation of the rule is therefore less than abvious. A clear example of a structure where it is apparent, is the subject + intransitive predicate construction. An example is (B), where I've got is $[$-focus]:

(8) I've got me 'SON coming round to dinner [DBR]

Here, coming round to dinner should be seen as a single predicate that combines with the argument me son into a single focus domain. Note that although adverbials like in London, at the airport regularly function as conditions, and thus require their own focus domain when they are [+focus], such expressions can 
also function as predicates, in which case SAAR treats them as such, as lllustrated in (9)

(9) My LUGGage is stull at the aurport [ [ $\left.{ }^{n}\right]$

It may further be noted that, particularly in arguments, there is frequently more than one accentable syllable Thus, an elderly person or electrification wll have both accentable syllables 'switched on' by SAAR if these arguments are (entirely) [+focus] Finally, note that many adverbials, of which stell in (9) is an example, are typically treated as [-focus] These adverbials are accounted for in section 5

Obviously, a classification of tals will have to distinguish between tails that are [+focus], but are not assigned an accent given the operation of SAAR, and those that are [-focus] Also, a distinction should be made between expressions that are typically [-focus], even on first introduction, and items that are [-focus] because they have explicitly or implicitly been introduced into the discourse model The three main categories therefore are

- Category I [+focus] tals

- Category II typically [-focus] expressions

- Category III pragmatıcally [-focus] expressions

This division interestingly reflects the three general factors that are involved in the determination of the location of the nucleus Category I might be said to grammatical in nature in so far as arguments are typically expressed in NPs and predicates typically in VPs (in the sense of Quirk et al 1972) Category II could be said to be semantic in nature in so far as the class of expressions in it can be given a semantic characterisation Category III is more clearly pragmatic in nature, in that expressions in it refer to entities that the speaker assumes are avalable in the discourse model by virtue of prior introduction 


\subsection{CATEGORY I: [+FOCUS] TAILS}

Apart from the frequent, but relatively trivial case of [+focus] parts of compounds, nearly all items in this category concern instances of the operation of SAAR. Rules responsible for the assignment of accents in compounded constituents, such as problem in (10) and book in (11), may create tails that consist of [+focus] subconstituents:

(10) O: You are the man with the sewage ${ }^{` B A C K f l o w}$ problem? [DBR]

(11) G: I've still got me 'RATion book [DBR]

These compound rules will not concern us here. There were two other types of [+focus] tails that did not concern full-focus argument + predicate combinations. One resulted from the use of verbs like to KILL oneself, to CUT oneself. When [+focus], these verbs have the accent on the verbal element, as in (12).

(12) I must stop 'TALKing to myself [R]

They are discussed further in section 8.2.2. The other case concerned the occurrence of an adverb of 'proper functioning' (e.g. right, well, properly). As is shown in Gussenhoven (1983), these adverbs, unlike other adverbs, are treated as unaccented parts of predicates:

(13) O: But one doesn't want one's 'SON I mixing with 'PEOPle I who can't 'SPEAK properly [FK]

The remainder of this section is devoted to the types of full-focus argument + predicate combination that occurred in the corpus. Rather than necessitate a reformulation of SAAR, these structures demonstrate that SAAR expresses a significant linguistic generalisation.

When seen from the point of view of syntactic structure, there were four structures that had the right sort of word order for the operation of SAAR to be apparent. These are discussed below. A fifth type, though unattested in the corpus, has been added for the sake of completeness. 


\subsection{TYPE 1: SUBJECT + INTRANSITIVE VERB / (BE) COMPLEMENT}

This may be said to be the basic type. It is the structure that led Schmerling in 1976 to postulate her principle II, which said that 'news sentences', i.e. sentences in which everything is 'new information', received accents on their arguments rather than their predicates. Examples in the corpus are numerous.

(14) G: ... with his 'HAIR all wet

(15) M: The 'FLAGS would have been out

(16) G: Her 'SON's turned up [all DBR]

(17) O: (I'm scared to ${ }^{`}$ PRESS the red one) I have a feeling the 'KITCHen will blast off [SC]

(18) G: Do you think the `TURkey will be unfrozen yet? [SC]

\subsection{TYPE 2: TRANSITIVE VERB + OBJECT + VERBAL PARTICLE}

In this type the predicate consists of a phrasal or phrasal-prepositional verb, with the verbal partıcle (out, at, to etc.) moved to a position after the object. While the operation of SAAR is not evident in e.g. I'll put on the KETTle, it is in I'll put the KETTle on. Although put in the latter sentence has a certain degree of (rhythmical) stress, it is not stress that derives from SAAR, which would of course select the particle if only the predicate was [+focus], and it was assigned an accent, as in stop fiddling about with the KETTle. Put it ON. Examples of this type are:

(19) M: Keep your 'VOICE down

(20) M: Are you going to bring the 'PRAM in?

(21) O: I'll put the `KETTle on [all DBR]

(22) 0 : If you don't change those 'WIRES over ... [SC]

As a subtype in this category we may include object + predicate combinations that contain an object complement. For example, in to paint the door green, door is the argument. The status of green, an object complement, is interesting: it would seem that, for the purposes of SAAR, such object complements, particularly when adjectival, are part of the predicate. Thus, if such structures are entirely [+focus], and the accent goes to the object (the argument), the object complement is left in the tail, like the verbal particle discussed 
above. Note that within the predicate it is the object complement that is the accentable part ( $\mathrm{cf}$ to paint (it) GREEN). In (23), the context is included.

(23) Tristram: Where does most of our 'COFFee come from?

Mildred : $(\ldots \ldots)$ Bra 'ZIL!

Tristram: (slowly, to co-occur with his spelling of the word) Bra'ZIL...

- RUBber!

Mildred : That'll be Ma 'LAYa dear

Tristram: NO. I've spelt Bra 'ZIL wrong

[DBR]

\subsection{TYPE 3: WH-MOVEMENT IN QUESTIONS}

This category comprises utterances in which an element is moved to the beginning of the clause by the syntactic rule of WH-movement, and in which as a result the predicate is left in rightmost position. It should be noted that the queried element in WH-questions is always a separate [+focus] focus domain and is, for that reason, always assigned an accent, in addition to any accents assigned to other [+focus] tocus domains in the tone group. This is not only plausible from a pragmatic point of view (the speaker is after all crucially interested in the queried bit of information), but is also apparent from the 'untransformed' versions of such structures, which naturally have the nucleus on the WH-word if it is final (You like WHAT?, Most of your coffee comes from WHERE? etc.). These 'untransformed' sentences, incidentally, are in fact much more frequent than may be thought, and regularly occur in (low-brow) TV quiz programmes. Additional evidence for the view that $\mathrm{WH}$-words must be assumed to have a focus domain to themselves lies in the fact that when they occur exclusively with a single predicate, the WH-word and the predicate do not fuse into a single focus domain. Rather, both are assigned an accent, as in (24) and (25), in both of which what has a (pre-nuclear) SAAR accent.

(24) $\mathrm{M}$ : What are you 'DOing? [FK]

(25) $\mathrm{M}$ : 'SO... What's so 'SPECial about it? [FK]

If we did not postulate separate focus domains for the two elements, SAAR would obviously apply incorrectly so as to assign the nucleus to the WH-word: 
WH-words are arguments, and as such would be candidates for merging with predicates, leading to "WHAT are you doing for (24).

Examples illustrating final unaccented predicates in this type are:

(26) O: How's the 'HOMEwork coming on? [DBR]

(27) O: I wonder what 'IT means (spoken when $O$ interrupted his reading of a letter after 'It finally 'HAPpened') [DBR]

(28) O: Where does most of our 'COFFee come from? [DBR]

(29) O: Did Mr Roper find out who that `CREDit card belonged to? [FK]

Type 3 is the first type of tail to be commented on in Crystal (1975: 25). There it says that the nucleus is placed on the word that is governed by the question word, as in What TIME does your watch say, Whose CAT's in the doorway, Isn't it wonderful how NICE she looks. This formulation of course misses the generalisation expressed by SAAR. More significantly, it would seem to make incorrect predictions by tying the nucleus to the head of the NP in which the WH-word is a modifier and ignoring the fact that there may be more arguments later in the utterance. That is, What COUNtries does most of our coffee come from, with a nucleus location as predicted by Crystal's formulation, is not in fact well-formed unless at least our coffee is [-focus]. SAAR, conversely, does account for Crystal's examples, if your watch in the first and she in the second example are taken to be [-focus]. The first question is equivalent to what TIME is it: the fact that the time is to be read off from the hearer's watch is taken for granted by the speaker. Similarly, she in the second example is [-focus], its referent being assumed by the speaker to be available in the discourse model.

\subsection{TYPE 4: [-FOCUS] POST-VERBAL ARGUMENT}

If, in an SVO or SVAdv structure, the final (accentable) element is [-focus], the nucleus goes to the pre-verbal subject by SAAR (the next argument up), rather than to the predicate. In the following examples, it, you and me are [-focus] arguments:

(30) M: Let's hope 'GEORGE doesn't see it

(31) O: (Imagine you're in $\mathrm{a}^{\vee} \mathrm{PUB}$ ) and a perfect ${ }^{\vee} \mathrm{STRANGer}$ comes up to you...

(32) O: Mrs 'ROPer has been helping me [all DBR] 
In this category we should include as a subtype relative clauses in which what would have been a post-verbal element is relativised. Like the construction discussed under Type 3 above, relativisation also involves WH-movement. It is intonationally distinct from WH-movement in WH-questions, in that the element that is moved is [-focus] rather than [+focus]. That is, the fact that the relative is moved has no consequences for the location of the nucleus, since it is not assigned an accent anyway. Perhaps more correctly, we should say that it is a condition on relativisation that the item to be relativised is [-focus]. An example is :

\section{O: That's what 'GOERing said [DBR]}

Example (33) concerns an utterance in which the verb is arguably non-salient from a pragmatic point of view. It is, however, not the case that it is this non-salience that accounts for its not being nuclear. The nucleus location would be preserved if we replaced said with the semantically weightier died, and we could have the well-formed exchange as in (34).

(34) A: Shall we meet in ${ }^{`} X$ ?

B: That's where 'GOERing died

(Note, incidentally, that how in the last of Crystal's examples quoted in 3.3 is not a question word, but an independent wative pronoun, being equivalent to the way in which in the same way that what is equivalent to the thing which, cf Quirk et al 1972: 730, 864).

\subsection{TYPE 5: SUBJECT + PASSIVE VERB}

Although utterances in this category were expected to be rather lberally represented, there was not a single example in the corpus in which a passive verb phrase was tone-group final and the preceding subject was [+focus]. Passive constructions generally are surprisingly infrequent: in DBR the total number was six. The two of these that had the predicate in final position had a [-focus] subject:

(35) $\mathrm{M}:$ He'll have it towed a'WAY [DBR]

(36) (O: I'm `SORry | you're an arrogant little 'TWERP)

G: Apology ac 'CEPted [DBR] 
(Note that in (36) the accent on twerp serves to support the 'comedy' effect achieved by the deletion of I said that, and that the [-focus] treatment of apology by George enhances this effect.) Subject + passive verb constructions that are entirely [+focus] can easily be supplied from other sources:

(37) CLASSes have been cancelled (Bing 1979: 176)

\subsection{EXCEPTIONS TO SAAR}

Prosodic data are often viewed in a less absolute light than syntactic data. Rules of syntax are generally - and rightly - seen as being absolute statements about syntactic well-formedness. The fact that speakers may on occasion choose not to apply the rule should not be seen as 'invalidating' that rule in any way. The utterance Here's the CAR... the gentleman says that the car is STOLen cannot serve as evidence that RELATIVISATION is not a true rule of English syntax. And the fact that speakers may be heard to say Helsinki is the capital of WHICH country does not mean that WH-MOVEMENT in questions is not a 'rule' of English, but rather indicates that there may be an area of pragmatic research into why speakers do or do not employ the options available to them. In the area of prosody, by contrast, it is sometimes expected that the rules that one postulates should actually predict speakers' options rather than specify surface structures that are the result of these options. Clearly, just as speakers may or may not employ certain syntactic options available to them, so they may freely exploit the set of prosodic options available to them. The view taken here is that we should first of all concentrate on the structure of this set of options and their effect on surface structure, and only secondarily investigate the reasons for their employment. As an example of such an apparent exception, consider (38), in which me dad is treated as [-focus] by the speaker:

(38) O: I was just curious to see what my dad 'LOOKED like

[DBR]

In the context, George, much to his dismay, was taken by the speaker to be his father. After a volley of disclaimers on George's part, the speaker expresses his surprise at George's reaction, and then utters (38). The fact that my dad was marked [-focus] by the speaker considerably added to George's discomfort, as it underscored the fact that his parental status was being taken for granted. It would of course have been possible for the speaker to have explained his visit 
with ... my 'DAD looked like, but the option he did employ was natural enough. In the circumstances, full focus (i.e. including my dad) would have made the reason for his visit sound somewhat more casual, and would have suggested that he was not so much interested in George as his father, as in his father, whoever that might be. Thus, the issue here is not whether SAAR is a rule of English (which It is), but what the speaker's motivation was for choosing the focus distribution he did choose.

It is stressed that there are different types of apparent counterexample to SAAR, some of them occurring in our corpus. These can be given structural explanantions, i.e. can be analysed as resulting from the employment of linguistic options that prevent the pattern of accented argument + unaccented predicate from surfacing, such as topicalised arguments, which require a focus domain to themselves ${ }^{6}$, independent permutation of argument and predicate, the use of non-eventive sentences, etc.. For these analyses, see Gussenhoven (1983).

Somewhat surprisingly, there were two genuine exceptions to SAAR in the corpus, both of them in DBR. Both concern what I would like to call 'idiomatic' nucleus placements. The first is (39).

(39) Stranger things have 'HAPpened [DBR]

SAAR requires the nucleus on stranger (assuming that things is [-focus]). The utterance would seem to be peculiar to English, and is possibly a quotation. Note that related languages have the nucleus on the equivalent of stranger: Es sind schon MERKwuirdigere Sachen passiert! (German), Er zijn wel GEKkere dingen gebeurd (Dutch). A possible explanation of the nucleus location in (39) was suggested to me by Gill Brown, who observed that (39) has a fuller version 'Stranger things have happened at sea'. When speakers left off at sea, they may have placed the nucleus on happened not unlike the way in which a teacher drilling the Lord's Prayer might say: Our father who ART (...) in ' $\underline{\text { HEAVen. }}$ Good 'LAD.

The second exception represents an instance of conventionalised usage in the world of broadcasting. It is also exceptional in that the 'nuclear tone' is not part of the paradigm of tones normally employed in English:

Germany CALLing Germany CALLing [DBR] 
(with raised larynx and strong nasalisation to imitate transmission distortion, and Germany with mid level pitch and callng a little lower, but also level)

Although simlar to what Ladd (1978) calls the 'stylised fall' (which would seem to have a greater step down from the first to the second 'level', from Germany to calling if Germany has the nucleus) and simlar to a level nuclear tone (Crystal 1969 215), it would appear to be different from either Note, incidentally, that this is not the normal usage in telephone conversation

(41) Ummmm this is Phulp 'ROATH speaking [R]

Both exceptions, I would suggest, only bring out the correctness of the generalisation expressed by SAAR

\subsection{CATEGORY II. TYPICALLY [-FOCUS] EXPRESSIONS}

Category II comprises expressions that can be given a semantic characterisation It could be argued that this group should really be seen as a subgroup of Category III, in so far as the expressions concerned refer to aspects that are somehow inherently present in the discourse madel, like tume, or the relationshıp with the interlocutor The bulk of the expressions fall into three classes

1 tıme-space markers

2 cohesion markers

3 hearer-appeal markers

The justification for treating them as a category separate from Category III is that they have an orientating function in common the propositions to which they are appended are anchored by them to points in, respectively, the outside world ('tume-space'), the surrounding discourse ('cohesion'), and some set of possible affective interpretations avalable to the hearer ('hearer-appeal') An example of a time-space marker is this morning, cohesion markers include ex- 
pressions like as a matter of fact, for example, whlle mind you, you know are examples of hearer-appeal markers

In addition to these three classes, two further classes have been included in this group

4 textual markers

5 epproxumatives

The first of these, the textual markers, comprises comment clauses like to be perfectly frank, I believe (Quirk et al 1972 778) and reportung sentences, like he said (Quirk et al 1972 785), also called 'direct speech markers' (Crystal 1975 25) While this class can sumlarly be said to have an orientating function, specifying the status of the 'text' they are appended to, they are virtually absent from our corpus The final class is that of the approximatives (e $g$ or something, and all that) It is unlike the others in not having a simlar orientating function It is, however, semantıcally easily identıfiable, and should as such be included in Category II

At the risk of labouring the obvious, it is pointed out that, in many cases, expressions in category II can themselves be [+focus], without thelr lexical meaning being different in any way Their membership of category II expressions is based on their occurrence as appendices to focused propositions Time-space markers, in particular, frequently form the crux of a proposition For example, when I caught them kissing this morning is uttered in response to When did you catch them kissing?, then, evidently, we wll expect this morning to be treated as [+focus], and $I$ found them kissing as $[$-focus] Thus, when time-expressions like this morning are said to belong to Category II, this should be taken to mean that when I caught them kissing this morning is uttered in response to, for instance, What are you so excited about John and Mary for?, the expression this morning wll typically treated as [-focus], desplte the fact that the information provided by the expression may be assumed to be 'new' to the hearer Note also that it is not impossible for such expressions to be [+focus] in addition to a [+focus] marking for some other part of the utterance When this is the case, they require a focus domain to themselves An example of a focused time adverbial which is appended to another focused element is given in

Here the focus for this year, in addition to that for the eleventh, serves 
to bring out the high frequency of dental treatments that the hearer, an office worker, claims to have to undergo.

(42) A: You had a `DENtal appointment this morning?

B: 'YEAH

A: The eleventh this 'YEAR? [R]

Category II is the category of [-focus] expressions that is discussed by Bing (1979: ch2), who calls them Class $O$ expressions, taking the view that they lie outside ('O') the domain to which 'prominence tones' (equatable with nuclear tones) are assigned. This latter domain is filled by Class I ('inside') expressions. In addition to challenging Bing's inclusion of certain expressions in the category of Class $O$ expressions and her exclusion of certain others, I will argue that this particular view of 'intonational domain' is incorrect. But first, let us turn to the expressions themselves.

\subsection{TIME-SPACE MARKERS}

Time

This is a particularly frequent class. It is noted, for instance, in Brown (1977: 89) that 'time-phrases which modify a predicate are very frequently placed last in the tone group and do not receive the tonic'. These time-markers often denote 'time-when' (including 'relational' words like yet, (not) any more), but may also refer to 'duration' and 'frequency' (including again). Bing (1979), who has a general category 'sentence adverbials', gives one time-space marker among her examples, the time-frequency adverb from time to time. Firbas (1980), however, explicitly refers to 'adverbials of time and place'. The following examples are representative (cf also (18)):

(43) G: I booked his 'DAD today

(44) G: 'EH ... 'WAIT a minute

(45) O: I always like to tuck her ${ }^{`}$ IN last thing at night

(46) G: Special oc'CASion tonight

(47) G: I haven't got the 'BALance anymore

(48) G: I was reading the `PAPer the other day...

(49) O: You moved a `ROUND a lot

[all DBR] 
Space

Only the most general place indicators fall in this class. They occur considerably less frequently than time indicators.

(50) O: 'LOOK. Do your ${ }^{` C O A T}$ up while you're in here [DBR]

(51) O: Does... a Mr...eh George 'ROPer live here [FK]

(52) Trevor did 'WELL in life

(53) Have your Cosmic Researches 'LED you anywhere?

There are of course examples of focused locatives in the corpus. In (54), the focus for your serves to contrast the liveliness at her mother's house with the depressing tedium of her own.

(54) M: (on the telephone to het mother) It sounds pretty 'LIVEly / at YYOUR end [SD]

\subsection{COHESION MARKERS}

This class comprises expressions that make explicit the logical relationship between the utterance they are appended to and its context. This relationship may be:

- (parenthetically) additive, expressing something like 'Now that you've mentioned it', exemplified by in fact, as a matter of fact, really, actually. These often have a downtoning effect, and the latter two in particular may be apologetic in force;

- inferential, exemplified by then or so... then, of course;

- concessive, exemplified by though;

- reinforcing, exemplified by thank you very much, of course, if necessary;

- contrastive, exemplified by for a change, on the other hand. 
Many others exist (cf for example, however, in other words, in that case), as can be seen in Quirk et al. (1972: 821-3), although not all of those listed there would actually be placed in the tail. Many of those that do, moreover, can also be placed in sentence-initial position, in which case they are often given a fall-rise tone, less frequently a fall (cf Allerton \& Cruttenden 1974). The meaning of many items varies according to whether they occur initially or finally.

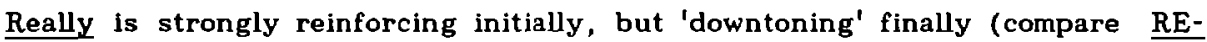
ALLy I I think you should GO and I think you should GO really). Also, the same expression may serve different functions in final position, such as of course, which may be inferential or reinforcing, or then, which may be inferential or serve as a hearer-appeal marker (see section 4.3). Note that then is not typically used as a time-space marker, a fact that, not surprisingly, is capitalIsed on for 'comic' effect:

(55) (A and B are talking about how miserable life is and of fear of death) A: Well what 'DO you think that happens then?

B: 'WHEN?

A: After 'DEATH [R]

The following are representative examples:

(56) G: Her hooter wasn't `THAT big. Bit like `YOURS really [DBR]

(57) G: Nothing to ${ }^{`} D O$ with you in fact [DBR]

(58) O: Still 'DOESn't (=approve of sex) as a matter of fact [DBR]

(59) Is sex a 'PROblem then? [R]

(60) I've just got over Cliff 'RICHard's rebelliousness thank you very much [R]

(61) $M$ : Bit by 'BIT if necessary [SC]

(62) G: Not your own flesh and `BLOOD of course [DBR]

(63) $\mathrm{O}$ : Nice to be on our ' $\mathrm{OWN}$ for a change [SC]

(64) O: Must have been a bit of a 'SHOCK though [DBR]

Crystal (1975: 25) mentions a few of the above items under the heading 'final adverbial disjuncts/conjuncts'. In Bing's list, they fall under the general heading of 'sentence adverbials'. As such, they are also mentioned by Schubiger (1958: 91), Bauer et al. (1980: 230) and, with refinements, by Firbas (1980). 


\subsection{HEARER-APPEAL MARKERS}

The class comprises items that are used by the speaker to appeal to the hearer. Most of them serve to enhance the solidarity the speaker intends to establish with his hearer, but some are 'challenging' and as such have a distancing effect. Another term for them might therefore be 'solidarity modifiers'. They fall Into two groups:

1. A variety of expressions, often conventionalised sentence fragments (I mean, you know). They are called 'softeners' or 'softening phrases' by Crystal (Crystal 1975: 6, Crystal \& Davy 1975: 92). In Bing (1979) they are called 'polite expressions'.

\section{Vocatives.}

Hearer-appeal markers are collectively referred to as 'phatic elements' by Firbas (1980).

\section{Softeners}

In the corpus, the following occur: you know, I mean, then, thanks and please. Examples are:

(65) G: I was only obeying me `ORDers you know [DBR]

(66) $O$ : If you'd 'HAD one I mean [FK]

(67) $O: I ' l l$ say cheeri'O then [DBR]

(68) $O$ : Not for 'ME thanks (declining an offer of sherry) [SC]

(69) G: I'd like a word with Bill 'ALbright please [DBR]

Unlike what is suggested In Crystal \& Davy (1975: 92-100), these items, when final, are typically included in the tail. It may be true that many of them typically co-occur with a fall-rise in the host sentence, and that they are therefore frequently associated with the rise-element of the fall-rise, but this does not elevate them to the status of a separate tone group. Whlle you know, for example, occurs far more frequently with the fall-rise in the host sentence than with the fall, the latter type does occur:

(70) O: It's time you learned to do this for your'SELF you know Ann [SC]

(71) We have a 'BRANCH $l$ in Milton 'KEYNES you know [R] 
There are no instances in the corpus of you know being appended to a host sentence that has a rise, however. The expressions you see, mind you, though unattested in the corpus, also belong in this group (Crystal \& Davy 1975: 79-9). The item see, which occurred once:

(72) O: I mean I'm a shop 'STEward I'SEE [FK]

may well be different from you see, y'see in typically requiring its own tone group, like eh (cf section 5.3.1), but without further data, we cannot be certain that the enalysis of (72) is correct. It should in any event be kept distinct from the see? meaning 'I told you so' or 'QED', which certainly forms a separate tone group, as in

(73) O: 'AH I 'SEE? [FK]

\section{Vocatives}

Vocatives occur frequently. In DBR alone there are 26 occurrences. They are included in Crystal's list and in Bing's. Examples from the corpus are:

(74) G: Hel`LO Moby

(75) $\mathrm{M}$ : O hel`LO love

(76) M: 'NO George

(77) G: Good = NIGHT son

(78) O: Mr and Mrs 'ROPer sir [all DBR]

(79) O: Don't 'FUSS woman [SC]

(80) G: `GLEETings rotus brossom [SC]

(81) O: Ready for `COFFee you two? [SC]

As is well-known, vocatives are given a separate tone group when they occur in Initial positjon:

(82) G: `MILdred. Fancy an early `NIGHT [DBR]

In final position, vocatives contrast with similar expressions that have a different function. Lee (1960: 55), Crystal (1975: 25), Bing (1979: 27) and Pierrehumbert (1980: 96), for instance, note that apposittves are given a separate tone group: 
From the corpus, it appears that also the specification of the sender of a quoted message is so separated from the preceding material:

(84) M: 'THANK you | for twenty-six glorious 'YEARS |

All my 'LOVE | 'GEORGE [FK]

Note that in the latter function, the name is normally given a fall, but that when the name is appositive, it tends to agree with the nuclear tone of the element it is an appositive to (cf Palmer 1922: 87ff, Halliday 1967: 209). Of course, names also occur as separate tone groups when the speaker inquires after the hearer's name or identity, addresses the hearer selectively, calls his attention, or introduces somebody to the hearer. An example of the first function is (85) and of the last (86).

(85) O: Ex`CUSE me | Mr 'ROPer? [DBR]

(86) M: It's `ME mother | 'MILdred [SC]

\subsubsection{Tags}

There are certain tags that behave like the class of 'softeners' discussed above, but certain others that do not. The regular tag is formed by inverting the polarity of the host sentence and repeating the subject and the predicate in proforms (with modal auxiliaries standing in for the whole predicate). The tag always has subject-verb inversion, and the host sentence is always declarative in form. This tag is referred to as Tag $I$. There is another type of tag which is syntactically distinct from Tag $I$ in that it agrees in polarity with the host sentence (normally both are positive, but negative-negative sequences are reported, e.g. O'Connor \& Arnold 1973: 61, Quirk et al. 1972 - 392), and can also be appended to host sentences that have the form of yes-no questions. As the two types are also phonologically distinct, I will discuss them separately.

Tag I. Tag I forms a separate tone group. While the tag itself either has a fall or a rise (always on the auxiliary), there seem to be no restrictions on nuclear tone choice in the host sentence, and, as far as the present corpus is con- 
cerned, no restrictions on the tone sequence between host sentence and tag. ( $O$ 'Connor \& Arnold observe that a rise-fall on the tag requires a rise-fall on

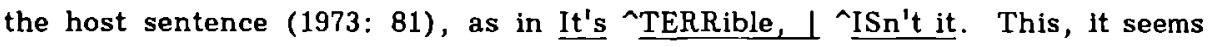
to me, may indicate that we are here dealing with a parameter that is independent of nuclear tone choice proper. That is, the difference between the rise-fall and the fall may be of a different order from that between the fall and the rise, or the fall and the fall-rise.) The following examples are illustrative of the various combinations of host sentence tone and tag tone that occur in the corpus:

(87) G: Something has up'SET you | 'HASn't it

(88) G: You're not from the H'P company I 'ARE you?

(89) G: He's a nice 'LAD | 'ISn't he?

(90) G: 'NICE I 'ISn't it?

(91) G: He was a 'NICE looking lad | 'WASn't he

(92) G: I don't think I 'KNOW you I'DO I?' [all DBR]

There are more tag-like structures in the corpus that require their own tone group. One is eh, which would seem to be obligatorily marked with a rise. It also shows a strong preference for combining with a host sentence that has a fall. While it is thus intonationally more restricted than Tag $I$, it is syntactically less restricted in that it can also combine with host sentences that are WH-questions:

(93) G: I got a 'DAUGHter-in-law I 'EH?

(94) G: Worth a few 'MARBles I EH?

(95) G: What are you im'PLYing |'EH? [all DBR]

Tag I and eh have different meanings. Tag I either invites the hearer to respond positively or negatively to the proposition conveyed by the host sentence (rise on the tag), or to confirm it (fall on the tag, as stated by e.g. O'Connor \& Arnold 1973: 59-61, Quirk et al. 1972: 391). The meaning of eh seems much more general, and in fact is not unlike the meaning of the rise nuclear tone itself, of which it might be said to be the 'dummy' carrier. That is, it is suggested that the more formal counterparts of (93) to (95) consist of the host sentences by themselves with a rise instead of a fall. 
Tag II. Tag II agrees in polarity with the host sentence. If the present corpus is anything to go by, it may occur with host sentences that have the form of yes-no questions $((96))$, but not with WH-questions ((97)).

(96) G: Is it one of your ${ }^{\sim}$ PREsents is it? [SC]

(97) *What are you im `PLYing are you?

Significantly, however, in practically all instances in the corpus either the operator or the operator and the subject were ellipted in the host sentence:

(98) Been WORKing have you? [R]

(99) O: You in the 'CHAIR are you? [FK]

(100) Nall varnish drled `OUT now has it? [R]

Unlike Tag I, it does not appeal to the hearer either to confirm or to deny the proposition expressed by the host sentence, but rather expresses the fact that the speaker draws a conclusion on the basis of (non-) linguistic information just received (which conclusion may of course be presented to the hearer for comment). As Quirk et al. (1972: 390) say, it is frequently used for sarcastic effect. It also often sounds challenging, and Rando (1980), for instance, refers to It as the 'belligerent' tag. Interestingly, Siertsema (1980), who, following Schubiger's analysis of British English intonation and German modal particles (Schubiger (1965, 1980)), investigated the equivalences between English tags and Dutch modal adverbs, lists only examples of Tag II as the equivalent of Dutch dus ('so'). In the present corpus, it is always included in the tall of the nuclear tone in the host sentence, a finding that confirms Bing's analysis of the status of Tag II (1979: 37). The host sentence either contains a rise or a fall-rise, which may account for the fact that Quirk et al. (1972: 390) state that Tag II (seen by them as a separate tone group) 'always has a rise': the 'rise', then, is either the rise-element of the fall-rise, or a continuation of the rise nuclear tone. Examples are:

(101) G: ${ }^{\circ} \mathrm{OH}$ । About the `CREDit card is it? [FK]

(102) G: Gonna be la-di- ${ }^{\sim} D A$ are we? [SC]

(103) Seeing out 'NAME I in car park 'YELLow are we? [R]

(104) You specialise in cheering people 'UP do you? [R]

It should be observed that a pattern like (102) is 'theory-neutral' in the sense that it could be argued that the pattern might also be analysed as a nuclear fall 
followed by a nuclear rise. Importantly, however, we did not find instances like (105), which would be a counterexample to the generalisation that Tag II is non-nuclear: a one-nucleus interpretation would be impossible, as there is no fall-rise-fall nuclear tone in English.

(105) ??Gonna be la-di-`DA I'ARE we?

The missing pattern that is allowed by the generalisation, viz. one with a fall in the host sentence, is reported by Bald (1980) as occurring in Svartvik \& Quirk (1980). This pattern is also given by Halliday (1967: 26, 1970: 28).

(106) Thls is contingent on the central 'HEATing is it (S.7.1.a.41)

Because of the differences of analysis, we should, again, be cautious when comparing these findings with spontaneous speech data as presented in Svartvik \& Quirk (1980). Bald (1980) presents a number of breakdowns of a collection of 439 tag questions taken from this corpus, all based on the tonetic transcription offered in the corpus. His research broadly confirms our analysis in that he concludes that Tag II 'presents a patently different prosodic pattern' from Tag I. Indeed, if we compare Tag I and Tag II on the basis of whether it is classed as a separate 'tone unit', we get a strikingly biased distribution. If we exclude Bald's 'complex' category VI, containing tags whose syntax is determined by a clause other than the immediately preceding one and for which no tonal specification is given, the figures are for Tag $I$ : 189 separate tone units and 78 tone units shared with the host sentence, while for Tag II the figures are 10 and 69 , respectively. Moreover, of the 78 instances in which Tag I was analysed as occurring in the same tone unit as the host sentence, 23 concern the 'theory -neutral' pattern of a fall followed by a rise. In other words, these could also be analysed as sequences of two tone groups. Of the remaining 55, 47 are instances of 'subordination'. Subordinated tone groups are, however, intended to constitute separate tone units, though of a special type (cf Crystal 1969: 245, or Bald 1980, Note 10), and there would therefore seem to be no reason, even remaining within the confines of the transcription conventions adopted in Svartvik \& Quirk (1980), to regard these as belonging to the 'shared-tone unlt' category.

Of the 10 instances of Tag II as a separate tone unit, 7 appear to consist of $W$ and one of ', sequences that, again, could be analysed as single tone groups, marked by a (rise-) fall-rise nuclear tone. Thus, Bald's study strongly sug- 
gests that the data in Svartvik \& Quirk (1980) confirm the analysis offered above It should also be noted that there are no patterns like (105) in Bald's corpus

There were two sentences in the corpus of Tag II appended to an umperative host sentence Although semantically this tag is different from the 'regular' Tag II (e g Get a decent bottle of ' $\mathrm{SCOTCH}$ will you? [R]) phonologically it would seem to behave lke it in that it is typically non-nuclear The different distributions of Tag $I$ and $\mathrm{Tag}$ II do not support the analysis given in Ladd (1981) In that analysis, Tag II is seen as post-nuclear, as in Bing (1979) and in this article, but Tag $I$ is only regarded as nuclear when it has a fall, not when it has a rise The examples in the corpus, however, suggest that the freedom of nuclear tone choice in the host sentence is as great when the tag has a fall as when it has a rise

\subsection{TEXTUAL MARKERS}

The class of textual markers, also termed 'parenthetıcals' (e g Huckin 1977 33), has been supplied from the literature it is not represented in the corpus It falls in to two groups

Reporting sentences

These are mentioned by Crystal ('final direct speech markers' 1975 25) and Bing (1979), who uses the term 'parenthetical verbs' for this subclass

(107) / I don't want to go OUT he said / (Crystal 1975 25)

Although such reporting sentences would not seem to be infrequent in spoken English, particularly non-standard spoken English, they do not appear to be typically employed in the sort of quasi-spontaneous speech the corpus consists of There are no occurrences of them, elther in tone-group final or in other positions

\section{Comment clauses}

These are mentioned by Bing (1979 33), who calls them epistemic verbs Examples given by Bing are think, suppose, know, realise, wonder, hope, 
imagine. There need be no doubt that such verbs are typically post-nuclear, as in

(108) To`MORRow I think (Bing 1979: 33)

Curiously, there is only one example of a comment clause in the corpus, and there it was given a separate nucleus, which should perhaps be explained as the actor's attempt at being sarcastic.

(109) $\ldots$... and found ac'CEPTable | I be'LIEVE

$[R]$

\subsection{APPROXIMATIVES}

The final class of expressions in Category II is that of the approximatives. It is not mentioned by Crystal, Bing or Firbas. It comprises expressions that indicate the approximative nature of the expressions they are appended to, and it is fairly liberally represented in our corpus. Although the expressions are quite varied from a syntactic point of view, and include adverbials, coordinated expressions and finite clauses, their status as a semantic class is reflected in their being kept outside the focus. Note that clausal approximatives would appear to be restricted to 'empty' comparatives like the way he did. Examples are:

(110) O: Oh 'YEAH । I suppose they ${ }^{\vee} A R E$ in a way

(111) $O$ : Oh it must be eleven 'YEARS or more

(112) G: Just for a 'DAY or two

(113) O: `ME | Turning `UP like I did [all DBR]

(114) It's a 'RULE | they're always `LOCal or something [R]

(115) Industrial Tri'BUNal and all that [R]

(116) Rotting in the 'GROUND? | Burrowing 'WORMS and so on? [R]

(117) Do you think we can get on to thinning `HAIR | and sexual $1 n^{2}$ ADequacy kind of thing? [R] 


\subsection{COMPARISON WITH OTHER INVESTIGATIONS}

It may at this point be useful to summarise our findings in sections 3 and 4 in tabular form (see Table 4), and to compare them with the results of the investigations reported in Crystal (1975: 25-6), Bing (1979: ch2) and Firbas (1980).

From the point of view of the classification of tail-types offered here, Crystal's list presents a rather mixed picture. In addition to such items as were quoted above, Crystal gives a number of miscellaneous ones, including items that concern what we might call 'pragmatically old' information, as in: A: That was some terrible ACcident WASn't it. B: a TERRible accident. In others they would seem to concern compound stress rules, as in That shelf is a da-it-yourSELF job or It's a verPLOORG grammar; or contrastive accentuation of the type this book costs FIVE dollars $\mid$ and this one THREE dollars, or items that are difficult to interpret out of context, such as he has a YELLow streak, while in one case $a$ time adverbial is included: It's the in-THING these days.

Bing's list resembles our Category-II list rather more closely. However, in addition to vocatives, polite expressions (here: softeners), sentence adverbs, what I called Tag II, parenthetical verbs and epistemic verbs, all of which were covered above, Bing mentions epithets and expletives. Among other examples, the following are given to illustrate epithets:

(118) John wouldn't give me his cak the stupid bastght (Bing [47])

(119) My next-door neighbours, the finks, have been coming over every night (Bing [48b])

Bing quotes O'Connor \& Arrold's

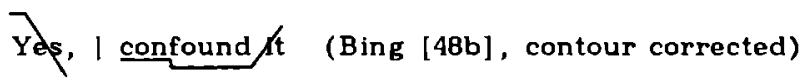

as an example of an expletive. I believe Bing is mistaken when she classifies expletives and epithets as Class $O$ expressions. Contrary to what this Implies, they do not form the tail of the preceding nucleus, but are assigned a separate nuclear tone. What may have led her to including them as Class $O$ expressions is that this nuclear tone is typically a low rise, and as such phonetically similar to the optional boundary tone, which is her interpretation of the rise element of the fall-rise. Since the presence of the boundary tone is her main criterion for 


\begin{tabular}{|c|c|c|c|}
\hline & & Type & Example \\
\hline I & SAAR & $\begin{array}{l}\text { 1. Subject+Intransitive V/ } \\
\qquad B E+\text { complement } \\
\text { 2. Object+Verb+Particle } \\
\text { 3. WH-movement } \\
\text { 4. Subj+Verb+[-focus] Obj } \\
\text { 5. [Subject+Passive verb] }\end{array}$ & $\begin{array}{l}\text { I have a feeling the 'KITchen will blast off } \\
\text { Keep your 'VOICE down } \\
\text { Where does most of our 'COFFee come from? } \\
\text { Mrs 'ROPer has been helping me } \\
\text { [CLASSes have been cancelled] }\end{array}$ \\
\hline \multirow{5}{*}{ II } & Time-space marker & $\begin{array}{l}\text { Time } \\
\text { Space } \\
\text { Addition } \\
\text { Inference }\end{array}$ & $\begin{array}{l}\text { Can we sit 'DOWN for a minute? } \\
\text { Do your `COAT up while you're in here } \\
\text { Bit like `YOURS really } \\
\text { Is sex a 'PROblem then? }\end{array}$ \\
\hline & Cohesion marker & $\begin{array}{l}\text { Concession } \\
\text { Reinforcement } \\
\text { Contrast } \\
\end{array}$ & $\begin{array}{l}\text { Must have been a bit of a 'SHOCK though } \\
\text { Bit by 'BIT if necessary } \\
\text { Nice to be on your 'OWN for a change }\end{array}$ \\
\hline & Hearer-appeal marker & $\begin{array}{l}\text { Softener } \\
\text { Vocative } \\
\text { Tag II }\end{array}$ & $\begin{array}{l}\text { I was only obeying me `ORDers you know } \\
\text { Don't 'FUSS woman } \\
\text { You in the 'CHAIR are you? }\end{array}$ \\
\hline & Textual marker & $\begin{array}{l}\text { [Reporting sentence] } \\
\text { [Comment clause] }\end{array}$ & $\begin{array}{l}\text { [NO, he said] } \\
\text { [FIVE, I suppose] }\end{array}$ \\
\hline & Approximative & & Industrial tri 'BUnal and all that \\
\hline
\end{tabular}

Table 4. Types of tall in Categorles $I$ and II. Bracketed entries are not represented in the corpus, and have been supplied from the literature 
classifying expressions as Class $O$ expressions, it is not surprising to find that her list includes expressions that typically have a low rise. Bing's case for this interpretation of epithets rests, among other things, on the contrast between (119) and (121): in (121) the Finks is an appositive with a fall-rise.

(121) My next-door neighbours, the Finks/ have been coming over every night (Bing [49a])

Since the two tones cannot be interchanged, so she argues, they differ in the way she says they do. I would agree that the patterns do have the meanings given, but of course this could also be used as an argument for saying that the low rise does not mean the same thing as the fall-rise in English. Note that Class $O$ expressions, e.g. vocatives, to give Bing's canonical example, have the following characteristics:

- They are not assigned a prominence tone;

- They may be assigned a boundary tone.

Translated into a nuclear tone description, these two characteristics would come out as:

- They may not be assigned a nuclear tone;

- If the sentence they are appended to is assigned a fall-rise, they will carry the rise element of that tone.

Below I will retain Bing's terminology. If we compare epithets and vocatives, three differences emerge that Bing's analysis cannot account for:

1. After a completed A-rise contour (a fall-rise), vocatives cannot be given an optional boundary tone, but epithets can:

(122) They are my next-door neighbour's the figks

(123) "They are my next-door neighbouts Pamfla

Note that the pattern in (123) would have been well-formed if Pamela is added, after a suitable pause, as a means of (literally) calling the hearer's at- 
tention (see 5.3). It would then not be a vocative in the sense employed here, and be assigned a separate tone group.

2. Vocatives can occur without the optional boundary tone, but - paradoxically - epithets must have the optional boundary tone ((126)).

(124) They're my next-door neighbours Pamela

(125) *They're my next-door neighbours the finks

(126) They're my next-door neighbours the figks

3. If a B-contour (a high-rise) is used, a vocative is high in the pitch range (continuing the rise started on the nuclear syllable), but an epithet picks up from the bottom of the pitch range:

Were they your next-door neighbgars Pamela?

"Were they your next-door neighbgars the finks?

(129) Were they your next-door neighbolurs the finks?

Observe, incidentally, that (129) may be given a different interpretation. Since appositives are characterised not just by the fact that they are assigned a nuclear tone, but also by the fact that this tone agrees with the tone on the element they are appositive to (see section 5.3), (129) is ambiguous between an appositive reading and an epithet reading. It may in fact be felt that an appositive reading is the more immediately probable one, possibly because questions like (129) are not easily compatible with declarations of the type expressed by epithets. This should not, of course, allow us to lose sight of the important point, and that is that all three differences noted above are naturally explained by assuming that epithets are separate tone groups, that is, Class I expressions. In (122) it follows a fall-rise, in (126) it follows a fall, and in (129) a rise. Similar reasoning would show that expletives, too, are given a low rise nuclear tone. Summarising, vocatives are included in the tail, appositives are given a separate tone group and agree in tone with their 'head', and epithets 
and expletives are given a separate tone group and are typically assigned a low rise nucleus.

Firbas (1980), finally, attempts to account for the frequent occurrence of predicates in the tail not by postulating a focus-realisation rule (like SAAR), but by appealing to semantic factors. He would thus view our Category $I$ as a subpart of Category II. It is difficult to see how this can be done. Neither is Firbas' account very clear: "[It] is because in the development of discourse the primary function of the verb is an introductory one. It consists in introducing into the discourse notions conveyed by context independent elements. This explains why the verb comparatively rarely comes to carry the highest degree of CD [communicative dynamism] and to function as an IC [intonation centre] bearer."

\subsection{THEORETICAL IMPLICATIONS}

It is In the nature of things that tals that must be assigned to Category III (pragmatically [-focus] expressions) will not be amenable to the same sort of 'linguistic' generalisations that were made for tails in Categories I and II. At thls point we will therefore turn to a justification of the interpretation of the falling-rising pitch contours that was adopted in section 1.3. The first section below argues against certain interpretations proposed in the British literature, the second against a recent proposal by Bing (1979).

\subsection{THE STATUS OF THE FALL-RISE}

When placed beside treatments of English intonation like those found in Trager \& Smith (1957), Liberman (1975) or Pierrehumbert (1980), descriptions in the 'British tradition' begun by Palmer (1922) are conspicuous in showing considerable agreement with respect to broad questions concerning the segmentation of intonation contours ( $\mathrm{cf}$ e.g. Ashby 1979 for a short characterisation). On closer Inspection, however, certain dlfferences of opinion emerge, most significantly in the very area we are dealing with here, that of the designation of particular pitch-marked syllables as either nuclear or non-nuclear. Most notably, the disagreement concerns the theoretical status of 
1. rising movements followed by falling movements;

2. falling movements followed by rising movements,

in situations in which the two movements do not occur on the same syllable. If we ignore Bing's treatment for the moment, such sequences have, between them, been described as:

- a sequence of two nuclear tones;

- a compound, bi-nuclear tone, with both pitch-marked syllables characterised as nuclear;

- a simple nuclear tone on the first syllable;

- a simple nuclear tone on the second syllable.

Such issues are of theoretical significance, and need not simply be considered out of an Occam's razor-guided desire for descriptive elegance. Their chief importance lies in the implications different solutions will have for a semantic analysis of intonation: different interpretations of pitch movements may affect our decision about what is 'given' (or [-focus]) and what 'new' (or [+focus]), in addition to determining our classification of the pitch movements in terms of the paradigm of nuclear tones, which, after all, are widely held to be strong candidates for meaning-carrying units.

The present analysis of talls can really only claim to have a bearing on the interpretation of the second of the two pitch sequences mentioned above. The first, a rise followed by a fall, is either uncontroversially Interpreted as a 'rise-fall', marking a single nucleus, as in (4), or is variably interpreted without affecting the decision about what is 'tail'. Thus, if Crystal (1975: 27) analyses I 'ROUND the 'CORner I and Crystal \& Davy (1975: 127) | 'PuLling his 'BAT away | the way they do, 1.e. as compound rise-plus-falls, where Deakin (1981) would analyse these utterances as having nuclear falls preceded by rlsing heads, or if Svartvik \& Quirk (1980: 294) analyse I actually you'd go 'DOWN to Fulham 'PALace Road | as a compound rise-plus-fall, where Brazil, Coulthard \& Johns (1980: 8) would analyse the same thing as a sequence of a rise and a fall, we end up with the same interpretation of what is 'tail', since the falling movement is seen as nuclear in all three analyses. A different case is presented 
by the second of the two patterns mentioned earlier, a fall followed by a rise, because here, one of the rival analyses - the one adopted in section 1.5 - claims that it is only the fall that marks a nuclear syllable, the rise being placed later in the tail (irrespective of its length), and together with the fall forming part of a single nuclear tone, the fall-rise. This may be said to be Kingdon's position (1958: 19) (who, confusingly, does have a 'compound tone' in his analysis, which would seem to be equivalent to a falling head followed by a nuclear rise in other analyses, as in 'Do sit 'DOWN (1958: 127, cf Schubiger 1961)). It is probably also Schubiger's position, who, however, distinguishes between a unitary (distributed) fall-rise and a fall followed by a tail which is 'modified by a rise' (1958: 22 Note), and, less ambiguously, Gimson's (1980: 279), although he adds that both the fall and the rise take place on 'accented syllables'. It is also explicitly the position adopted by Firbas (1980), who, in order to emphasise the distinction between his view and one espousing a bi- or double-nucleus analysis, chooses to replace the term 'tail' with the term 'shade'. Such a 'unitary' analysis contrasts with an analysis of the two pitch movements as separate nuclei (Brazil, Coulthard \& Johns 1980), as well as with one in which both movements are seen as nuclear, but together make up a single, compound 'fall-plus-rise' nuclear tone (Halliday 1967, Crystal 1969, O'Connor \& Arnold 1973). For some analysts, both a unitary nucleus interpretation (with the rise in the tail) and a compound one are avalable, with (optional) phonetic differences being claimed between them (Halliday's Tone 4 vs Tone 13, 1967: 20, or O'Connor \& Arnold's simple vs compound fall-rise, 1973: 29). Ignoring this potentiality for alternative analyses by some authors, three interpretations are therefore possible for (2) (repeated here):

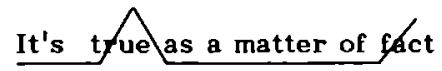

$$
\text { | It's `TRUE as a matter of fact | }
$$

(e.g. Bauer et al. 1980: 231)

$$
\text { I It's 'TRUE as a matter of 'FACT | }
$$$$
\text { (e.g. Halliday 1967: 15) }
$$$$
\text { | It's 'TRUE | as a matter of 'FACT | }
$$

(cf Brazil 1978: 59)

Our analysis of tails in this article has assumed the first of the above three interpretations. It follows that all the generalisations arrived at in sections 4 and 5 will have to be abandoned, If we adopt either the analysis under (ii) or that under (iii). Any arguments for preferring either of the latter two analyses to (i) must therefore be seen as pitched against this, what I would regard as overwhelming evidence to the contrary. Clearly, drawing a distinction between a fall-rise and a fall-plus-rise nuclear tone would considerably complicate the de- 
scription of the data 'This conclusion is in direct conflict with that reached by Crystal (1969 220), who says 'The phonetic and linguistic contrast between complex (e g a monosyllabic $`$ ) and compound (e g a distributed $W$ ) tones thus seems sufficiently great to justify separate phonological discussion ' Crystal's conclusion, however, is misleadingly strengthened by the very misconception it seeks to establish because he regards both the fall element and the rise element as nuclear, he is able to contrast the compound fall-plus-rise not just with a (phonetically different?) pattern which is described as having the fall-rise in the position of the fall element in the compound version, as in I 'YOU don't know | well, who does, then' versus | 'YOU don't 'KNOW I So why are you saying you dol, but also with one in which the fall-rise is placed on the syllable that has the rise element in the compound version, as in | I thought it would `RAIN | versus | I 'THOUGHT it would 'RAIN |. Three of the four supporting examples he gives are of the second type It should be clear that in the rival, uni-nuclear analysis, comparisons of the latter type concern a difference of nuclear-tone position, not one of nuclear-tone type

Our analysis also makes it clear that an across-the-board interpretation of such sequences of falls and rises as separate tone groups ( 1 e interpretation (iii)) would equally effectively wipe out the generalisations we have made Observe, however, that although the generalisations may be used as a guiding principle in a large number of cases where a distinction between a one-tone group and a two-tone group solution is at issue, a problem that remains to be solved is how to draw the distinction between a tone group with a non-final fall-rise and a sequence of two tone groups, one with a nuclear fall and one with a nuclear rise, both of which are of course allowed by our analysis Unlike Schubiger, who plays down the significance of this question to an uncomfortable extent (1958 89 Note), I believe that the question is - or should be - answerable in an absolute sense, and should not be 'a matter of convention', as Schubiger says For discussion of this question see Kingdon (1958 33-7, 78-80), Crystal (1969 236-9, 248), Gussenhoven (forthcoming)

There is, as far as I can see, only one other analysis possible that would leave the generalisations intact This is an analysis whereby the rise element of the fall-rise is partitioned off from the nuclear-tone paradigm, and accommodated in a separate, two-term paradigm of boundary tones (an analysis which is perhaps implied in Schubiger 1958 19, 84, at least for part of her data) In such a description, (2) and (130) would be said to have the same nuclear tone (a fall), but to differ in that (2) has a high boundary tone and (130) a low boundary 
tone, or, alternatively, no boundary tone. If it is possible to define a certain subset of tails, say Category II expressions, then, obviously, the generalisation that can be made is that that subset is the purview of the boundary tone paradigm.

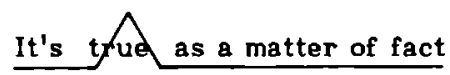

It is precisely such an analysis that has been proposed by Bing (1979). The next section is devoted to it.

\subsection{THE QUESTION OF A SEPARATE 'INTONATIONAL DOMAIN'}

Bing's description of Class $O$ expressions differs from a description of such expressions in terms of the more traditional 'British' concepts of nucleus and tail, such as the one offered here, in that she sees those expressions as falling outside the domain for the assignment of the 'prominence tones'. In her system, there are four such tones (the second and fourth of which are subsequently argued to be variants of each other). They are given here with their 'British' translations (Bing 1979: 10):
A contour : fall
A-rise contour : fall-rise
$\mathrm{B}$ contour : high rise
C contour : low rise

Class $O$ expressions are then given either no tone or a (low rise) boundary tone. That is, the domain formed by Class $O$ expressions is separated intonationally from the stretch of speech to which these expressions are 'appended' (Liberman (1978) speaks of 'tags', although his position with respect to the question of domain appears to be neutral). Put differently, the host sentences, which contain Class I expressions, are assigned 'prominence tones' and these tones are not allowed to spill over into the Class $O$ expressions. Thus, (2) would be said to consist of the $A$ contour followed by the boundary tone, and (130) to have the A contour, but not the boundary tone. Conversely, (131) and (132) would be said to contain different prominence tones (an A-rise contour and an $A$ contour respectively) and also to differ in that (132) has the boundary tone but (131) has not. 
(131) I suppose you can take the cats (Bing [60])

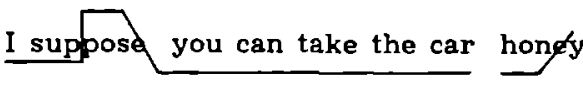

There 1s, moreover, an important semantic correlate of these two tonal paradigms prominence tones have meaning, the boundary tone does not The notion of separate tonal paradigms also occurs in Pierrehumbert, who, in order to generate the $\mathrm{Fl}$ contours of American English intonation, postulates three paradigms pitch accents, phrase accents and boundary accents (Plerrehumbert 1980. 16)

I believe that the notion of separate domains and the associated concept of boundary tones lack theoretical justification Before arguing against these notions, let us see what Bing's arguments for her solution are If we discount the discussion about the different derivational histories of Class I (coming from Root Sentences) and Class $O$ expressions (coming from non-sententıal Expressions) as irrelevant to the point at issue, there being no reason to assume that differences in syntactic status, certainly those of the deep-level type she is concerned with, should be precisely parallelled by differences in intonational structure, Bing puts forward only two arguments whose force does not depend on an a priori analysis of the data in terms of the analysis she proposes (Bing in fact concedes that part of her argumentation is circular) Both arguments focus on the most important consequence of her boundary-tone analysis the fact that, in that analysis, the addition of a boundary tone to an utterance does not alter the semantics of that utterance In an attempt to demonstrate that this prediction is borne out, Bing starts from the well-known pair (133) and (134).

(133) John doesn't drink because he is un happy (A contour, Bing [22])

(134) John doesn't drink because he is un happy (A-rise, Bing [23])

For (133), the most probable interpretation is 'Because of his unhappiness, John doesn't drink', whle for (134) it is 'John drinks for reasons other than his unhappiness' (Bing 1979 27) Now, instead of comparing these versions with (135) and (136)

(135) John doesn't drink because he is un happy, Pamela [*]

(136) John doesn't drink because he is un hakpy, Pamela (Bing [25]) 
which would be the respective counterparts of (133) and (134) in a nuclear tone analysis, Bung argues, as indeed she is forced to argue, that (136) is the counterpart of (133), since here a meaningless boundary tone has been added to an A contour (a fall) While leaving (135) undiscussed, she then boldly states about (136) that it gets the same interpretation as (133) Although discussions of this sort should really not take place outside the context of independently obtained judgements (and Bing does not provide any), it is not difficult to choose from 'Why don't you try and cheer hum up' and 'He drinks because he is a bloody alcoholic' the most natural sequel to (136) Although, as far as my own intuition is concerned, either sequence would be well-formed, the most inmediately probable one is that with the latter sequel, and not that with the former, quite the reverse of what Bing claims Observe further that by equating (136) with (133), Bing is left with the problem of giving a vocative counterpart to (134) She does this by allowing the rise element of the fall-rise (or the boundary tone, in Bing's terms) to set in a little earlier than in (136), representing it as follows

(137) John doesn't drink because he's un haqpy, Pamela (A-rise + boundary

Now, at least in standard British descriptions of Fnglish intonation, it is not uncustomary to describe the rise element of the fall-rise as picking up from a syllable before the last rather than from the last, either from the first post-nuclear syllable (e g Jones 1975 303) or from the last secodarly accented (stressed) syllable (e $\mathrm{g}$ Gimson 1980 268), the assumption in this tradition apparently being that there are no semantic or phonological differences between (136) and (137) But even if we assume that the situation in American English is different, Bing is left with an awkward gap in her analysis, provided by (135), as well as with an awkward case of overgeneration the apparently non-existent pattern consisting of (134) followed by a vocative without the boundary tone

Bing's second argument likewise tries to capitalise on the tact that her treatment predicts that presence or absence of the boundary tone is semantically neutral Thus, in (138) and (139), where we are dealing with expletives (which, it will be recalled, are regarded as Class $O$ expressions by Bing), the addition of the boundary tone does not alter the meaning of the expletive 
(139)

Screw the she hes! (A contour with boundary tone) (=Bing [138a,b])

Note that the assumption here is that when an expression in Class $O$ occurs in isolation, it must receive a prominence tone, which is then optionally followed by a boundary tone. Bing contrasts this pair with the pair in (140) and (141), which are not expletives, and which do differ in meaning:

(140) Screw the shelves (A contour)

(141) Screw the sheley (A-rise contour)

(i.e. but leave the sides for me to do) (=Bing [139a,b])

Bing then notes that this difference is accounted for by the fact that different prominence tones have different meanings ((140) and (141)), and that (138) and (139) after all have the same prominence tone. The argument is faulty, even if we take the view that expletives are post-nuclear (which as we saw they are not). Note first of all that no reason is given why part of the contour in (139) is assigned a prominence tone and part a boundary tone. What, in other words, would the contour look like with an A-rise contour? And how would its meaning differ from (139)? Note, second, that if (138) and (139) are said to have the same meaning, this sameness refers to the fact that they are both expletives: at best, a different tone can modify the effect of the expletive, but not 'change its interpretation'. And note, thirdly, that if it did, it would no longer be an expletive, and Bing could dismiss the 'change' as being the result of a shift from Class $O$ to Class I! The argument is wholly void.

An observation made by Liberman (1978: 13) might well have provided Bing with another argument for her proposal. Liberman notes that (142), in which the predicate has the nucleus and my friend follows in the tail, differs from (143), where my friend is a vocative, in that the fall in (142) is allowed to spread on to my, but in (143) is completed before my, the net effect being that my in (143) has lower pitch:

(142) Sam struck 'OLT my friend

(143) Sam struck 'OUT, my friend (Liberman 1978: 13)

It would, to my mind, be a mistake to try and account for this difference by postulating different units - tones or domains - in the intonational system. Neither, to be sure, do we postulate a long / $t /$ phoneme by the side of a short $/ t$ / 
phoneme to account for the durational difference in the alveolar closure for / $t$ / in out, which may be another phonetic difference accompanying the syntactic difference. It is suggested that the only 'emic' difference is a syntactic one (cf Liberman 1978: 10), and that the phonetic differences noted are 'etic' effects of this difference. Of course, low-level phonetic rules, whether segmental or non-segmental, will have to be made sensitive to the difference in syntactic bond between struck out and my friend, but adding units either to the intonational system or to the phoneme inventory to account for cases represented by (142) and (143) would open the floodgates to whole regiments of phonological units that will soon make a mockery of the concept of a 'phonological system'. In a sense, this is what is proposed in the section on tags in Pierrehumbert (1980: 95-102), in whose description the phonological level and the phonetic level largely coincide. It should be noted that Bing does not bring Liberman's example to bear on her hypothesis.

What are the arguments against Bing's proposal? There are, it would seem, two major problems. One is that the boundary-tone-is-meaningless theory conflicts with the semantic facts, and the other that the boundary tone paradigm leads to the generation of pitch contours that do not occur.

1. One consequence of the fact that the boundary tone is meaningless is that (144) and (145), to take one example, cannot differ in meaning:
(144) I ` KNOW, Mildred
(A contour $+\mathrm{H}^{\circ}$ )
$[:]$
(145) I 'KNOW, Mildred
(A contour + $\theta$ ) [ac]
( $H^{\circ}$ is here used for Blng's boundary tone, for its absence)

Bing's only comment on this type of difference is that (144) would be characteristic of female speakers and (145) more characteristic of male speakers, but, she adds ingenuously, 'both patterns are acceptable to either' (1979: 22). The following frame brings out their different semantic effects rather glaringly :

(146) Mildred: And what's `MORE | the police will find out that you haven't returned that 'CREDit card you found 
where the use of the fall on know will cause shut up about it to sound like an injunction to Mildred to stop talking about it to George, but the use of a fall-rise may well be taken by Mildred to mean that she is not to let on about it to the police, or to other people in general. The effects would not, of course, be different from those achieved by I 'KNOW and 1 ${ }^{\vee}$ KNOW, respectively, which Bing would regard as having different prominence tones. And what to think of the ludicrously pally effect if Julius Caesar were be be portrayed as saying

(147) Et `TU, Brute (Shakespeare, Julfus Caesar Act III, Sc I)

when recelving the final stab from Brutus (instead of 'TU, 'TU or $\underline{\text { TU) }}$ Surely, this is not caused by the fact that Julius Caesar is a male rather than a female character, as Bing would presumably have it.

Another consequence of her analysis is that (131) and (132) do differ in intonational meaning, since (132) has an A contour on suppose and (131) an A-rise contour. It would be difficult to demonstrate that these utterances differ in anything other than a measure of politeness introduced by the addition of the vocative.

Bing's postulation of separate Class $O$ domains generates many patterns that do not occur. Among them are the following:"

$$
\begin{array}{ll}
(148): \mathrm{Ng} / \text { Mildrdd } & \text { (A-rise }+\mathrm{H} \%) \\
(149): \mathrm{Ng} \text { Mildred } & \text { (C contour }+\emptyset \text { ) } \\
(150) \div \mathrm{No} \text { Mildred } & \text { (B contour }+\emptyset \text { ) }
\end{array}
$$

In fact, the only patterns that do occur are the ones predicted by the standard view of vocatives being included in the tail of the nuclear tone:

(151) M: It's ri 'DIC ulous George (A contour)

(152) M: Look at it THIS way Geopte (A-rise contour)

(153) O: I would have MARRjed her George (C contour) [all DBR]

summary, Bing's proposal to look upon Class $O$ expressions as constituting a parate intonational domain must be rejected. All the evidence points to the 
correctness of the traditional view whereby the tail is included in the domain of the nuclear tone, also when this tail is fulled by a Class $O$ expression.

\subsection{CATEGORY III: PRAGMATICALLY [-FOCUS] EXPRESSIONS}

\subsection{PRELIMINARY REMARKS}

Sentence accents, in the sense of the things that are assigned by rules like SAAR, are either there or are not there. Phonologically speaking, there is no place for 'degrees' of them. As such, they must be distinguished from other phenomena that might conceivably be discussed under the heading 'sentence stress'. These phemomena include at least the following:

1. The existence of suprasegmental durational structure in tails (i.e. durational variation that is explained by the presence or absence of 'word accent', the potential location for 'assigned accents'). Thus, rid in (154) may be more prominent than get, reflecting a potential pronunciation get RID (of).

(154) Why 'DID you get rid of Lucy? [R]

2. Various suprasegmental means of making a syllable stand out so as to cause the meaning of the word it is part of to be 'significant'. These concern modifications of duration, loudness and voice quality. Examples are (155), where wade was lengthened, and pronounced with softer-than-usual, lax voice, and (156), with me extra loud, and with harsh voice. While such paralinguistic features may be expected to be amenable to systematic description, they are unrelated to the concept of focus and sentence accent.

(155) O: Of course I could wade through yesterday's ac'COUNTS [FK] (156) M: Don't you 'LIE to me! [FK]

3. The employment of pauses to create suspense. An illustrating example here is (157). The pause serves to underline the fact that the speaker continues 
to regard George as his father, in spite of the latter's remonstrations The pause, however, does not disturb the mapping of the fall-rise the rise element goes to the stranded dad just as it would have done if no pause had occurred

(157) O (to George) I think it's pretty ` OBvious dad [DBR]

4 High-pitched onsets of tone groups in other than sentence-accent positions, as in (158), where say has high onset, but is not assigned an accent by SAAR (say being a cohesion marker, ef a POUND say?)

(158) O Shall we have a Iittle 'SIDE bet | ^Say a 'POUND? [SC]

The sentence accents that we are concerned with, in other words, are those that are assigned by SAAR on the basis of the focus marking of the utterance Recall that, unlike what is sometimes assumed, 'accent' and 'focus' are not directly relatable in the sense that what is unaccented is therefore [-focus] In particular, we saw in section 3 that predicates in focused argument + predicate combinations are unaccented, and that therefore an utterance like Your FRIEND has called is ambiguous between a sentence with [+focus] just for your friend and one with full focus marking In its turn, the intonational option [+focus], like the syntactic option [ \pm past], is avalable to speakers to express certain meanings As is well-known, these meanings are not easy to describe The most convenient short-hand descriptions of them are probably Halliday's terms 'given' and 'new' (1967 204) 'o The marking of [+focus] is invariably reserved for what speakers consider to be the crux of their contribution to the conversation (hence 'new'), while [-focus] goes with what speakers somehow assume - or want to be seen as assuming - to be the starting point of what they are contributing (hence 'given') (Note that Halliday used 'glven' and 'new' to refer to the terms in the focus paradigm themselves, rather than to their meanings )

It would clearly not be worthwhle to attempt to bring order in the large collection of Category-III tals on the basis of formal linguistic criteria of the type 'repetition of words', 'second mention of concept', 'use of proform', etc For one thing, such a classification would soon prove to be vold, inasmuch as there would almost certanly be a [+focus] example in our corpus for every sub-category that is set up For another, the basis of a description of pragmat- 
ically [-focus] expressions must surely be pragmatic. It is not clear to me, however, to what extent such a description is either possible or desirable.

So, rather than attempt to give a more complete definition of what 'focus' means, I would in a final section like to select from the corpus some examples of focus distribution that are used to create particular effects. This, at least, will make it clear that focus is a semantically powerful linguistic option.

\subsection{FOCUS EFFECTS}

Special effects of focus distribution as employed in the corpus are of two kinds:

1. narrative effects, i.e. such effects as are used to give structure to the narrative;

2. 'comedy' effects.

\subsubsection{Narrative effects}

A strategy that is not infrequent in the G\&M data is to allow [-focus] marking to suggest the occurrence of a preceding conversation. The technique enables the producer of the drama to leave out bits of verbal exchange that would only serve to lead up to 'comedy' situations, and thus results in a higher density of such situations. For example, a scene may begin as follows:

(159) G: Well of 'COURSE I remember ve night [DBR]

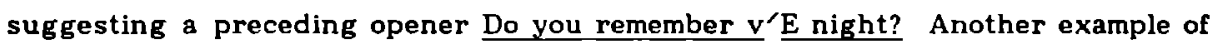
such an opening is

(160) O: And 'THAT'S | my opinion of 'YOU | What do you think of 'THAT?

G: Well, some people might be of ₹FENDed by the phrase "arrogant little twerp" [DBR]

A somewhat different technique involving [-focus] is used in (161), where a character speaking on the telephone uses [-focus] to represent the speech of his interlocutor, who, as a character in the series, remains imaginary. 
(161) I do 'NOT see too many spy films I I `DON'T know the facts and fallacies of call tracing... [R]

While techniques of this kind would also appear to be employed in novels, the spoken medium clearly offers much more scope for them.

\subsection{2 'Comedy' effects}

Within this group, two types can perhaps be distinguished: conventional 'come$d y^{\prime}$ uses of [-focus], and specific ones. In neither case, incidentally, need we be dealing with focus distributions that exclusively occur in 'sitcom' speech. The conventional type, in particular, would seem to be fairly frequent also in real spontaneous speech.

Conventional uses. Conventional 'comedy' effects of [-focus] rely on the [-focus] marking of semantic material that could objectively be characterised as unexpected, but that. incongruously, because it is not marked [+focus], acquires a certain measure of self-evidence. That is, the effect is created by the presentation of the unexpected material as material that both the hearer and the speaker had taken for granted all along. In all cases that this technique occurred in the corpus, the preceding nucleus had a fall-rise. For example, in (162), the focus marking suggests that, contrary to fact, it is somehow common knowledge that Rolls Royces need two parking bays:

(162) G (temporarlly employed as a traffic warden): I gave out thirty "TICKets today | Thirty-'ONE | if you count the Rolls `ROYCE parked at two meters [DBR]

Other examples are (163) to (165).

(163) A: (muttering and moaning)

B: You're quite ${ }^{`}$ HANDsome when you are paranole [DBR]

(164) (shopkeeper, reluctantly replying to a request to produce an invoice): It'll only take an ${ }^{\curlyvee}$ HOUR or two to trace it [FK]

(165) (on receiving news that his boss wants to see him): 'THAT'll be the sack I I had hoped to `KEEP this job long enough to buy a toupee [R] 
In a related type, it is unfavourable attendant circumstances that are incongruously not marked [+focus], the [+focus] marking being restricted to the conjunction and, as in (166).

(166) O: Last year I queued all `NIGHT for Harrod's sale I `AND it was raining $[\mathrm{SC}]$

Here the effect depends on the contrast between the suggestion that the two events expressed by the sentential conjuncts naturally go hand in hand and the objective fact that they are unrelated.

And, stretching the term 'comedy' effect somewhat, we should here perhaps also include such conventionalised [-focus] uses as are given by Firbas (1980) and are represented in our corpus by (167) - (169).

(167) 'THAT's for sure! [DBR]

(168) `THAT'l interest you [DBR]

(169) 'THAT'll be the sack! [R]

Specific uses. In the group of specific uses of focus distribution for 'comedy' effects we find both instances of the (objectively unjustifled) absence of [+focus] marking, and of its presence. To begin with the latter, an evidently popular structure here is reflexive verbs, like to KILL oneself, to TALK to oneself, to asSERT oneself, which are accented on the verbal element when they are [+focus] (cf section 4.0). Observe that for the purposes of SAAR, these verbs are predicates rather than predicate + argument combinations: when they are combined with an argument, SAAR applies regularly ( $B^{\prime}$ s reply in (170) being entirely [+focus]):

(170) A: What's all the 'RUCKus about?

B: Uncle 'SID's killed himself! [ [i: $]$

When, however, the [+focus] marking is restricted to the reflexive pronoun, this will get the nucleus. It is this restricted focus distribution that 'ought' to have been used in O's utterance in (171). Instead, $O$ used full focus for the reflexive verb, which results in a Category-I tail for yourself. The same ploy is used in (172). 
(171) O: (to George, who keeps intruding on $\mathrm{O}$ ) $\mathrm{Mr}^{-} \mathrm{ROPer}$ I do you ever 'TALK to yourself?

G: NO

O: Now's your 'CHANCE (turns his back on George) [FK]

(172) M: (to George, who is playing scrabble all by hinself) What are you 'DOing?

G: I'm 'PLAYing with meself [FK]

Tails resulting from the unwarranted absence of [+focus] marking are theoretically less interesting. An example is (173), where the 'comedy' effect relies on the occurrence of a homophone, constituting a case of pseudo-repetition.

(173) G: Germany CALLing, Germany CALLing! (cf (40))

$M$ : (about visitor who just left, bored by George's war-stories) 'HE won't be calling again! [DBR]

Another example is (174), where [-focus] for the dependent question enhances the sarcastic effect: the utterance was intended as a dismissal of the hearer. Observe that full focus (i.e. with the nucleus on door) would have been less effective. The unmediacy of the dismissal depends crucially on the (untruthful) suggestion that the hearer must already have been working on the logistics of his retreat, and was about to go anyway.

(174) 'NOW | Da you 'KNOW how the door warks? [R]

Finally, observe how in (175) the 'comedy' effect relies on George's ignoring the well-formed focus distribution in the first clause of Mildred's utterance, treating it as if not you was [+focus], but bought a present (which ought to have given the nucleus on present).

(175) M: I bought `YOU a present, George | Now what are `YOU going to do? G: I'L say ${ }^{\vee}$ THANK you, Mildred [FK] 


\subsection{SUMMARY}

As a result of our analysis of tails, a number of important theoretical points about the intonation of English could be established.

1. SAAR expresses an important generalisation. No theoretical consequences could be detected that necessitated a reformulation. Its explanatory power goes well beyond that of statements that NPs are stressed in preference to VPs (section 4).

2. There is no direct relationship between focus and accent such that what is [+focus] is necessarily accented. Examples of [+focus] elements that are unaccented include predicates in focused argument + predicate combinations, certain compound constituents in focused arguments, adverbs of 'proper functioning' and reflexive pronouns in focused predicates (sections 4.0, 8.2).

3. A large subclass of [-focus] tails (Category II tails) can be given a semantic characterisation (section 5 ).

4. No justification could be found for the postulation of bi-nuclear tones. Indeed, the postulation of a bi-nuclear fall-plus-rise causes important generalisations (cf 1 and 3 above) to be lost (section 7.1).

5. A theory postulating a separate intonational domain for Category II expressions, served by a paradigm of boundary tones, causes Important semantlc distinctions to fall outside the scope of its explanatory power. Moreover, such a theory generates contours that do not occur. Neither problem exists in the theory it seeks to replace, that of the theory of nuclear tones (section 7.2).

6. While we have been unable to give structure to the set of pragmatic conditions under which speakers feel it is justified or imperative to use [-focus], it was demonstrated that focus is a semantically powerful linguistic option, which can readily be exploited to give temporal structure to a narrative, and to produce particular 'comedy' effects (section 7). 
Notes

1. I should like to thank Flor Aarts, Ton Broeders, Gill Brown, Bob Ladd and Elizabeth Couper-Kuhlen for the helpful suggestions they made after reading an earlier version of this article. I thank Pieter de Haan for helping me count the nuclear tones with the help of a computer.

2. I should like to thank Mr James Corsan, Ms Alexa Dalby and Mr Bob Louie of Thames Television Studios for their cooperation in making the tapes available to me. The instalments transcribed were Days of Beer and Rosie (Series 4, episode 2), Finders Keepers? (Series 5, Episode 1) and On the Second Day of Christmas (Series 4, Episode 7). The series was written by Johnnie Mortimer and Brian Cooke and the main characters are played by the late Yootha Joyce and by Brian Murphy. I thank all those involved for permission to reproduce extracts from the instalments here, the copyright to which belongs to Thames Television Ltd. The Instalment from the Roath material is Endangered Species. This series is written by Peter Tilbury, who himself plays the main character in it. The copyright also belongs to Thames Television Ltd.

3. Other numerical data for British English are the histograms given in Pellowe \& Jones (1978, 1979) and Local (1982), which are based on the figures given in Quirk et al. (1964), who give a breakdown over a number of parts of speech. A rough estimate of these percentages, applying the same conversions as for the Davy data, is $\backslash 53, \cdots 14,>25,-4, \wedge 3$. Although they are based on a corpus of spontaneous speech, the figures seem closer to those for reading-style than to those for conversation, as given by Davy (1968). Fries (1964) presents interesting figures on the incidence of rises and falls in yes-no questions in the specch of panelists taking part in a radio qulz programme. The panelists, who were speakers of American English, attempted to elicit information from a number of contestants by just asking yes-no questions. Lee (1980) presents similar data for British English, and compares his data with data for yes-no questions in radio programmes in which the questions are not quite so densely packed. Although Lee discusses the difference between his two corpora, the proportions he gives are not in fact significantly different. The overall figures given by Frles are: falls $61.7 \%$ and rises $38.3 \%$, and those by Lee: falls $43 \%$ and rises $57 \%$. No attempt has been made to split out the data in the G\&M corpus according to sentence type.

4. The non-assertive role of George as the fall guy can also be related to the differential use by $h$ im and Mlldred of tag questions(You're not from the H'P company 1 'ARE you? of Quirk et al. 1972: 390): out of 16 tag questions in DBR, 14 were spoken by George and none by Mildred, and the other instalments show a similar pattern. (Five of the 14 tags by George were not in fact in the script.) In addition, there were five instances of EH (e.g. What are you in'PLYing ${ }^{\prime}$ 'EH), all of them by George, and unscripted.

5. The terms 'argument' and 'predicate', also used by Schmerling (1976), are chosen so as to underscore the fact that focus marks sementic constituents, rather than syntactic ones.

6. Observe that this is the solution to the problem offered in the Preface to Postal (1971). Postal notes that topicalised him in e.g. Him Charlie wouldn't put the bag near (from Charlie wouldn't put the bag near him) is no longer ambiguous between a coreferential and a non-coreferential reading, as it is when it is not topicalised. If him is to be toplcalised, it must be [+focus]; if it is to be [+focus], it must be treated as 'new' by the speaker; if it is 
'new', it cannot be coreferential with Charlie. The fact that him and Charlie have 'crossed over' (Postal's explanantion) is not really relevant.

7. Note that in the last example the negative in the host clause is raised to the main clause, and that this does not affect the polarity of the tag, as is pointed out by Quirk et al. (1972: 392).

8. Note, for instance, Crystal's statement that adverbial disjuncts/conjuncts are expounded as a nuclear tail (or as prosodically subordinate, or as the second part of a complex (sic; read: compound) tone)' (1975: 25), and his lamentation after his rather mixed collection of tail-types that it is unlikely that any greater precision will be introduced into the analysis of the semantic conditioning of pre-final tonic placement until more adequate studies of semantic relationships are written' (1975: 26).

9. Bing is none too explicit about what the eight patterns that are generated by her description (four prominence tones times two boundary options) look like, and the three patterns given here may not represent her own idea of the realisations of the phonological representations given. Neither, by the way, is any indication given with which, if any, of those eight contours the four contours that are generable for NO mul did (as an answer to Which mill used child labour?) correspond, or why whatever contours are possible on No, Mildred but not on NO mill did, should be so restricted.

10. As Brown (1983) observes, it is to be deplored that the 'glven/new' distinction has come to be applied to linguistic options of a completely different nature, like pronominalisation, word order, (in)definite articles and second mention of the same referent, which concern syntactic options in their own right and do not necessarily go hand in hand with the way speakers employ focus.

\section{References}

Allerton, D.J. \& A. Cruttenden (1974). 'English sentence adverbials: their syntax and their intonation in British English'. Lingua 34, 1-29.

Ashby, M.G. (1978). 'A study of two English nuclear tones'. Language \& Speech $21,32-6$.

Bald, W.D. (1980). 'English tag questions and intonation'. In: Anglistentag 1979. Berlin: TUB-dokumentation, Kongresse und Tagungen, Heft 7. 263-89.

Bauer, L., J.M. Dienhart, H.H. Hartvigson \& L. Kvistgaard Jakobsen (1980). American English pronunciation. Copenhagen: Gyldendal.

Bing, J.M. (1979). Aspects of English prosody. Bloomington (Indiana): IULC.

Brazil, D. (1978). Discourse intonation, Vol. 2. English Language Research, University of Birmingham.

Brazil, D., M. Coulthard \& C. Johns (1980). Discourse intonation and language teaching. London: Longman.

Brown, G. (1977). Listening to spoken English. London: Longman.

Brown, G. (1983). 'Prosodic structure and the Given/New distinction'. In A. Cutler \& D.R. Ladd (edd). Prosody: Models and measurements. Berlin: Springer. 67-77. 
Crystal, D. (1969). Prosodic systems and intonation in English. Cambridge: Cambridge University Press.

Crystal, D. (1975). The English tone of voice. London: Arnold.

Crystal, D. \& D. Davy (1969). Investigating English style. London: Longman.

Crystal, D. \& D. Davy (1975). Advanced conversational English. London: Longman.

Davy, D. (1968). 'A study of intonation and analogous features as exponents of stylistic variation, with special reference to a comparison of conversation with written English read aloud'. University of London MA thesis. (Not consulted, cited in Crystal 1969).

Deakin, G. (1981). 'Overlap and gradient relationships in English intonation'. Melbourne Working Papers in Lingulstics 7, 39-77.

Firbes, J. (1980). 'Post-intonation-centre prosodic shade in the modern English clause'. In: S. Greenbaum, G. Leech \& J. Svartvik (eds). Studies in English linguistics for Randolph Quirk. London: Longman. 125-33.

Fries, C.C. (1964). 'On the intonation in "yes-no" questions in English'. In: D. Abercrombie, D.B. Fry, P.A.D. MacCarthy, N.S. Scott \& J.L.M. Trim (eds). In honour of Daniel Jones. London: Longman. 242-54.

Gibbon, D. (1976). Perspectives on intonation analysis. Forum Linguisticum, vol. 9. Bern: Lang.

Gimson, A.C. (1980). An introduction to the pronunciation of English. 3rd edition. London: Arnold.

Gussenhoven, C. (1983). 'Focus, mode and the nucleus'. Journal of Linguistics $19,377-417$ (Also this volume).

Gussenhoven, C. (forthcoming). 'Stress shift and the nucleus'. Linguistics (Also this volume).

Halliday, M.A.K. (1967a). Intonation and grammar in British English. The Hague: Mouton.

Halliday, M.A.K. (1967b). 'Notes on transitivity and theme in English, part 2' Journal of Itinguistics 3, 199-244.

Halliday, M.A.K. (1970). A course in spoken English: Intonation. Oxford: Oxford University Press.

Huckin, T.N. (1977). An integrated theory of English intonation. Ann Arbor: Xerox University Microflums.

Kingdon, R. (1958). The Groundwork of English intonation. London: Longman. Jones, D. (1975). An outline of English phonetics. 9th edition. Cambridge: Cambridge University Press.

Ladd, D.R. (1978). 'Stylized intonation'. Language 54, 517-40. 
Ladd, D.R. (1980). The structure of intonational meaning: evidence from Eng lish. Bloomington: Indiana University Press.

Ladd, D.R. (1981). 'A first look at the semantics and pragmatics of negative questions and tag questions'. Papers from the seventeenth regional meeting of the Chicago Linguistic Society, 164-71.

Lee, W.R. (1960). An English intonational reader. London: Macmillan.

Lee, W.R. (1980). 'A point about the rise-endings and fall-endings of yes-no questions'. In: Waugh \& van Schooneveld (1980). 165-8.

Liberman, M. (1975). The intonational system of English. MIT dissertation. Reproduced by IULC 1978, Bloomington, Indiana.

Local, J. (1982). 'Modelling intonational variability in children's speech'. In S. Romaine (ed). Sociolinguistic variation in speech communities. London: Arnold. 85-103.

O'Connor, J.D. \& G.F. Arnold (1973). Intonation of colloquial English. 2nd edition. London: Longman.

Palmer, H.E. (1922). English intonation with systematic exercises. Cambridge: Heffer.

Pellowe, J. \& V. Jones (1978). 'On intonational variability in Tyneside speech'. In P. Trudgll (ed). Sociolinguistic patterns in British English. London: Arnold. 101-122.

Pellowe, J. \& V. Jones (1979). 'Establishing Intonationally variable systems in a multidimensional linguistic space'. Language \& Speech 22, 97-116.

Pierrehumbert, J.B. (1980). The phonology and phonetics of English Intonation. MIT dissertation.

Plke, K.L. (1945). The intonation of Americen English. Ann Arbor: University of Michigan Press.

Postal, P.M. (1971). Cross-over phenomena. New York: Holt, Rinehart \& Winston.

Quirk, R., J. Svartvik, A.P. Duckworth, J.P.L. Rusiecki \& A.J.T. Colin (1964). 'Studies in the correspondence of prosodic to grammatical features in English'. Proceedings of the IXth Congress of Linguistics (Boston 1962). The Hague: Mouton. 679-91. Reprinted in R. Quirk (1968). Essays in the English lenguage: Medieval and modern. London: Longman. 120-35.

Quirk, R., S. Greenbaum, G. Leech \& J. Svartvik (1972). A grammar of contemporary English. London: Longman.

Rando, E. (1980). 'Intonation in discourse'. In Waugh \& van Schooneveld (1980). 243-77.

Schmerling, S.F. (1976). Aspects of English sentence stress. Austin: Univers1ty of Texas Press.

Schubiger, M. (1958). English intonation: Its form and function. Tubingen: Max Niemeyer. 
Schubiger, M. (1961). Review of Kingdon (1958). English Studies 42, 51-5.

Schubiger,M. (1965). 'English intonation and German modal particles: a comparative study'. Phonetica 12, 65-84. Reprinted in D. Bolinger (ed) (1972). Intonation: Selected readings. Harmondsworth: Penguin Books. 175-93.

Schubiger, M. (1980). 'English intonation and German modal particles II: a comparative study'. In Waugh \& van Schooneveld (1980). 279-98.

Siertsema, B. (1980). 'Sidelights on tag questions'. In Waugh \& van Schooneveld (1980). 299-314.

Svartvik, J. \& R. Quirk (1980). A corpus of English conversation. Lund: Gleerup.

Trager, G.L. \& H.L. Smith (1957). Outline of English structure. Washington: American Council of Learned Societies (revised edition).

Waugh, L.R. \& C.H. van Schooneveld (eds) (1980). The melody of language. Baltimore: University Park Press. 



\section{Testing the reality of focus domains}

\section{Summary}

An experiment was carried out which was aimed at testing the hypothesis that, in English, prominence on a predicate contains no information about the 'given-new' status of that predicate if it is followed by a (lexical) object which carries a sentence accent. The results are taken to lend support to a view of English prosody whereby (a) prosodic structure is not (fully) predictable from syntactic structure, and (b) the relation between 'new'-ness and a sentence accent is indirect.

\subsection{INTRODUCTION}

From the model for the assignment of sentence accents described in Gussenhoven (1983), a number of testable hypotheses can be derived. One of the more important of these concerns the phonological status of pre-final (or pre-nuclear) accents. ${ }^{1}$ In order to fully appreciate both the genesis and the claims of the hypothesis it is necessary to outline certain features of the model here.

One of the assumptions in the model is that a sentence accent is the surface manifestation of the speaker's employment of the linguistic category 'focus': sentence accents signal the focus distribution of sentences, the division of the semantic material into [+focus] (or 'new') and [-focus] (or 'given') material (cf Halliday 1967). Crucially, the two concepts 'focus' and 'sentence accent' are only relatable through accent assignment rules, in much the same way that, say, [+passive] and the occurrence of passive verb forms are related to each other. In our case, accent assignment rules take focus markings as input and give surface structures with sentence accents on particular words as output. The relation between [+focus] and a sentence accent is thus indirect, and determined by the form of the sentence accent assignment rule that happens to be applicable. There is, therefore, no a priori reason why, either, a word that is [+fo- 
cus] should be accented, or, that an accented word should be [+focus] It is the former circumstance that wlll appear to be relevant to our hypothesis

The main rule in our model is the Sentence Accent Assignment Rule, or SAAR SAAR is applicable if at least one major semantic constituent is [+focus] Thus, not counting partial marking of constituents, major semantic constituents are as sumed to be exther [-focus] or [+focus] There are three major semantic constituents (1) Arguments, which figure in sentences as subjects and objects (A's), (2) Predicates, which figure as syntactic predicates ( $P^{\prime} s$ ), and (3) Conditions, which tigure as adverbials ( $C^{\prime} s$ ) Minimally, a complete sentence consists of an $A$ and a $P$ Maxumally, leaving embedded sentences out of account, there is only one $P$, there may be up to three $A$ 's, and there may be any number of C's In (1), there are two A's (I and Jane), a P (met) and a C (nn London), in (2), there is one $A$ (the television) and a $P$ (has gone on the blink)

(1) I met Jane in London

(2) The television has gone on the blink

The minumum sentence structure, 1 e an $A$ and $a$, is at the same time the maxumum focus domain A focus domain is any structure that can be marked entirely [+focus] with only a single accent In the maximum focus domain (AP or PA), SAAR assigns the accent to the $A^{2}$ Any additional constituents form their own focus domain, and are therefore assigned an accent (always assuming they are [+focus]) Putting this differently, all (+focus] constituents are assigned an accent by SAAR, except a [+focus] $P$ that has merged with a [+focus] A into a single focus domain SAAR thus divides the sentence into focus domains and gives every domain an accent The rule could be formulated as in (3), where underlining stands for [+focus] and absence of underlining for [-focus], where $I$ is a focus domain boundary, and $X$ stands for any constituent

(3) SAAR

$\begin{array}{lll}\text { a Domain assignment } & \underline{P}(X) \underline{A} \rightarrow|P(X) A| \\ \text { (ordered) } & \underline{A}(X) \underline{P} \rightarrow|A(X) P| \\ & \underline{Y} & \rightarrow|Y| \\ b \text { Accent assignment } & || & \rightarrow|+| \quad \text { In }|A P / P A|, \text { "goes to } A\end{array}$

To lllustrate, if in (1) everything except the subject is [+focus], SAAR applies as llustrated in (4) If also Jane is [-focus], it applies as llustrated In (5) And if all of (2) is [+focus], SAAR produces (6) 
(4) Focus distribution

Domain assignment

Accent assignment

(5) Focus distribution

Domain assignment

Accent assignment

(6) Focus distribution

Domain assignment

Accent assignment
A PAC

$A|\underline{P A}| \underline{C} \mid$

APÄ (I met Jăne in Löndon)

AP्A $\underline{\text { C }}$

$A|\underline{P}| A|\underline{C}|$

$A{ }^{\circ} A C$ (I mêtt Jane in Lôndon)

AP

$|\underline{A P}|$

AP (The tèlevision has gone on the blink)

There are a number of constraints on the construction of maximum focus domains. That is, not all $A^{\prime}$ 's are capable of merging with $P^{\prime} s$, and not all $P^{\prime} s$ are capable of being merged with $A^{\prime} s$. In such cases, $A^{\prime}$ 's and $P^{\prime}$ s are separated by a focus boundary, and - if both are [+focus] - SAAR applies so as to put an accent on each of them. One type of A that cannot merge with $P^{\prime} s$ is the class of independent quantifier, containing items like nothing, no one, everyone. Thus, while we can have an AP focus domain in (7), we cannot have one in (8):

(7) A: What happened? B: The prisoners have escaped

(8) A: What happened? B:

the correct structure for $B^{\prime}$ s reply in (8) being $\underline{A}$ (quantifier) $\underline{P}$, giving $|\underline{A}| \underline{P} \mid$, or Everybody has escăped.

\subsection{A CONSEQUENCE OF THE MODEL}

While the above remarks are necessarly sketchy, they suffice to enable the following consequences to be derived:

(9) 1. A sentence with a regularly merging PA combination in final position with an accent on the $A$, is ambiguous between a structure in which the $P$ is [+focus] and one in which the $P$ is [-focus], since in either case SAAR will assign an accent to the $A$ : in the version in which the $P$ is [-focus], the [+focus] A forms a focus domain by itself, and in the version in which the $P$ is $[+$ focus], the $P$ shares its focus domain with the $[+$ focus] $A$, which will get assigned the accent. 
2. A sentence with, for example, a PC sequence in final position in which the $C$ is accented, and where the $P$ is [+focus], is phonetically distinct from an otherwise identical sentence in which the $P$ is [-focus]: if the $P$ is [-focus], no accent is assigned to it, but if it is [+focus], it is assigned an accent, as it has a focus domain to itself.

Symbolically, the situation can be represented as in (10),

$\begin{array}{lllll} & \mathbf{a} & \mathrm{b} & \mathrm{c} & \mathrm{d} \\ \text { Focus distribution } & \underline{\mathrm{PA}} & \mathrm{PA} & \underline{\mathrm{PC}} & \mathrm{PC} \\ \text { Domain assignment } & |\underline{\mathrm{PA}}| & \mathrm{P}|\underline{A}| & |\underline{\mathrm{P}}| \underline{\mathrm{C}} \mid & \mathrm{P}|\underline{\mathrm{C}}| \\ \text { Accent assignment } & \mathrm{PA} & \mathrm{PA} & \underline{\mathrm{PA}} & \mathrm{PC}\end{array}$

where the surface forms in (a) and (b) are identical, but those in (c) and (d) are not. In terms of a concrete example, this would mean that if to the question What does he do?, the answer is given He teaches linguistics, then this answer could equally well have served as an answer to the question what does he teach? ( $(a)$ and (b) in (10)). In either case, SAAR assigns an accent to linguistics, and the fact that teaches is [+focus] in one case and [-focus] in another has no effect on the surface forms. But if to the question What does he do? the answer Is given He teaches in Ghana, then this latter utterance cannot serve as a well-formed answer to the question Where does he teach?, since in the former situation the $P$ teaches and the $C$ in Ghana form separate focus domains and are each assigned an accent, while in the latter only the [+focus] in Ghana is assigned an accent ((c) and (d)).

Investigation of the literature shows that the issue that this prediction raises, has in fact been discussed, though usually only cursorily, and no unambiguous answer can be establıshed. Thus, Halliday (1967, p.208) claims that a pronunciation of They teach classics with teach 'new', is rhythmically distinct from one with teach 'given'. Postal (1971,p. 234) claims that Charlie insulted his father with 'contrastive stress' on father is phonetically distinct from a version with 'ordinary stress throughout'. Palmer (1974,pp. 222-3) claims that This student wants to drop IinGUIStics can be equivalent both to This student wants to give linGUIStics up and to This student wants to give linguistics UP, implying that drop can be unaccented as well as accented in the way illustrated in the two putative paraphrases. Enkvist (1979) claims that Did Charlie kick the bucket? must have an accent on kick in addition to one on bucket if kick the bucket is to be understood as 'die'; if only bucket has an accent, so he says, the sentence 
will be given its literal interpretation. Chafe (1970,p. 225), by contrast, says that David emptied the BOX is ambiguous between a reading with 'both the verb root and the patient noun [as] new' and one with only the patient noun as new, quite in line with the first consequence of our model. And, notwithstanding their disagreement over other aspects of sentence accents, Chafe's position would be supported by both Chomsky (1972, p.203) and Bing (1979, p.180). In none of these cases was experimental evidence provided. Neither did we find an indication that not all PA sequences can be treated alike.

\section{A hypothesis}

If the consequences in (10) can be shown to hold good in experimental conditions, then, obviously, this would constitute important evidence in favour of our model, and, more generally, against any model that relies on syntactic considerations alone. Subsequent to the derivation of the consequences in (9), therefore, a testable hypothesis needed to be formulated. To this end, 32 dyads were constructed, each consisting of a question, henceforth the context, and an answer, henceforth an utterance. The utterances in one half of the dyads had a merging PA combination in final position. This group of 16 dyads is referred to as Structure $A$. The utterances in the other half of the dyads contained various combinations of semantic constituents in final position (PC, AC, a non-merging PA) both of which would be assigned a SAAR accent if they are [+focus]. This group of 16 dyads is referred to as Structure $B$. In each Structure, one half of the dyads comprised contexts that may be expected to force the corresponding utterances to have a [+focus] pre-final constituent followed by a [+focus] final constituent, while the other half comprised contexts that would produce identical utterances, except for the fact that the pre-final consituent is [-focus]. These two groups of dyads are referred to as the [+focus] and the [-focus] groups, respectively. Crossing the two variables gives us four sets of eight dyads. The following are representative examples in each set :

(11) Structure A, [+focus]

C: Do you live by yourself?

U: I share a flat

[-focus]

C: I'hate sharing things, don't you? 
Structure B, [+focus]

[-focus ]
C Please tell me what happened that night

U I remember nothing

C What do you remember from your last lesson?

U I remember nothing

Our model predicts that if in taped recording of these dyads we interchanged each [+focus] utterance with its [-focus] counterpart, listeners wll be unable to tell the spliced dyads from the original ones in the case of Structure A, but, in the case of Structure $B$, ought to be able to tell the spliced dyads and the or - $^{-}$ ginal dyads apart with a certain measure of success We will refer to this measure of success as the Context Retrievabulty Score, or CRS, to be expressed in of This provides us with the following testable hypothesis

(12) Utterances in Group A have a chance $\left(50^{\circ}\right) \mathrm{CRS}$, while utterances in Group $B$ have a CRS of between $50^{\circ}$ and $100^{\circ}$

Observe that the CRS in Structure B wll depend on the extent to which the presence or absence of the pre-final accent can be perceived it is reasonable to assume that the ease with which this can be done is related to the distance between the accentable syllable of the pre-final constituent and the accentable syllable of the final constituent If no unaccented syllables intervene, the difference between presence and absence of the accent on the pre-final constituent wlll be more difficult to establish for a listener than when some three or four unaccented syllables intervene In this latter case, the pre-final accent will have more scope to stand out For this reason, the utterances in Structure $A$ and Structure $B$ were matched for the number of unaccented syllables occurring between the accentable syllable of the pre-final constituent and the accented syllable of the final constituent Four out of the 16 dyads in each group had utterances with zero intervening syllables, whle there were four with one, four with two and four with three intervening syllables in their utterances A sec- 
ond clause should therefore be added to our hypothesis:

1. (=12)

2. Distance between potential accents will have no effect on the CRS in Structure A, but a graded positive effect in the case of Structure B.

It was thought desirable to define a practical upper limit of perceivability. Maximum perceivability of an accent was taken to be achieved if instead of occurring before another accent, the potential accent was itself final. This would allow the presence or absence of an accent on that syllable to be perceived as the occurrence of what is frequently called 'normal' nucleus placement versus 'contrastive' nucleus placement. To this end, a third group of 16 dyads was constructed, all of them having an Argument in final position. Contexts were chosen so as to force the Argument in one half of the utterances to be [+focus], and in the other half to be [-focus], these two groups of utterances being otherwise identical. The effect, of course, is that the [+focus] utterances, but not the [-focus] ones, will have a sentence accent on the final word. This group of 16 dyads is referred to as Structure C. A representative example of a [+focus] dyad in this group and its [-focus] counterpart is given in (13). A complete list of all the dyads in all groups is given in the Appendix.

\section{(13) Structure C}

[+focus] C: Anything in particular you want me to say to her?

$\mathrm{U}$ : Tell her I'm planning a coup

[-focus] C: She seemed sort of sorry there'd never be another coup

$\mathrm{U}$ : Tell her I'm planning a coup

If contexts and utterances are switched as in Structures $A$ and $B$, we would expect the spliced dyads to be perceived as grossly ill-formed in comparison to the original dyads. In the dyads in Stucture $C$, distance between potential accents was varied: taken in sets of four dyads, utterances varied from zero intervening words, via one and two, to as many as seven and 12. For obvious reasons, this distance was not expected to have an effect on the CRS. We revise our hy- 
pothesis as follows:

1. Utterances in Structure A have a chance CRS, utterances in Structure C have a CRS approaching $100 \%$, while utterances in Stucture B will have a CRS between those for Structures $A$ and $C$.

2. Only in Structure B will the distance between potential accents have an effect on the CRS. This will take the form of a positive correlation.

As far as could be established, the literature provides no indication that (12") is a correct prediction. Thus, irrespective of whether the answer to what does he do? is He teaches linguistics or He teaches in Ghana, the British literature would consider teaches as 'stressed' in either case. Simllarly, a SPE description (Chomsky \& Halle 1968,p. 18) would assign a [2stress] to the first syllable of teaches in either case, and neither would any version of metrical phonology ( $\mathrm{Li}^{-}$ berman \& Prince 1977, Selkirk 1980) discriminate between the two stresses. This suggests that our hypothesis is not one that readily emerges from the exercise of any form of linguistic intuition. Indeed, informal interviews showed that native speakers do not consciously regard the prosodic statuses of the two instances of teaches above to be different, and consider both 'stressed'. Now, our hypothesis does not rule out that at the position of the $P$ in a Structure-A utterance, prosodic options can be employed that are unrelated to the option [ \pm focus], but which may - though need not - be realised by some use of $F$ or of other phonetic variables that is different from the way focus-expressing accents are realised. What our hypothesis does claim is that at the position of the $P$ in Structure-A utterances, no prosodic features will be found that realise an accent of the sort here represented as *. Specifically, the hypothesis does not rule out the use of high onset at teach- in He teaches linguistics. Again, what it does claim is that this high onset will not be taken by listeners to signal that teaches is [+focus], or rather that it will be taken to be irrelevant to focus.

What this would mean is that when asked to give 'stress' judgements, listeners will respond non-differentially to 'phonetic prominence', and will not allow their judgements to be guided by the phonological source of that prominence. Hence, if prediction (10) is correct, then the presence or absence of prominence-lending features on the $P$ in Structure-A utterances should not have an 
influence on the success with which listeners are able to match utterances and contexts By contrast, in the case of Structure-B utterances, there should be a positive correlation between the degree of perceived stress on the pre-final constituent and the extent to which listeners are prepared to consider the utterance a [+focus] one, since it was clamed earlier that in this group the ease with which the pre-final accent could be perceived was going to be related the CRS

We should therefore revise our hypothesis as follows

$1\left(\operatorname{see}\left(12^{\prime \prime}\right)\right)$

$2\left(\right.$ see $\left.\left(12^{\prime \prime}\right)\right)$

3 The CRS of the utterances in Structure B, but not that of the utterances in Structure A, correlates positively with the perceived stress on the pre-final constituent

Note, incidentally, that although the correlation in Structure $\mathrm{C}$ wll, predictably, be positive, no theoretical interest is at stake here, and the prediction should not figure in the hypothesis

In order to test (12'"'), two experunents were carried out

1 A context-switching experiment

2 A stress perception experiment

The first test was needed to test the first and the second clause of the hypothesis (see (12"), and requires the following design given in Figure 1

The second test was needed to test the third clause (see (12'") This is a straightforward test whose results are to be correlated with the results of the first test The prediction is that there is a positive correlation for Structure $B$ and no correlation for Structure A 


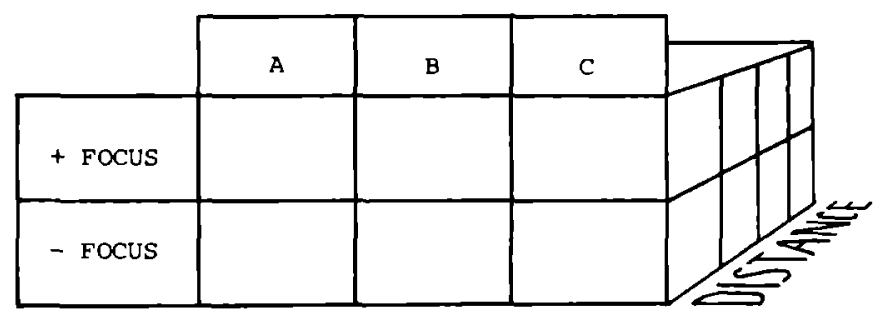

Figure 1. Design of the context-switching experiment

The tests are described, and their results given, in separate sections. In a final section, some implications are discussed.

\subsection{THE CONTEXT-SWITCHING EXPERIMENT}

In order to obtain the stimuli required for the Context Switching Test, six native speakers of Standard British English were recruited. Four of them were slightly Scottlsh accented. They were variously combined in pairs. Pairs of speakers were seated comfortably on opposite sides of a table in a spacious studio, and were provided with scripts containing the 48 dyads to be used in the experiment. Dyads containing lexically identical utterances were spread as wide as possible in the script. One speaker in each pair then read out the context, and the other the utterance of each dyad, which speech was recorded on magnetic tape. The exercise proved more difficult than was expected. Although five of the six speakers were students at a Drama College, speakers frequently read out the utterances in a mode that Brazil, Coulthard \& Johns (1980, p.83) refer to as reading 'what it says', putting stresses on all major words, quite regardless of context. The problem seemed most acute in Structure $C$, where the 
utterances that were intended as [-focus] were of ten given an accent on the last word. Also, some speakers tended to overact. These problems, which were no doubt partly due to the fact that speakers were unaware of the purpose of the sessions, could up to a point be solved by asking the speaker of the utterances to look up from their script when listening to the context and giving the utterance. In addition, speakers were frequently asked to do certain dyads again. These sessions produced some two hours' worth of recordings.

From these recording one complete set of 48 dyads was selected that (a) were not obviously instances of 'overacting' or reading 'what it says', (b) had a reasonable spread over the different speakers, and (c) if belonging to Structure A, did not display a clear step-up in pitch on [-focus] Ps, or clearly lack a step-up in pitch on [+focus] Ps. This third criterion ensured that it was possible to test the third clause in hypothesis (12'"). Clearly, if we are to be able to demonstrate that stress differences on the Ps in Structure A are not related to the perception of focus, we must make sure that these stress differences are there to begin with. In addition, a set of 48 contexts was selected.

\section{Composition of the test tape}

A test tape was prepared, in which the 48 contexts were combined both with the 48 corresponding utterances and with the 48 utterances that had the opposite focus value for the constituent concerned. These 48 patrs of dyads thus consisted of two identical occurrences of a context, one followed by a [+focus] utterance, and the other by the lexically identical [-focus] utterance. The following criteria were applied when compiling dyads and test tape:

1. The two utterances in each pair of dyads were spoken by the same speaker. This speaker was different from the speaker of the context.

2. In no case was the utterance actually spoken in the context it combined with on the test tape: the original pairs of speakers were split up and crossed. This was done in order to avoid tessitura-matching effects. Brown, Currie \& Kenworthy (1980,P.123) found that speakers tended to match the tessitura or 'key' of their utterance with that of the last utterance of their interlocutor, which tendency could well have had a blasing effect on our scores.

3. If a pair of utterances appeared in one order in the [+focus] context, it appeared in the same order in the [-focus] context. This was done in order 
to cancel out possible order effects of the sort reported in Gussenhoven \& Blom (1978). They found that for the first of a pair of stimuli, a perceptually small amount of stimulus attribute is overrated by listeners, and a perceptually large amount is underrated. The effect is explained as resulting from the judges' concern that the small amount of the first stimulus is going to be swamped by the expected larger amount of the second stimulus, which concern then causes the overestimation. Conversely, a large amount might induce subjects to feel over-confident about having mentally registered it, causing them to underestimate it when the second stimulus comes along.

4. If a pair of lexically identical utterances appeared in one order (see 3 . above) then the pair that had the same specification for Structure and distance between potential stresses, appeared in the opposite order.

5. Clusterings of speakers and utterance-types were avoided.

Stimulus-to-stimulus periods varied with the duration of the dyads, and averaged approximately 18 secs. The duration of the test tape, including trial items, was 16 minutes.

\section{Presentation of the test tape}

The test was presented to a group of 24 judges in a language laboratory provided with headphones. The judges, all native speakers of English, were recruited on a voluntary, no-fee basis from groups of first- and second year students at the Unjversity of Edinburgh, attending classes a few days before the test was given. In the instruction, they were told that they would hear a series of question-and-answer combinations, in which one combination was actually spoken as such, and the other was made up of the same question and an answer that was spoken in response to some other question, and that if they listened carefully, it was always possible to tell which was the correct combination. It was pointed out to them that in both the correct and the incorrect combination, they would hear traces of editing. On their score sheet, the context was given by way of stimulus identification. They were asked to register their judgement by writing either ' 1 ' or ' 2 ' in a box provided for each stimulus. 


\section{Results}

A score of $100 \%$ for a group corresponds to a CRS of 16 (utterances) times 24 (judges), or 384. Figure 1 gives the overall CRS per Structure in percentages. As predicted, the CRS in Structure B is poised between those of Structure $A$ and Structure $C$. A three-way analysis of variance was performed on the data (Dixon \& Brown 1979). The dependent variables were 'Structures' (Structures A, B and C), 'Distance' (distance between potential stresses: four levels, only Structures $A$ and $B$ being precisely matched), and 'Focus' ([+focus] and [-focus] groups). There was a main effect for 'Structures' ( $F=38.67, p^{<}$ .0001), and there were significant interaction effects of 'Distance' by 'Structures' ( $F=4.26, \mathrm{p}<.001$ ) and 'Focus' by 'Structures' ( $F=5.77, \mathrm{p}<.01)$. The scores or Structure $C$ differed both from those in Structure $A$ and from those in Structure B at $p<.01$, according to a post-hoc Scheffé-test. As our interest in Structure $C$ was really confined to its status as an indication of the maximum CRS that is obtainable in practice, scores in this group should really not be allowed to affect the significance of the differences between the CRS in Structure $A$ and that in Structure $B$. Therefore, a second analysis of variance was performed on the data in Structures A and B only. Table 1 gives the results.

Table 1. Three-way analysis of variance of the scores in Structures $\mathrm{A}$ and $\mathrm{B}$

$\begin{array}{lllcl} & \mathrm{df1} & \mathrm{df2} & \mathrm{F} & \mathrm{P} \\ \text { Structures } & 1 & 23 & 14.4 & <.001 \\ \text { Distance } & 3 & 69 & 2.2 & \mathrm{n.s} . \\ \text { Focus } & 1 & 23 & .35 & \mathrm{n.s} \\ \text { Interaction Structures-Distance } & 3 & 69 & 4.45 & <.01 \\ \text { Interaction Structures-Focus } & 1 & 23 & 9.36 & <.01\end{array}$

Observe that the significant effects noted earlier are retained in this analysis. The significant effect for 'Structures' indicates very clearly that a null hypothesis that the utterances in Structure B were drawn from the same population as those in Structure $A$ must be rejected at a very high level of significance. It thus supports the claim made in the first clause of (12"').

The interaction of the distance between potential prominence peaks with the Structure to which the utterance belongs has been plotted in Figure 3, in which also the $\mathrm{C}$ scores have been included for comparison. The important point to 


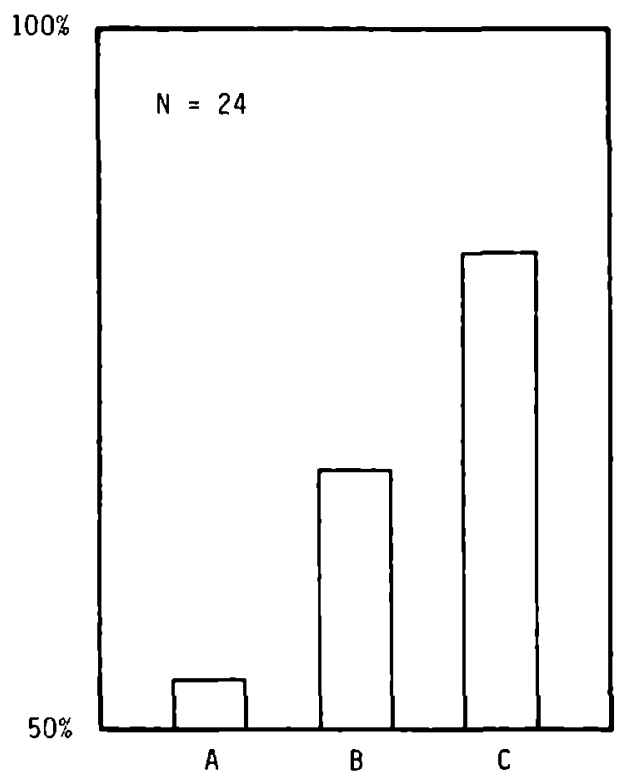

Figure 2. Overall CRS $(q)$ in Structures A, B and C

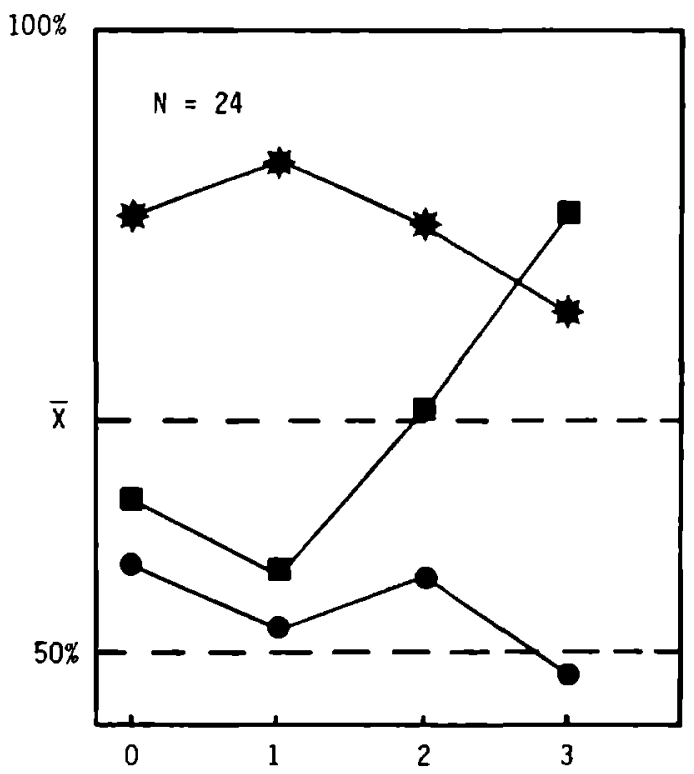

Figure 3. CRS as a function of the distance between potential accents in Structure $B(\bullet=$ Structure A, $=$ =Structure $B, *=$ Structure $C$; for $0,1,2,3$ see text) 
notice is that 'Distance' does not improve the CRS in Structure A, but, with the exception of the category 'one syllable intervening between potential stresses', does do so in Structure $B$. The irrelevance of pre-nuclear prominence on the $P$ of the utterances in Structure $A$ to the perception of focus is thereby further underlined. These results support the second clause of hypothesis (12'"').

The significant interaction between the focus value of the pre-final constituent and the Structure to which the utterance belongs was unexpected. From the scores it appears that, on the whole, the [-focus] utterances in Structure A did better than the [+focus] utterances (with scores of 115 and 91 respectively), while in Structure B the opposite tendency could be detected (with scores of 124 and 139 respectively). That is, in Structure $A$, but not in Structure $B$, judges were somewhat more successful in matching the [-focus] context with the [-focus] utterance than in matching the [+focus] context with the [+focus] utterance. Since we have no theory as to how pre-nuclear stress on the predicate in Structure A could be relevant to the CRS, and since, moreover, within either Structure A or Structure B the differences do not even begin to approach a significant level, we will not further investigate these results here.

Since each 'cell' formed by Structure, Distance and Focus contained two pairs of lextcally identical utterances, we were able to split the materials into two halves, and treat these as the experiment and its replication. An analysis of variance was performed on the data in Structures $A$ and $B$ with a grouping variable representing these two halves of the data. There was no significant effect for this grouping variable $(F=.01, P=.94)$. Moreover, when each half was analysed separately, differences between Structure $A$ and Structure $B$ remained significant in both halves ( $p<.01$ In one case and $p<.05$ in another). The Interaction between 'Distance' and 'Structures' remained significant in one half at $p<.05$, while there was a trend in the other half for this interaction. Thus, for two different groups of stimuli, the same pattern of results was found. This strongly suggests that the effects observed do not result from the particular stimuli used in each condition, but reflect more general differences between the structures listed under (9). 


\subsection{THE STRESS JUDGEMENT TEST}

In order to adduce evidence bearing on the third clause of hypothesis (12"'), a Stress Judgement Test was carried out An additional reason for carrying out this test was that the material used in the Context Switching Experiment had been (non-randomly) selected It is therefore concelvable that differences in stress value between the [-focus] and [+focus] utterances in Structure A were very much smaller than those in Structure $B$, and that a potential cue to context in Structure A might thus have been effectively removed In spite of the care that was taken when selecting the utterances, we needed to be sure that this was not the case

The 48 utterances that were used in the Context Switching Experiment were randomised, and a new test tape was prepared Stunulı consisted of two occurrences of each utterance, and were approximately 14 secs apart, the total test duration being about 12 minutes The test was presented to a group of 14 native speakers of British English They were recruited in the same way as the judges who took part in the Context Switching Experiment, and took part on the same basis None of them had also taken part in the Context Switching Experunent The test was presented to them in a language laboratory equipped with headphones Judges were instructed to rate the degree of stress on the experimental syllable of each utterance ( 1 e the pre-final accentable syllables in Structures $A$ and $B$, and the final accentable syllable in Structure $C$ ), on a scale from 1 (for "no stress") to 5 (for "maxumum stress") On their score sheets, each utterance was given, with a large box over the syllable to be rated for stress Subjects did not appear to find the task difficult ${ }^{3}$

\section{Results}

Mean scores for the [-focus] and [+focus] groups in each of the Structures $A$, $B$ and $C$ are given in Figure 4

Observe that although the utterances in Structure $B$ were somewhat more favourably discriminable than those in Structure A, in all three structures there were considerable differences between the subjective stress values of [+focus] and [-focus] utterances Only in one case in Structure $A$ and in one case in Structure $B$, did stress judgements turn out to be the reverse of what might have been expected 1 e the [+focus] utterance of a pair was judged to have 


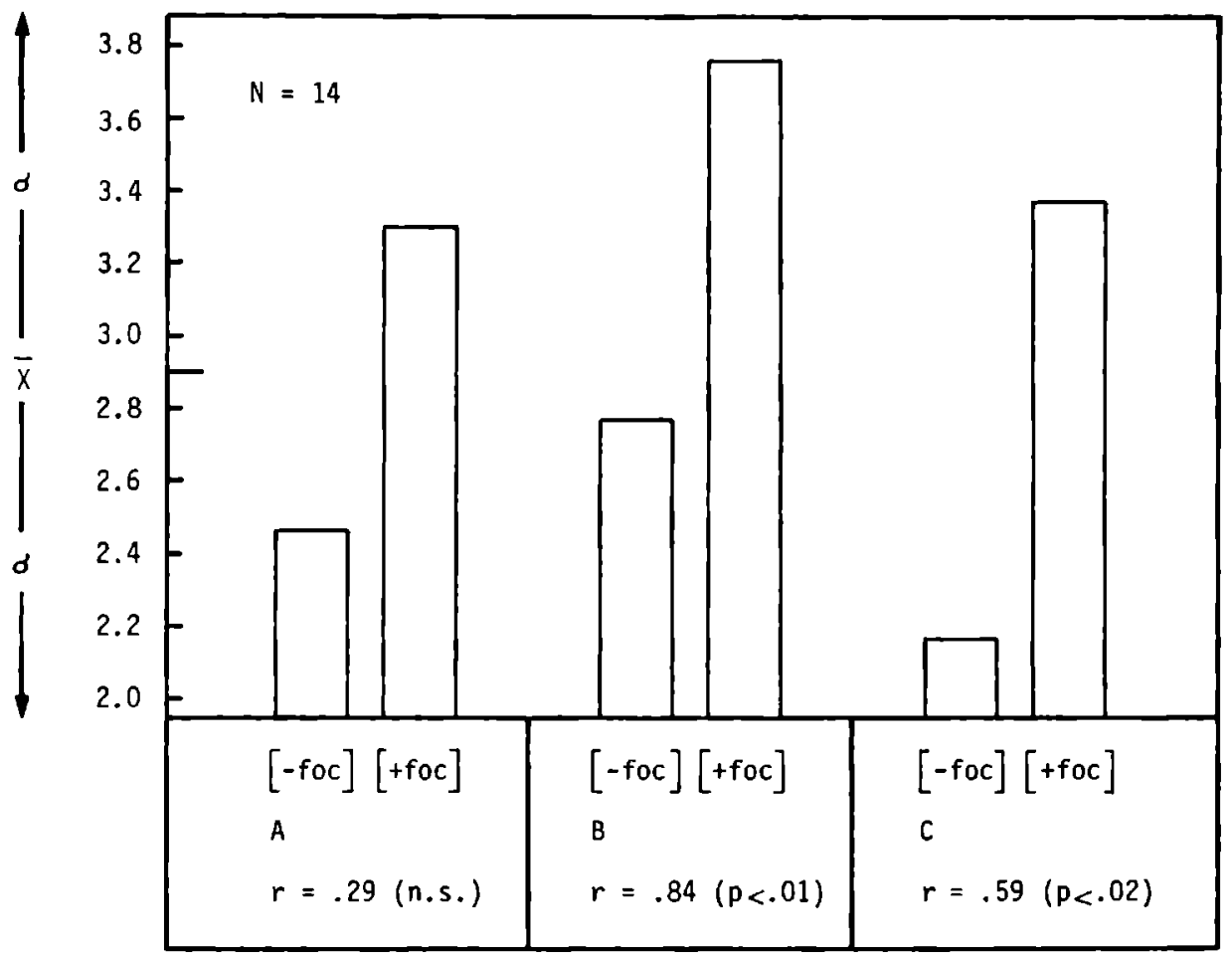

Figure 4. Observed 'stress' levels for the [-focus] and [+focus] utterancesin Structures $\mathrm{A}, \mathrm{B}$ and $\mathrm{C}$, and the product-moment correlations between the observed 'stress' levels and CRS for each group.

marginally less stress ( -0.14 in either case) on its experimental syllable than the [-focus] utterance. In both cases this concerned a pair with 'one syllable between potential stresses', which would appear to provide a possible explanation for the dip in the B-curve in Figure 3.

Product-moment correlations between CRS and stress judgements were calculated (see Figure 4). As predicted, a high correlation of $r=.84$ between the CRS and the independently obtained stress judgements was observed for Structure B. The difference between the correlation coefficients obtained for Structures $A$ 
and $B$ was significant at $p<.02$. The correlation coefficient obtained for Structure $A$ is itself not significant. On the basis of these results, a null hypothesis that there is no difference between Structure A and Structure $B$ in the way their CRS correlates with the perceived stress on the predicates, must be rejected. The results strongly suggest that in the Context Switching Experiment judges responded categorically differently to the stimuli in Structure $A$ and those in Structure B.

The differences between the correlation coefficient obtained for Structure $C$ and each of the other two correlation coefficients are not significant. While the finding has no bearing on our hypothesis, it may be observed that the intermediate value of the correlation coefficient observed in Structure $C$ may be a reflection of the fact that presence $\underline{v}$ absence of a nuclear accent on the final word will not be perceived as a continuum, but categorically. It is either there or it is not there, but whether it is unobtrusively or emphatically there, is unlikely to influence judges' behaviour in a context retrieval task, and thus not be reflected in the correlation coefficient.

\subsection{DISCUSSION}

The results of the experiment confirm the assumption underlying the model for sentence accent assignment descrlbed in Gussenhoven (1983), in which sentence accents are viewed as morphemes manifesting the focus distribution of sentences. As was stated in the introduction, the relation between sentence accents and 'focus' (or 'importance') is indirect in the sense that absence or presence of a sentence accent on a word does not in itself provide a label indicating the status of that word. Example (2) showed how a $P$ can be both unaccented and [+focus]. As a further illustration of the indirectness of this link, consider (13), where the words now definitely (a [+focus] C) have been moved between the [+focus] $A$ and the $[+$ focus] $P$ :

(14) The têtlevision has now dêtfinitely gone on the blink

The $P$ receives its sentence accent not because it is now more 'important' than in (2), but because it is prevented from merging with the $A$ into a single focus domain by the interposed [+focus] $\mathrm{C}$. 
Since focus is a linguistic (semantic) category in its own right, the results support a view of English prosodic structure that is much less dependent on syntactic structure than current descriptions of English prosody suggest. Generally, prosodic structure is believed to be largely derivable from syntactic structure, and much research reflects this in that the aim is to predict the former from the latter. This includes such authoritative accounts of English stress as Chomsky \& Halle (1968), Liberman \& Prince (1977), and Selkirk (1980). While there is no denying that identical representations of 'normal' or 'neutral' renderings of $I$ know John and $I$ know no one capture much of our intuition concerning the surface prosody of such sentences, and no denying even that predicting prosody from syntax/lexis may be an extremely valuable research activity in its own right in an area of applied linguistics (cf automatic readers for the blind), the point must be made that too much emphasis on the 'interpretive' role of the phonological component may cause an important part of the linguistic structure of sentences to be obscured. One condition on any description must surely be that it should distinguish between prominence peaks that result from focus-manifesting accents and those that result from other sources.

Selkirk (1980) in fact provides the elements for a description that is capable of incorporating our findings. She presents a hierachy of metrically organised phonological units: syllables, feet, phonological words, phonological phrases, intonational phrases and utterances. While a 'phonetic packaging' view would seem to be appropriate for the first three types of unit, it is with the introduction of phonological phrases that linguistic facts of the sort the experiment was concerned with begin to fall by the board. Selkirk defines the phonological phrase (\$) derivatively, allowing it to coincide with syntactic phrases, like NP, VP, PP. (For details see Selkirk 1980, and for experimental support for her analysis, Nespor \& Vogel (1983)). As a result, the difference between merging and non-merging PA combinations, or that between a merging PA combination and a PC sequence, or that between a non-merging PA with a [+focus] $P$ and one with a [-focus] $P$, all of which must be assumed to be prosodically different, cannot be expressed. If, however, we allowed each to correspond to the focussed constltuent(s) in a single focus domain, together with any associated [-focus] material, then we would have a description that does capture these manifestations of focus distribution. This would produce (15a) as the representation of I know John with John [+focus] and know [+focus] or [-focus]; likewise, (15b) would be the representation of 1 know no one with both know and no one [+focus], and (15c) that of I know no one with only no one [tfocus]. In 
(15) I stands for 'Intonational phrase', as in Selkırk (1980), units above and below $\phi$ and I have been dispensed with

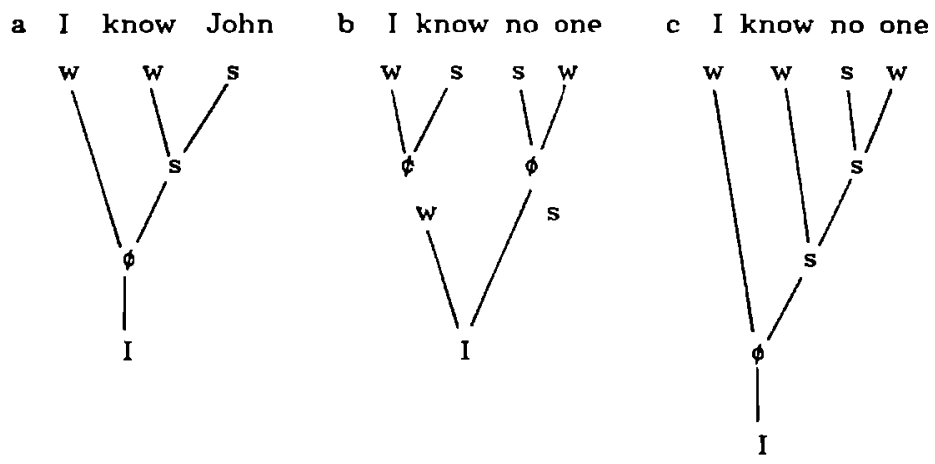

It is unportant to observe that in (15ab) different prosodic structures are postulated for identical syntactic structures, which by any definition are assumed to have 'normal intonation' That is, we are not concerned merely - or even mainly - to point out that prosodic phonology should take 'contrastive' accentuation into account

While the main result of the experiment bears on the principled difference between 'real' pre-final accents (or 's), and 'pseudo' accents, 1 e prominence peaks having a different phonological source, the results also confirm the conclusion reached in Brown, Currie \& Kenworthy (1980 115), who point out that there may be more than one accent peak in an utterance, and that a view of the tone group as a single unit of information (e g Halliday 1970,p 3) is incorrect, at least to the extent that this statement implies that a tone group is characterised by a single, most prominent syllable, the nucleus That is, [+focus] utterances in Structure $B$ must be assumed to have (at least) two accents that are semantically on a par, both of them signaling the focussed status of the constituents they are found on This statement has, of course, no bearing on the fact that the last of the SAAR accents will have to be singled out for considerations of 'form' (as opposed to 'function') Thus, in Dutch, for example, there exists a rhythm rule that has the tone group as its domain words that are subject to the rule obligatorly have an unshifted pronunciation when they carry the last SAAR accent of the tone group (e g alTIJD 'always'), and a shifted one (ALtı]d) when they occur anywhere before that accent in the same tone 
group. For this last accent the term 'nucleus' could be retained (cf Gussenhoven, forthcoming).

One of the questions that the results of the experiment raise is whether the judges' differential response to Structures $A$ and $B$ was determined solely by their (tacit) knowledge of focus structure, or that it was at least partly determined by phonetic considerations. Phrased more concretely, is the 'stress' that judges claimed to hear on the [+focus] Ps in Structure A phonetically different from the 'stress' they claimed to hear on the [+focus] Ps in Structure B? Our stimuli do not provide us with suitable material to answer this question: in practically all cases Ps are segmentally not comparable. Arguably, an experiment with synthetic stimuli would be the best way of determining the answer. Variables to be considered here include duration, size of $F /$ step-up on the $P$, and the occurrence of a valley between this prominence peak and the final accent. 
Notes

1 I am indebted to Gll Brown for her suggestion to use context retrievablity as a means of establishing the linguistic structure of utterances I thank Mr A Dunbar of Queen Margaret College, Edınburgh, for arranging the recording sessions, and his students and Janet Mackenzie for doing the recordings I thank Anne Anderson for her advice on the statistical processing of the results The BMDP programs were developed at the National Health Sciences Computing Facility, UCLA, and sponsored by NIH Special Research Resources Grant RR-3 The date of the latest revision of the program that was used (PV2) is November 1979 I should like to thank Anne Anderson, Ton Broeders, Gill Brown, Anne Cutler and Bob Ladd for their comments on earlier versions of this report

2 Linguists in fact frequently display the effect of the rule when discussing the syntactic concept of object incorporation, glossing such instances as, for example, I FISH-like, He BEER-drinks, rather than I fish-LIKE, He beer-DRINKS Note that it is not suggested that it is impossible for both the argument and the predicate in a PA combination to be assigned an accent, as in You EAT FISH, but you DRINK BEER

3 It might have been expected that it would be easier to rate SAAR accents for stress (as in Structures $B$ and $C$ ) than 'onset prommence' (as in Structure A) Or that pre-nuclear prominences (as in Structures A and B) are more difficult to rate than nuclear prominence (as in Structure $C$ ) This might have shown up in differences between standard population variances in the various groups This turned out not to be the case (A 98, $B \quad 95$ and $C$ 94) Neither was absence of stress more difficult to rate than presence of stress ([-focus] group 93, [+focus] group 97)

4 During an informal presentation of this report it turned out that he promised me to sort them is not in fact an acceptable sentence to all native speakers, some of whom require finite clause complementation ( me that he would sort them) We have no reason to suppose that this circumstance will have had an effect on the results of the experiment

\section{Appendix}

Below are listed the contexts and utterances in all stumuli in Structures A, B and $C$, ordered according to distance between potential accents Experimental syllables have been underlined, whle the last SAAR accent, or nucleus, is capitalised

\section{Structure A}

C And what is your contribution to society?

C What exactly is it you are creating?

$\mathrm{U}$ We create BUSiness

C What is the nature of your business?

C What is it you repair?

$\mathrm{U}$ We repair RADios

C Do you live by yourself?

C I hate sharing things, don't you?

U I share a FLAT 
$\mathrm{C}$ : What are those boys doing in the water?

$\mathrm{C}$ : What are they catching?

$\mathrm{U}$ : They are catching FISH

C: What does he do?

C: What does he teach?

$\mathrm{U}$ : He teaches linGUIStics

C: What did he make that move for?

C: Has he started attacking anything yet?

$\mathrm{U}$ : $\mathrm{He}$ is attacking the BISHop

C: What did he say about the invoices this morning?

C: Just what did he promise to do with them?

$U$ : He promised me to SORT them "

C: How did Pat and Vernon spend their time?

$\mathrm{C}$ : What were they building there?

$\mathrm{U}$ : They were building a caNOE

\section{Structure B}

C: Could it be that you take the wrong view of people in general?

C: Do you distrust me?

$\mathrm{U}$ : I distrust NO one

C: I am sorry we cannot employ her

C: Does she sing?

$\mathrm{U}$ : She sings BEAUtifully

C: Please tell us what happened that night

C: What do you remember from your last lesson?

$\mathrm{U}:$ I remember NOTHing

C: Why are you looking so worried, dear?

C: Where were they shooting?

$\mathrm{U}$ : They were shooting EVerywhere

C: What does he do?

C: Where does he teach?

$\mathrm{U}$ : He teaches in GHAna

C: Where will you be in January?

C: Where will you be skiing?

$\mathrm{U}$ : We will be skiing in SCOTland

C: Do you know anyone in Scotland?

C: Do you know any vicars?

U: I know a vicar in DunDEE

C: What did you think of their house?

C: There were three very nice chimneys...

$\mathrm{U}$ : I liked the chimney in the DRAWing-room 


\section{Structure C}

C: What is the best representation of the shortest distance between two points?

C: Now please draw a line

$\mathrm{U}$ : A straight line? (A straight LINE/ STRAJGHT line)

C: What is the demand this time, Mr Johnston?

C: I thought you had a canteen

$\mathrm{U}$ : We want another canteen (another canTEEN/ aNOTHer canteen)

C: Anything in particular you want me to say to her?

C: She seemed sort of sorry there'd never be another coup

U: Tell her I'm planning a coup (planning a COUP/ PLANning a coup)

C: Susan's looking after daddy

C: He may be running a temperature

$\mathrm{U}$ : Has she taken his temperature? (taken his TEMPerature/ TAKen his temperature)

C: Why doesn't "nuance" count as a word?

C: Have you looked in the dictionary?

$\mathrm{U}$ : Sorry, it wasn't in the dictionary (in the DICtionary/ IN the dictionary)

C: Are you sure we're out of sausages?

C: You might have brought me the jars on the shelves

$\mathrm{U}$ : There were none on the shelves (on the SHELVES/ ON the shelves)

C: They said all sorts of things about her

C: They called her a "bastion of common sense"

U: Surely she was pleased with the fact that they called her a "bastion of common sense" (...SENSE/...PLE $\triangle$ SED ...)

C: I wonder why he seemed so piqued

C: A "young woolly liberal" is what they described him as

$U$ : He must have been offended by the phrase a "young woolly liberal" (... IIBeral/...ofFENded... )

\section{Bibliography}

Bing, J.M. (1979). Aspects of English prosody (Bloomington, Indiana).

Brazil, D., M. Coulthard \& C. Johns (1980). Discourse intonation and language teaching (London).

Brown, G., Currie, K.L \& Kenworthy, J. (1980). Questions of intonation (London).

Chafe, W.J. (1970). Meaning and the structure of language (Chicago).

Chomsky, N. (1972). Studies on semantics in generative grammar (The Hague).

Chomsky, N. \& Halle, M. (1968). The sound pattern of English (New York).

Dixon, W.J. \& Brown, M.D. (eds) (1979) Biomedical computer programs, P-series (Los Angeles).

Enkvist, N.E. (1979). Marked focus: functions and constraints. In S. Greenbaum, G. Leech \& J. Svartvik (eds) Studies in English linguistics for Randolph Quirk. (London), pp. 134-52. 
Gussenhoven, C. (1983). Focus, mode and the nucleus. Journal of Linguistics $19,377-417$ (Also this volume).

Gussenhoven, C. (forthcoming). Stress shift and the nucleus. Linguistics (Also this volume).

Gussenhoven, C. \& Blom, J.G. (1978). Perception of prominence by Dutch listeners. Phonetica, 35, 216-30.

Halliday, M.A.K. (1967). Notes on transitivity and theme in English, Part 2. Journal of Linguistics, 3, 199-244.

Halliday, M.A.K. (1970). A course in spoken English: Intonation (Oxford).

Liberman, M. \& Prince, A. (1977). On stress and linguistle rhythm. Linguistic Inquiry, 8, 249-336.

Nespor, M. \& Vogel, I. (1983). Prosodic structure above the word. In A. Cutler \& D.R. Ladd (eds) Prosody: models and measurements (Heidelberg).

Palmer, F.R. (1974). The English verb (London).

Postal, M. (1971). Cross-over phenomena (New York).

Selkirk, E.O. (1980). On prosodic structure and its relation to syntactic structure (Bloomington, Indiana). 



\section{Idiomaticity in sentence accent location in English and Dutch}

\subsection{INTRODUCTION}

In this article a number of differences between English and Dutch sentence accentuation are discussed ${ }^{1}$. These differences concern fairly clearly definable sentence types. By the side of a central rule like SAAR, which the two languages have in common (Gussenhoven 1983), the rules we are concerned with here are clearly 'minor'. Inasmuch as these locations frequently deviate from what SAAR would predict, they could be termed 'Idiomatic'. The Instances discussed below are felt to be representative of the differences between the two languages, but no claims to exhaustiveness are made.

\subsection{ON 'PREPOSITION STRESSING'}

A rather complex area in which differences between English and Dutch accent locations turn up is that of sentences in which very little of the semantic material is under focus, and in which accents on prepositions, the verbal to-particle and auxiliaries are encountered. Data of this kind were discussed in a number of contributions to English Studies some years ago (Doodkorte \& Zandvoort 1962, Posthumus 1962, Zandvoort 1962, Schubiger 1963 and Sфrensen 1971) and more recently by Oakeshott-Taylor (1981). In Gussenhoven (1983) an attempt is made to pair off part of the data as polarity focus: sentences like I've never BEEN 11 (Du. Ik BEN nooit ziek geweest 'I have never 11 ll been') and I didn't know he was born IN Poland (Du. Ik wist niet DAT hij in Polen geboren was 'I knew not that he in Poland born was $^{12}$ ) are dealt with there by a Polarity Focus Rule. Other data, too, can fairly easily be accommodated. Differences in accent locations in WH-questions in which the content of a PP is queried, as in (1) to (4), point to interesting syntactic facts in Dutch, but are not problematic from the point of view of accent assignment. In such sentences, the focus is on the 
queried PP, and the accent goes to whichever element (the preposition or the WH-word) comes later, a point overlooked by Kingdon (1956:207) and Posthumus (1962): compare With WHOM were you travelling? with Who were you travelling WITH?. In English this is more commonly the (post-positioned) preposition, in Dutch it is the WH-word in the case of the [+human] wie ('who') and the preposition in the case of the [-human] waar ('what').

(1) Who were you travelling WITH?

Met WIE was je op reis?

(2) What are you fed up WITH?

WaarVAN heb je genoeg?

(3) What did you scratch it FROM?

Waar krabde je het vanAF?

(4) What was it demaged BY?

WaarDOOR werd het beschadigd?

Assuming this focus distribution, the syntactic facts in Dutch in the [-human] case are interesting. There appear to be two groups of prepositions: ${ }^{3}$

Case prepositions like aan ('to'), met (instrumental 'with', rewritten as mee in combination with the NP-proform er), door (passive agent), voor ('for'), van ('from', 'of') and in general all prepositions introducing prepositional objects, are never post-positioned (cf. (2) and (4)), except when the focus is on the preposition itself. Thus, WaarAAN geef je de schuld? ('What to give you the blame': What do vou blame it ON?), "Waar geef je de schuld AAN?. A version with the eccented preposition in final position is possible only if the preposition itself is under focus, conceivable if also another preposition could have been used. Thus, Waar biljart je MEE? has a different focus distribution from WaarMEE biljart je? (both What do you play snooker WITH?). In the former case, the question is corrective ('I didn't ask what you play snooker on, or for, but with'), while in the latter sentence there need be no such implication that other information about how the game is played had already been at issue. (Hence the ungrammaticality of Tussen twee haakjes, waar biljart je MEE eigenlijk? tussen twee haakjes ('incidentally') making it explicit that the questioner addresses the question of the method of playing the game for the first time.)

Relational prepositions are semantically weightier prepositions, such as the direction prepositions door ('through'), naar (directional 'to'), om ('around'), over ('across'), uit ('out of'), van ('from', 'off'), the place prepositions in 
('in'), op ('on'), voor ('in front of'), achter ('behind'), time prepositions like voor ('before'), na ('after') and the 'accompanitive' met ('with'). All direction

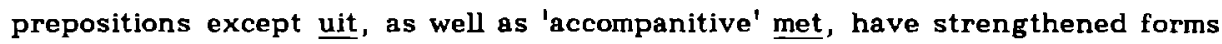
(respectively, doorHEEN, HEEN/naarTOE, omHEEN, overHEEN, vanAF/vanDAAN and met MEE). Relational prepositions show the opposite behaviour: they can only occur in post-position, but occur optionally after the WH-word if the focus is on the preposition. Thus, Waar liep je doorHEEN? (What did you walk THROUGH?), Waar sta je VOOR? (What are you standing in FRONT of?), Waar komt dit NA? (What does this come AFter?). Again, the other order is possible in a context like 'I didn't ask WHEN it came, I asked what it

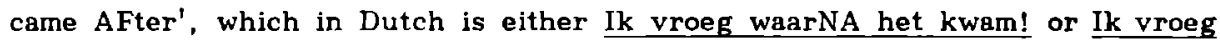
waar het NA kwam!. Of course, when these prepositions do not have their relational sense, they behave like the case prepostions: WaarNAAR verlang je zo? "Waar verlang je zo NAAR? (What are you longing FOR?) or WaarUIT bestaat een atoom? *Waar bestaat een atoom UIT? (What does an atom consist OF?).

We also dismiss lexical items like to beat somebody TO it and to be AT it again in English and er AAN gaan ('be killed') er VAN weten ('know about it') in Dutch, as well as focussed prepositions as in You can have it with or wiTHOUT sauce.

It is to the remaining data that the contributions in English Studies devote most of their comment. Below, I will argue that for both languages a distinction between case prepositions and relational prepositions needs to be made. In addltion, a distinction between relational prepositions with and without strengthened forms must be made for Dutch. Examples (5) and (6) are from a small corpus presented by Doodkorte \& Zandvoort.

(5) Farmers also use it to feed their animals. They add considerable quantities of salt TO the feed

(6) When you emptied the till, did you count the money IN the till?

In (5) and (6) the PP, including the preposition, is [-focus], i.e. In (6), no implication of 'in' as opposed to 'outside' is intended. (Doodkorte \& Zandvoort formulate this as 'the preposition is stressed, not because of any particular significance, but because of its anaphoric function'. "). In such cases, English appears quite freely to allow the accent to go to the preposition. Similarly, in (7), quoted by Zandvoort (1972) from Dickens' Little Dorrit (Book I, ch. 30), the to-particle is accented, the verb being $[$-focus]. 
(7) I ought to have been here hours ago, and then I should not have to apologise - permit me to apologise - for presenting myself so unseasonably...

Dutch is much more restricted here. In (5), (6) and (7) the accent would be on the equivalents of salt (possibly quantities, If it and salt are coreferential), money and permit, respectively. Such eccent locations are possible in English, too. Indeed, for much of these data it would appear that where Dutch differs from English, the English placements are governed by a variable rule. What are the restrictions in Dutch? First, an accent location on the verbal te-particle is never possible. Second, if the PP is a postmodifier in an NP, PP or an Adjective Phrase, the preposition is never accented (i.e. the literal translation of money IN the till can only represent a [+focus] preposition: 'not the money beside it or underneath it, but IN it'). ${ }^{5}$ If the PP is not phrase-internal, the situation is more complex. It seems convenient to divide the prepositions into three classes.

1. Relational prepositions with strengthened forms (e.g. door - doorheen) take the accent if the PP is [-focus] and there is no [+focus] object NP. Thus, in (8), where the knife and the canvas are [-focus], accent locations are equivalent in the two languages, but in (9), where a knife is [+focus], Dutch requires the last accent on that NP, whlle English can accent either knife or the following preposition.

(8) At last he stuck the knife THROUGH the canvas Eindellfk stak hij het mes door het doek HEEN

(9) Unexpectedly he stuck a KNIFE through/knife THROUGH the canvas Onverwacht stak hij een MES door het doek (heen)

Within the preposition, the accent always goes to the strengthening morpheme. It is relevant to observe here that simple relational prepositions like uit, in, op acquire a strengthened status by post-position, if used with a verb of motion. In that position they are treated like strengthened prepositions. Example (10) is equivalent to (B) ('he', 'the child' and 'the hill' are [-focus]).

(10) Toen droeg hij het kind de heuvel OP He then carried the child UP the hill 
2. Relational prepositions without strengthened forms (simple relational prepositions) in Dutch are subject to the further restriction that the prepositional object (e.g the hill in (10), henceforth the P-NP) must be a proform (er for [-animate], a personal pronoun for [tanımate] NPs). The other restrictions remain in force The b-examples in (11) and (12) contain proforms for the P-NPs.

(11) He then took the rabbit OUT of the hat

a. Toen haalde hij het konyn uit de HOED ("

b. Toen haalde hij het konijn erUIT

(12) He then took a large RABBit out/ rabbit OUT of the hat

a Toen haalde hij een groot koNIJN uit de hoed

b. Toen haalde hy er een groot koNIJN uit

Alternatively, we should say that Dutch does not allow a lexical P-NP with a sumple preposition to be treated as [-focus] if it is specified, it must be focus. In cases like (11)a, the preposition is often given prominence in addition to the accent on the P-NP, compare also But how do you get a thing like that ON the tower! Maar hoe krujg je zolets nou 'op de TORen!. Other examples of accented prepositions with proform P-NPs are Toen zette hij het scherm erVOOR (Then he put the screen in FRONT of it), Voorzichtıg zette hij de muis erOP (Carefully he put the mouse on TOP of it).

In English the group of relational prepositions is characterised oy obligatory accentuation if there is no [+focus] NP between the $([+$ focus]) verb and the PP, as in (9), (10) and (11), and optional accentuation if there is, as in (8) and (12). Observe that English from often behaves like a case preposition Thus, Have you HEARD from hyn? has the accent optionally on from: compare from in Did you scrape this FROM it? or the relational preposition off: Talking about the lid, did you take the lid OFF it', where the preposition is obligatorily accented ('SCRAPE, "TAKE)

3. Case prepositions in Dutch are never accented. Even if the P-NP is a proform (and [-focus]) and no [+focus] NP occurs in the sentence, they do not attract the accent In English, case prepositions are only optionally accented, even if no [tfocus] NP occurs between verb and PP. Thus, where English may have either I gave it TO it or I GAVE it to it as an answer to 'What did you do when the chump started clawung at your hat'', Dutch only has Toen GAF ik het maar aan hem. Sumlarly, But the question realy is can you cure people OF the disease?, which has the accent on the verb in Dutch. Note that when an Eng- 
Lsh preposition like for is used in a relational sense ('on behalf of/in place of' rather than 'for the benefit of'), it patterns like relational prepositions discussed above This machine mixes, mashes, grinds, grates It does everything but eat the food FOR you or I need somebody to do the work FOR me (Cf A John, could you give me a hand with this vegetarian meal? B Anything you say darling, I'd even be prepared to EAT the food for you and For some reason this student refuses to do the WORK for me, which accentuation is ruled out if for is a relational preposition )

To summarise, let us state the conditions in which preposition stressing is variable in English, and blocked in Dutch In all cases, the PP is [-focus]

1 The PP is phrase-internal (in a NP, AdjP or PP) Note that the focus markIng of the head of the phrase is Irrelevant, 1 e English could accent either on or of in Now that we are on the subject of fungl, Dutch must accent the verb, which is the 'alternative English' pattern, too (Cf (6) )

2 The PP is attached to a VP, and a [+focus] NP precedes Dutch and 'alternatıve Englısh' accent the preceding NP (Cf (5), (9), (12) )

3 The $\mathrm{PP}$ is attached to a VP and no [+focus] NP precedes

a If there is a case preposition Dutch and 'alternative English' accent the preceding ([+focus]) verb (cf section 3 above),

b (only for Dutch) if there is a simple relational preposition and the P-NP is lexical The accent must go to the lexical P-NP, with optional extra prominence for the preposition, of (11) and section 2 above (English has no alternative here, and stresses the relational preposition)

The variable nature of the situation in English naturally raises two questions One is what, If any, stylistic differences there are between an accent on a late preposition and the alternative stressing (and we could include here variable accent placements in polarity-focus sentences) In a footnote to Doodkorte \& Zandvoort (1962), Osselton already observed that preposition stressing seemed partıcularly frequent in 'publıc' speech (broadcasting, meetıngs, etc ). where he must have had the varıable cases in mind Indeed, a plausible hypothesis is that such placements have a function simular to that of stress retraction in monomorphemic adverbs and adjectives in Dutch, which rule appears to be applied 
more frequently as the degree of rhetoricity of the (spoken) text is higher (Gussenhoven, this volume). The other question that must be left unanswered here concerns the linguistic factors that influence variable preposition stressing. It is for example fairly natural (in the stylistic situation indicated above) for phrase-internal prepositions to be accented (cf (6)). But in sentences in which an independent PP with a case preposition follows a ([+focus]) verb directly, stressing the preposition often seems a highly marked option. Consider, for instance, (13) to (15).

(13) ?"Good old Mary! Yes, 1 of ten think OF her

(14) A: Shall I get a nice CLAret?

B: ?'Actually, I don't care FOR wine

(15) ? You can try, but they're not really the kind of people to put up WITH that sort of thing

(These structures should be distinguished from sentences in which also the verb is [-focus], as in polarity focus: A: Now, THINK of me. HARD! B: I AM thinking of you/ I'm thinking OF you!, or in which only the modal auxiliary is [+focus], as in Oakeshott-Taylor's (1981) example I'm SURE it's worth going ON with, and I'm going to go on WITH it.) Possibly the answer should mainly be sought in stylistic factors. Note that (13) to (15) concern 'non-public' situations. More 'public' utterances like I therefore urge you to conform TO these standards and (A: Why don't we scrap the whole plan B:) But we're committed TO it! are clearly less marked. For a non-structural, semantic analysis of these and similar data, see Bolinger (1983).

\subsection{EXCLAMATIONS}

An area of some interest for our subject is provided by exclamatory sentences. I will deal with simple exclamations, complex exclemations and exclamatory questions.

Simple exclamations. Simple exclamations in English are introduced by what or how. What functions as a predeterminer of an indefinite NP, how as an intensifier of an adjective, adverb or clause (Quirk et al. 1972: 57,406-7). In Dutch, 
these structures have the introducers wat een and wat, respectively. If we refer to the structure governed by the introducer as the exclamandum, then, according to Quirk et al., poor is the exclamandum in How poor she is! and I admired my grandfather in How I admired my grandfather!. In this latter case, it would appear preferable to consider the verb the exclamandum: verbs can be excluded from preposing in the same way that they cannot be subject to WH-movement. This analysis enables one to state that exclamanda are phrase-level constituents which are (presented as) gradable. Syntactically, exclamations are kept distinct from questions in English by the retention of the subject-operator word order of declarative sentences. The exclamandum, however, is preposed as is the Q-element in WH-questions. Dutch is rather different from English: Dutch does have subject-operator inversion, as in questions (cf Zandvoort 1974, §696), but exclamandum-preposing is optional. In effect, this means that the word order is either that of a polar question or that of a WH-question. The introducers wat een and wat contrast with wat voor/ welke ('what, which') and hoe ('how') in questions. In the version without preposing, een (of wat een) is proclitic to the NP.'

(16) How high the mountains are!

How high are the mountains?

(17) How loud John played the piano!

How loud did John play the piano?

(18) What a goal he scored!

Which goal did he score?
Wat zijn de bergen hoog! Wat hoog zijn de bergen! Hoe hoog zijn de bergen? Wat speelde Jan hard piano! Wat hard speelde Jan piano! Hoe hard speelde Jan piano? Wat maakte hij een doelpunt! Wat een doelpunt makk hij! Welk doelpunt maakte hij?

Turning to prosody, it is observed that in English simple exclamations with intensive $B E$, the sentence accent can go either to the subject complement or to be. In Dutch, zljn cannot have a sentence accent when the exclamandum (the subject complement) is preposed. It can have a prenuclear accent, though, if the exclamandum follows. Illustrations are given in (19) and (20); the subjects in these sentences are [-focus].

(19) How HIGH the mountains are! How high the mountains ARE!
Wat HOOG zijn de bergen!

Wat (') zijn de bergen HOOG!

*Wat hoog ZIJN de bergen! 
(20) What a funny MAN John is ' What a funny man John IS '
Wat een grappige MAN is Jan'

Wat (') Is (')Jan een grappige MAN'

*Wat een grappige man IS Jan

The different accent locations in the English examples are unrelated to focus distribution By contrast, questions with these prosodic surface forms do have different focus distributions How HIGH are the mountains? has 'the mountains' marked [-focus] presumably, height had not been considered as a property of the mountains before the question was asked How high ARE the mountains? differs from this example in having 'the mountains are $x$ high' as the [-focus] material, and this question is appropriate only if the height of the mountains had been considered before the question was asked No such meaning difference attaches to (19) and (20) And, equally unsurprisingly, the two questions above have parallel prosodic structures in Dutch

Complex exclamations. Complex exclamations are of two types The furst type is the embedded sumple exclamation discussed above Its superordinate clause is typically I never knew, Then I discovered, I suddenly remembered etc Recall that embedded questions do not have subject-operator inversion (Quirk et al 1972 736) Inevitably, the syntactic difference between questions and exclamations is lost under embedding, and structures like I then discovered how lovely Maida Vale is are therefore ambiguous Dutch may sumlarly lose its exclamation marker when introducing adverbs or adjectives, wat is variably replaced with hoe The prosodic difference between questions and exclamations in English remains in force, however Thus, the embedded exclamation in (21) has a Dutch equivalent with the accent on mool ('lovely'), in addition to allowing wat for hoe, though hoe seems more natural The embedded question in (22), by contrast, has a hteral equivalent

(21) Then I discovered how lovely Maida Vale IS (Crystal \& Davy 1975, 6 10) Toen ontdekte ik hoe/"wat MOOI Maida Vale is

(22) We must establish how lovely Maida Vale really IS

We moeten vaststellen hoe mool Marda Vale eigenlyjk IS ("wat)

The second type of complex exclamation is introduced by a WH-word The superordinate clause is typically I don't know, She had no idea etc, and never has you as a sublect Accent placement is obligatorly on the WH-word (Examples of this structure are included in Schubiger 1958108 ) Dutch lacks a di- 
rect equivalent, and a variety of idionatic expressions may be used to create a sumilar effect, as in (23) to (25)

(23) I don't know HOW many of these little muce we caught (C\&D 8 52)

We hebben $1 k$ 'weet niet hoeveel van die musjes geVANGen

We have I know not how many of these mouse-lets caught

(24) She didn't know WHO to turn to

Nou wist ze heleMAAL niet meer waar ze nartoe moest

Now knew she at-all not anymore where she to had (1 e to go)

(25) I don't know WHAT happened

Ik weet bij 'god niet wat er geBEURD is

I know by god not what happened has

Exclamatory questions Exclamatory questions (Quirk et al 1972 400) are polar questions in form, but exclamations as far as their function is concerned They can be positive, or, if the listener is appealed to for comment, negative in form Accent placement is as in the corresponding question The tone is generally a tall, unlike that in questions Dutch lacks a formal equivalent, but has two other structures that fill this communicative slot One is a declarative sentence with the accent on the operator The exclamatory nature is otherwise apparent trom the use of the singular article een for both plural and singular indefinite nouns From informal informant responses it would appear that this structure is restricted to Dutch as spoken north of the great rivers in the South, the accent is as in a full-focus sentence The second structure has the accent on the preposed exclamandum, followed by the rest of the clause introduced by the conjuction dat ( $c f$ van den Toorn 1979 106) If the preposed constituent is the verb, it has the infinitive form, the verb slot in the dat-clause being tilled by a form of doen ('do') The accent in both structures is conventionally realised by a rise followed by a high plateau for the tal (' 1 ' in Collier \& 't Hart 1981) Examples are given in (26) to (29)

(26) Am I HUNGry'

(27) Wasn't it a lovely OLTing

(28) Didn't he write POems'

(29) Did he SMOKE'
Ik HEB een honger'

Een HONGer dat $\mathrm{lk}$ heb'

Het WAS een leuk uitje!

Een leuk UITje dat het was'

Hıj SCHREEF een gedichten'

Een geDICHten dat hij schreef '

Hı ROOKte'

ROken dat hij deed' 
Paardekooper (1963, 1971 160) quite correctly points out that the second structure should be distinguished from expanded vocative forms like Lieve JOVGen van mamme dat je bent' ('Dear boy of mummy's that you are''), in which the vocatıve proper lacks an article, dat may be replaced with the relative die, and, it may be added, where the accent may also be realused by a fall-rise (or ' $1 \mathrm{A2}$ ' in Coller \& 't Hart 1981)

English, too, possesses an exclamation-like utterance with the accent on the operator (do if the verb is lexical), as pointed out for instance by Schubiger (1958 107) In this type of sentence, the communicative inport is not so much the high degree of the exclamandum, but the definiteness of the proposition The tone is usually a fall Dutch does not have a formal device that creates the same effect (Schubiger notes that 'if used too abundantly, it produces an effect of "gush" ' The Dutch pattern with the accent on the operator has no such effect) The English pattern seems particularly frequent in polite appreciations, as llustrated in (31) and (32)

(30) God' You ARE desperate

(31) He DOES look finel

(32) That WAS a lovely outing'
Jil bent wel wanHOpig zeg'

Hij ziet er prachtig UIT'

Dat was een erg leuk UITje!

\section{MISCELLANEOUS}

There exist some other differences in accent placement between the two languages that seem worth noting

Correlative conjunctions. English permits accent placement on the second element of a correlative conjunction like both and, either or, as well as if the conjoins are [-focus] Dutch, surprisingly, does not, as llustrated in (33) and (34)

(33) Sorry, you can have either cereals OR fruitjuice Sorry, je mag 'of cereals 'of VRUCHtensap

(34) You change either the rules or the underlying forms, or both the rules AND the underlying forms of zo'wel de regels 'als de onderliggende VORMen 
No restriction is in force if the conjunction is not correlative English for men AND women equals Dutch voor mannen EN vrouwen Also, sheer repetition does not appear to provide the explanation When the conjunctions are not correlative, but concatenative, Dutch allows deaccenting of the conjoins in the situation where irritation over somebody's greediness is expressed (cf (35)), though not elsewhere ((36))

(35) EN een elektrische treın, EN voetbalschoenen, EN een duur T-shırt Ga jly je HUISwerk maar 's maken'

AND an electric train, AND football boots, AND an expensive T-shirt Why don't you go and do your HOMEwork'

(36) He's got a house AND a wife A $\backslash D$ a chlld AND a dog

Hy heeft een HUIS en een VROUW en een KIND en een HOND

$\mathrm{BE}$ in complement clauses. If between $\mathrm{BE}$ and a complement clause a prosodic break is made, English accents either the form of be or the subject NP Dutch only permits accentuation of the subject, as llustrated in (37)

(37) The THING is/The thing IS they don't really have the MONey Het proBLEEM 15 dat ze eigenluk het GELD niet hebben

Beside thing, the subject may be reason, problem, fact (of the matter), truth, Idea, point, question, etc As pointed out by Bolinger ( $p$ c ), the Iikelihood of the accent on be decreases considerablv in less formulaic cases "One problem IS

Possessives. If a [+focus] NP is tollowed by [-focus] material containing a possessive in anaphoric relation to that $\lambda P$. English permits accentuation of the possessive, but Dutch does not, ds llustrated in (38) to (40)

(38) Yesterday Bll lost his WALLet and now John has lost HIS wallet en nu heeft JAN zun portemonnee verloren

(39) Meanwhlle Britain launched ITS submarine

Ondertussen had ooh ENGeland een onderzeeboot klaar

(40) A calf always looks like its MOTHer A lamb always looks like ITS mother een lam ziet er OOK altıjd als zin moeder uit 
(In (39) an (40) the nucleus in the Dutch sentences is determined by word order both ook and the noun governed by it recejve a sentence accent ) Of course, accentuation of the possessive is obligatory in Dutch if it is itself under focus In (41) the possessive is used to identify the correct referent ( 1 e not the one assumed by the hearer 'counterassertive' mode)

(41) (Father tured of carrying child piggyback) Just as I am standing on MY legs, you're going to stand on YOUR legs ga jly op JOUW benen staan

As was said in the introduction, this inventory of differences between Dutch and English accent locations is not meant to be exhaustive Together with the differences encountered in polarity-focus sentences, however, they do constitute the differences about which reasonably comprehensive generalisations can be made 
Notes

1 I thank Flor Aarts, Dwight Bolnger and Ton Broeders for ther comments on an earher draft of this paper

2 A context for this sentence might be 'How can you say that his first language is JapaNESE if he was born in POland?' It is observed that it is not impossible for a conjunction like that to be accented in English This would require the focus to be withdrawn from the embedded sentence entirely (1 e also the polarity is [-focus]), as in a translation of the following quotation from W F Hermans (Houten leeuwen en leeuwen van goud, Bezige B1j, 1979, p 251) 'Noolt zegt, verklaart of vertelt hij lets Hij verhaalt Maar dat is niet mijn enige bezuaar Waarom er aldoor bij vermelden dat hij lets verhaalt of za] gaan verhalen?' ('He never says, explains or tells us anything He relates But that is not my only objection Why always inform the reader $T I \bar{A} T$ he is relating something or going to relate something ') It should alo be noted that by the side of COMP-stressing in embedded polarity-focus sertences in Dutch, some speakers may have the accent on the operator, as in unembedded sentences Ih wist niet dat hij in Polen geboren WAS Cf also 'Dan had ik njet die struktuur kunnen maken die ik heb gemakt', instead of 'die ik heb gemaakt' ( $\mathrm{J}$ van Tun's interview with Harry Mulisch in Vry Neder land 20-8 83)

3 For more extensive attempts at classifying Dutch prepositions see van Geffen (1963) and Wellnen (1964)

4 Doodkorte \& Zandvoort's comment that there is often a causal relationship is rightly dismissed as incidental by Schubiger Posthumus observes that the [-focus] status of the P-NP accounts for its being unaccented all right, but that this does not explain why the accent goes to the preposition Schubiger suggests the answer ljes in the inability of such phrases to occur initially ( IN the tلll did they count the money?), presumably considering it less problematic that in sentences lihe Tro thousand demonstrators marched against the Commumst Party Headquarters in Warsaw today FROM Warsaw, John Clyde sends us this rePORT trom is accented and Warsaw unaccented

5 An exception concerns P-NPs promoditied by zo'n, een dergeluke (unaccented 'such $a^{\prime}$ ) The pattern is stylistucally marked, and optional, as in Maar wie is dan voorzitter VA` zo'n vakgroepsbestuur' ('Then who is the chairman OF such a departmental board?') The exception also seems to hold for lexical P-NPs with simple relational prepositions, such as (11)

6 Preposing of NP-exclamanda seems more natural than preposing adverbial and adiectival exclamanda These comments on the syntactic properties of exclamations in Dutch should be seen in an observational light For a syntactic analysis see Krijgsman (1982)

\section{References}

Bolınger, D (1983) 'Affirmation and default' Folia Linguistica 17, 99-116

Crystal, D \& D Davy (1975) Advanced conversational English London Longman

Coller, R \& J 't Hart (1981) Cursus Vederlandse intonatie Louvaln Acco 
Doodkorte, $A$ \& $R$ W Zandvoort (1962) 'On the stressing of prepositions' English Studies 43, 96-101

Geffen, C P van (1963) 'De locale voorzetsels van het hedendaags Nederlands' In A W de Groot \& H Schultink (edd) Studies op het gebied van het hedendaags Nederlands Den Haag Mouton

Gussenhoven, C (1983) 'Focus, mode and the nucleus' Journal of Linguistics 19, 377-417 (Also this volume)

Gussenhoven C (this volume) 'Stress shift in Dutch as a rhetorical device' (To appear in Linguistics)

Kingdon, R (1958) The groundwork of English intonation London Longman

Krijgsman, K J (1982) 'Wat-uitroepen en WH-verplaatsing' GLOT 5, 123-56

Oakeshott-Taylor, J (1981) '/Nót to stress, or tó stress/? On the location of "tonic prominence" in English' LAUT paper, Series A, No 86

Paardekooper, P C (1963) 'Stommelıng dat je bent' N1euwe Taalgıds 56, 160-4

Paardekooper, P C (1971) Beknopte ABN-syntaksis, 4th edition Den Bosch Malmberg

Posthumus, J (1962) 'Further comments on the stressing of prepositions' English Studies 43, 492-5

Quirk, R , S Greenbaum, G Leech \& J Svartvik (1972) A grammar of contemporary English London Longman

Schubıger, M (1958) Englısh intonation Its form and function Tũbıngen Niemeyer

Schubiger, M (1963) 'Again the stressing of prepositions' English Studies 44, 275-7

S $\phi$ rensen, $K$ (1971) 'On the stressing of be, been and as' English Studies $52,305-9$

Toorn, M C van den (1979) Nederlandse grammatica, 6th edition Groningen Wolters-Noordhoff

Wejnen, A (1964) 'Structuren van Nederlandse voorzetsels' Tijdschrift voor Nederlandse taal- en letterkunde 80, 116-32

Zandvoort, R W (1962) 'On the stressing of prepositions' English Studies 43, 497

Zandvoort, $\mathrm{R} \mathrm{W}$ (1974) A handbook of English grammar Groningen Tjeenk Willink 



\section{A semantic analysis of the nuclear tones of English}

\section{Summary}

It is hypothesised that the nuclear tones of English are morphemes with independent, consistent meanings. The variability in their semantic effect is argued to be a function of the speaker's communicative intentions. It is demonstrated that this variability can to a large extent be accounted for by specifying (1) whether the communication is speaker-serving or hearer-serving, and (2) whether the meaning of the tone is employed literally or metaphorically, and if the latter, what the meaning refers to.

It is demonstrated that English has three tones: the fall, the fall-rise and the rise. Additional tone variants are produced by the application of a number of phonetically specifiable modifications, which are also assigned morphemic status. A modification is thus both phonetically and sementically constant across tones. Modifications and tones are like columns and rows in a matrix. The phonetic and semantic effects of the modifications on the tones are discussed, and pitch contours are given of the twelve resultant tones (three unmodified and nine modified tones). In addition, range is postulated as an independently specifiable, gradient variable. It, too, is given semantic status, and its meaning is argued to be independent of those of the modifications. The analysis attempts to present the facts in terms of an autosegmental framework. The modifications as well as a tone linking rule are taken to lend support to the superiority of such a description. The article concludes with a discussion of a few alternative proposals.

The discussion is with reference to standard British English. However, most of the conclusions may be equally applicable to American English, and literature dealing with data from either variety is taken account of where this seems relevant. 


\subsection{INTRODUCTION}

Proposals concerning the relation between intonation and meaning vary along two dimensions ${ }^{1}$ The first is the segmentation dimension, which determines how the analyst cuts up the intonation contour into commutable chunks The second dimension determines the manner in which the analyst views the contribution of intonation to the meaning of the utterance On the segmentation dimension, proposals range from the structuralist pitch level analyses (Wells 1945, Pike 1945, Trager \& Smith 1951) to holıstic contour analyses (Lıberman \& Sag 1974, Sag \& Lıberman 1975, Glenn 1977), 1 e from 'atomistic' to 'global' (Bolınger 1972a 51) For the second dumension, the image of a unidimensional scale seems less appropriate Rather, proposals he around a centre of linguistic normalcy Examples of extreme positions may be O'Connor \& Arnold's (1973) (implicit) suggestion that the meaning of intonational units varies with sentence type and lexical content, or Glenn's (1977) exploration of the thesis that whole contour shapes are linked to particular speech acts I call these positions extreme, because they deviate greatly from what linguists would so far seem to have established language is like There are, as far as I know, no examples of morphemes whose meaning changes when the context is changed Usually, it is either assumed that there is a case of homonymy - in which case both meaning a should in principle be employable in any context - or that different contexts force different interpretations of the morpheme's meaning - in which case it is believed that a characterisation of that meaning can be given that underlies all instances of its use (Compare, for example, the interpretations of blue in The bay was blue and $\mathrm{My}$ hands are blue (with cold) ) And, apart from the isolated case of please as an unambiguous marker of the speech act 'request', it is not generally believed that there exist any kınd of one-to-one correpondences between linguistic forms and speech acts, or between utterance acts and llocutionary acts (Searle 1969) Indeed, the concept of speech act seems so umportant partly because there is not

There are therefore two decisions that a semantic analysis must face before it can get under way, one on segmentation and one on distance from linguistic normalcy 


\section{SEGMENTATION}

The units that are recognised here are the 'nuclear tones' of the British tradition of intonation analysis (Palmer 1922, Kingdon 1958, Schubiger 1958, Crystal 1969, Halliday 1970, O'Connor \& Arnold 1973, Brazll 1975, 1978) Nuclear tones are pitch configurations like 'fall', 'rise', 'fall-rise', 'rise-fall', 'level', which are associated with an accented syllable and any following unaccented ones While detals of mapping may vary from tone to tone, tones will typically expand and contract depending on the length of the stretch of speech they are mapped onto Minimally, this stretch is one syllable long (the accented syllable) There is no upper limit, as there is no principled limit to the amount of unaccented speech that can be produced after an accented word Within this tradition there are considerable differences of opinion regarding the identification of tones It is not generally recognised, for example, that a fall-rise which is mapped onto a longish stretch of speech, as in

\section{(1) Isn't that where 'YOU were thinking of going then?}

where the fall-part is mapped onto you and the rise-part onto the last syllable (then), is in fact a single tone Some analyses have it that (1) constitutes a sequence of two tones, others that it contains a compound tone, which has the special characteristic of marking two syllables as accented - or 'tonic' (Halliday), or 'nuclear' (Crystal) - but at the same time that of creating a certain bond between them In the present analysis, the unitary interpretation of instances like (1) is adopted, 1 e it is assumed that in (1) there is a nuclear tone, the fall-rise, on you, which may commutate wholesale with such phonetically less complex tones as the rise or the level tone, always marking only the accented syllable you For arguments supporting this solution see Gussenhoven (in press)

There is also disagreement about the inventory of nuclear tones authors differ with respect to their number and the relations between them Thus, Brazil et al (1980) assume that the 'rise' is a reinforced variant of the 'fall-rise', whlle others see these tones as different and unrelated In this article, a structure of the nuclear tone paradigm is presented in the course of the exposition of the meanings of the tones

Finally, although in the mainstream of the tradition there seems to be general agreement on there being only a single nucleus in a tone group, authors may 
differ with respect to the number of tone groups a given utterance consists of, and hence on the status (prenuclear or nuclear) of certain accented syllables For a discussion of this question and an alternative view, see Brown et al (1980) In section 10 it is suggested that it is not only the last accented syllable in a tone group that is assigned a nuclear tone All accented syllables must address the paradigm of nuclear tones Sequences of tones may be linked by tone linking rules, whose application may produce contours that elsewhere are classified as 'head contours' (pre-nuclear pitch configurations)

\subsection{MEANING}

The assumption of linguistic normalcy dictates that the units one identifies as the commutable chunks of the contour are units that make up a system in much the same way that segmental units do Intonation is, in this view, not on a par with segmental phonology, but is more like the system of syntax/lexis That is, it is a system of morphemes and of rules that operate on those morphemes to produce well-formed surface structures The products of the two systems will have to be mapped onto each other, without giving one of the two priority over the other A superficial comparison of the two systems reveals the following differences

a Since for the expression of intonational units there is only a single, unitary phonetic variable avaulable (fundamental frequency against tume), but for the expression of segmental morphemes a far more richly exploitable, complex phonetic variable (spectral composition against time), the linguistic subsystem of intonation is likely to be vastly less complex than the linguistic subsystem of syntax/lexis

b Also because of this difference in phonetic packaging, units in the linguistic subsystem of intonation are much less easily identifiable than units in the linguistic subsystem of syntax/lexis, where cues to correct segmentation can fairly readily be found in changes in spectral composition (cf 't Hart \& Collier 1975 237) In fact, there is even no guarantee that segmentation should proceed in linear fashion, as some units might intertwine with other units, and/or may have differently-sized domains from others For example, it may well be necessary to consider a high range fall-rise to consist of two non-linear units a fall-rise and an option 'high range' 
It is, however, more revealing to consider the similarities that emerge when the assumption of linguistic normalcy is made. Three points can be made:

1. Just as between syntax/lexis and surface structure there is a level of formal organisation providing 'a bridge between form and substance', specifying how 'the given language organises its resources in such a way as to carry (or 'expound') its grammatical and lexical patterns' (Halliday 1967a: 9), so we may recognise a level between the intonational system and $F$ variations. That is, if we choose to postulate the 'fall' as an intonational morpheme, representing it HL (a la Goldsmith 1976), then $H$ and $L$ could be seen as purely formal units making up the morpheme $\mathrm{HL}$, in a way similar to that in which English / $t /$ and $/ i(y) /$ make up the morpheme tea. Observe that either type of unit can enter into other well-formed sequences (cf. eat and LH, or 'rise').

2. Cross-linguistic comparison of intonational data should be based on a morphemic analysis of the languages concerned. If there are such things as syntactic universals, we do not, after all, expect to find them in the phonologies of the languages concerned. English and Dutch will be said to have the syntactic option [ \pm plural], despite the fact that the phonological shapes of their morphemes differ. In the same way, we should be prepared to expect a morpheme that in one language or dialect comes out as HL, to eppear in another as LHL (cf Ladd 1981). ${ }^{2}$

3. Just as lexico-syntactic choices are assumed to have consistent meanings that are independent of whatever other choices go into the making of any utterance, so intonational choices should be expected to have such meaning. The meaning of 'perfect', or of the adverbial clause conjunction 'if', however varied their contributions to the interpretation of a collection of utterances they happen to occur in may look, are (assumed to be) essentially independent of those utterances, and therefore, if we try hard enough, we ought to be able to give them a unique characterisation. Why are we inclined to expect the meanings of intonational units to be different in kind? Why should not the meanings of nuclear tones be so describable? When Cutler (1977) says: 'No proponent of the "contours-have-meaning" proposal is foolhardy enough to claim that contour meanings are specific, referential, and analogous to word-meanings', we should be careful not to be misled into assuming that intonational meaning is principally different from what we have so far believed linguistic meaning is like. It would be foolhardy, too, 
to assume that intonational meaning is variable, depends on other choices it combines with, and cannot therefore be given specific characterisations. If this was true, how would language be learnable? Just how many combinations of tune and text are there? It must be added that Cutler's remark was made in the context of a proposal that involved assigning meaning to entire, tone group-long contours, a proposal she rightly rejects. It is important, however, to prevent her comments from being read in a more general light, as applying to the concept of intonational meaning as such. When she points out, for example, that intonation contours 'can be shown to be context-dependent to such a degree that the attempt to extract from them an element of commonality valid in all contexts must be reckoned a futile endeavour', it may well be true that this is in fact a hopeless exercise, but certainly not a pointless one, as this is precisely what linguists should see as a major research objective in the area of intonation. Note also that such context-dependency of 'meaning' is rarely seen as a prohibitive phenomenon in other areas of linguistic research. No one would ever maintain that the meaning of Didn't John kiss Mary cannot be got at because that meaning is so context-dependent:
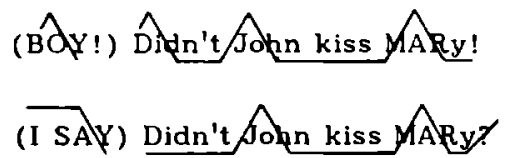

(2c) (You don't SAY!) Didn't John kiss MARYy?

There is, as far as I can see, no a priori reason to go on the assumption that intonational meaning is different from linguistic meaning generally, and I will therefore here tentatively assume maximum linguistlc normalcy for the nuclear tones of English. Deviations from this position will have to be forced by the data, and justified: the burden of proof now lies where it ought to lie.

\subsection{ON THE SORT OF MEANING INTONATION IS CONCERNED WITH}

An intriguing paradox that emerges from even a cursory inspection of the semantic effects of intonational phenomena is that these effects seem extremely va- 
gue and subtle in one situation, and unambiguously precise in another (cf Liberman 1975 142) Proposals for the description of intonational meaning (tacitly or explicitly subscribing to a position of normalcy) reflect this paradox Cruttenden (1981) proposes a number of vague notions like 'open' and 'closed' as the meanings of rising and falling contours respectively Sinlarly, Bolinger (1982) speaks of 'non-finality' and 'finality' for the same concepts On the other hand, very specific proposals have been made Liberman \& Sag (1975) have Identified a contour that means 'contradiction', and Ladd (1977) proposes that the fall-rise tone signals that the referent of the word marked by it is tagged as one of a defined set of sumlar referents

Before attempting to assign specific meanings to intonational units, therefore, it would seem to be prudent to consider the question of what kund of meaning intonation is concerned with Even if we assume that intonational meaning is Innguistic in nature, we are still left with a great deal of latitude The definition of the meaning of bachelor can be more specific than the definition of the meaning of this While the former can be given in terms of easly identifiable properties of things in the world (adultness, maleness and unmarried status), a characterisation of the meaning of this must be vaguer in that in addition to the properties 'singularity' and 'definiteness' we must have recourse to some such W-defined notion of 'intimacy of association with the speaker' Compare, for instance, Can I have this apple? and Can I have that apple? in a situation where physical distances between speaker, hearer and apple are constant (at table, say) It can even be said that whle the use of this as opposed to that clearly results from a choice from a linguistic paradigm, the effect of either option is wholly attitudinal A simlar point can be made with the help of quite a number of 'segmental' options (Dutch dimınutives, English progressive, etc)

If it is clamed, as was done in the introduction, that the meanings of the nuclear tones of English are constant, this does not imply that it is postulated that those meanings are therefore as easuly specifiable as the meanings of many 'major class' segmental morphemes What we should expect, however, is that the meanungs of terms in the same paradigm are concerned with a particular kind of meaning Man, woman, boy and girl are variations on a common theme of humanness, and this/these and that/those are placed along some dumension of 'intimacy of association with the speaker' Clearly, if linguistic normalcy obtains in the paradigm of nuclear tones, a simular common denominator ought to be identifiable It is for this reason sound policy to avoid assigning meanings to only part of the paradigm of nuclear tones, leaving the meanings of others for 
future analysis The danger here is that the perspective on the paradigm as a whole is lost, and that meanings are proposed that later turn out to clash with those of the others

In the area of intonation there is at least one semantic concept which, however problematic its definition has turned out to be, is uncontroversial in that its existence is generally acknowledged This concept is focus, or the division of the sentence into a part that is 'guven' and a part that is 'new' (e g Halliday 1967b) In view of the variety of (non-intonational) interpretations that these terms have been given (Brown 1983), it is justifiable to present the distınction in somewhat different terms every sentence (fragment) obligatorly has all or part of its material marked as [+focus] This material is thereby semantically marked as the speaker's 'contribution' The (optional) part that is not so marked, the [-focus] material, is thereby presented as the 'starting point' for that contribution While certain structures or exchanges would appear to require particular focus distributions, the speaker is generally at bberty to choose his focus distribution according to his intentions (cf Bolinger 1972b)

In other words, part of what intonation is used for is to mark the status of the information conveyed by the sentence with respect to a 'background' (starting point) hypothesised by the speaker For every sentence he uses, the speaker must decide how much of it he will mark as his contribution, and what he will leave as his starting point For example, in (3), which gives different versions of an answer to And who was born in Idaho?, the speaker understandably marks daddy as his contribution, the requested bit of information (In this example, underlining symbolises [+focus] )

(3a) Daddy

(3b) Daddy was born in Idaho

(3c) Idaho is where daddy was born

Focus distributions are reaised by sentence accents the focus distribution in B's answers in (3abc) is signalled by a sentence accent on daddy (As is well-known, there is no bi-uniqueness here a sentence accent on a particular word may be the result of more than one focus distribution, and there are therefore numerous ambiguous sentences) Sentence accents do not have a unique phonetic realisation (cf Bolinger 1958), and a mere identification of the position of the sentence accent leaves the surface structure grossly underspecified This variation in the realisation of sentence accents is prumarily due to 
the fact that for every sentence accent the speaker must make a choice from the paradigm of nuclear tones ' Now, if sentence accents, which as we have seen are there to realise the speaker's focus options, receive a further specification in terms of the Fo movements that nuclear tones consist of, it is natural to assume that the semantic contribution of these tones consist in a further specification of the status of the 'contribution' with respect to the 'background' Specifying the focus distribution is not enough the speaker must specify what relationship exists between contribution and background It is proposed that it is this relationship that provides the common element in the semantics of the nuclear tone paradigm

\subsection{THREE NUCLEAR TONES AND THEIR MEANINGS}

To continue to argue in this abstract way for just a little longer, we may say that linguistic communication can be seen as a process whereby participants strive towards some common understanding about a particular segment of the world The understanding they think they have reached at any one point in that process 15 called the background Background should thus not be seen as some grand, static backcloth of knowledge against which that communication takes place, but rather as a miniature body of knowledge, which has either been explicitly created as a result of the exchanges so far, or is felt by the speaker to be implicitly called up by those exchanges, by virtue of common-sense hypotheses about the hearer's knowledge of the world which the speaker judges to be relevant to his purpose of reaching that common understanding Because the word 'contribution' is semantically rather close to the meaning of one of the tones to be formulated below, this term will from now on be replaced with the more neutral term 'Varıble'

Three options are avaulable These options are here termed manipulations

1 The speaker may add the Variable to the background (ADDITION),

2 The speaker may select a Variable from the background (SELECTION),

3 The speaker may choose not to commit humself as to whether the Variable belongs to the background Since by far the most common purpose for which 
this option is employed would appear to be characterisable as the speaker's testing whether a Variable belongs to the background, this option is referred to as (RELEVANCE) TESTING It should be remembered, therefore, that the term strictly refers to the meaning given earlier *

These meanings are expressed by (1) the fall, (2) the fall-ruse and (3) the rise These are therefore proposed as the three basic tones of English They are the only ones that are independent of each other, all other tones being modifications of them Observe that, in different ways, both SELECTION and TESTING are opposites of ADDITION The first opposition is that between 'putting in' and 'taking out', the second between 'putting in' and 'not putting in' ADDITION and SELECTION may be compared with Brazl's notions of 'proclaiming' and 'referring', respectively (Brazll 1975)

Whle the meanings identıfied above clearly belong to the less easly identifiable kind, they do satisfy the requirement of being constant across utterances The evident variablity that is encountered in actual data (cf O'Connor \& Arnold 1973) should therefore be accounted for as resulting from pragmatic computations, into which enter such variables as the (textual and situational) context of the utterance, its lexico-syntactic composition, and intonational phenomena that are independent of the nuclear tone itself (such as the height of unaccented syllables, cf Bolinger 1970) This article does not pretend to even begin to approach the problem of the workings of these computations Nevertheless, it would appear to be possible to bring about some order in the wide variety of semantic effects of nuclear tones This can be done by introducing the distinction speaker-serving/hearer-serving and the distinction between literal and metaphorical orientation The first distinction is binary the tone is either speaker-serving or hearer-serving It is discussed in section 4 The second is multiple it is determined by whether the manipulation refers to the Variable (in which case the manipulation is literal) or to some other aspect of the speech situation (in which case it is metaphorical) These aspects, as wll be seen, include the relation between speaker and hearer, the textual structure, and the locution This distinction is discussed in section 5 


\subsection{SPEAKER- AND HEARER-SERVING TONES}

The choice between speaker-serving and hearer-serving manipulations is determined by whether the manipulation is employed for the benefit of the speaker or for that of the hearer. The meanings of the nuclear tones given above acquire a more specific character when this distinction is applied to them: different interpretations emerge depending on which is used. Table 1 paraphrases these meanings, jllustrating them with (is) a unicorn as the Variable. Observe that all uses are literal: the manipulations always refer to the Variable. The following comments should be made:

1. Hearer-serving orientations cannot be made in the absence of a hearer. Speaker-serving orientations may, but need not, be made in the absence of a hearer. In fact, speaker-serving manipulations are often used to let the hearer know what the position of the speaker is with respect to the latest (attempted) update of the background. Often, too, the manipulation may be deliberately ambiguous. When two participants in a quiz game are together trying to guess the answer to the question It's animal, mythical, and often figures in discussions on semantics, an utterance It's a 'UNicorn! by one of them might well be ambiguous between speaker-serving and hearer-serving, the hearer being either the quizmaster or the other participant or both.

2. Observe that in the intonational system there is no marker for a category 'interrogative' comparable to subject-verb inversion in syntax. There are, however, combinations of tone and the 'serving' parameter that produce speech acts that can be described as 'requests for information', independently of the syntactic option 'interrogative/affirmative'. Speaker-serving TESTING addressed to the hearer is perhaps the clearest case: the speaker unambiguously appeals to the hearer to resolve his TESTING, and an answer is required. But also speaker-serving SELECTION can serve as a question. The difference is that because of the SELECTION, the hearer is not so much called upon to resolve the issue as to confirm the speaker's 'discovery' that the Variable is in fact part of the background (cf the examples in Table 1). It would even be possible for ADDITION to function as a question (again, if speaker-serving). In such situations the speaker enables the hearer to give only a perfunctory (dis)confirmation of the 'question'. Because of its lexis, It's a 'UNicorn is perhaps not easily forced into 


\begin{tabular}{|c|c|c|}
\hline & Speaker-serving & Hearer-serving \\
\hline ADDITION & $\begin{array}{l}\text { 'I add this } V \text { to the background for } \\
\text { my own benefit' + } \\
\text { 'I infer this is background' } \\
\text { (Of 'COURSE') It's a 'UNicorn' }\end{array}$ & $\begin{array}{l}\text { 'I add this } V \text { to the background for } \\
\text { your benefit' } \rightarrow \\
\text { 'I tell you this is background' } \\
\text { ('SEE') It's a 'UNicorn' }\end{array}$ \\
\hline SELECTION & $\begin{array}{l}\text { 'I select this } V \text { from the background } \\
\text { for my own benefit' } \rightarrow \\
\text { 'I take note of the fact that this is } \\
\text { (was) background' } \\
\text { ('REALly') It's a 'UNicorn'? }\end{array}$ & $\begin{array}{l}\text { 'I select this } V \text { from the background } \\
\text { for your benefit' } \rightarrow \\
\text { 'I remind you of the fact that this is } \\
\text { background' } \\
\text { (After 'ALL) It's a 'UNicorn' }\end{array}$ \\
\hline TESTING & $\begin{array}{l}\text { 'I choose not to commit myself as to } \\
\text { whether this } V \text { is background for my } \\
\text { own benefit' } \\
\text { 'I ask you/ I wonder } \\
\text { background' } \\
\text { It's a 'UNicorn' } \\
\text { ') depending on whether a resolution } \\
\text { of the manipulation is elicited }\end{array}$ & $\begin{array}{l}\text { 'I choose not to commit myself as to } \\
\text { whether this } V \text { is background for } \\
\text { your benefit' } \rightarrow \\
\text { 'Make up your mind as to whether this } \\
\text { is background' } \\
\text { It's a 'UNicorn' } \\
\text { (e g angry zoo visitor daring an at- } \\
\text { tendant who has just mocked him by } \\
\text { telling him a certain animal is a uni- } \\
\text { corn, to say that again) }\end{array}$ \\
\hline
\end{tabular}

Table 1 The meanings of three nuclear tones with (a) speaker-serving and (b) hearer-serving manipulations ( $V=$ Variable) 
such a context. Imagine, however, a conversation between a boy and a girl - I owe the example to B (1982) - in which the boy says I'm going to Gone with the Wind tomorrow, at the Calley, to which the girl replies

(4) You're going with 'BETsy

The girl knows he frequently goes out with Betsy. With her utterance she tentatively adds the Variable to the background, leaving the boy free to correct it, if necessary, without having to feel that the answer is going to be of any importance to the questioner, who after all, by not using TESTING, never indicated that the answer was really needed for an update of their background. The effect, of course, is that it is now not relevant that it was she who asked the question. The boy can say No, I preferably see such films by myself, without needing to feel as if he is turning down an offer for a date.

3. It may be hypothesised that the frequency distributions of speaker-serving and hearer-serving vary with tone. Speaker-serving may be expected to be less frequent than hearer-serving in the case of ADDITION, but more frequent in the case of TESTING. Observe that hearer-serving TESTING is not restricted to the production of the speech act 'challenging'. It could also be used to 'suggest' (with the Variable of Table 1, this would give us 'How about unicorn as the answer to the question'), or to give gratuitous characterisations of the type occurring in But it's 'TRUE, 'DUMbo.

\subsection{LITERAL VERSUS METAPHORICAL ORIENTATIONS}

Where intonational morphemes of the type we are concerned with differ Importantly from most segmental morphemes is in the extreme flexibility of their 'orientation'. Instead of referring to the Variable (literal orientation), the manipulations may refer to a variety of aspects of the speech situation (metaphorical orientations). The aim of this section is to demonstrate, by means of a number of examples of both literal and metaphorical uses of the three tones, that the relations that were established between the point of orientation and the background remain constant, despite the great variety of interpretations and implications that emerge. ${ }^{5}$ 


\subsection{LITERAL ORIENTATIONS}

Literal orientations are of two types. In the first type, the manipulation refers to the speaker's Variable, in the second it refers to the Variable elicited by the speaker from the hearer. The latter type is referred to below as transferred literal orientation.

\subsubsection{Untransferred literal orientations}

To put the discussion in its right perspective, consider first what may be regarded as a canonical case of literal orientation: the answer to a question for information." In this situation, the manipulation is most likely to refer to the Variable offered.

(5) A: Where shall we take Aunt Annie for lunch?

B: Howard 'JOHNson's

ADDITION is the most reasonable option for a speaker who is merely concerned to commit the Variable to the background in response to the hearer's request to do so. The use of SELECTION would be quite contradictory. B cannot select from the background what $A$ has just unambiguously declared not to be there: A, after all, is concerned to get his empty-restaurant slot filled. At the same time, this explains why B's reply can be well-formed. If Howard Johnson's is the only restaurant in town, B might want to imply 'You know that in our background there only is one restaurant I can fill your slot with, and therefore I am telling you it was already there: Where else could we take her?'. Conceivably, another reason for $B$ to employ this manipulation might have been to signal that A had already asked the question and been given the answer: If $B$ is of a caring and patient disposition and $A$ a geriatric whose memory has deteriorated, (6) would, again, be a possible answer.

(6) Howard `JOHNson's

The use of TESTING would signal that, although B offers the information, he chooses not to add it to the background, possibly because he wishes to allow $A$ to give an opinion on his choice first. The effect is that of a proffer-suggestion: ${ }^{7}$ 
(7) Howard 'JOHNson's?

Observe that it is not claimed that a given combination of manipulation and orientation results in one particular interpretation Just what semantic effect wll be achieved is stlll, as Gunter (1972) and Cutler (1977) observed, context-dependent If in (7) we change the context so as to make it an answer to What's the best restaurant in this place?, (7) might well be interpreted as 'uncertainty' rather than as 'proffer-suggestion', and if we changed it into What's the best restaurant in New York? (7) would be interpreted as signalling 'sarcasm' What is clamed is that such interpretations can ultumately be traced back to interactions between manipulation and context

\section{1.2 Transferred literal orientations}

A somewhat different type of literal orientation occurs in questions In what on a purely intuitive basis - could be regarded as a 'neutral' situation, the manipulations in requests for information do not refer to the Variable in the question, but to (the speaker's appreciation of) the status of the requested bit of information Strictly speaking, this should be classed as a metaphorical orientation, but because of the evident unmarked nature of this situation, the type is classed as a case of transferred Irteral orientation

ADDITION, then, in an utterance like (8)

(8) Have you got 'CHILdren?

does not sumply cause the speaker to put the Variable ' $Q$ have chldren' in the background, but signals that the hearer's answer is going to have to be an addition to the background Example (8) would thus fit quite appropriately in conversations in doctor's consulting rooms, police stations and in who-are you-type quiz games Observe that in (4) we had a case of an untransferred literal orientation There, the speaker was concerned merely to add the question to the background as her contribution to the continuation of the conversation If in (4) we transferred the manipulation to the requested bit of information, we would thereby turn the speaker into a determined interrogator, who, for some reason known only to herself, needed to have the answer, which interpretation would obviously be quite inappropriate (In either case, the question would be speaker-serving ) 
Transferred literal SELECTION might seem an internally contradictory option By asking the question, the speaker signals that he does not know the answer, but by using SELECTION he indicates that the answer is already part of the speaker's and hearer's background In fact, Sag \& Liberman (1975) explicitly characterise this intonation as 'strange' (cf their example 7a) Yet, it is precisely when we create the contradictory situation sketched above that the option becomes possible Example (9) could be spoken to a chld in a 'reminding' fashion, without in the least sounding unnatural

(9) Now where did you put it `YESterday?

which question implies that the answer is really already present in the background However, if WH-questions are to serve as command-suggestions, the intonational morpheme SELECTION should really be avoided, as the contradiction created defies interpretation "I urge you to do $X$ - $X$, in view of your behavlour, not being something you had already thought of, and I remind you of at' That is, the speaker is trying to 'add' the Variable ('command-suggestion') and 'select' it (fall-rise) at the same tume

(10) TWhy don't you go and talk to somebody `ELSE?

But if we move the command-suggestion in the direction of a reminder again, it becomes ummediately less strange for it to have SELECTION If one was giving helpful hints to a child on how best to colour in the sea in his or her picture book, (11) is perfectly natural

(11) Now why don't you use the `BLUE one?

especially if the blue crayon had earlier been used for a sinlar purpose

TESTING with this orientation ought to imply that the questioner does not, as yet, consider that the answer wll necessarly be relevantly part of the background This may, again, seem to result in a somewhat contradictory speech act, but it is in fact far from infrequent If we transpose (8) from a situation in which the speaker was a concerned psychiatrist, probing whether the client's complaints are related to his or her (not) having chuldren (ADDITION) to the office of a civil servant responsible for the granting of welfare benefits, the question might well have criterion-status, in the worst case umplying that if the 
answer is 'no', the interview will be terminated. TESTING with transferred Iiteral orientation would then be a suitable option.

\section{(12) Have you got 'CHILdren?}

Another user might be the participant in a quiz game, who, after drawing a blank on a number of questions with ADDITION, asks another with a rise, in order to imply that now he is at a loss and is probably, again, not going to hit on the right kind of information that will be relevant for a further definition of the background. Not surprisingly, too, the option can have a casual, perhaps even uninterested effect, if it is meant to signal that the answer is really not going to matter one way or the other:

\section{(13) A: I'm going on a 'HOLiday \\ - B: Where are you 'GOing?}

In the analysis presented here, the of ten observed tendency for falls to be more frequent with WH-questions than for polar questions may be related to the tendency for speakers to (pretend to) have a better defined idea of what information they are after when asking a WH-question than when asking a polar question, and accordingly consider it less neccessary to doubt that the information will be relevant for a further development of the background.

\subsection{METAPHORICAL ORIENTATIONS}

\subsubsection{Manipulations referring to the initiation of the conversation}

When a speaker opens a conversation with (14)

(14) `MAry

he is, quite obvlously, not using SELECTION in the sense that he is highlighting the part of the background occupied by Mary: he is not reminding the hearer of her existence. Here, the manipulation refers to the status of the hearer as a participant in conversations with the speaker: it is this that the speaker presents as part of the background. Note that SELECTION is quite inappropriate as an 'initiatory' manipulation if the speaker cannot so take the hearer for 
granted as a participant in discourse, say, if the speaker was a schoolboy and the hearer his headmaster, or, indeed, if his hearer were his pet cat.

If in this same metaphorical usage, TESTING is used, the meaning would have to be: 'I cannot (as yet) commit myself as to whether the initiation of this conversation can be put in a background' or 'I am testing the relevance of my initiating', an option that would obviously be appropriate if the speaker is addressing a sleeping patient who may or may not hear the speaker, or if the speaker is not certain if the intended hearer is in fact within earshot.

MAry?

Again, keeping the orientation constant, a fall (ADDITION) would then mean that the speaker considers the initiation of a conversation with the hearer as an addition to the background: it would create a background where before there was none. We may think of a teacher in a classroom, who, after having asked a question to no one in particular, creates a conversational relation with one of his pupils by saying

(16) 'MAry

\subsubsection{Manipulations referring to the narrative structure}

It is frequently observed in discussions about the functions of intonation that falls signal 'finality' and rises 'non-finality'. An example might be (17):

(17) While John was chattering a ${ }^{\vee}$ WAY like this, she crossed to the other side of the 'ROOM, and took Uncle Laurie's portrait off the 'WALL

The first relation can fairly easily be accommodated in the analysis: the manipulation ADDITION can be said to refer to the textual structure, and to signal that the linguistic unit concerned, a sentence, say, can be committed to the background: It is 'done'. The function of rises to signal non-finality is less clear, however. In the present analysis, the 'rises' referred to in the first sentence of this section must of course be split into two crucially different sorts, 1.e. fall-rises, signalling SELECTION, and rises, signalling TESTING. The 
fact that both signal non-finality must then be a fortuitous similarity of the effects of different manipulations.

If the manipulations are taken as the starting point for the discussion, then, assuming the orientation is 'textual', the following predictions can be made:

1. Use of the fall-rise will signal that the speaker is dealing with a background for some event yet to be mentioned. It would express: 'You with me so far? Now for the main point.' The manipulation would typically not create suspense, but rather define a setting.

2. Use of the rise would signal: 'I don't want to commit this to the background as yet: there's more to come - you've only got half the story so far'. The manipulation would typically be used to create suspense: the hearer is explicitly told that at that point in the narrative he has only got half the information.

Observe how in (17) these predictions are borne out. First consider how the reader would have produced a considerably less competent product, if he had switched the fall-rise and the rise round:

(18) ??While John was chattering a'WAY like this, she crossed to the other side of the 'ROOM, and took Uncle Laurie's portrait off the 'WALL

Observe, secondly, that changing the order of the clauses does not help, for, in the competent reading, the tones move with them, as in (19).

(19) She crossed to the other side of the 'ROOM - and John just continued to chatter a 'WAY to her - and took Uncle Laurie's portrait off the 'WALL

Switching the tones round in (19), again, leads to 'incompetent reading'. (Of course, many situations can be thought of in which the orientation of the manipulation is changed so as to make another tone plausible. A teacher reading (19) to a class might opt for a rise in the middle clause in order to warn certain of her pupils: 'Am I still relevantly reading this to you?' is what she might intend her TESTING to mean. Other cases are imaginable.) 
On so-called 'listing intonation'. Listing intonation, as in

(20) 'BEER 'BREAD 'CHEESE and 'EGGS

is likewise an instance of the use of tones that have the textual organisation as their referent. The speaker chooses not to commit items to the background until the list is complete. As such, listing intonation is not theoretically 'special' in the sense that languages should reserve particular intonation patterns for lists. Put differently, the function of the rises in (20) is the same as that in (21).

(21) And they lived 'HAPPily 'EVer 'AFter!

Bolinger ( $[1958]$ 1965: 55 ) observes that a prenuclear fall is more likely to express 'unexpectedness' or 'newness', and that a prenuclear rise is more likely to be used for things that have already been introduced. This tendency can perhaps be explained as resulting from the speaker's strategy not to 'waste' an unexpected item on narrative-structure orientation, but, in view of its importance, to add it to the background straightaway. Indeed, our so-called 'listing intonation' is less likely if the speaker is making a complaint at the police station about a neighbour's misconduct. In (22) the speaker is itemising the reasons for the complaint:

(22) Loose 'WOMen, 'PONCes, loud 'PARTies, co'CAINE, runaway 'KIDS! You NAME it, they've 'GOT it!

Observe, too, the suggestion of non-finality in (22).

\subsubsection{Manipulations referring to the locution}

Manipulations may refer to the locution in the case of (first or foreign) language learners. Children learning to read may use rises for no other reason than that they are leaving it up to their hearers to say whether they are reading it right. Similarly, foreign language learners may use rises when reading bits of foreign language, leaving it up to their tutors to judge if they are pronouncing it right. Sometimes, this type of orientation may override the presence of particular tones in an imitation task: although the words may be presented with falls, the imitator may perform locution-oriented TESTING, and thus replace the falls with 
rises. Clearly, the use of ADDITION in such situations will inevitably make the imitator sound much more confident of his or her performance.

\subsection{AUTOSEGMENTAL REPRESENTATIONS}

Before we discuss any of the modifications of the three nuclear tones, an excursus on the formal representation of tones is called for. The modifications strongly suggest that the autosegmental approach proposed by Goldsmith (1976) and Leben (1976) (also adopted and developed in their own ways by Liberman 1975, Pierrehumbert 1980 and Ladd 1983) lead to far more insightful formulations than representations like 'fall', 'rise' or ', ', (however useful these devices are notationally) allow. In an autosegmental description of intonation, the segmental (CV) tier is formally separated from the tonal tier. Rules that operate on segments on either tier have - unless special provision is made to the contrary - no effect on the segments on the other tier: the two remain distinct until the event of articulation causes them to co-occur. The timing of the articulation of the two tiers relative to one another is defined by mapping rules specifying the necessary associations between segments on different tiers. Notationally, these take the form of association lines. Mapping proceeds according to both universal conventions and language-specific conventions or rules. There is some controversy over what the correct universal mapping conventions are (Halle \& Vergnaud 1982), but, for our purposes, we may adopt Goldsmith's Well-Formedness Condition (1976: 27), which states (a) that association lines do not cross, and (b) that mapping must be exhaustive: that is, all segments on both tiers must be associated. In addition, the association of certain segments is uniquely defined by means of the asterisk convention. Asterisks specify the accented syllable on the segmental tier and the tonal segment on the tonal tier that is to be associated with it. If there are more syllables than tonal segments, certain tonal segments will spread.

We here assume as a convention that - unless provision is made to the contrary - only unstarred tones can spread. (Cf. Pierrehumbert's tone spreading rule for 'phrase accents', 1.e. tone segments coming after the starred segments, which is responsible, for example, for the formation of a mid plateau between the nuclear and the final syllable in a post-rise tail, or a low plateau between these syllables in a post-fall-rise tall $(1980: 220)$.) Thus, if on the segmental 
tier we have the two morphemes tier and autosegment and on the tonal tier the morpheme HL, we get the following results: ${ }^{10}$
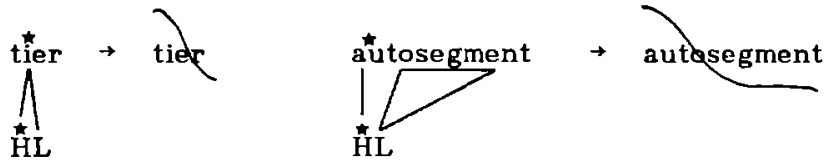

A preference for an autosegmental framework need not only be based on the fact that the independence of the tonal tier is explicitly part of the theory, rather than some, perhaps self-evident, but unexpressed assumption. The chief justification is that the framework admits of the formulation of significant generalisations that cannot be insightfully captured if pitch movements are labelled and classified as purely phenomenal concepts. Just as calling a spade a spade may be bad advice when one is dealing with the phonological (voiceless) status of Canadian English / $t$ / as well as with its phonetic (voiced) status in a word like writer, so one must be prepared to see a morpheme that, for good reasons, is classified as a 'fall', actually turn up as a rise on the surface. One example of this happening is when a fall on a non-final syllable is delayed: when we restrict our attention to the accented syllable, we may just observe a rising pitch movement there, instead of a rising-falling one, as in the case of an undelayed fall. Yet both contours represent instances of the fall. Another example will be discussed in the section on tone linking.

The above comments on the separation of a phonetic level and a more abstract morphemic level, bring out what I perceive as the most important difference between previous autosegmental descriptions of English intonation and the present proposal. Ours bears a greater resemblance to the conventional treatment of segmental phonology. Thus, more or less abstract representations of the same linguistic structure are possible, depending on the extent to which we allow the underlying options to be implemented on the $F \emptyset$ contour. The description is therefore in sharp contrast to that given in Pierrehumbert, who says in her introduction: 'In other languages [than English] rules which alter tonal values or delete tones can apply to such a [phonological] representation. English appears to lack such rules, with the result that the underlying and derived phonological representations of intonation are identical' (1980:11). Although we should be careful not to jump the gun with respect to the description that is to follow, an illustration will make the difference in approach clear. A contour like (24) (e.g. You can't ask John to accompany MAry...) : 


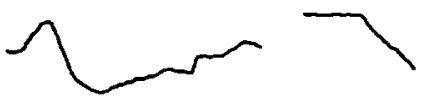

John will want to go with Pamela

is derived by postulating two accents, one on John and one on Pam- (This contour and those reproduced in Figures 1 and 3 were obtained with the help of the program SIFT in the ILS package) For these accents the morphemes 'fall-rise' and 'fall', or HLH and HL are used, respectively. If no other options applied, the contour would be realised as (25).

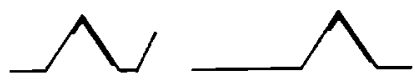

To the second accent, however, the modification 'half-completion' has applied, causing the tal -ela to be realised at mid level ( $\mathrm{HL} \rightarrow \mathrm{HM}$ ). The optional tone linking rule (discussed in section 10) then applies so as to delete the final $\mathrm{H}$ of the first tone and to produce a gradually rising slope from (wi) 니 to Pam-, as in (26), the diagrammatic version of (24).

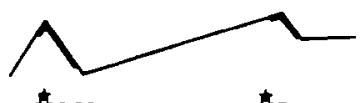

$$
\text { HLH HL +TONE LINKING }
$$

In Plerrehumbert's model, the contour would be generated at one go (presumably as $\mathrm{H}^{\prime \prime} \mathrm{L}-\mathrm{H}^{\circ} \mathrm{H}^{\prime+}+\mathrm{L}-\mathrm{H}-\mathrm{L}_{0}^{\circ}$ ). In short, in our approach intonation is a full-fledged linguistic subsystem by the side of the segmental subsystem (syntax/lexis).

\subsection{MODIFICATIONS}

The fall, the fall-rise and the rise are the three basic nuclear tones of English. Other nuclear tones are created by modifications of the basıc tones. Like tones, modifications should be seen as morphemes. That is, a modification is semantically constant across tones. As wull be shown, the phonetic specification, too, can be sald to be constant across tones. Observe that this formulation implies that for any one tone varıant encountered in any data, there wlll have to be two 
further variants, representing the other two tones under the same modification: tones thus always come in sets of three.

There are naturally limits to the ways in which nuclear tones, which are basically 'Gestalts' or 'configurations' (Bolinger 1951), can be modified without being altered beyond all recognition. As it is, the formal changes that do occur may seem quite drastic.

There would appear to be four (phonetic) variables that could be exploited:

1. Timing:

The association of the tone with the text can vary as a function of time. The modification based on this variable will be discussed as the modification delay.

2. Stretching: The tones can be extended in time by lengthening the syllables onto which they are mapped. This type of variation is exploited by the modification stylisation (Ladd 1978). It will be seen that the phonetic specifications per tone have to be more detailed than in the case of delay.

3. Completion: The tones can be clipped so as to prevent them from carrying out their canonical, unmodified trajectories: the movement is prevented from crossing the mid level. This modification will be discussed as the madification half-completion. The modification would seem to be less frequently discussed in the literature than either delay or stylisation.

4. Shrinking: The excursions of the tones can be reduced in size, and be carried out closer to the baseline. This variation is not in fact employed in the way the other three are. It is more clearly of a gradient nature than the others, and, more importantly, cross-cuts the others in the sense that all four modificatory states (three modificatlons and absence of modIfication) are specifiable for this variable. It will be discussed in a separate section as the variable range.

In addition, there are more subtle (and less frequent) ways of exploiting the timing parameter, such as the tempo-differentiation used by the modification crescendoing, mentioned in section 9 . 


\subsection{DELAY}

The modification delay postpones the association of the tone with the text." Delay has recently been independently claimed as a 'peak feature' by Ladd 1983. It is emphasised that delay is here seen as an operation on tones, not on peaks." Indeed, as will be argued, it affects the rise as much as it does the fall and the fall-rise. If we represent the fall, the fall-rise and the rise as HL, HLH and LH respectively, it is more immediately clear what the effect of delay is. In the unmodified case, the starred element is associated with the nuclear syllable, and following elements are associated as follows: the $L$ spreads to the end of the tail, with the exception of the last syllable in the case of a following $H$, which is reserved for that syllable; the $H$ in $L_{H}$ spreads over the tail, such that the first syllable of the tail is higher than the nuclear syllable and no following syllables are lower (but may be higher). The representation of the delayed fall is now not LHL, as in Leben (1976) or Pierrehumbert (1980, e.g. Fig. 2.22), but remains HL: the association of the starred element is simply shifted to the right (and with it the association of the following element, of course). Note that the starred element does not 'spread': it is its association target that is shifted. Similar descriptions apply to delayed fall-rises and rises. In (27) the unmodified associations are given, in (28) the delayed ones.

(27) UNMODIFIED

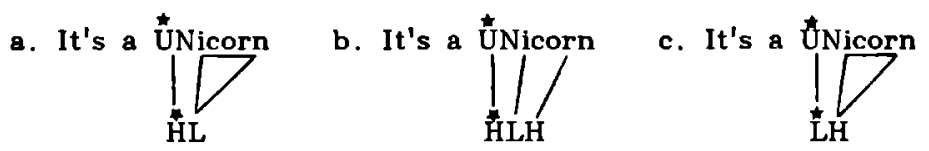

(28) DELAY

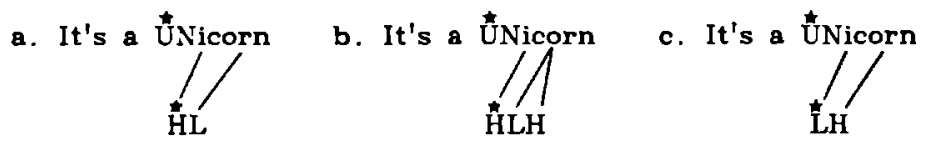

Thus, in (28), (a) is the rise-fall, (b) the rise-fall-rise and (c) the delayed rise, a nuclear tone (variant) I have not found discussed in the literature. It is to be noted that the place of the nuclear syllable in the contour in the case of delayed tones may be marked by a depression if the prenuclear stretch has mid 
or high pitch. The three delayed variants of the three basic tones are symbolIsed as $\wedge, \sim$ and $\sim$ below.

The meaning of the modification delay is: 'This manipulation is very non-routine, very significant', which meaning agrees well with comments about the effect of the rise-fall (and the rise-fall-rise) that are found in the literature (e.g. O'Connor \& Arnold 1973: 78-82, Gimson 1980: 271).

In the autosegmental literature it is normally assumed that there are 'tone-bearers' on the segmental tier (vowels, syllables) with which the tones can be associated. However, the phonetic facts suggest that the association target does not jump in blocks that can be defined in terms of units on the segmental tier. Rather, they move to points in the time domain that have to be specified considerably more precisely. For example, the delay of the association relative to an idealised unmodified value may be varied independently of the size of the units on the CV tier, as illustrated in (29).
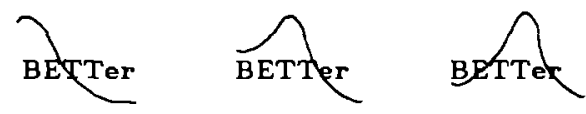

This also suggests that while there may be an 'ideal' target for delay (say, one syllable after the nuclear one if there is one), delay is a gradual modification. For British English, at any rate, it has been observed that the position of the rise-part of the 'rise-fall' may vary (cf O'Connor \& Arnold's representation of the rise-fall, 1973: 9), and this observation in implicit in analyses that postulate a 'fall-rise-fall' by the side of a 'rise-fall' (Crystal 1969: 218), the former being an 'intensification' of the latter (Crystal 1975: 39). Thus, for (30), contours with different degrees of delay are possible. Interestingly, the degree of the meaning of the modification (non-routineness) would appear to correlate with the degree of delay:

(30) I most ^CERtainly believe this is true

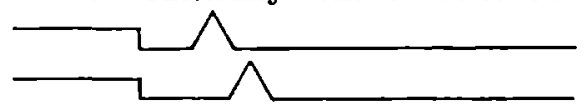

It may be that the 'ideal' position for delay was different in certain circles in Britain some time ago. Today, a delayed fall-rise on Rather! would probably come out as (31a), but (31b) apparently represents an upper-class pronunciation of the exclamation meaning 'Yes, very much so'. The usage is old-fashioned. It is used by actors portraying early twentieth-century charac- 
ters (for instance, in the BBC television dramatisation of Evelyn Waugh's Brideshead Revisited).

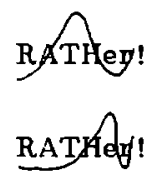

Its survival may well be due to the fact that the use of rather in this meaning has gone out of fashion. Observe that if we did not postulate delay as an independent modification, this one word would add yet another nuclear tone to the inventory of British English.

A delayed rise can similarly be delayed to a greater or lesser extent, as in (32), which is assumed to be spoken by a police interrogator. In it, the degree of non-routineness and the degree of delay increase proportionately.

(32) So you have never -MET Julio Ignacio?

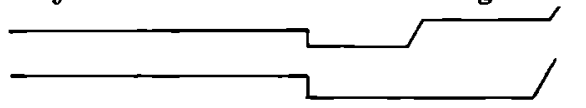

As will be clear, the meaning here is: 'I am leaving it up to you to decide whether the Variable really belongs to our background, and I consider giving you this option (very) significant'. As suggested by (32), delayed rises may occur in (humerous portrayals of) conversations where the intended suggestion is: 'We have ways of making you talk'. A quite different use may be found in speech to children, in which delay generally seems more frequent than in other types of speech. The explanation for the 'significance'-morpheme here lies presumably in the adult speaker's concern at getting through to the Inexperienced, and possibly inattentive, language user, as in (33).

(33) (to sobbing child) Would you rather have your -MUMmy take you to the hospital?

Note that patterns like these can never be mistaken for fall-rises. This is because of the absence of the $\mathrm{H}$ segment. A tone cannot be shifted to the left: any fall-rise must have its $h$ after the beginning of the starred syllable, never before it. The hump caused by the association of the midway through the syllable, though frequent, does not appear to be an essential feature, however. Halliday calls a humpless 'fall-rise' a 'pointed fall-rise', tone $\underline{2}$ in his system (oddly classed as a variant of the rise, tone 2 , rather than as a varaint of the 
fall-rise, tone 4 , see e $g$ Halliday 1970 17) In the case of the fall, the hump does not appear to be an essential feature, either (Willems 1982 86) Uldall (1982) suggests that it may have attitudinal significance

\subsection{STYLISATION}

The modification stylisation is taken from Ladd (1978), in which two umportant points are argued for

1 The 'Type I call contour' (Abe 1962) or the 'vocative chant' (Liberman 1975), as in

$$
\text { John--- }
$$

is a stylised variant of the fall in the same way that the level tone (Crystal 1969) or Mid-Level tone (O'Connor \& Arnold 1973), as in

(35) They were all 'THERE -BILL, MAry, JoHNny

is a stylised variant of the rise

2 The meaning of stylisation is 'This is a matter of everyday occurrence/routine'

The tone in (34), therefore, does not signal that the speaker is calling the hearer, as had been widely assumed (cf Gibbon 1976 276), but that the act of initiating a conversation with the hearer is presented as a matter of routine by the speaker As Ladd points out, whlle there is no denying that (34) would appear to be frequently used in situations where speaker and hearer are some distance apart, this is not the decisive factor (cf his contrast between Look out for the broken $=$ STEP and " $\underline{\text { Look out for the cre }}$-VASSE', where the latter was assumed to be uttered in a non-routine situation)

Simularly, Ladd claums that the level tone signals 'routineness' Crystal (1975 38) in fact also notes 'an implication of routıneness', although he gives 'absence of emotional involvement' as the more general characterisation (cf also Brazl et al , 1980) He postulates no connection with the rise, however 
If we adopt Ladd's interpretation of the call contour as the stylised fall and the level tone as a stylised rise, ${ }^{11}$ we are left with a gap in the paradigm for the stylised fall-rise Pierrehumbert (1980) in fact makes reference to a stylised fall-rise, there said to be identical with the stylised fall except for the high boundary tone ( $\mathrm{H}^{\circ}$ in her notation) The tone may be a less frequent option It is not uncommon, however, in the vocabulary of children

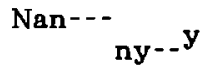

This should be interpreted as 'I, as is now a matter of routine (stylisation), want to initiate a conversation with you (vocative), whose participation I am taking for granted (fall-rise) ' The symbols,$--{ }^{-}$and ${ }^{-}$wll be used for the stylised fall, the stylised fall-rise and the stylised rise, respectively

Another usage of the stylised fall-rise may be more subtle Utterance (37) was spoken (the name of the street has been changed) by a wornan speakmg on the telephone to a close friend, who had apparently just expressed her surprise over the fact that the speaker intended to make a long trip to city $X$ for what appeared to her insufficient reason Utterance (37) was used to suggest that an important additional reason for the trip was a visit to a boyfriend who lived in Park Road

(37) I'll also go to Park - ROAD

The option 'stylised fall-rise' was obviously employed to suggest that the fact that the boyfriend lived there was well-known to the hearer (SELECTION) and that the speaker's visit there should be regarded as a matter of routine (stylisation)

The phonetic implementation of stylisation necessitates the postulation of some such concept as 'fusion' In the case of LH the two segments fuse as [M] For HL, fusion is partial both segments are allowed to creep up towards the midline, but they do not coalesce The realisation could be represented as [ $\left.\mathrm{M}_{\uparrow} \mathrm{M} \downarrow\right]$, where the arrows are used to indicate intermediate values ('raised mid', 'lowered mid') There is some evidence (see below) that fusion of HLH leaves LH unaffected $[\dot{M} \uparrow L H]$ Two further points should be noted $\dot{M}$, unlike $H$ and $L$, does spread In the case of the rise, the $M$ spreads all the way to the end of the tall, whle the $M \uparrow$ of the fall and the fall-rise is associated not just with the nuclear syllable, but also with any unstressed syllables ('weak vowels', Gimson 1980 
226, or 'reduced vowels', Bolinger 1981), except the last (cf Leben 1976). Secondly, syllables are lengthened.

(38) STYLISATION

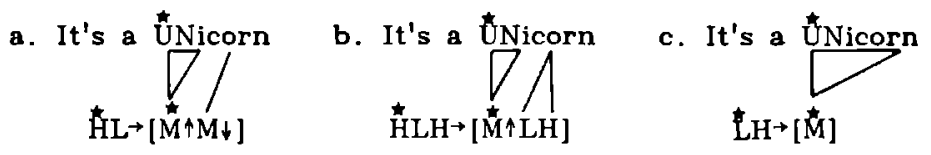

The contour in (38) b. is based on the results of $F($ measurements of seven pronunciations of the tone by a speaker of British English. It is on this basis that we do not follow Pierrehumbert's suggestion and give it with a $L$ rather than a $M \downarrow$, unlike the stylised fall. Synthesised versions of the nine tones have been used in a multidimensional scaling experiment. The results of this experiment strongly suggest that a single dimension can be interpreted, with delay at one end, 'unmodified' in the middle, and stylisation at the other end, representing a psychological dimension of 'routineness'. The results also suggest that there is a stable relationship between the fall and the stylised fall, just as there is between the fall-rise and the stylised fall-rise. For details see Gussenhoven (1983b).

\subsection{HALF-COMPLETION}

Phonetically, half-completion is defined as the failure of the tone to cross the midline: $\mathrm{HL}(\mathrm{H})$ becomes $\mathrm{HM}(\mathrm{H})$, and $\mathrm{L} H$ becomes $\mathrm{LM}$. The phonetic and/or semantic effects of this modification are much less frequently discussed in the literature than those of either delay or stylisation. The first reference is Uldall (1961), who notes that a fall from high to mid 'makes a "yes" unconvincing and uncommitted as opposed to a "yes" falling all the way to the bottom of the range' (cf Gibbon 1976: 135). Crystal (1969: 147,224) discusses the opposition between unmodifled and half-completed falls in terms of contrastivity in the tall as opposed to contrastivity in the nuclear syllable. Observe that the autosegmental position adopted here rules out such 'local' interpretations of pitch phenomena in the tail, and must instead assume that these result from operations on the nuclear tone itself. Half-completed fall-rises are given by Crystal (1969: 218), there analysed as 'high' (a simple pitch range variable) and 'narrow' (a complex pitch range variable) fall-rises. I have no unambiguous references to half-completed rises. Indeed, in the present analysis, the notion of a separate tone-variant 'half-completed rise' by the side of an ordinary rise with non-high 
range (see next section) may seem to create some embarrassment for the description, since in both cases a rise from bottom to middish is produced: in the one case because the tone is not completed, in the other because it was never 'intended' to go any further in the first place. It turns out, however, that the two tones are clearly distinct. The half-completed rise begins in or inmediately after the nuclear syllable and rises briskly to the midline, from which point the pitch is sustained at that level for any following unaccented syllables. The low-range unmodified rise rises in the syllable after the nuclear tone (or later in the nuclear syllable if there are no unaccented syllables after it), while the slope is gradual rather than steep, and may stretch over the entire tail (for illustrations see Figure 1.) Durational differences apart, the half-completed fall and the stylised fall are distinguished by the spreading of the fused $M \uparrow$ to post-nuclear weak syllables, as opposed to no spreading of the starred tone of the half-completed fall. In monosyllables, the stylised fall, but not the half-completed fall, is characterised by the well-known two-plateau contour.

(39) HALF-COMPLETION
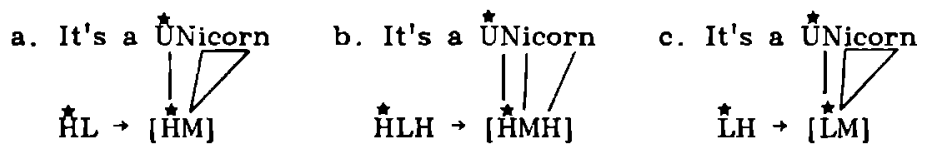

In spite of the obviously all-or-none nature of the opposition between half-completion and stylisation, it is hard to see how this opposition is parallelled by an equally clear-cut semantic distinction. Rather, it would appear as if, semantically, half-completion is somewhere between 'unmodified' and stylisation on the same scale of routine/non-routine. By using the morpheme half-completion, the speaker signals to his hearer that the latter should take the Variable as one that the hearer might somehow have expected, and that it should therefore come as no surprise to him. 'This is my Variable, but please don't make a big thing of it', might be a suitable paraphrase. Often, the effect is one of non-seriousness or light-heartedness, but in other contexts the modification may express perfunctoriness, or lack of interest or conviction. Note that all of these effects can be traced back to the meaning given above. Half-completed tones will be symbolised by placing the diacritic [=] before the symbol for the unmodified counterpart.

An example of a half-completed fall, expressing 'Add this to our background, but consider the addition as for-the-record only' is given in (40). 


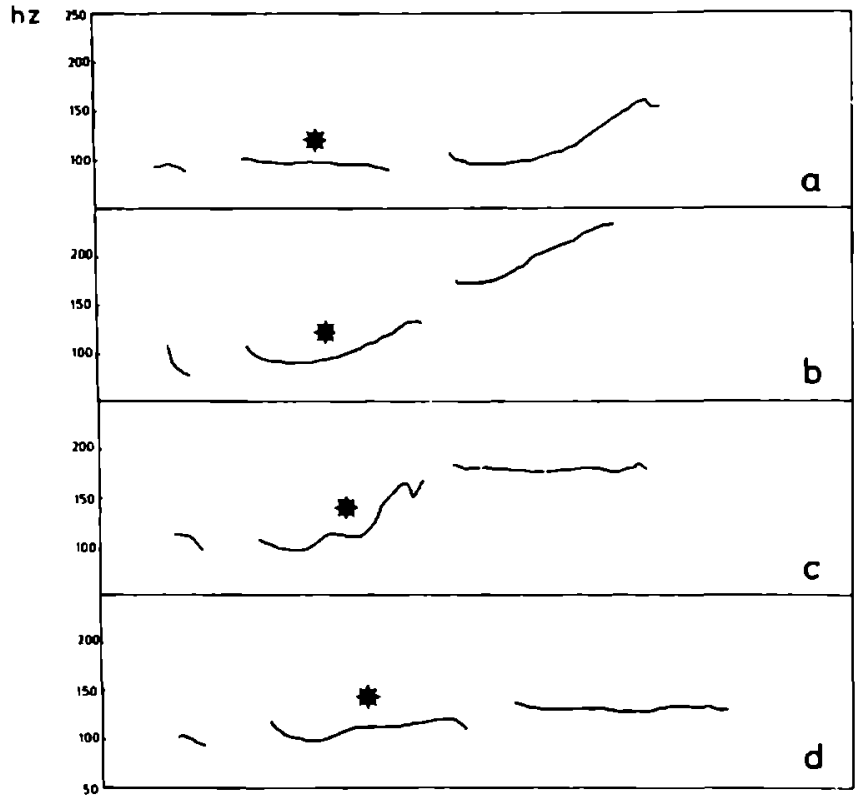

Figure 1. Delayed (a), unmodifled (b), half-completed (c) and stylised rise (d) on 'It's a UNicorn'. (Ranges not equivalent.) Speaker PH.

(40) ='I'LL get it!

spoken in reaction to the ringing of the doorbell or telephone. Another is (41), where the modification sounds pleasantly informal, because the ADDITION is not presented as a favour but as something that follows naturally from the situation (with high-pitched please).

(41) Please sit $='$ DOWN

Possibly, this is also the variant described by Leben (1976) as conventionally used by, for example, train conductors:

(42) Next stop = 'OTTawa! 
The tone is described by him as HMM, and is explicitly distinguished from the 'regular' call contour (the stylised fall), which is HHM in his notation.

Half-completed fall-rises, expressing 'This is (now) our background, but I'm not forcing the point ${ }^{\prime}$, are frequently used to signal a note of playfulness. Example (43) might be the lighthearted termination of a none-too-serious difference of opinion between speaker and hearer.

(43) But it's = ${ }^{\sim T R U E !}$

while (44) could be used as a cooperative adult's response to a child pretending to hide or run away.

(44) I'll =`GET you!

Observe that stylisation in these contexts would give too much weight to the meaning 'routine'. Example (43) might be interpreted as a taunt, and In (44) it might undesirably emphasise the overtone of pretense.

Half-completed rises are similarly used in contexts in which the stylised rise (the level tone) would emphasise the routineness too heavily. Observe that although the phonetic difference is slight, the difference in effect is unmistakable. Example (45) could be spoken by a form-filling clerk, entrusted with the initial processing of a fresh levy of conscripts.

(45) $\ldots$ Are you ='MARRied. . .ever been to see a psy='CHIatrist... is there elephan='Tlasis in the family ...any ='OTHer hereditary diseases... $=$ NEXT please.

Note how in this context unmodified rises would increase the impression of genuine interest on the part of the clerk, and that stylised rises would increase the effect of routineness. Precisely the same relationships hold if the speaker does not require resolution of his TESTING.

(46) I don't under'STAND. The ='POWer's on...there's ='FEED in the hopper... I've set the ='GRAIN switch... Should I'KICK it? 
The modification half-completion has a semi-conventionalised use in the speech of speakers who do not wish their speech to be overheard by third parties Low-volume speech, if used for this purpose, is frequently half-completed

(47) (e g whispery volce) You've got the ='GUN ready? Sh' Here he ='IS He's a='LONE Can you $=`$ SEE hım?

The explanation for this use of the modification may be that the meaning 'not make much of a point of the manipulation' is extended to apply to physical distance It is as if the speaker does not want the point to be made anywhere other than in the restricted physical area where he and his hearer carry on their exclusive conversation (The reverse does clearly not hold shouted speech may also be half-completed )

\section{RANGE}

Range is here interpreted as a gradient variable, which is specif iable independently of tone and modification That is, all twelve tones (tone variants) discussed so far are continuums on a phonetic scale ranging from 'carried out close to the baseline' to 'carried out with maximal excursion above the baseline', as Illustrated in Figure 2

In order not to confuse the effects of range with that of the modification half-completion, the terms 'low-range' and 'wide-range' wll be used to refer to the ends of the scale, rather than 'low' and 'high' or 'wide' and 'narrow' Terms like 'high rise', 'low fall' wll continue to be used if they are used by the authors of work discussed here Observe that whatever touches the baseline in the low-range variant, does so in the wide-range one, and that what does not, is higher above the baseline in the wide-range variant than in the low-range one Thus, the stylised rise (or 'level tone') is placed higher in the pitch range as the range is wider

There are frequent suggestions in the literature that range is not a gradient variable, but a set of two or three categories For example, O'Connor \& Arnold (1973) postulate two variants for the rise and the fall, high and low, and Brazl (1978) postulates three keys, high, mid and low (which are applicable not just 


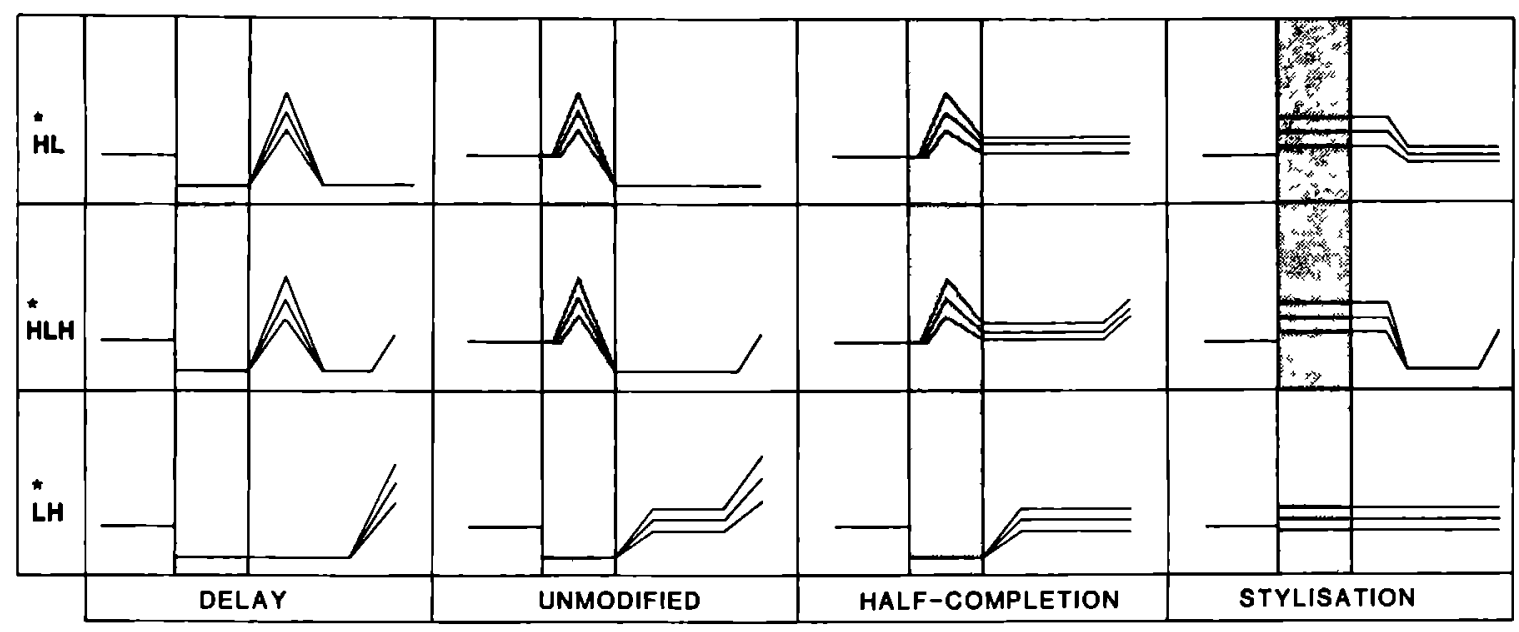

Figure 2. Diagrammatic representation of the effect of the variable 'range' on twelve nuclear tones (e.g. 'It's a UNicorn'). The shaded area represents the accented syllable. 
to the nuclear tone, but rather to the first accented syllable of the tone group). With respect to the meaning of range rather disparate comments can be found in the literature. Brazil (1978: 8) classifies the low rise as a 'neutral' tone (together with the level tone), signalling a 'withdrawal from the interactive situation'. Ladd (1980:111), who considers range gradient in the case of the fall and the fall-rise, but all-or-none in the case of the rise (i.e. the low rise and the high rise are taken as separate categories), notes that answers to WH-questions sound 'self-assured' if they have a low rise, but 'hesitant' if they have a high rise, and that effirmative sentences are 'questions' if they have a high rise, but 'contradictions' if they have a low rise. O'Connor \& Arnold give a number of more specific characterisations, like 'soothing', 'genuinely interested', 'alry' etc., depending on the type of sentence the tone combines with.

It may well turn out to be convenient to recognise categories on the range continuum that represent clearly distinguishable semantic effects in the case of certain tones. However, as a theoretical option, range is clearly gradient. Certainly phonetically, there is no question that range represents a continuum, as is evident, for example, from the experiment Pierrehumbert (1980: 119) did for the fall and the fall-rise. It is hypothesised that the meaning of range is insistence on the meaning of the manipulation (cum modification, if any): the speaker signals a greater degree of insistence om the meaning expressed by the tone as the range is greater. To take a straightforward case:

(48) I said come 'HERE

Example (48) represents a more forceful command as the span of the fall is wider.

While it is not difficult to draw a distinction between the everyday notion of 'insistence' as a speaker intention (in the sense of the speaker insisting on some kind of adequate response, verbal or otherwise, on the part of the hearer) and the notion of 'insistence on the meaning of the tone', as introduced here, it may not be immediately clear how the latter notion should be distinguished from the semantic scale 'routine' - 'non-routine' on which the four madificatory states of the three tones are placed. It could be argued that the extreme ends of the scale produce, by their very nature, 'insistent' variants of the three tones, e.g. ' $\mathrm{X}$ is very non-routine'. How then should the semantic relationship, re- 
presented graphically in (49), be understood?

(49)

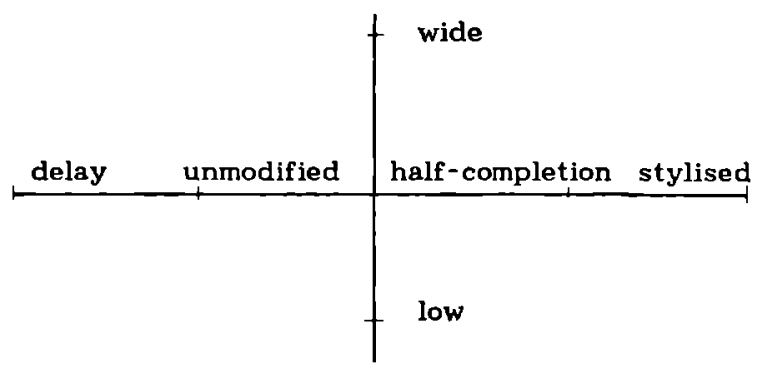

Intuitively, the difference between a wide fall and a low fall and that between a wide fall and a wide delayed fall ('rise-fall') are not on the same level. And the same goes for the former difference and that between, say, a wide fall and a wide stylised fall ('call contour'). The representation in (49), and more generally the theoretical framework presented here, enable us to formulate this intuition meaningfully. The answer to the question why the above contrasts do not seem to be of the same order is that modifications add a meaning element to the manipulation, and that range enhances or reduces the satiation of that meaning (manipulation) or those meanings (manipulation and modification). To give an example, if in (50) the speaker uses an Increasingly wide range for the sequence of falls on John, he is merely increasing the effect of his meaning 'I am adding the initiation of a conversation with you to our background'.

$$
\text { JoHN, JoHN, ЈoHN! }
$$

If a reply continues not to be made, he may choose to change his strategy: If he knows the hearer can hear him (because they are in the same house, say), he might indicate that his speech act has (by now) become a matter of routine, and switch to stylisation, and - if he is optimistic enough - repeat it with wider range:

(51) \онн, ذонN, ЈoHN, =JoHN, ־онN1!

Alternatively, If he doubts whether the hearer can really hear him, he can change his manipulation from ADDITION to TESTING, and again, if undeterred, repeat it with wide range:

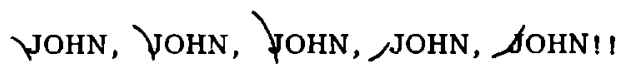


What this is meant to illustrate is that there are clear shifts of meaning with the change of either the modification or the manipulation, but that only greater intensities for those meanings are introduced as the range is increased in width.

When this prediction is checked against the data presented in $\mathrm{O}^{\prime}$ Connor \& Arnold, it appears that the characterisations given for the low fall violate it. WH-questions with a low fall, to take one example, are said to be 'searching' 'serious', 'intense' and 'urgent', while with a high fall they are 'brisk', 'businesslike', 'considerate' and 'not unfriendly'. It turns out, however, that these meanings importantly depend on the lexis of the WH-questions concerned. In our analysis, the fall expresses that the answer is considered a relevant addition to the background. It is significant that of the five examples for the 'low fall' given by O'Connor \& Arnold (1973: 47) four do not really seem to require the hearer to give an answer: the addition of the Variable is not insisted upon.

(53) Now where did I put my \PIPE

(54) Why did you $、 D O$ such a thing

(=I think that was a stupid thing to do [CG])

(55) Why don't you 、LOOK where you are going (=Look where you are going [CG])

(56) How can I TTHANK you

( $=I$ know this is a silly question [CG])

One example concerns a question that does require an answer, but presumably the speaker feels that here insistence on the ADDITION is unnecessary:

(57) What can I get you to \DRINK?

By contrast, the examples given for the high fall (1973: 55) much more clearly require an answer:

(58) What's the 'TIME?

(59) When did you ar'RIVE?

(60) How long did it take you to 'GET there?

(61) Where on earth have you 'BEEN all this time

It is in combination with rises that range would appear to be capable of producing the most dramatic semantic effects, which is reflected in the frequent postu- 
lation of the low rise and the high rise as separate tone categories (Bing 1979, Ladd 1980). Our analysis predicts that a low rise expresses a low degree of insistence on the meaning TESTING: it signals that the speaker not only leaves the background status of the Variable open, but also refrains from forcing the hearer to resolve the issue. It is suggested that it is this distinction that lies at the basis of contrasts between high and low rises. For example, the 'self-assuredness' that Ladd (1980: 111) notes as the effect of the low rise in answers to WH-questions, as in (62), is due to the fact that the speaker considers the hearer's comment ultimately unnecessary ('Is that good enough for you ?').

(62) A: Where did you get your de'GREE?

B: Cor, NELL

The 'hesitancy' which Ladd says is signalled by a high rise in this same dialogue, is the effect of the speaker's submission to the judgement he invites his hearer to give. He now actually invites the hearer to give an answer to the question 'Is that good enough for you?'.

Simllarly, the 'genuine interest' noted by O'Connor \& Arnold as the effect of the low rise in yes/no-questions seems due to the fact that the speaker signals that the resolution of the TESTING does not have to be provided, but that it would be nice if it was. This 'genuine interest' will predictably disappear if the speaker signals a high degree of insistence on his TESTING. Also, this interpretation provides the solution to the problem addressed by Sag \& Liberman (1975), who wonder why it is that Would you stop hitting 'GWENdolyn? tends to be taken as a genuine question when it has a high rise (e.g. spoken by a psychlatrist: 'If I were to give you this new therapy...'), but as an indirect speech act (command-suggestion) when it has a low rise. In the latter case, the speaker is not really interested in the hearer's opinion. The manipulation is employed for the hearer's benefit only: the speaker merely 'invites' the hearer to add the 'answer' to the background himself. Note that this speech act is pragmatically very 'insistent' in the sense of being an effective way of conveying a command. What I am concerned to point out is that this effect is created by the speaker's non-insistence on the resolution of his TESTING. Needless to add, a high rise, again, does insist on such resolution (and is speaker-serving), and leads to the interpretation 'real question'. 
Note, finally, that inasmuch as a low-range rise signals that the speaker leaves the background status of the Variable open, but at the same time refrains from forcing the hearer to resolve the issue, this tone variant is eminently suitable for gratuitous characterisations, such as epithets. In (63) and (64), the speaker is concerned both to make the hearer feel he is free to agree or disagree with the characterisations given (the Variables have not been committed to the background) and to excuse him from openly coming down on elther side (the low range signalling that he need not bother to resolve it).

(63) It's 'JOHN, the stupid, BAStard

(64) It's 'JOHN, the poor, SOUL

(For arguments why epithets, unlike vocatives, are assigned nuclear tones, see Gussenhoven, in press).

Range, like other intonational options, can have a syntactic effect. For example, in sentences of the type It's A, not B, the speaker may use ADDITION for both clauses. If he does, he is likely to give the main point of his statement the wider fall (It's $A$ ). If he now adds a third term (It's $A$, not $B, C$ ), the range of the fall on $C$ will in effect behave like a structuring device: If it is appositional to the main point $(\underline{A})$, it will share its wide range, but if it is appositional to the minor point (B), it will have a low-range fall. Thus, in We need a man who's got 'COURage, not a 'COWard, a man with 'KETso, the nonsense word ketso can be made to mean either 'guts' or 'cowardice', depending on the range we use. Note that it would be uninsightful to say that intonation has a 'syntactic function', just as it would be uninsightful to say that it has a 'lexical function': the structuring behaviour of range here is caused by the meaning of range (degree of insistence on, in this case, ADDITION). Whichever term $C$ agrees with for this meaning will agree with $C$ in range.

\subsection{COMBINING MODIFICATIONS}

The twelve nuclear tones that are generated by applying the four modificatory states to the three basic tone categories fall, fall-rise and rise do not exhaust the inventory of well-formed nuclear $F$ contours, even when the continuous variable range is taken into account. Some, which seem extremely rare, must 
be accounted for by postulating further modifications (e.g. crescendoing). For others, however, we do not need to postulate additional intonational units tones, modifications or other variables. The contention is that all tones can be described in terms of our framework, and importantly, that this framework adequately expresses the correlation between complexity of formal representation and the complexity, or 'markedness', of the linguistic event it describes. ${ }^{12}$ Thus, an unmodified fall is in an intuitively convincing way less 'marked' than a delayed fall or a half-completed fall, which intuition is formally expressed by the specification of a modification for the latter two tones. Although the postulation of a single semantic dimension 'special-routine' would appear to suggest that modifications are mutually exclusive (such that a tone cannot be both stylised and delayed, for instance), this is not in fact a prediction that the framework should be interpreted to make. Rather, it predicts that such tones are heavily marked: they must be specified for two modifications. This linguistic complexity is reflected in the fact that these tones are semantically rather loaded, as well as in the fact that not all speakers may feel they should go in for them. A likely assumption is that they are typically used by speakers who are on fairly familiar terms with their hearers. As an example, consider (65), which is a fall combining the semantically extreme modifications stylisation and delay. Delay is evidenced by the low-pitched nuclear syllable, stylisation by the two plateaus characterising the stylised fall.

(65) It's a ǗN i corn!

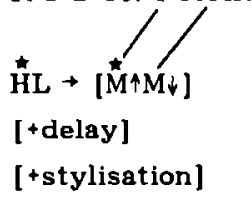

The example could occur in motherese: with it, the speaker offers the solution to a problem in a mock guessing game played with a child in its prelinguistic phase, as in a peek-a-boo situation. Here, the delay signifies that the speaker considers it important that the child should pay attention to this addition to their background, and should try to remember it the next time the question comes up. At the same time, however, she wishes to impress it upon the child that this should be an easy task, i.e. that the fact the object is called a unicorn is a matter of routine (stylisation).

Delay can also be combined with half-completion. In (66) both modifications have 
applied to the fall.

(66) It's a ÛNicorn

$$
\begin{aligned}
& \mathrm{HL} \rightarrow[\mathrm{HM}] \\
& \text { [+delay] } \\
& \text { [+half-completion] }
\end{aligned}
$$

Example (66) could be used by someone establishing the nature of the contents of a mysterious parcel which arrived without sender's name. The speaker is at a loss as to what the significance of parcel or contents might be, applying delay to express his assessment of the non-routineness of the communication, and half-completion to express the fact that in the absence of any reasonable explanation of why he was sent the thing, he has very little in the way of a contribution to make to the background. The tone thus sounds both surprised and reserved.

Combining half-completion and stylisation in a fall leads to a tone that maintains a tenuous, but interesting opposition with an ordinary stylised fall, which it will be difficult to capture for any framework that links F contours directly to phonological representations (cf Pierrehumbert 1980, whose system would seem be able to offer just $\mathrm{H}+\mathrm{L}-\mathrm{H}-\mathrm{L} \%$ to serve the half-completed fall, the stylised fall and the half-completed stylised fall). The half-completed stylised fall is appropriate in situations where, in addition to the meaning 'routine', either a note of light-heartedness or a note of secrecy is required, in line with what was said about the meaning of half-completion in section 7.3. Thus, the speaker may be involved in a game of hide-and-seek, and together with the hearer be hiding form a third person. If the speaker wants to draw the hearer's attention without at the same time giving his hiding-place away to the third person, he might use a low-range, half-completed stylised fall on the hearer's name (with low-volume, whispery voice). A wider-range version might be appropriate for a speaker who wished to make her presence known to a hearer (a child, for instance) and to intumate that she intends whatever social interaction may ensue to have a playful character. In (67), the hearer's name is assumed to be unicorn for the sake of 
the uniformity of the lexis

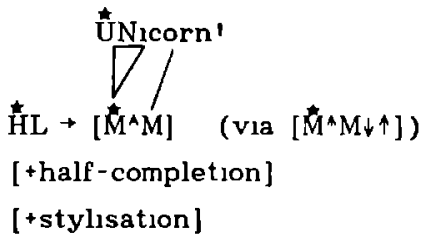

With middish range, the sizes of the intervals might be $150-100 \mathrm{~Hz}$ for the stylssed fall, and $150-120 \mathrm{~Hz}$ for the half-completed version

The half-completed stylised fall should not be confused with the 'reproaching' tone that speakers sometumes use to call their hearers to order This tone would seem to be stereotypical on isolated vocatives in the situation where $a$ henpecked husband is told off by his wife (esp low-range JEFFrey' Don't say that when other people can hear you l) The tone has nothing whatever to do with stylisation neither its semantics nor its phonetics fit Phonetically, a stylised fall is characterised by syllable-stretching, spreading of the starred tone to reduced syllables, and plateau-formation Observe that in the 'reproaching' tone the nuclear syllable is typically not lengthened, no spreading of the starred tone takes place (cf unicorn with the tone for Jeffrey above) and thirdly that there is no plateau in the lengthened tal, but rather a drawn-out, very weakly falling slope, which speeds up its downward course in the very last part of the syllable We are here in fact dealing with a further modification, which may be termed 'crescendoing' It seems to be characterised by a lengthening of the final sylable and by the tempo-differentiation noted, but it does not have the fusion characteristic of stylisation Further research is needed to determine its significance

As was said before, tones with two modifications may be rare phenomena Our chief motivation for discussing them is to demonstrate that the descriptive framework lays bare the linguistic parameters by which the nuclear tones of English are defined The tramework is predictive in that application of the postulated options predicts (generates) well-formed tone contours as well as their semantics A purely observationalist approach wll, for example, not lead one to suppose that a contour on unicorn with $\underline{u}$ - low-pitched and -nicorn at a middish level, may represent either of two linguistic constructs It could be a half-completed rise of the type llustrated in (45) and (46), or it could be a delayed stylised rise In this more marked tone, the nuclear syllable is 
low-pitched not because of the $\mathrm{L}$ in $\mathrm{LH}$, but because delay has applied, the plateau on the tal being the realisation of stylisation We may Imagine this latter tone to be used by a speaker who was getting impatient with someone who is supposed to read out a list of simple sentences beginning with It's a unicorn, but despite the simplicity of this task, keeps tarrying The speaker might then say

(68) Oh come ON'I It's a ÜNicorn

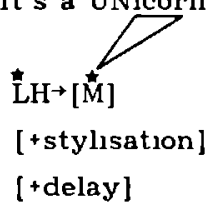

in an effort to start him off The delay in this hearer-serving TESTING is to be interpreted as an expression of the speaker's impatience with the reader's slowness in getting started ('Please consider my TESTING a significant act'), the stylisation as an expression of the fact that, in the opinion of the speaker, the task is easy (routine) Phonetically, the tone may only differ from the half-completed rise in the lengthening of the syllables, typical of stylisation (Further research is needed to establish whether the level stretch in the stylised tone is lower than that in the half-completed tone, assuming equivalent range specifications )

\subsection{A TONE-LINKING RULE}

In the discussion so far, the bulk of the examples that have been discussed either had one sentence accent (and hence one nuclear tone), or had more, but were only analysed with reference to the last The theoretical status of prenuclear prominences, to use a neutral term, is problematic Partly, this is because prominence-lending intonational optuons appear to be avalable that can be employed in a position other than those marked by sentence accents Thus, a full-focus version of Write it down! has one sentence accent (on down) and hence one position at which the nuclear tone paradigm can be addressed Yet, assuming a low-range fall on down, write can be given high pitch (which makes it prominent in a subjective sense) or low pitch, a choice that clearly affects the overall semantic effect (cf also Bolinger's discussion of two pronunciations of 
allegations (1981 27), and his references to Bing and Schubiger) It can sometumes be difficult to distinguish between pre-final accent prominence and pre-final prominence of the kind we find on Write in the example above Consider the sentence fragments Even John and Also John At first sight, the prosodic characteristics might seem identical There is some sort of weaker stress on even and also, and a stronger one on John It is, however, anything but trivial that John even and John also have clearly different prosodic characteristics even has no sentence accent, also does The position taken here is that in Even John one nuclear tone is assigned, and in Also John two, and, moreover, that whatever meaningful options are employable on even in Even John fall outside the scope of this article they are taken to constitute an issue separate from that of the nuclear tone paradigm For experimental evidence supporting the above distinction between two kinds of prenuclear prominences, see Gussenhoven (1983a)

Assuming, then, that many utterances have more than one sentence accent, and that at each sentence accent position the nuclear tone paradigm must be addressed, the question arises of how these tone sequences are realised This seems particularly relevant in situations where they are close together and/or close-knit syntactically Typically, it is not found that the tone in the penult1mate position is allowed to run its full course in the way the final tone is the speaker may not be prepared to take the time to keep all of the trajectory of the prefinal tone intact That is, tone linking rules are employed to ease these transitions between sentence accents

The Tone-Linking Rule given below perhaps llustrates the superiority of an autosegmental description even more clearly that did the three modifications given above This is mainly because it can be stated quite unambiguously in terms of operations on certain tonal elements without the addition of timing-sensitive specifications

Theoretically, any tone can be linked to any other tone, and, with three (basic) tones, nine linked contours should be generated As it happens, two of these would seem to be rare a rise followed by a fall-rise, and a fall-rise followed by a rise The most common situation is for a tone to be preceded by a fall As for the question which of a sequence of more than two tones are linked, it would appear that linking operates from right to left it is typically the penultimate tone that is linked to the final one This is in accordance with Coller \& 't Hart's (1978 20) observation that, in Dutch, the 'flat-hat pattern' can be preceded by 
a 'pointed hat', but not vice versa. 'For the last two accented syllables, it is possible to accentuate the first with only a rise and the last with only a fall. $\mathrm{Be}^{-}$ tween these two pitch movements the pitch remains high, and we get what we might call a 'flat hat' [i.e. as opposed to a 'pointed hat' marking only a single accented syllable $\underline{\mathrm{CG}}$ ]'. It will be shown below that the 'flat hat' postulated by Cohen \& 't Hart (1967) should be Interpreted as the result of a tone linking rule linking HL+HL.

The English Tone Linking Rule can be stated as follows.

(69) TONE LINKING

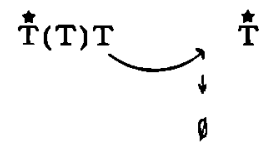

The formulation attempts to capture the fact that linking may occur in two steps: partial linking occurs when the last tone element of the penultimate tone is moved across the intervening unaccented stretch to a position adjacent to the final tone, and complete linking occurs when this last tone segment is deleted. Thus, if HL....HL is partially linked, we get $\stackrel{\hbar}{H} \ldots . . . H L$, the intervening stretch being a gradually falling slope. If complete linking applies, we derive H....... (see Figure 3). In many cases the distinction between complete and partial linking is vacuous, since both options may amount to the same thing if the moved tone segment is the same as the first (starred) tone segment of the right-hand tone.

If we take Toronto is the capital of Ontario from a context where the discussion is about capital cities, and thus ensure that both Toronto and Ontario have a sentence accent, then (69) gives us the contours represented in Figure 3 . In the contours, the unaccented To- is set at a low level.

Below, the description of prenuclear contours allowed by the TONE LINKING RULE is compared with the traditional British description of such data in terms of 'head contours'. O'Connor \& Arnold's description is taken as the reference point. The following claims are made and argued for:

1. It is not the shape of the head contour as such that is the significant feature, but the tones that it links. 
2. The analysis enables one to tease apart cases of unaccented prenuclear contours and phonetically similar contours that contain an accented syllable.

3. The analysis enables one to bring together semantically similar contours that are treated as categorically different contours in a 'head contour' analysis.

\subsection{TONE LINKING VERSUS HEAD CONTOURS}

Linking accounts for part of the 'head contours' described for British English (Crystal 1969, O'Connor \& Arnold 1973: 20-38). Below, some of these head contours are reinterpreted in terms of the TONE LINKING RULE: these are the ones given by $O^{\prime}$ Connor \& Arnold.

\subsubsection{Rising Heads}

Rising heads occur in a variety of situations, among which is linked $\mathrm{LH}_{\mathrm{H}}^{\mathrm{H} L}$, a pattern described by O'Connor \& Arnold (1973: 195) as the 'Long Jump' and analysed by them as a rising head followed by a high fall. Linked $H L H+H L(H)$ also presents a rising slope between the accented syllables. For Dutch, this pattern is given by 't Hart \& Collier (1975), Collier \& 't Hart (1978), who label the slope concerned ' 4 ', the whole contour being ' $1 \& \mathrm{~A} 4 \mathrm{~A}$ '. In fact, the concept of a tone linking rule readily emerges from their description. At one point they introduce the notion of 'transformation'. The idea there is that contour $\mathrm{X}$ can be transformed into contour $\mathrm{Y}$ by replacing one of the slope segments in $\mathrm{X}$ by some other slope segment. However, because their grammar is written in terms of allowable concatenations of monotonic pitch movernents (an 'A-fall', a '4-rise', etc.), the connections between one pattern and the next remain arbitrary, and fail to get an interpretation in terms of phonological elements. It does not become clear, for example, that a transformation may in one case involve a change of tone in the first accented syllable, but in another the application versus the non-application of a tone linking rule. The suggestion in their description is that the different contours included in it represent a list of alternative ways of realising accented syllables. In 't Hart (1975) they are explicltly referred to as 'free variants'. Why this list of strings of pitch movements is composed the way it is, and why the strings are what they are, thus remains obscure. 


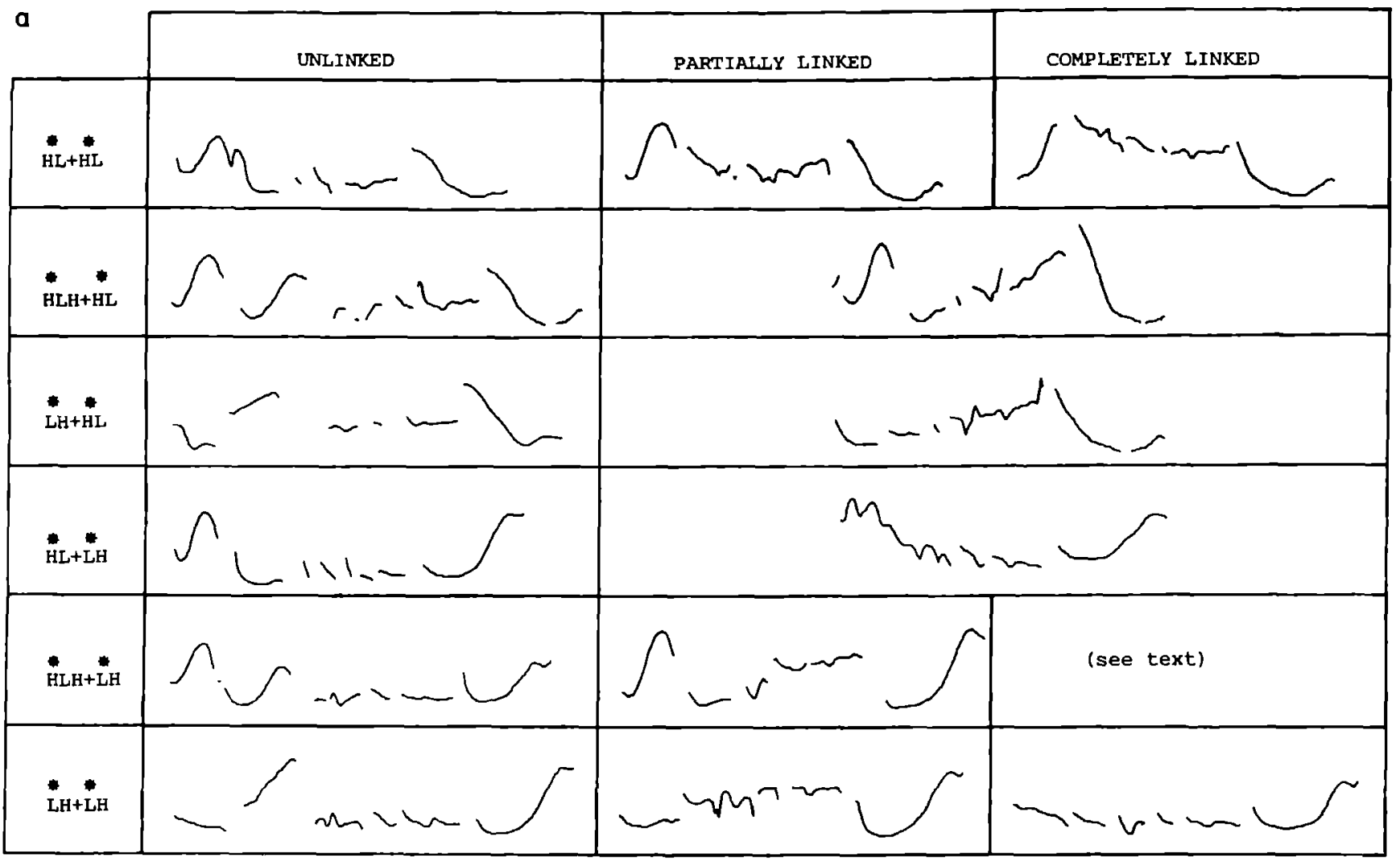




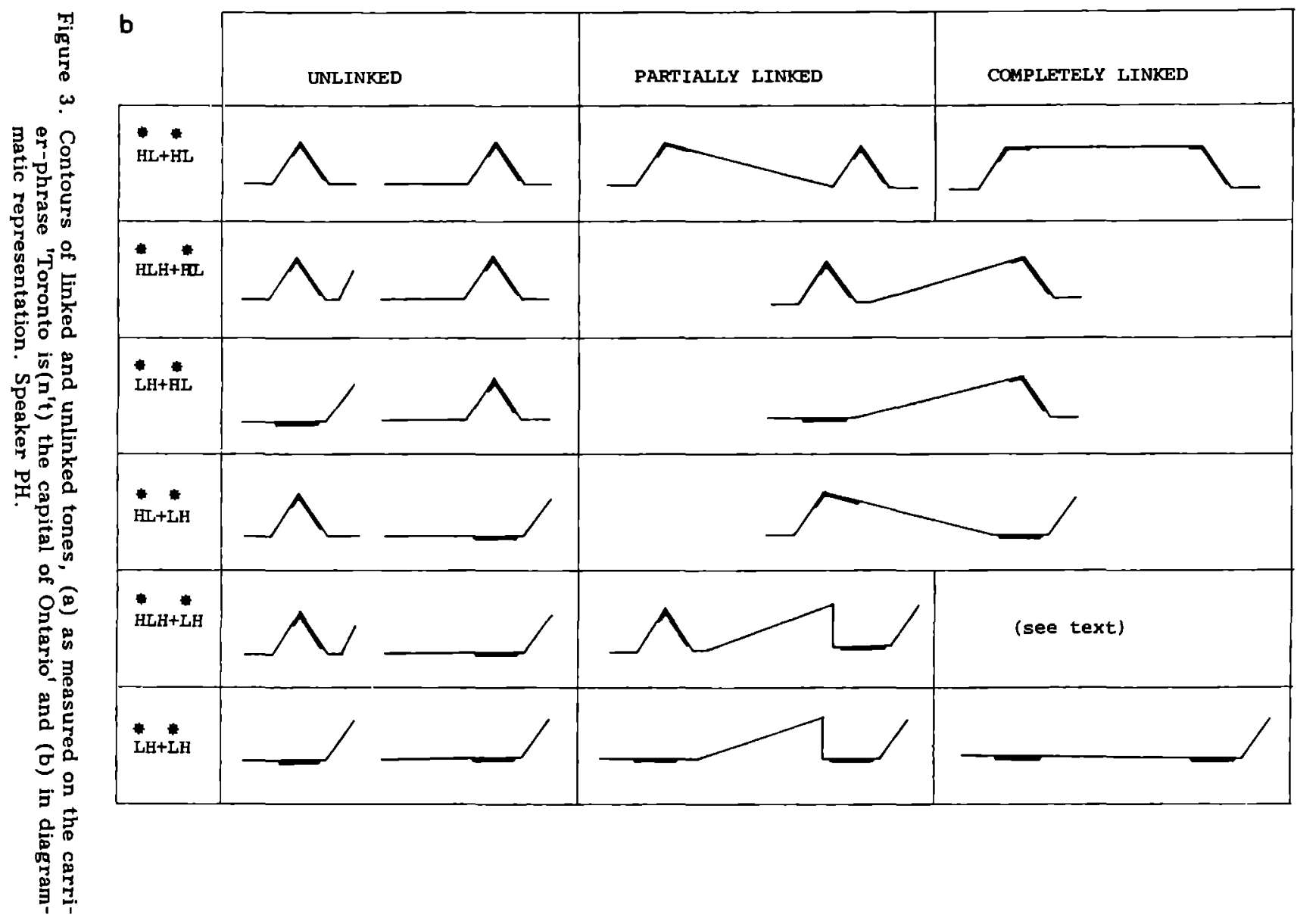




\subsubsection{Falling Heads}

Falling heads may result from partially linked $\mathrm{HL}+\mathrm{HL}(\mathrm{H})$ and from linked $\mathrm{HL}+\mathrm{L}$. $\mathrm{HL}+\mathrm{HLH}$ occurs in $\mathrm{O}^{\prime}$ Connor \& Arnold's 'Switchback', a falling head followed by a fall-rise. Note that linked or unlinked $\mathrm{HL}+\mathrm{LH}$ should not be confused with O'Connor \& Arnold's 'High Dive', which consists of a fall-plus-rise (compound fall-rise) nuclear tone. In our analysis, this pattern corresponds to a (single) fall-rise on the syllable that carries the fall-element in O'Connor \& Arnold's description, i.e. it represents the occurrence of the fall-rise on a non-final word (see section 1). In an unlinked version, $\mathrm{HL}_{\mathrm{L}}+\mathrm{L}_{\mathrm{H}}$ is discussed by Liberman \& Sag (1975) as the 'contradiction contour' (see section 11.4).

\subsubsection{Low Heads}

Low heads result from the linking of $\mathrm{LH}+\mathrm{LH}$. In $\mathrm{O}^{\prime} \mathrm{Connor} \&$ Arnold's analysis the low head exclusively occurs with a (low) rise (the 'Take-off'), as in (70).

(70) A: You shouldn't have 'DONE it

B: And what's it got to do with 'YOU may I ask?

Observe that a very similar pattern may be obtained if we allow what to be [-focus], as in (71)

(71) A: And what's it got to do with 'BO[zsi...] (unintelligible)

B: And what's it got to do with 'WHO?

The difference between (70) and (71) quite naturally falls out of our analysis. In (70) there are two sentence accents, in (71) only one. That is, the analysis predicts that the low-pitched what before a rise can be both accented and unaccented. What is more, it specifies that if it is accented, it is an instance of the rise. Observe how this explains that in (70) it is perfectly normal to allow the pitch to go up from what to you (partially linked contour), but that this rising middle section in the slope is wholly inappropriate in (71): here there is no accent, and no tones to be linked. Linking of $\mathrm{LH}+\mathrm{LH}$ so happens to produce a pattern very much like an accentless baseline followed by a rise. The analysis is of course also supported by the fact that $O^{\prime}$ Connor \& Arnold, on an intuitive basis, included a low head in their analysis (recall that 'head' is defined as a stretch of speech starting with an accented syllable). 
There may in fact well be phonetic differences between the two low-pitched stretches concerned. Thus, what in (70) may be lower in pitch than its surroundings and be longer, while in (71) the whole prenuclear stretch may have a more constant, lowish pitch.

\subsubsection{High Heads}

High heads occur between fully linked $\mathrm{HL}+\stackrel{\mathrm{H}}{\mathrm{H}}(\mathrm{H})$. With fully linked $\stackrel{k}{\mathrm{H}}+\stackrel{\hbar}{\mathrm{HL}}$ we produce the canonical pattern described by Cohen \& 't Hart (1967) as the 'hat pattern' (later 'flat hat pattern') for Dutch, and for English by O'Connor \& Arnold as either the 'Low Drop' or the 'High Drop', depending on the range of the second fall. In their description, these are the first two of the ten tunes discussed. They also include as a separate tune the 'Jackknife', which in this analysis is the same pattern, with the fall in second position delayed.

If the second tone is a fall-rise, a pattern results that $O$ 'Connor \& Arnold label the 'High Dive'. As was said above, this tune always has a 'compound fall-rise', an option that in the present analysis is just a fall-rise in early (non-final) position. Where the fall-rise is not classed as compound by O'Connor \& Arnold, they always assume a falling head for the prenuclear accent (referred to earlier as the 'Switchback'). Observe how these two categorically distinct tunes in $O^{\prime}$ Connor \& Arnold's analysis, come out as variants of the same contour in ours. The Switchback is a partially linked $H_{L}+\hat{H} L H$, and the High Dive, if preceded by the high head of course, a fully linked $\mathrm{HL}+\mathrm{HLH}$. Compare the two descriptions for (72) and (73), examples given by $O^{\prime}$ Connor \& Arnold.

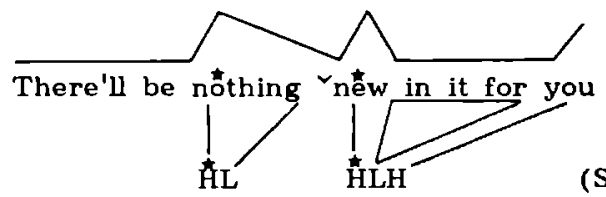

(Switchback, p. 188)

(73)

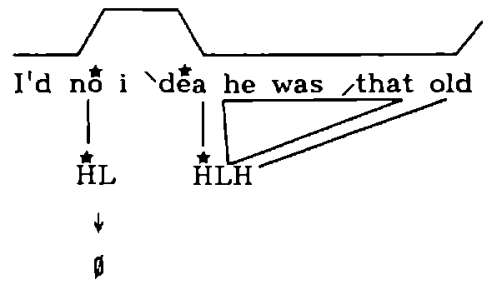

(High Dive, p. 238) 
These two categorically different contours in $O^{\prime}$ Connor \& Arnold's analysis (agreeing neither in head nor in tone) are, in the present analysis, classed as two instances of $\mathrm{HL}+\mathrm{HLH}$, one with partial and one with complete linking respectively. Observe that these examples already suggest what linking does semantically. It would appear to deplete the semantics of the first tone and present the two tones as a single unit ('no idea'). Without linking the tone on no, the speaker would seem to want to keep the effect of the accent on no fully in force, making him sound more surprised as a result. Conversely, linking the tones on nothing and new would seem to make 'nothing new' behave as a unit of some sort, rather than as a shortened version of nothing that would be new to you.

Two other tunes in O'Connor \& Arnold's analysis have High Heads: the 'Low Bounce' and the 'High Bounce'. Both have a rise in second position (low-range and wide-range, respectively). As can be seen in Figure 3, the pattern is not generated by our Tone Linking Rule: a rise can be preceded by a Low Head, a Falling Head or a Rising Head, but not by a High Head. Inspection of O'Connor \& Arnold's examples suggests that in many cases this seems precisely what would be required of a theory: the High Heads concern [-focus] material, with no accents. An example is:

(74) A: The blue one's larger than the 'BLACK

B: The blue one's larger than the 'WHICH one?

which sort of exchange is particularly frequently given for the High Bounce. For these patterns we should therefore assume that some 'onset' option is employed for the unaccented prenuclear stretch, which option is quite independent of tone assignment. However, not all contours can be explained in this way. Consider (75).

(75) A: I haven't included `ROBert

B: Why have you left 'HIM out? (p. 161)

This reply must be assumed to have two accents, one on why and one on him. Observe that it does not seem to be the case that the difference between O'Connor \& Arnold's pattern and the pattern produced by linking $A L+\hbar_{H}$ is dismissable as free variation. Our pattern (with a falling slope for have you left) sounds decidedly less friendly, in the context of (75), that is. Two options are open to us to account for cases like (75): 
1. The Tone Linking Rule could be revised such that the starred $H$ in the first tone is allowed to spread to the syllable before the next starred tone, which ploy would produce the missing contour, and leave the other patterns in Figure 4 intact. A drawback to this solution is its arbitrary nature. If $\mathrm{H}$ spreads in this situation, then why not $\stackrel{L}{\mathrm{~L}}$ ? And if $\mathrm{H}$ spreads here, why not elsewhere? (Note that the spreading of $\mathrm{L}$ would generate, for instance, a Low Head for $\mathrm{LH}+\mathrm{AL}$, which contour would be very different from the ones given in Figure 4, and, also, is absent from O'Connor \& Arnold's description.)

2. The high onset option could be allowed to apply to unaccented as well as accented prenuclear stretches. In the latter case, the tone would ride on the crest of the high onset, theoretically detectable as an appropriate obtrusion at the accented syllable. The consequence of this solution is, of course, that the high onset option would have to be extended to the other prenuclear accents as well. High onset for HLH, for instance, would considerably reduce the phonetic difference between $\mathrm{HLH}+\mathrm{HL}$ and linked $\mathrm{HL}+\mathrm{HL}$. That is, the solution would force us to class (76a) with (76c) rather than with (76b):
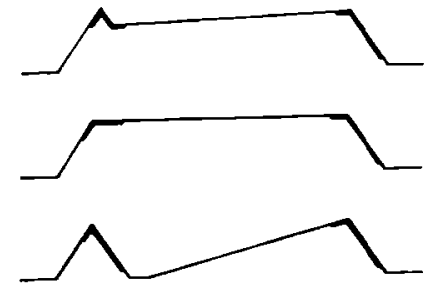

HLH + HL with high onset

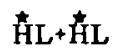

$(76 c)$

$\mathrm{HLH}+\mathrm{HL}$

Clearly, perceptual research is needed to confirm this prediction. Meanwhile, it is clear that the second solution is preferable. Not only does it save us from having to add an arbitrary condition on the Tone Linking Rule, but it predicts that High Heads, like Low Heads, may contain accented as well as unaccented syllables. It would clearly be desirable for a theary to be able to distinguish (75), in which why and him are accented, from (77), an echo-question with only who in focus, which, like (75), has a High Head:

(77) A: Why have you left 'BO[zsei..] out?

B: Why have I left 'WHO out?

Observe that our account predicts that that pattern with a downward slope for have you left does not fit in the context of (77): the sentence accent on why 
that is suggested by the pattern would be incompatible with the [-focus] status of why It would appear, then, that the lumping together of (75) and (77) should be exposed as a spurious generalisation based on vague phonetic sumlarity

\subsection{ON THE SEMANTICS OF TONE LINKING}

With the Tone Linking Rule we have brought prenuclear accents within the compass of our semantic account of nuclear tones The discussion below is kept brief, and intended only to indicate that such prenuclear accents aval themselves of the same semantic features as nuclear accents do In addition, it is pointed out that linking provides conceptual unity to the stretch of speech spanned by the linked tones

Patterns with HL in second position provide the clearest llustration Thus, $\mathrm{HL}+\mathrm{HL}$ for our example sentence Toronto is the capital of Ontario gives us 'I add Toronto to the background and $I$ add that it is Ontario that it is the capital of (' $x$ is the capital of $y^{\prime}$ being the starting point)' If SELECTION is used for Toronto, the first clause should be replaced with 'I select Toronto', e g 'Now that you've mentioned it ', and if TESTING is used, with 'I have a Variable I do not (as yet) commit to the background', e g 'Hang on, the main point is to come' or 'If you want to know about Toronto ' The latter two sentences are more readily inaginable in a conversational context than the first, which may strike one as an uncalled-for piece of information of the 'Look-what-I-know' type With speaker-serving manipulation, however, it could easly be an inference ('So that's the situation')

When the second tone is $\mathrm{LH}$, the second part of the paraphrase becomes 1 and I wonder/ask you/challenge you as to whether it is Ontario that it is the capital of' Pattern HL $+\mathrm{LH}$ might mean 'If $\mathrm{I}$ add Toronto, then is "it is the capital of Ontario" part of our background?', which, with speaker-serving could be used to convey 'This is an odd outcome of my deductions' and with hearer-serving to convey a challenge, the latter umaginable if the hearer had just implied that Toronto is not the capital of Ontario (What's 'WRONG with you? To' RONto is the capital of On'TARıo' 'YOU should know that', preferably with high onset for To-) A polar reversal here of course gives us the well-known situation for Liberman \& Sag's (1975) 'contradiction contour' LH+LH seems unproblematic the challenge might be extended to both Variables, as in a sur- 
prised echo-question $\mathrm{ALH}+\mathrm{LH}$, however, is odd, or at least heavly marked It is rarely given in the literature (e g Pakosz 1981, example (15a)) The tones do not seem linkable in fact, the tone-deleting operation in the Tone Linking Rule must be blocked for this combination, in order to prevent it from producing the pattern for linked $\mathrm{HL}+\mathrm{LH}$ Yet, the paraphrase seems perfectly decodable 'I select Toronto, and wonder/ask you (speaker-serving), challenge you as to whether (hearer-serving), the predicate belongs in the background' The significance of SELECTION here is clearly 'This of all places (just mentioned by you)' Presumably, both the tones are phonetically and semantically self-contained, and do not allow linking A simlar problem arises in the case of LH+HLH Here the linked pattern can be formed, but the combination would appear to be marked The paraphrase 'I do not commit to the background Toronto, and select from the background the predication' is possibly interpretable as 'If you want to know about Toronto, then may I remind you that (we have just established that) it is the capital of Ontario' The sentence might be used on a note of polite surprise, for instance, and addressed to someone who just made the proposal to make Toronto the capital of British Columbia, shortly after the decision had been reached to make it the capital of Ontario

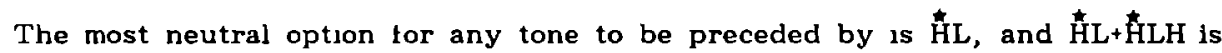
unproblematic Pattern HLH+HLH, too, is not difficult to interpret, although, again, it seems a fairly marked option. The double SELECTION is clearly appropriate if the Variables had recently been added to the background, either as a result of the speaker's own deductions or because the hearer put them there, in which case the speaker may take them out in order for participants to have a closer look at them If SELECTION for the second tone is meant to convey a reminder, the first tone is likely to have HL, though

Semantically, linking causes a certain degree of semantic depletion of the penultumate tone, the general effect being that the stretch of speech concerned is presented as an integral chunk of information Absence of linking in evidently integral expressions like John the Baptist is therefore rare Neither do we expect people to pronounce Dear Mary with two unlinked falls, while Dear me' is preferably unlunked to enhance the effect of the exclamation Sumlarly, the $\mathrm{Na}$ tional Coalboard or a national joke are linked, but a speaker may well wish to keep a national disaster unlinked, in order to give the indication of the scope of the drama its proper weight This function of linking explains why the Tone Linking Rule cannot be applied if the last two accents occur on items that belong to syntactically different domains, in particular if the accent before them be- 
longs to the same domain as the middle accent, as in the bottom rung of the ladder. In such cases, downstepping of the accents (not dealt with in this paper, see Pierrehumbert 1980: ch 4) would appear to be the more appropriate option.

\subsection{OTHER PROPOSALS}

This last section is devoted to a discussion of a few rival proposals concerning the meaning of English intonation. The discussion is restricted to (aspects of) the proposals made by Jackendoff, Ladd, Bing, Brazil and Liberman \& Sag. Other proposals, which are not discussed here, include those by Crystal (1975: 1-46), Glenn (1977), Cruttenden (1981), Deakin (1981), and Pakosz (1982).

\subsection{JACKENDOFF}

Jackendoff (1972: $\mathrm{ch}$ 6) is the first attempt to assign meaning to nuclear tones that went beyond a vague association of falls with finality and rises with non-finality. His analysis concerns the fall and the fall-rise in American English, referred to by Jackendoff as the A-accent and the B-accent, respectively. After dividing the constituents of sentences into 'presupposition' and 'focus', he associates the tones with the focus. The fall is taken to mark a dependent variable, 1.e. 'a variable not chosen freely, but rather in such a way as to make the sentence true' ( $P .263$ ). If it is true, for example, that Fred ate the beans, then in this analysis, we must get 'FRED ate the beans as the answer to Who ate the BEANS?, Fred being the dependent variable in the presupposition ' $x$ ate the beans'. By contrast, a fall-rise is said to mark an independent variable. The second speaker in the above conversation could continue by saying But MAry ate the 'MEAT in which Mary is freely chosen, but (given 'Mary ate $x$ ') the meat is not. In those cases in which a fall-rise is not attended by a fall in the same tone group, the dependent variable is said to be provided by the polarity, as in `FRED didn't eat the meat. Once the independent variable is chosen (Fred), then, given the presupposition ' $x$ (unknown polarity) eat the meat', the polarity is determined uniquely. The case for this analysis of the 'unattended' fall-rise rests on two arguments: 
1. In sentences in which the polarity is under focus, only the fall is possible, as in (78).

(78) Max $\left[\begin{array}{c}\text { 'DOESn't } \\ \longleftarrow \text { DOESn't } t\end{array}\right]$

2. Negative written sentences that are ambiguous between a reading with not associating with the focus ( $I$ will use the term 'focus governing') and not included in the presupposition, such as:

(79) Karl doesn't write political pamphlets in the BATHroom

are disambiguated by the nuclear tone used. With a fall on bathroom, not is included in the presupposition ('It is in the bathroom that Karl doesn't write political pamphlets'), but if a fall-rise is used, not is focus governing ('It is not in the bathroom that Karl writes political pamphlets'). The explanation is said to be that, with a fall-rise, bathroom is an independent variable: If not was not attracted to the focus (and was allowed to be in the presupposition), there would be no dependent variable. When, however, bathroom is a dependent variable (with a fall) not is not called upon to provide the dependent variable, and will be in the presupposition. Similar reasoning is applied to ALL the men didn't go: with a fall on all we get 'The number of men that did not go is all' or 'None of the men went', and with a fall-rise 'The number of men that went is not all' or 'Some of the men went'.

This analysis of single-tone sentences illustrates rather clearly that Jackendoff's approach is misguided. Although it is clear that the contextless sentences he presents tend to get the interpretations he gives, it is not difficult to demonstrate that exchange of the tones is possible without at the same time exchanging the interpretations. (See also Bolinger (1982).) In other words, the interpretations given are by no means obligatory. It is clear that (79) with a fall-rise will be interpreted as 'He does write them, but not in the bathroom' in isolation, but this same interpretation would be glven to $(80)$, in spite of the fall:

(80) A: Now let me 'SEE... Karl doesn't write political pamphlets in the 'BATHroom... 'AH... Could it be that he writes political pamphlets in the 'KITCHen 
B - SORRy He 'DOESn't, but do go on 'GUESSing

Conversely, although a contextless (79) with a fall will be interpreted as 'His not-writing of them is in the bathroom', with not in the presupposition, that same reading is obtained in ( 81$)$, although bathroom, quite naturally, has a fall-rıse

(81) A- I'm glad Karl doesn't write political pamphlets 'ANywhere in the house these days

B Well, Karl doesn't write political pamphlets in the `BATHroom, but have you checked the 'KITchen?

For ALL the men didn't go, too, counterexamples are not difficult to find In (82) and (83) we have a fall marking all with not focus governing, and in (83) we have a fall-rise on all, with not in the presupposition

(82) O'K So 'TOM would go if Mary `DIDn't go, and she `DIDn't, but 'BILL wouldn't go if ${ }^{`} \mathrm{TOM}$ went So far 'ONE thing is certain 'ALL the men didn't go, but be`YOND that

(83) A (God, remorsefully) But there must have been at least 'ONE man in Sodom who regularly went to the -TEMPle, and WORshipped, and B (angel) Don't 'WORRy 'ALL the men didn't go I 'TOLD you I checked 'EVerybody

The analysis of the fall-rise and the fall given here enables one to give a different, though perhaps less spectacular explanation of the effects noted Unless a context like the one in (83) dictates otherwise, the reader/hearer of the sentence ${ }^{\mathrm{ALL}}$ the men didn't go wll assume that some Variable in the background (SELECTION) is being removed from it (negation) what else could negative selection be doing? That is, he will assume not is focus governing, leaving ' $x$ men went' as the starting point In (83) this interpretation is frustrated because the context makes it clear that '(at least) $x$ men did not go' is part of the background In fact, so is all, but the whole point of the utterance was to remind the hearer of this fact If he perceives 'ALL the men didn't go, he wll argue that some Variable is being added to the background that wasn't there previously (ADDITION) The hearer will now not assume that not is focus governing ('He cannot take out what wasn't there in the first place', he will argue), and not must be part of the starting point (' $x$ men did not go') If he is to assume that not is focus governing, we must frustrate the process whereby not is 
placed in the starting point, by choosing a context in which 'some men/man went' is part of the background, as in (82). The speaker there is - somewhat unexpectedly perhaps - trying to remove from 'his' background the notion that ' $a l l$ ' is true for ' $x$ men went', and therefore needs a not as a focus governer for all. Note that ADDITION here has speaker-orientation.

As for the starred version of (78), here too, natural contexts can be thought of. There is no reason why it could not be a polite reminder, or an indignant repetition of somebody else's statement to the effect that Max does not like Myra's cooking.

\subsection{LADD AND BING}

Ladd (1980: 152-62) discusses Jackendoff's examples, finds his explanations of them wanting and proposes a different meaning for the fall-rise: it marks the focus as being part of a limited set of entities. If, for example, I fed the ${ }^{\mathrm{C}} \mathrm{CAT}$ is given as an answer to Did you feed the 'DOG?, the significance of the fall-rise of cat is, says Ladd, that it marks this animal out as a member of a limited set of animals that could have been fed. Bringing this analysis to bear on ALL the men didn't go, Ladd notes that if all is given a fall-rise, it is thereby tagged as being within a limited set: since 'all the men' cannot be a limited set, constituting as it does the whole set, this interpretation is ruled out, and the hearer therefore resorts to 'not all the men', which does conform to the requirement of being part of a set. Since no such limiting effect is given by the fall, the hearer is free to interpret 'ALL the men didn't go as 'none of the men went'. It will be clear that this analysis, too, conflicts with the data presented above. It may be added that the meaning 'focus within a set' is, when it is there, the result of the fact that the fall-rise selects from the background, and that many things will be organised there in sets.

Bing (1979: 185-90) defends Ladd's analysis and interprets the fall-rise on an item as marking the speaker's intention to contrast that item with another in the set. (For a similar characterisation, see Tibbitts 1975.) While, again, there is no problem with her interpretation of (84), for example

I don't JEAT avocados (Bing ch $6[76]$ ) 
as carrying the implication that the speaker does something else with avocados, this interpretation is not the only one possible If it is spoken in response to And I'll get some avocados for 'STARTers when you're here, it could sumply be meant as a reminder that avocados are not among the things the speaker eats, eat being the only member in its set, and not being contrasted with anything

Bing tries to extend the interpretation to include the frequently observed effect of 'reservation' (cf Halliday's oft-quoted 'there's a "but" about 1t' (1967a 27, 41)) If the contrast is not immediately clear from the situation, Bing says, the fall-rise acquires an aspect of reservation Note that example (84) (in the second interpretation) is a counterexample to this clam To llustrate the point, Bing gives (85)

(85) A What do you think of Henry's 'WIFE?

B Well, she's `PRETty (=Bing ch 6, [78])

where the reservation derives from the implied contrast with rich, inteligent, etc. Note, however, that at least some of this reservation derives from the lexis, and that a fall or a rise on pretty would hardly make the speaker sound more enthusiastic The extra effect of reservation contributed by the fall-rise is due to the fact the 'pretty' is presented as background knowledge 'I'm not going to say anything beyond what I assume both of us expect Henry's wife to be, v1z pretty' Thus, the 'reservation' meaning is an effect of the meaning of the fall-rise (selection from background) in certain contexts, not the meaning itself

\subsection{BRAZIL}

In spirit, our proposal concerning the meaning of English tones is perhaps most akin to Brazll $(1975,1978)$, Brazl et al (1980), where what was earlier called 'linguistic normalcy' is clearly the working hypothesis The formulation of our proposal has - it is hoped - been explicit enough to simultaneously serve as a refutation of those aspects of Brazl's description that differ trom ours, and as corroboration of those elements the proposals have in common I will therefore restrict myself to stating what I see as the main characteristics of Brazl's proposal, and giving a brief indication of what $I$ regard as the main flaws The main characterıstıcs are 
1. Nuclear tones are of three types:

a. Proclaiming: signalling 'I mean to say', marking 'the matter as new';

b. Referring: signalling 'you know', marking the matter as 'part of the shared, already negotiated common ground occupied by the participants at a particular moment in an on-going relationship';

c. Neutral: signalling a withdrawal from the interactive situation.

Proclaiming tones are the fall (unmarked) and the rise-fall (intensified). Referring tones are the fall-rise (unmarked) and the high rise (intensifled). Neutral tones are the low rise and the level tone. If 'proclaiming' and 'referring' are equated with ADDITION and SELECTION respectively, then the differences concern the classification and semantics of the high rise, the low rise and the level tone, all of which are the same manipulation, in our view, with the first two differing in range and the third differing from the others in being stylised. In Brazil et al (1980) the low rise is reclassified as an intensified fall-rise, with low 'termination'.

2. Key and termination are postulated as separate paradigms. Key marks the whole tone group as high, mid or low, and is employed at the first accented syllable. If that is not the nucleus, termination can also be employed, which has the same three contrasts. Thus, termination would appear to correspond to what is here called 'range', though without the division into three categories. The status of key is less clear, as it is not clear on what basis prenuclear syllables are called 'accented' (or 'prominent').

There would seem to be two main problems with Brazil's account. The first is that there is a preoccupation with pitch movements per se, without a proper differentiation between those that mark accented syllables and those that do not. Every movement is accounted for in terms of the same set of units, ignoring the fact that a lot may be going on in a contour that is unrelated to the marking of accents. When a child utters A book with high-pitched a and a low rise for book as a flippant answer to her teacher's question What have you got there?, Brazll would appear to have two choices: ignore the high-pitched a, or treat it as an accented ('prominent', 'onset') syllable. Neither solution seems adequate. The same preoccupation also causes the fall-part and the rise-part of a non-final fall-rise to turn up as two tonics, and, because Brazil does not employ 'com- 
pound tones', to occur in different tone units Examples of this type of analysis are (It's extraordinary that the Government can ask people to compress their differentials) when at the 'SAME/ 'TIME (1t's offering ) (1980 194), mullions of 'POUNDS/ involved 'HERE ( $p$ 196), (I believe the CBI) are 'RIGHT/ in 'SAYing ( $p$ 187) In these examples, it is of course the first syllable that is nuclear same, pounds, or possibly even mil(lions), which is given with 'high key', with pounds marked as a mid termination fall, and right, the 'rıse' marking the last syllable of the tal If we remain within the confines of his analysis, there appears a curious contradiction between regarding, for example, at the 'SAME/ 'TIME as an instance of 'unmarked proclaiming' followed by 'intensified referring', and regarding the intuitively more marked utterance at the 'SAME/ 'TIME as an instance of the same linguistic structure minus the 'intensification' of the second tone In our analysis these structures are at the ${ }^{` S A M E ~ t y m e ~ a n d ~ a t ~ t h e ~}$ 'SAME/ `TIME respectively

This last point also reveals the second weakness, which concerns the classification of the tones (and their semantics) Ultimately, the classıfication is an elaboration of the tume-honoured, but, in our view, spurious opposition between rises and falls ${ }^{13}$ Clearly, the classification of the rise as a kind of fall-rise is unjustifiable There are too many instances where the two are non-commutable (cf tag questions), or are commutable, but lead to very different semantic effects from the substitution of rise-falls for falls (cf the use of fall-rises unstead of rises in a 'listing' situation)

\subsection{LIBERMAN \& SAG}

In Lıberman \& Sag (1974) and Sag \& Luberman (1975) the proposal is made that the intonational semantic units consist of contours that embrace entire tone groups These contours are thus seen as holistic units, which may, within limits, be modified by 'contrastive accents' on certain items The quotations from Cutler (1977) in section 1 were taken out of a context which argued agannst just this approach The key example the authors use to support their approach is the 'contradiction contour' (Liberman \& Sag 1974) In addition, Sag \& Liberman (1975) deal with the 'surprise/redundancy contour' and the 'tulde-contour', of which the 'contradiction contour' may be a subtype The discussion here will concentrate on the 'contradiction contour' In its canonical form, it looks like (86) (cf their description on pp 420-1) 
(86)

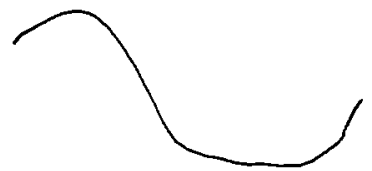

And their example is

(87) Elephantiasis isn't incurable

A possible context (from Ladd 1980: 150) is: I just found out I am going to die of elephanTIasis. Liberman \& Sag represent the pattern as showing the initial peak early in the word elephantiasis, which suggests that stress shift has applied to it (from - $\underline{t i}-$ to $\underline{e l}^{-}$). We can be fairly certain, therefore, that incurable is nuclear. If elephantiasis was the nucleus and incurable was in the tail of a fall-rise nuclear tone, no stress shift could have applied, for, as Liberman \& Prince have it 'iambic reversal does not apply to the Designated Terminal Element of the intonation contour' (1977: 319). This analysis squares with Ladd's statement that the contour is 'a high-falling head and a low-rising nuclear tone' (1980: 15). Liberman \& Sag, of course, do not ascribe the initial peak to stress shift, or even accent, but to a feature of the contradiction contour, a view relterated in Sag \& Liberman, where the peak is said to be linked to the initial boundary of the sentence. More specifically, the contour is said to be characterised by an initial rise of some $200 \mathrm{~ms}$, followed by a steep fall. This specification causes the peak to take place in the second syllable of elephantiasis, which suggests that delay has applied to this shifted accent, as indicated in (88).

(88)

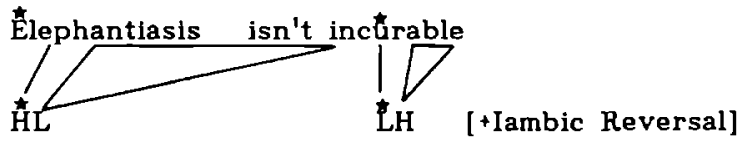

[+delay ]

The pattern, with or without delay, is not used for this sort of speech act in British English. In fact, the contour does not occur in O'Connor \& Arnold (1973), although HL+LH is normal on 'granting' expressions like 'All ' $\underline{\text { RIGHT}}$. The British equivalent for (88) would have a fall-rise rather than a rise on the second accent, giving an $O^{\prime}$ Connor \& Arnold 'Switchback'. This pattern is also given by Liberman \& Sag, who consider it the same 'contradiction contour' with the superimposition of a contrastive accent on incurable.

There are at least three things that require an explanation: 
1. How is it that the 'contradiction contour' is well-formed in American English, but not in British English?

2. Why should the 'contradiction contour', as Liberman \& Sag claim, not be embeddable?

3. Why should $\stackrel{H}{\mathrm{H}}+\mathrm{L} \mathrm{H}$ mean contradiction?

The first point, I would suggest, simply concerns a cultural difference of the type 'We don't say It that way'. The more interesting fact is that both HL+LH and HL+HLH are possible in American English, and that therefore, in this dialect, there ought to be an interpretation difference produced by the difference in manipulation on incurable. This difference may in this particular case be subtle, but is nevertheless real. The fall-rise presents the predicate as part of the background, the rise leaves that background status for the hearer to comment upon. If we imagine the hearer to reply to the $\hat{H} L+L H$ contour with Yes it IS!, he would be seen to have superior information and on that basis reject the speaker's challenge to reconsider the background status of 'the disease is incurable'. If a fall-rise had been used, this same reply would sound more like a correction of the other's misconception that it is incurable.

The answer to the second question reinforces the answer to the first. As already pointed out by Bolinger (1982), the reason why the 'contradiction contour' seems unembeddable in Liberman \& Sag's example (here) (89)

(89) ?It's been demonstrated by medical science that 'elephantiasis isn't in'CURable!

is not that the contour is not embeddable per se, but that the options employed in it make it unsuitable as an argument for a factive predicate. We cannot declare to be a fact what we subsequently intend to be taken as a challenge. If, however, we replace TESTING with SELECTION the clash no longer occurs. Compare (90) with (91), and (92) with (89): 14

(90) ?I know for a fact that 'God doesn't $e^{\prime}$ XIST

(91) I know for a fact that 'God doesn't $e^{\curlyvee X I S T}$

(92) It's been demonstrated by medical science that 'elephantiasis isn't in`CURable 
Because of their negatives, they are perhaps difficult to contextualise. For (91) we may imagine a confirmed atheist trying to reassure an audience of fellow-atheists that, in spite of a peculiar dream he has had, he is still firmly committed to the atheist cause. And (92) could be uttered by a secret service official, defending his proposal that an artificially produced outbreak of elephantiasis might be the best way to dispose of a group of enemy agents, in spite of the fact that the disease is curable. His next utterance might be But may I point out that in the area concerned no medical help will be available?. Note further that if we include the factive matrix sentence in the challenge by removing the accent on elephantiasis, there is no problem: 'I challenge you to consider the background status of the fact that...'(cf Ladd 1981b, Bolinger 1982), as in (93).

(93) It's been demonstrated by medical 'science that elephantiasis isn't in'CURable!

and that with a (semantically non-clashing) non-factive matrix sentence the contour is naturally embeddable:

(94) Are you really sure that 'God doesn't e'XIST?

The answer to the third question has also already been given by Bolinger (1982): 'It doesn't' (cf also Cutler 1977). Bolinger gives numerous examples of the combination of the contour with different lexis/syntax from which the notion of 'contradiction' is absent. In our analysis (87) means something like: 'A (significant, if delay is applied) addition to the background concerning elephantiasis is this: your task to consider the background status of the notion that it is not incurable'. Here, TESTING has literal hearer-orientation. If we allow the final rise to have textual structure orientation, we get an entirely different interpretation. Note, however, that the manipulations used can still be said to have the meanings ADDITION and TESTING:

(95) A: Do any of these diseases not meet our criteria?

B: Well, 'Elephantiasis isn't in'CURable, 'smallpox isn't a'VAILable, and 'cancer 'TAKES too long... but all the others will 'DO. 


\subsection{CONCLUSION}

It can be said that the analysis of intonational meaning presented here does not compel us to relinquish the position of linguistic normalcy adopted in the introduction. It appears to be possible to maintain that the meaning of intonational morphemes is constant across utterances. Yet, some feeling of dissatisfaction remains. This feeling is perhaps chiefly based on the realisation that, although one may have some notion of what the linguistic units are and some notion even of what they mean, the bafflingly fast workings of the language user's pragmatic computations that produce the subjectively so sharply-defined interpretations we are all familiar with, remain uncharted. Perhaps we should seek consolation in the words of L.R. Palmer:

'Speech, indeed, is nothing more than a series of rough hints which the hearer must interpret in order to arrive at the meaning which the speaker wishes to convey.'

(In Introduction to Modern Linguistics, p. 82. Cited in Daniel Jones, The Phoneme: Its nature and use, p.215, Note 19) 15 
Notes

1. This paper has benefited greatly from the comments of a number of readers of earlier versions. I should like to thank in particular Flor Aarts, Ton Broeders, Gill Brown, Laurie Iles, Hans 't Hart, Phil Hyams, Bob Ladd, Toni Rietveld, Betsy Uldall and Nico Willems. I am also very grateful for Dwight Bolinger's extensive and incisive comments, which, however, through no fault of his, I have not been able to incorporate in this paper for lack of time.

2. An analysis can never succeed, incidentally, if it relies on phonetic considerations only. As Bolinger $(1961: 40)$ points out, John Peck with a fall-rise on John (Don't you mean GREGory Peck?) may be phonetically identical with the same phrase intoned with a fall on John and a (nuclear) rise on Peck ('merely showing surprise that the name as a whole should apply to this individual'). Cf also Pierrehumbert (1980: 72). Bolinger notes that the difference is absolute ('there is no middle ground'), and adds that replacing John with Gregory brings out the phonetic difference quite clearly.

3. When it is claimed that tones are morphemes, this statement should be read in much the same light as Bolinger intended his claim to be taken when he said that his A, B and C accents are morphemes (Bolinger [1958] 1965: 51), and not, of course, in the sense of Trager \& Smith (1957), who believed that tone levels were the significant levels in intonation the way phonemes are in segmental phonology. Bolinger's accents, by the way, which are defined in terms of $\mathrm{Fl}$ relations holding between the accented syllable and an adjacent one, cannot be equated with nuclear tones, which are pitch 'Gestalts', with definable, though stretchable, domains. Neither is there any one-to-one correspondence between these accents and our tones. While an A accent would invariably appear to correspond to a fall (assuming the fall-rise is paired off as the A-rise accent, Ladd 1977), the reverse is not the case: a $C$ accent, while usually corresponding to a rise, could also correspond to a downstepped or low-range fall. Similarly, a B accent could correspond to a fall or to a rise.

4. A number of people have sympathised with me on the difficulty of finding a suitable mnemonic, expressing 'being non-committal with respect to the background status of the Variable'. Of the terms suggested, perhaps 'VETTING' (unfortunately only BrE), '(CARROT-)DANGLING' or 'MATCHING' might be suitable.

5. It may be observed that variability of effect is of course commonplace in language generally. Thus, in spite of the fact that the morpheme have $\mathrm{V}$-en is ideally described as having single constant meaning (e.g. 'occurring at a time or in a period of time linked directly with the moment of time the utterance is anchored to, usually the moment of speaking'), we get different effects in I've broken my leg and I've lived here since 1980. Similarly, He was killed in action versus He was killed slowly, etc.

6. I am here exploiting an example I owe to Bob Ladd.

7. I use the term 'proffer-suggestion' for this kind of speech act to distinguish it from 'command-suggestion', as in Why don't you get lost?.

8. In fact, details of association may have to be specified per tone. While delay has a fairly predictable effect on the fall in English (the 'rise-fall'), a delayed fall in Dutch causes the fall to be placed right at the end of the tail, 
and has the rise-element (movement up to $\vec{H}$ ) half-way or late in the nuclear syllable (Collier \& 't Hart 1975, Coller \& 't Hart 1978 38), leaving a high plateau for the tal Readers famliar with Liverpudlian intonation may recognise the pattern as characteristic of this accent of English

9 Iadd 1983 points out that the effect of delay resembles the phenomenon observed for tonal accents in languages like Swedish and Serbo-Croatian, quotıng Bruce and Garding's work on Swedish tones A delayed fall or fall-rise is in fact much like a Tone II accent in the dialect investigated by Bruce and Gårding Earlier Malmberg (1963 102-8) showed that the position of the peak was the only relevant factor in the perception of tone 1 (early peak) and tone 2 (peak after $100 \mathrm{msec}$ from vowel onset) in Stockholm Swedish Gandour (1978) cites Purcell's (1975) work on the location of the peak in Serbo-Croatian accented syllables, and his finding that it alone was responsible for whether a 'falling' tone or a 'rising' tone was percesved Conceivably, such tonal contrasts may have arisen from a partial (forward) accent shift, comparable to the accent shift that has occurred in Welsh Wuliams (In press) has shown that, although Middle Welsh must be assumed to have had end-syllable accentuation, perceptually (for Welsh speakers, at least) the accent in Welsh words now regularly falls on the penult, but that, interestingly, the phonetic correlates (duration, $F\left(\right.$ ) still 'linger' on the $\mathrm{fl}_{1}$ nal syllable This may in fact cause non-Welsh listeners to hear the accent on the penult as an accent on the last syllable Grundt (1977), too, accounts for the difference between Norwegian Tone $I$ and Tone II in terms of accent retraction for Tone II, takıng her cue from such phenomena as Jeg vl gḱ (Tone I) hjem ('I'l GO home') versus Jeg vl gä (Tone II) hjem ('I'l go HOML') The fact that Swedish has tone II in past participle forms of verbs, and that Germanic had the accent on the stem-final past partjciple marker, may point to a sumilar development Delay and tonal contrasts may thus have very different origins

10 Goldsmith and Leben advocate MHL as the neutral tone of Lnglish The prenuclear $M$ would appear to have two functions to set the prenuclear stretch at some suitably 'neutral' value, and to prevent the starred $H$ from spreading to the left In the view adopted here, prenuclear Fo contours are either specified independently of nuclear tone choice, as in archipelago, where archi- may have high or low pitch irrespective of the nuclear tone chosen, or are the output of (nuclear) tone linking rules Clearly, with the non-spreading convention for starred elements adopted above, the prenuclear $M$ would fulfl one of its functions vacuously (containing the starred element) and the other badly (specifying the prenuclear F $\emptyset$ stretch)

11 Ladd 1983 reclassifies the call contour as a stylised fall-rise Also Pierrehumbert ( 1980115$)$ and Gunter (1982) prefer a connection with a fall-rise to the one postulated here Note that this interpretation throws out the stylised fall-rise given here, and also runs counter to the results of the experment referred to in section 72

12 The equation here is not between 'pragmatically unmarked form' and 'underlyıng form', but between 'pragmatically unmarked form' and 'linguistıc form to which few rather than many linguistic options have applied', in the sense that he might have been smoking is both linguistically and pragmatically more complex than he smokes Thus, Goldsmith's criticism (1982) of Ladd's claim that the stylised fall should be further removed from the underlying form of the category 'fall' than the 'plain fall' (which Goldsmith says is a non-sequitur, since speaking 'close to the underlying form', i e with no reductions, assimlations etc, may be a very marked sort of thing to do) does not apply to my clam 
13. A simlar dichotomy between 'falls' and 'rises' is (independently) made for Dutch by van Buuren (1980), who postulates a feature 'appealing' for the rise. The fall-rise is treated as a 'contrastive' variant of the rise, and is distinguished from it by allowing the former to have an 'upward jump' That is, in his system, the fall-rise is to the rise what the rise-fall is to the fall, which constitutes a reversal of the relation between the fall-rise and the rise relative to Brazl's dichotomy.

14 The oddity of (20) is also due to the application of stress shift The relative improbability of the kind of non-initial stress shift exemplified (1.e. with the stress shift rule operating over a non-initial domain larger then the phrase) can be demonstrated in other examples, Thus, (1) is somewhat less expected than (2), and (3) is more expected than (1).

(1) ?Are you a'ware that 'visiblity is 'poor?

(2) Are you a'ware that visi'bility is 'poor?

(3) 'Visiblity is 'poor

15. I thank Gll Brown for calling my attention to this quotation.

\section{References}

Abe, I (1962) 'Call contours'. Proceedings of the ninth International Congress of Phonetic Sciences, 519-23. The Hague: Mouton.

B. (1982). 'Toontje lager'. Propria Cures (Amsterdam) 93, No. 8, 7.

Bing, J M. (1979). Aspects of English prosody. Bloomington, Indiana: IULC

Bolinger, D.L (1951). 'Intonation: levels vs configurations' Word 7, 199-210. Reprinted in Bolinger (1965). 3-16.

Bolinger, D L (1958). 'A theory of pitch accent in English'. Word 14, 109-49. Reprinted in Bolınger (1965). 17-55.

Bolınger, D L (1961) Generality, gradience and the all-or-none. The Hague Mouton.

Bolınger, D L. (1965). Forms of English: Accent, morpheme, order. Ed. I. Abe \& T. Kanekiyo. Tokyo. Hokuou.

Bolinger, D L. (1970). 'Relative height'. In P Léon, G. Faure \& A. R1gault (eds), Prosodic feature analysis Parıs. Didier. 109-25. Reprinted in Bolinger (1972a) 137-57

Bolınger, D L (ed) (1972a) Intonatıon Selected readings Harmondsworth Penguin Books.

Bolinger, D L (1972b) 'Accent is predictable (1f you're a mind-reader)'. Language 48 633-44.

Bolınger, D L. (1981) 'Two kınds of vowels, two kinds of rhythm'. IULC. Bloomington, Indiana.

Bolinger, D.L (1982). 'Intonation and its parts' Language 58, 505-32. 
Brazl, D (1975) Discourse intonation I Birmingham English Language Research, Birmingham Lniversity

Brazl, D (1978) Discourse intonation II Birmingham English Language Research, Bırmingham University

Brazl, D , M Coulthard \& C Johns (1980) Discourse intonation and language teaching Longman London

Buuren, L van (1980) 'On Dutch intonation' In M Gerritsen (ed), Linguistics in the Netherlands Amsterdam North-Holland Publishing

Brown, G (1983) 'Prosodic Structure and the Given/New distinction' In A Cutler \& D R Ladd (eds) Prosody Models and measurements Heidelberg Springer

Brown, G , K L Currie \& J Kenworthy (1980) Questions of intonation London Croom Helm

Cohen, A \& J 't Hart (1967) 'On the anatomy of intonation' Lingua 19, 177-92

Cohen, A \& S G Nooteboom (1975) Structure and process in speech perception Berlin, Heidelberg, New York Springer

Collier, R \& J 't Hart (1975) 'The role of intonation in speech perception' In Cohen \& Nooteboom (1975) 107-21

Collier, R \& J 't Hart (1978) Cursus Nederlandse intonatie Diepenbeek (Belgium) Wetenschappelijk Onderwijs Limburg Reprinted (with minor revisions) 1981 Louvain Acco

Crystal, D (1969) Prosodic systems and intonation in Englısh Cambridge Cambridge University Press

Crystal, D (1975) The English tone of volce London Arnold

Cruttenden, A (1981) 'Falls and rises Meanıngs and universals', Journal of Linguistics 17, 77-91

Cutler, A (1977) 'The context-dependence of "intonational meanings"' Papers from the thirteenth regional meeting of the Chicago Linguistic Society, 104-15

Deakın, G (1981) 'Overlap and gradient relationships in English Intonation' Melbourne Working Papers in Linguistics 7, 39-77

Gandour, J $T$ (1978) 'The perception of tone' In V Fromkin (ed), Tone A linguistic survey London Academic Press 41-76

Gibbon, D (1976) Perspectives on intonation analysis Bern Lang (Forum Linguisticum, vol 9)

Gumson, A C (1980) An introduction to the pronunciation of English Third edition London Arnold

Glenn, M G (1977) Pragmatic functions of intonation Ann Arbor Xerox University Microflus 
Goldsmith, J. (1976). Autosegmental phonology. Bloomington, Indiana: IULC.

Goldsmith, J. (1982). Review of Ladd (1980). Language 58, 422-4.

Grundt, A.W. (1977). 'Syntactic accent in Norwegian morphology'. In L.M. Hyman (ed) Studies in stress and accent. Southern California Occasional Papers in Linguistics 4.

Gunter, R. (1972). 'Intonation and relevance'. In Bolinger (1972). 194-215.

Gunter, R. (1982). Review of Ladd (1980). Language in Society 11, 297-307.

Gussenhoven, C. (1983a) 'Testing the reality of focus domains'. Language and Speech 26, 61-80 (Also this volume).

Gussenhoven, C. (1983b) A three-dimensional scaling of nine English tones'. Journal of Semantics 2, 183-203 (Also this volume).

Gussenhoven, C. (in press). 'The intonation of "George \& Mildred": post-nuclear generalisations'. In C. Johns-Lewis (ed), Intonation in discourse. London: Croom Helm (Also this volume).

Halle, M. \& J.R. Vergnaud (1982). 'On the framework of autosegmental phonology'. In $H$. van der Hulst \& N. Smith (edd), The structure of phonological representations. Dordrecht: Foris. 65-82.

Halliday, M.A.K. (1967a). Intonation and grammar in British English. The Hague: Mouton.

Halliday, M.A.K. (1967b). 'Notes on transitivity and theme in English. Part 2'. Journal of Linguistics 2, 199-244.

Halliday, M.A.K. (1970). A course in spoken English: Intonation. Oxford: Oxford University Press.

Hart, J. 't \& R. Collier (1975). 'Integrating different levels of intonation analysis'. Journal of Phonetics 3, 235-55.

Jackendoff, R.S. (1972). Semantic interpretation in generative grammar. Cambridge (Mass): MIT Press.

Kingdon, R. (1958). The groundwork of English intonation. London: Longman.

Ladd, D.R. (1977). 'The function of the A-rise accent in English'. IULC. Bloomington, Indiana.

Ladd, D.R. (1978). 'Stylized intonation'. Language 54, 517-40.

Ladd, D.R. (1980). The structure of intonational meaning: Evidence from English. Bloomington and London: Indiana University Press.

Ladd, D.R. (1980b). 'Intonation, main clause phenomena, and points of view'. In Waugh \& van Schooneveld (1980). 149-63. 
Ladd, D.R. (1981). 'On intonational universals'. In T. Myers, J. Laver \& J. Anderson (eds), The cognitive representation of speech. Amsterdam: North-Holland Publishing. 389-97.

Ladd, D.R. (1983). 'Phonological features of intonational peaks'. Language 59, $721-59$.

Leben, W.R. (1976). 'The tones in English intonation'. Linguistic Analysis 2, 69-107.

Liberman, M. (1975). The intonational system of English. MIT dissertation. Published version 1978, Bloomington: IULC.

Liberman, M \& A. Prince (1977). 'On stress and linguistic rhythm'. Linguistic Inquiry 8, 249-336.

Liberman, M \& I. Sag (1974). 'Prosodic form and discourse function'. Papers from the tenth regional meeting of the Chicago Linguistic Society. 416-27.

Malmberg, B. (1963). Structural linguistics and human communication. Berlin: Springer.

O'Connor, J.D. \& G.F. Arnold (1973). Intonation of collogulal English. Second edition. London: Longman.

Pakosz, M. (1981). 'Prosodic introduction of thematic expressions in English'. Linguistics 19, 969-86.

Pakosz, M. (1982). 'Intonation and attitude'. Lingue 56, 153-78.

Palmer, H.E. (1922). English intonation with systematic exercises. Cambridge: Heffer.

Plerrehumbert, J.B. (1980). The phonology and phonetics of English intonation. MIT dissertation.

Pike, K.L. (1945). The intonation of American English. Ann Arbor: University of Michigan Press.

Purcell, E.T. (1975). 'Pitch peak location and the perception of Serbocroatian word tone'. Paper presented at the 50th meeting of the Linguistic Society of America. (Not consulted, cited in Gandour 1978).

Sag, I. \& M. Liberman (1975). 'The intonational disambiguation of indirect speech acts'. Papers from the eleventh regional meeting of the Chicago Linguistic Society. 487-97.

Schubiger, M. (1958). English intonation: Its form and function. Tubingen: Max Niemeyer.

Searle, J.R. (1969). Speech acts. Cambridge: Cambridge University Press.

't Hart - see under Hart.

Tibbitts, E.L. (1975). 'The "transferred negative" and nuclear tone in English'. Journal of the International Phonetic Association 5, 29-33. 
Trager, G.L. \& H.L. Smith (1957). Outline of English structure. Washington: American Council of Learned Societies (Revised edition).

Uldall, E. (1961). Review of Kingdon 1958. Archivum Linguisticum 13, 214-8.

Uldall, E. (1982). 'A footnote on intonation and attitude'. Edinburgh University Department of Linguistics Work in Progress 15, 26.

Waugh, L.R. \& C.H. van Schooneveld (eds) (1980). The melody of language. Baltimore: University Park Press.

Wells, R.S. (1945). 'The pitch phonemes in English'. Language 21, 27-39.

Willems, N.J. (1982). English intonation from a Dutch point of view. Dordrecht: Foris .

Williams, B. (in press). 'An acoustic study of some features of Welsh prosody'. In C. Johns-Lewis (ed) Intonation in discourse. London: Croom Helm. 



\title{
7. A three-dimensional scaling of nine English tones
}

\begin{abstract}
Dissinilarity judgements were obtained from 44 naive native speakers of British English on the semantics of nine synthetic English nuclear tones, presented pairwise on five carrier-sentences. The ain of the experiment was to test the hypothesis that the nine tones form a linguistic paradigm of three sets of three tones, each of which set represents a semantic continuum from 'special' to 'routine'. A three-dimensional scaling analysis was carried out on the data to see to what extent the configuration predicted on the basis of the hypothesis matched the one actually obtained. The similarity turned out to be very satisfactory for the tones in the sets 'fall' and 'fall-rise', but poor in the set 'rise'. The results are reported in such a way as to enable other researchers to test alternative hypotheses concerning the relationships between the tones.
\end{abstract}

\subsection{INTRODUCTION}

There have been a number of proposals concerning the paradigm of nuclear tones of British English (e.g. O'Connor \& Arnold 1973 [1961], Halliday 1967 [1963], Crystal 1969, Brazil 1975). To greater or lesser extents, these proposals attempt not simply to list a number of nuclear tones, but also postulate relations between certain tones of the type 'these two tones are variants of each other'. There has been no attempt, however, to collect exhaustive experimental evidence for any one of these proposals. Rather, the presence or absence of relations between tones is rendered plausible by means of appeals to (assumed) shared intuitions concerning the functions of the tones, and by considerations of phonetic similarity (cf the frequently claimed connection between the 'rise-fall' and the 'fall'). It is not surprising that this should be so. As Pierrehumbert observes (1980:60), we cannot, unfortunately, ask informants to tell us whether two intonation patterns belong to the same category or to differ- 
ent categories, because this question 'overtaxes the native speaker's powers of introspection'. However, linguistic experiments need not have the straightforward design envisaged in Pierrehumbert's statement There are other ways of getting at the structure of linguistic paradigms besides asking subjects to tel us what it is In Gussenhoven (1983) a structure of the nuclear tone paradigm is argued for which may be more amenable to experimental testing, by virtue of the fact that the tones are arranged in a coherent network of relationships that allows the prediction of differences in degree of association between pairs of tones In this proposal, there are three tone categories the fall, the fall-rise and the rise Within all three categories, modifications of basic tone variants are possible, each modification adding a semantic constant (morpheme) to the meanung of the basic tone A tone category is thus a 'free' morpheme (like nouns, say) and a modification a 'bound' morpheme (like a dumınutıve suff $\mathrm{x}$, for instance) One modification is 'delay', another 'stylisation' Delay causes the meaning of a tone to acquire a measure of 'special-ness' or 'non-routineness', and is phonetically realised by delaying the association of the tone with the text, for example by one syllable Stylisation, by contrast, causes the tone to acquire a measure of 'routineness' (Ladd 1978) If we restrict our attention to these two modifications, there are in each of the three basic tone categories therefore three variants, which are spaced on a single dimension of 'routineness' the unmodified variant is positioned in the centre, flanked by its delayed and stylised counterparts, as in Figures 1 and 2 Observe that these Figures imply that the delayed variant and the stylised variant in a tone category are 'further apart' than either of the above and the unmodufied variant However, because we are dealing with tone categories, the difference between one catego$r y$ and the next (between 'fall' and 'fall-rise', say) is equivalent to any other such difference (say, between a 'fall' and a 'rise')

The delayed fall and the delayed fall-rise are the 'rise-fall' and 'rise-fall-rise' of other descriptions The delayed rise had not previously been noted in the literature The stylused fall (also known as the 'call contour') and the stylised rise (also known as the level tone), as well as the meaning 'routine' for these tone, are taken from Ladd (1978) The stylısed fall-rise, again, is new in the sense the its occurrence and function had not previously been discussed, although the phonetic possiblity for such a tone is noted by Pierrehumbert (1980 115) The llustration of the tone she glves, however, is in fact more like a high, narrow-range fall-rise (called a half-completed fall-rise in Gussenhoven, 1983) rather than the one given in Figure 4ab (the sixth tone) 


\begin{tabular}{llcl} 
& $\wedge(1)$ & $\checkmark(2)$ & $-(3)$ \\
\cline { 2 - 4 } fall & $\sim(4)$ & $\sim(5)$ & $-(6)$ \\
fall-rise & $\sim(7)$ & $\sim(8)$ & $-(9)$ \\
\cline { 2 - 4 } & non-routine & neutral & routine \\
& (delay) & (unmodified) & (stylisation)
\end{tabular}

Figure 1 Structure of nuclear tone paradigm

Instead of asking subjects to say whether two tones belong to the same or to different categories, the hypothesised tone paradigm in Figure 1 permits the experimenter to ask informants to give an estumate of how how closely any two tones agree in meaning, since estumates of semantic proximities can be subjected to a multidimensional scaling analysis, whose outcome can be compared to the hypothetical configuration suggested by Figure 1 and given in Figure 2

Unlike the investigations by Uldall (1972) and Owen (1980), in which Osgood semantic differentials were applied to a number of intonation patterns and a factor analysis was made of the scores with a view to discovering the attitudinal attributes of those patterns, our investigation was hypothesis-testing, rather than exploratory in nature Multivariate techniques like factor analysis and multidimensional scaling, however, yield information that might typically be used by the experimenter as an and to the discovery of some kind of structure in data about which no prior hypotheses were entertained Thus, the configuration resulting from a three-dimensional analysis of the nine tones will enable us to recognise a certain resemblance between that obtained configuration and the theoretical one given in Figure 2, but it will not enable us to test the hypothesis that the latter configuration is in fact the one used by native speakers' behavlour in a simlarity judgement task

It is, however, possible to make comparisons between informants' responses to one tonal contrast and their responses to another we can compare perceived semantic differences between pairs of tones about which the structure in Figure 2 makes predictions, and test these difference scores for significance Figure 2 is a gross idealisation It is not in fact clauned, for example, that the distance between the stylised variants of any two tones equals the distance between their delayed variants, or even that distances between tone categories per modifica- 


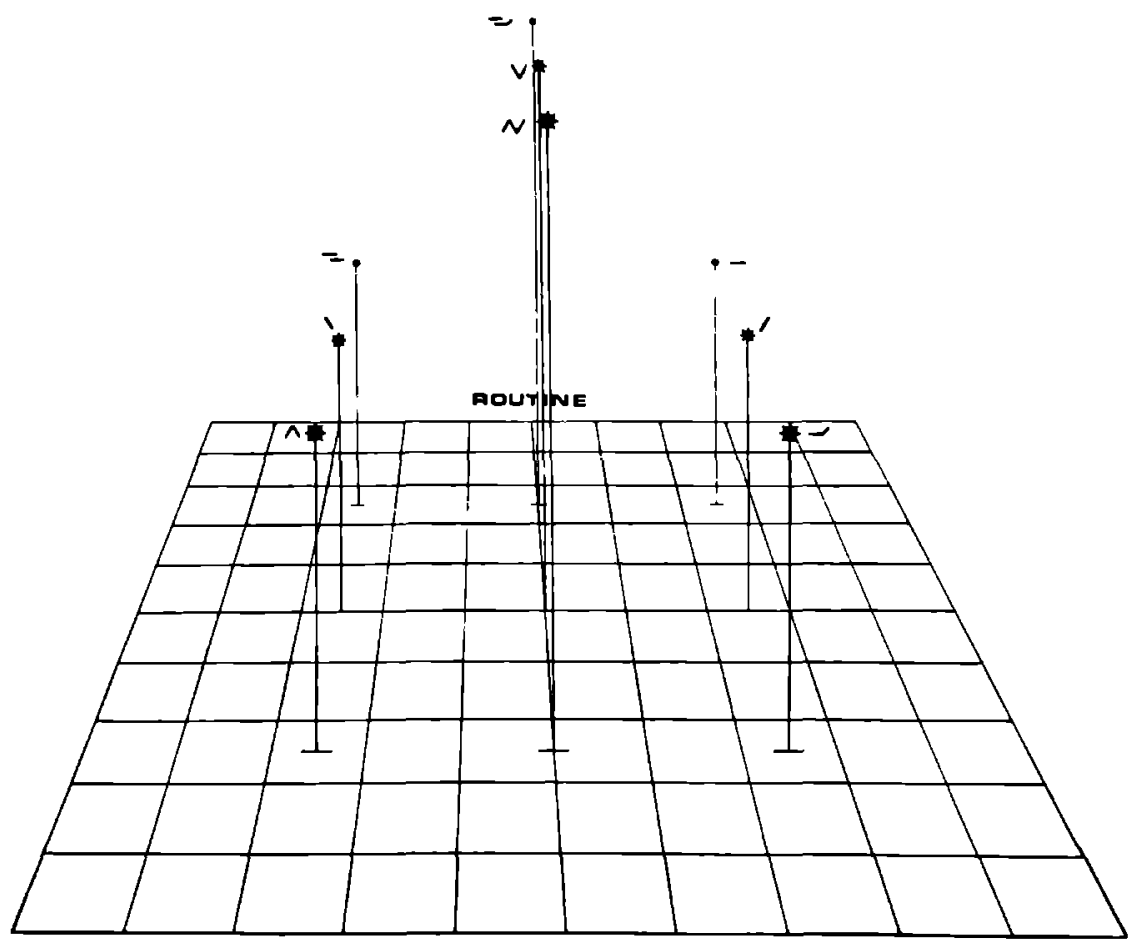

NON-ROUTINE

Figure 2. Hypothetical three-dimensional configuration of nine English tones

tion should actually be equal. It is rather that the configuration predicts certain inequalities. These inequalities are of seven types. They are listed below, with the number of actually occurring inequalities of each type given in brackets. (See Figure 1; '1 modification' stands for the distance between two adjacent tones in a tone category (e.g. $\wedge-1)$, and 'a tone' for the distance between tones in different tone categories that agree in modification (e.g. $\left.\wedge_{-}\right)$). An example of the first inequality would thus be $\hat{,} \backslash<\hat{\imath}=$ or equivalently, 
1,2<1,3; ef Appendix.)

1. 1 modification $<2$ modifications

2. a tone

$<$ a tone +1 modification

3. 1 modification

$<$ a tone +1 modification

4. a tone +1 modification $<$ a tone +2 modifications (12)

5. 1 modification

$<$ a tone +2 modifications (12)

6. a tone

$<$ a tone +2 modifications

7. 2 modifications

$<$ a tone +2 modifications (12)

(total 102)

Such comparisons will enable us, for example, to respond to Gunter's complaint (1982), that an analyst's claim that the 'call contour' is a variant of the fall would appear to be as legitimate as a claim that it is a variant of the fall-rise, if the only requirement for such claims is that it should satisfy the particular analyst's preference.

\subsection{MATERIALS}

For the synthesis of the stimuli, canonical versions of the nine tones on suitable carrier sentences were needed. The following were selected as carrier sentences:

1. Is it a unicorn?

2. Do you need a paperclip?

3. From Paddington

4. On Saturday

Two of these are syntactic questions, referred to from now on as 'Questions'. They were included because it was thought that since intonation cannot cause a functional shift from 'interrogative' to 'affirmative' in syntactic questions, but can cause such a shift in declarative sentences, they could be regarded as neutral carrier sentences where intonational meaning is concerned. The syntactically different structures 3 and 4 are referred to as 'Statements'. In addition, a nonsense carrier sentence was included (cf Uldall 1972). 
5. / o 'pa:s asa:/

The structures were chosen so as to make natural occurrence of only a single accent possible. This accent fell on the antepenult, so as to allow the $\mathrm{F}$ configurations of the tones to spread over three syllables and thus be maximally recognisable, also in the case of delayed tones.

A male speaker $(C G)$ read the five carrier sentences with the nine tones three times. These 135 utterances were recorded on magnetic tape and run through a Fr $\phi$ kjaer-Jensen Pitch Computer 1400, which produces, in real time, synchronous intensity and speech wave-form traces and a nearly-synchronous periodicity trace, in addition to a time trace. The records were used to establish segment durations of all segments. In a number of instances of $\mathrm{V}$ +nasal $\mathrm{C}$ comblnations, segment durations could not be established owing to the absence of obvious differences in intensity and speech wave form between the segments. In most of these cases, measurements were supplemented from spectrographic records produced by a Kay Sonograph. Mean segment durations were established per carrrier sentence-tone combination. Durations from the nuclear vowel onwards appeared to vary with tone. These were rounded off to the nearest 10 msec., the maximum time sample in the synthesis program to be used. Consonants appeared to vary less, and less consistently than vowels, and frequently a mean duration over all tones was established for these post-nuclear consonants. Pre-nuclear segments did not appear to vary greatly in duration, and for these, too, mean durations were established per carrier sentence across all nine tones. Subsequently, some normalisation of the segment durations that did clearly vary was achieved by ensuring that segment duration differences between any two versions of a carrier sentence did not deviate disproportionately from the mean difference between corresponding segments established over the five carrier sentences. The effect of this ad-hoc normalisation (and rounding) can be illustrated by plotting total durations of the last three syllables of the nine versions of each carrier sentence as measured (Figure 3a) and as used for the synthesis of the stimuli (Figure $3 b$ ).

One version of each carrier sentence was synthesised, with the segment durations that were to be used for the version with the (unmodified) fall. The synthesis program used was the Speech Imitation Device (SID), a modified version of the synthesis-by-rule program described in Holmes et al. (1964), available in the Phonetics Department of the University of Edinburgh. The fairly poor segmental quality of these initial versions was improved by trial and error, aid- 


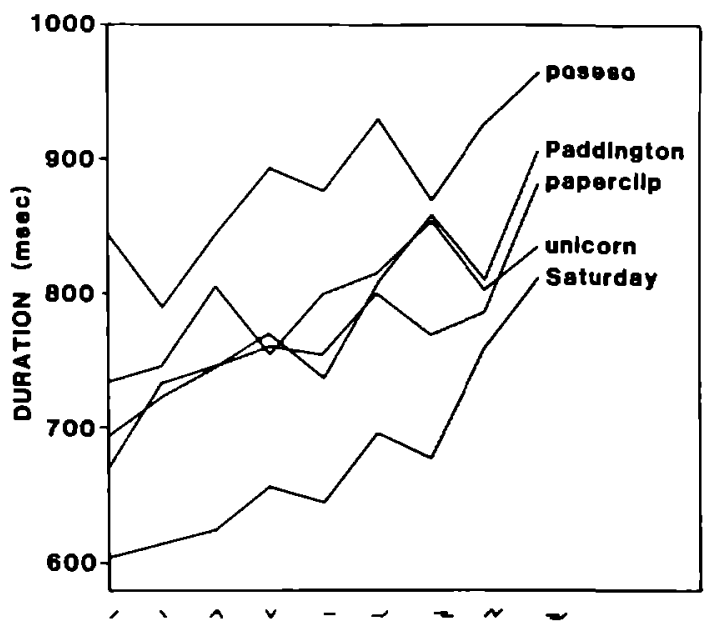

a

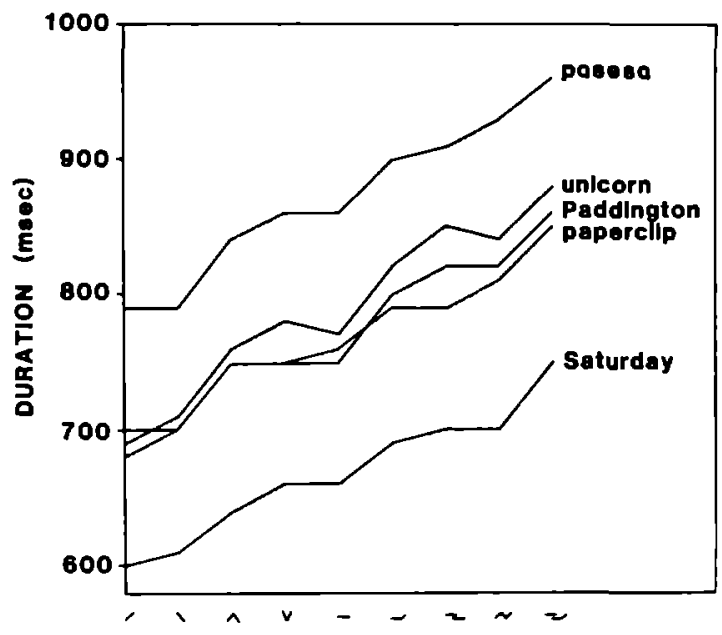

b

Figure 3. Durations of the last three syllables of all versions (a) as measured and (b) as used for synthesis 
a
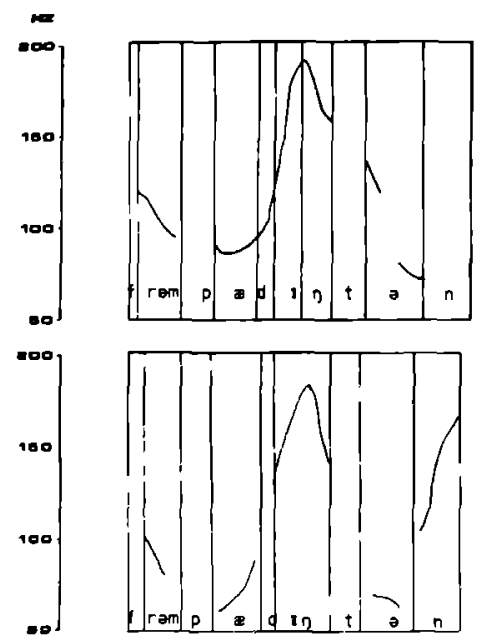

$-\infty$

$\left.\right|_{-0} ^{100}$

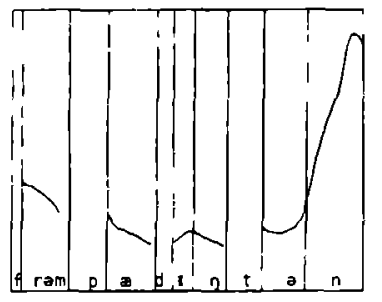

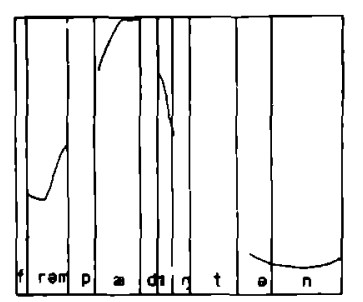
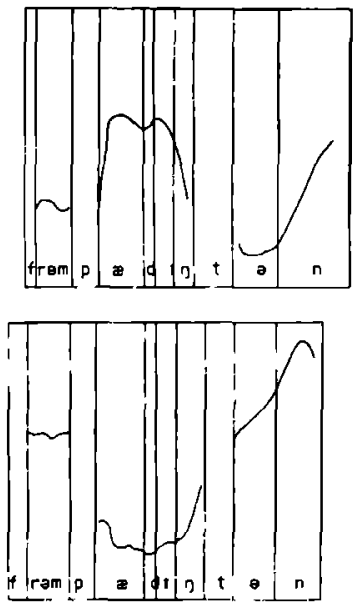
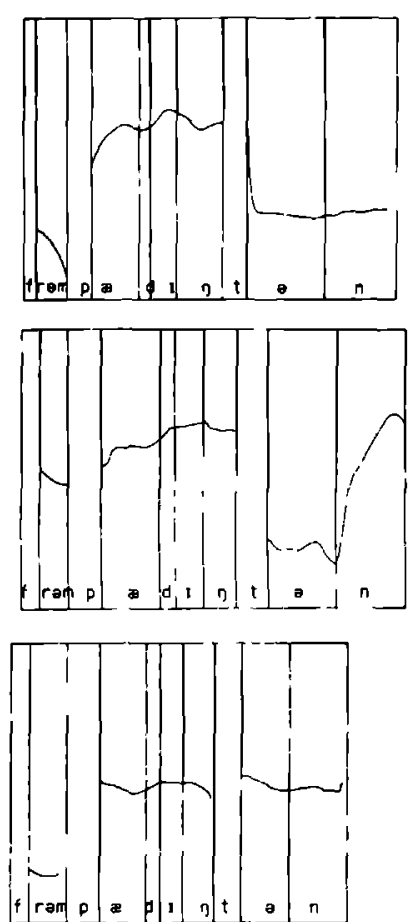

Figure 4. A representative set of nine measured Fo contours (a) and Fo contours used in the synthesis of the stimuli, with segment durations as for 'From Paddington' (b) 


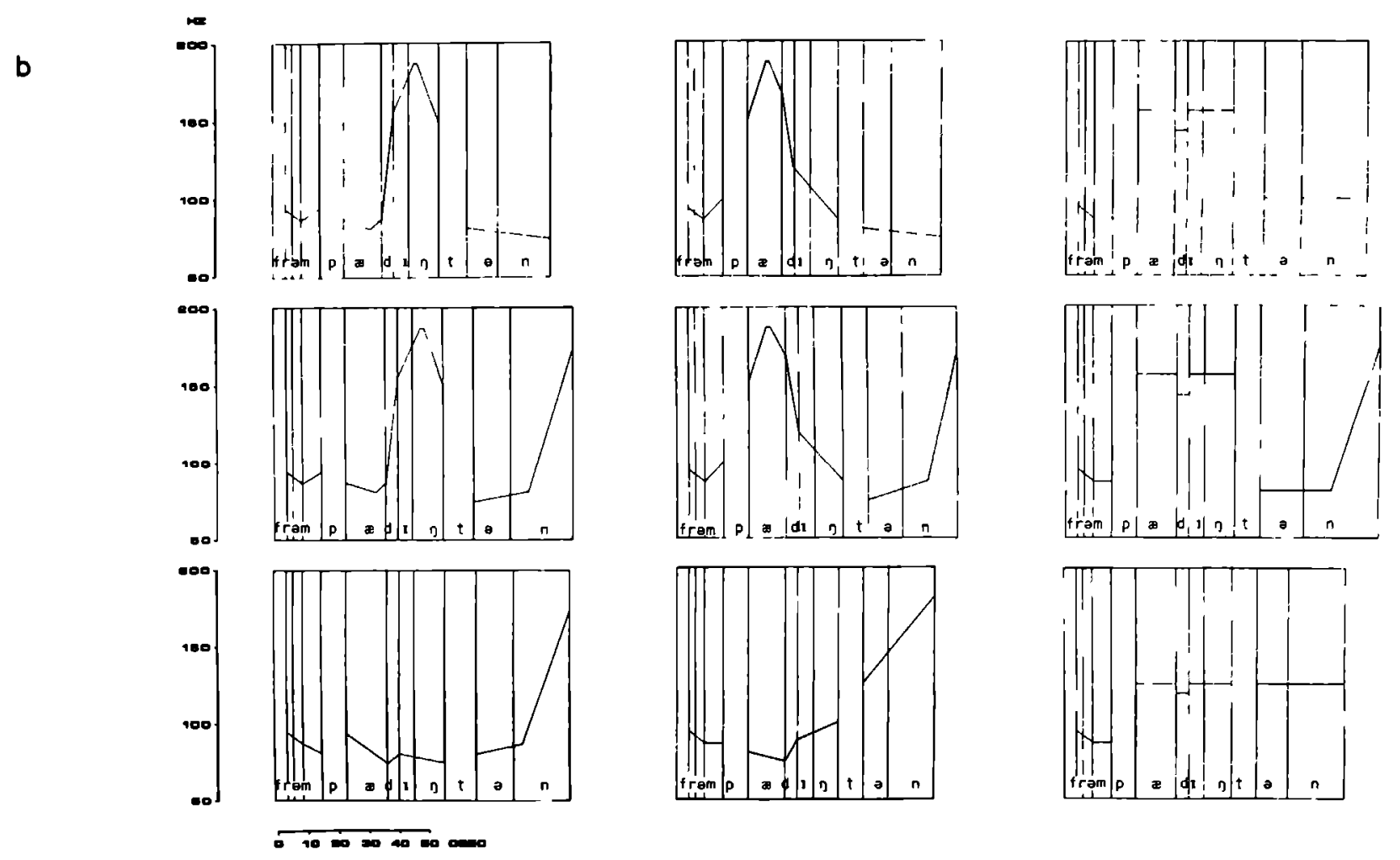


ed by selective inspection of spectrograms. After more satisfactory segmental versions had been produced, eight copies were made, in which segment durations were altered according to the values established earlier. This ensured that all nine versions of each carrier sentence would be identical, except for the duration and $\mathrm{F}$ of the last three syllables.

The records obtained from the FJ Pitch Computer were insufficiently detalled for establishing $F$ contours. Therefore, one utterance of each carrier sentence-tone combination (i.e. one third of the material) was analysed with the help of a pitch extraction program based on Gold \& Rabiner (1969), incorporated into the ILS package at the location mentioned above. The numerical output of this analysis (periodicity values for every $10 \mathrm{msec}$ sample) was plotted by hand on linear graph paper, which traces were supplied with segment boundaries as obtained from the earlier analysis. Mean values of $F$ turning points were established and their relative timings in the syllable estimated. The mean range for falling movements of delayed and unmodified falls and fall-rises was 178-75 $\mathrm{Hz}$, the mean peak for final rises of fall-rises was $160 \mathrm{~Hz}$, the mean range of the delayed rise was $75-170 \mathrm{~Hz}$, and that of the unmodified rise 75-185 $\mathrm{Hz}$. The two plateaus of the stylised fall averaged 150 and 100 , of the stylised fall-rise 148 and 80 , while the plateau of the stylised rise averaged $123 \mathrm{~Hz}$. These values were rounded off to the nearest programmable $F$ step ( 6 or $7 \mathrm{~Hz}$ ). Pre-nuclear stretches were made the same for all 45 stimuli: a weakly falling slope of 100-87 $\mathrm{Hz}$. After trial-synthesis with the values obtained, the first plateau of the stylised fall and fall-rise was raised to $156 \mathrm{~Hz}$, the peaks of the falling movements to $187 \mathrm{~Hz}$, and the peak of the final rise of fall-rises to $174 \mathrm{~Hz}$. Moreover, longish plateaus of stylised tones were interrupted by a $10 \mathrm{msec}$ step-up or step-down of one programmable step $(6 \mathrm{~Hz})$ somewhere along the way, in an attempt to get rid of the unnatural effect of perfect monotony. These measures seemed to improve the acceptability of the stimuli, and the final result was quite satisfactory. Figure $4 a$ gives measured $F$ traces for a representative set of tones (those for From Paddington) and Figure $4 b$ gives the contours used in the synthesis, with durations as for this carrier sentence. F values for time samples between two specifications are calculated by SID by linear interpolation. 


\subsection{THE EXPERIMENT}

The nine versions of each carrier sentence were combined pair-wise, such that every combination occurred once and every version occurred as frequently in first as in second position. This resulted in 36 stimulus pairs per carrier sentence, or 180 pairs in all. The test tape was recorded in real time, as the SID program made it possible to program pauses between stimuli and stimulus pairs. These were, respectively, 2 secs and 9 secs long. Each stimulus pair was preceded by a warning signal, while a longer pause (17 secs) was programmed between blocks of ten pairs. Mean stimulus duration was .96 secs. The total duration of the test tape was thus $180 \times((2 \times .96)+2+9)+17 \times 9$ secs, or 41 minutes, which made it necessary to split the test into two halves. Stimulus pairs were distributed over the two halves so as to make them maximally comparable: each half contained 36 occurrences of each carrier sentence, 20 occurrences of each tone, and either 2 or 3 occurrences of each combination of tones, ordered so as to avoid clusterings of either tone or carrier sentence. In each half, moreover, the stimulus pairs included for one of the two carrier-phrases in the categories 'Questions' and 'Statements' complemented those included for the other carrier-phrase, so that all the cells in the matrix for each category were represented in each half.

\subsection{PRESENTATION OF THE TEST TAPE}

The two test halves were presented through high-quality headphones to 24 female and 21 male judges, who were naive native speakers of British English. They were recruited from the student population of Edinburgh University, and were paid for their services. The score sheet of one male judge had to be discarded for technical reasons, so that in effect judgements were obtained from 44 judges, of whom 22 listened to the first half and 22 to the second half, i.e. each subject judged one half of the materials. Before doing the test, they received an oral instruction on the nature of their task, were played recordings of each of the synthesised carrier sentences (with unmodified falls), and were allowed to do three trial pairs. Their instruction was to decide whether they thought the two stimuli in each pair differed little or a lot in meaning. ${ }^{2}$ They recorded their judgements on five-point scales. Written versions of the carrier sentences were printed against each five-point scale, both to serve as identificatory labels and to obviate problems of intelligibility. Judges reported favourably on the 
quality of the stimuli, and - somewhat surprisingly to the experimenter - on the ease with which the task could be done.

\subsection{A 'PHONETIC' TEST}

The instruction to our subjects was to rate the stimuli for semantic difference. Although the two modifications alter the shapes of the unmodified tone trajectories in similar ways (roughly, delaying the crucial movement and stretching it, respectively), there is no a priori reason why phonetic differences between stimuli should equal semantic differences. If they do not, it would clearly be desirable to demonstrate that the judges did in fact respond to the semantic effects of the tones rather than to their physical characteristics.

In order to be able to compare the semantic judgements with phonetic judgements, the 36 pairs of nonsense sentence stimuli (i.e. / $\partial$ 'pa:sə.sa:/) were randomised, and recorded on a cassette tape.

Twelve phoneticians with varlous linguistic backgrounds (most of them either native speakers of English or of Dutch, and if not the former, always with extensive knowledge of English) were asked to rate these 36 stimulus pairs for phonetic similarity. They were given score sheets with five-point scales, similar to those used in the semantic experiment. Judges listened to the stimuli individually for as long as they wished, playing the tape on a portable cassette recorder. A number of judges commented on the difficulty of comparing disparate phonetic attributes like 'falling pattern' with 'mid level', and said that, for that reason, they could not help feeling dissatisfied with their performance. These data are referred to as 'Phoneticians' below.

\subsection{RESULTS}

Table 1 gives the raw-score matrices for Questions, Statements, Nonsense sentence and 'Phoneticians'. To the cells in the Nonsense-sentence matrix each of the 44 subjects contributed one half of the data, while to the first two matrices each subject contributed a complete matrix, representing the summation of his scores for the two carrier sentences in each of the categories Question and 
Statement. To the 'Phoneticians' matrix, of course, each of the twelve subjects contributed a complete matrix.

Table 1. Difference scores for Questions, Statements, Nonsense sentence and Phoneticians

(2) 94

(3) 137125

(4) $75 \quad 134 \quad 153$

(5) $145 \quad 92 \quad 145 \quad 119$

(6) $125 \quad 127 \quad 102 \quad 118 \quad 100$

(7) $\begin{array}{llllll}133 & 148 & 158 & 104 & 94 & 128\end{array}$

(8) $\begin{array}{lllllll}103 & 128 & 170 & 120 & 136 & 136 & 79\end{array}$

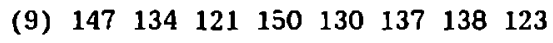
Questions

(2) 43

(3) $90 \quad 57$

(4) $44 \quad 65 \quad 65$

(5) $\begin{array}{llll}70 & 50 & 66 & 58\end{array}$

(6) $\begin{array}{lllll}73 & 61 & 63 & 56 & 53\end{array}$

(7) $\begin{array}{llllll}62 & 69 & 87 & 64 & 56 & 57\end{array}$

(8) $\begin{array}{lllllll}70 & 72 & 87 & 58 & 73 & 77 & 48\end{array}$

$\begin{array}{lllllllll}\text { (9) } & 64 & 65 & 54 & 82 & 83 & 71 & 76 & 89\end{array}$

(1) (2) (3) (4) (5) (6) (7) (8)

Nonsense sentence
101

132125

$\begin{array}{lll}95 & 149 & 130\end{array}$

$\begin{array}{llll}136 & 107 & 131 & 105\end{array}$

$\begin{array}{lllll}146 & 136 & 113 & 131 & 103\end{array}$

$\begin{array}{llllll}132 & 154 & 148 & 95 & 120 & 111\end{array}$

$\begin{array}{lllllll}139 & 163 & 163 & 132 & 128 & 152 & 90\end{array}$

$\begin{array}{llllllll}136 & 135 & 122 & 141 & 151 & 128 & 131 & 159\end{array}$

Statements

28

$50 \quad 44$

$\begin{array}{lll}24 & 41 & 37\end{array}$

$\begin{array}{llll}43 & 28 & 41 & 32\end{array}$

$\begin{array}{lllll}47 & 29 & 31 & 35 & 24\end{array}$

$\begin{array}{llllll}39 & 42 & 49 & 25 & 31 & 30\end{array}$

$\begin{array}{lllllll}37 & 41 & 51 & 32 & 41 & 43 & 25\end{array}$

$\begin{array}{llllllll}47 & 42 & 31 & 51 & 43 & 46 & 40 & 40\end{array}$

(1) (2) (3) (4) (5) (6) (7) (8)

Phoneticians

All inequalities predicted by the model in Figure 1 were tested by means of Wilcoxon matched pairs signed-rank tests for Questions, Statements and totals of Questions and Statements separately. Since for the Nonsense sentence only half a matrix was available per subject these data were not included in this analysis. The Appendix lists $z$-scores and significance levels for all comparisons. For the summed data, 71 out of the 102 inequalities appeared to show significant differences (at least at the 0.5 level, one-tailed), while a further 17 had the right sign, though did not reach a significant level. Of the remaining 14 that had the wrong sign, 4 were significant at the 0.5 level, two-tailed. Of these 14 differences that turned out to have the wrong sign, 13 involved comparisons that included a tone in the category 'rise'. The reasons why some of the results run 
counter to our predictions would appear to be that (1) the delayed rise and the unmodified rise are perceived as roughly equally different from the stylised rise, and (2) the delayed rise is perceived as much closer to the stylised fall-rise than would be expected on the basis of our model. The inequalities fared better in the Questions than in the Statements: in the Questions 14 inequalities appeared to have the wrong sign, in the Statements 23 . Note also that the inequalities of the type 'a tone +2 modifications $>$ a tone +1 modification' would appear to suffer from a ceiling-effect: differences of both types are relatively large (see Appendix).

It should be observed that the 102 inequalities listed in the Appendix are a mathematical hotbed of dependencles, in the sense that with the establishment of some of them, others are necessarily true. The reason why all of them are given is that they are independent in the sense that each one of them can be regarded as a self-contained mini-experiment, testing the hypothesis that tone $X$ is perceived as more akin to tone $Y$ than to tone $Z$. In answer to Gunter's que$r y$, for example, it is now possible to say that the 'call-contour' is perceived as more akin to the fall than to the fall-rise, both in Questions and in Statements, at an overall significance level of .04 . Or one could look at how Brazil's claim (1975) that the (high) rise is an intensified variant of the fall-rise stands up to our judges' responses: his classification predicts that the distance between the rise and the rise-fall (intensified variants of the fall-rise and the fall respectively) is smaller than that between the rise and the fall (difference of tone plus a difference in state of 'intensification'), whereas our proposal predicts the reverse. The $z$-score of 3.11 corresponds to significance level of .002, two-tailed, in our favour. Other researchers may be interested in other comparisons.'

In order to compare the observed perceptual behaviour of our subjects with the theoretical model of Figure 2, a non-metric three-dimensional scaling was performed on the three proximity matrices obtained for Questions, Statements and Nonsense utterance (INDSCAL). The analysis yields a single configuration of objects (tones, in our case) based on all matrices entered, as well as dimension weight indices for each matrix (Young \& Lewyckyj 1979).

Figure 5 glves the derived stimulus space, oriented (but not rotated) so as to make the derived dimensions coincide with those of the hypothetical configuration of Figure 2. Thus, the 'routine'-dimension runs back to front, the 'fall vs rise'-dimension runs left to right, while the vertical dimension separates the fall-rise from the other tones, referred to below as the 'fall-rise vs other' di- 


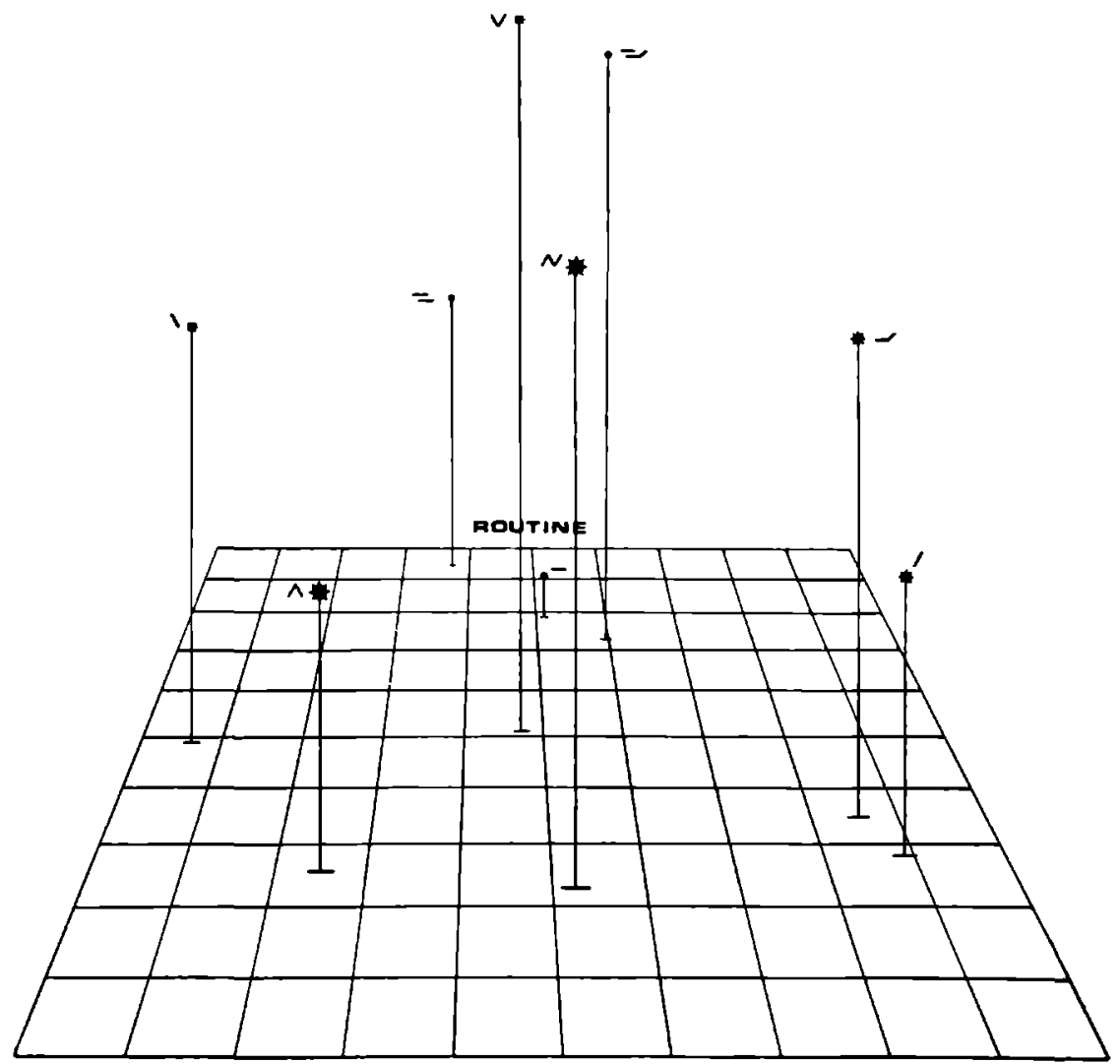

NON-ROUTINE

Figure 5. Derlved stimulus configuration in three dimensions

mension. As was also clear from the signed-rank tests, the fall and the fall-rise categories appear to behave roughly as predicted, while the positions of the three rise variants appear distorted with reference to the hypothetical configuration, in the way indicated above. Observe, however, that as a category, the rise is situated in the correct area of the space. Average Sstress (Kruskal's formula 1 ) is .12 and the squared correlation .81, representing the proportion of the variance of the disparities accounted for by the configuration. 


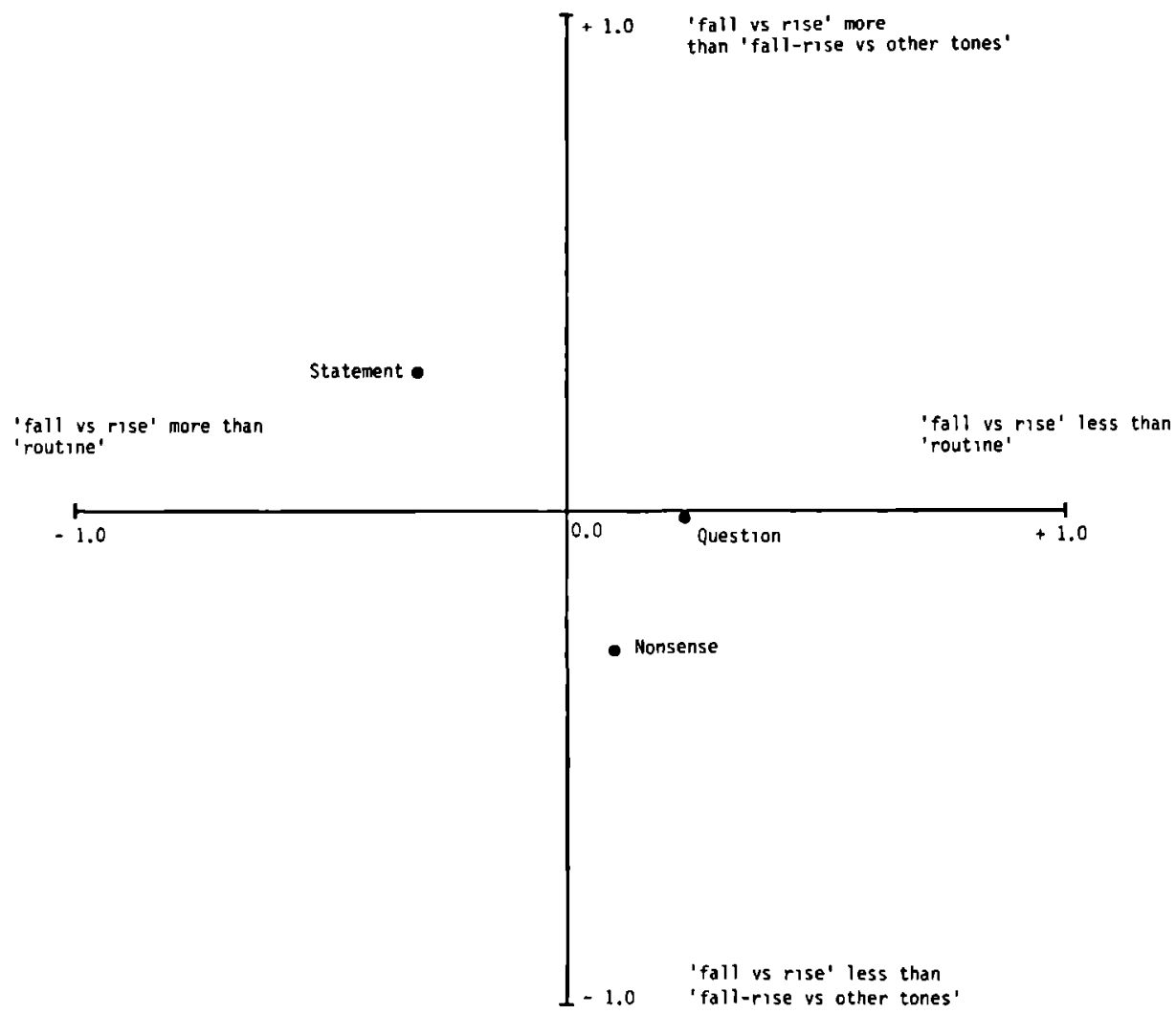

Figure 6. Dimension weight indices of three matrices on the 'fall vs rise' dimension relative to the other two dimensions

Figure 6 plots the weightıng indices for the three individual matrices. The diagram should be interpreted to mean that distance from the origin indicates the extent to which a matrix favours one dimension over another. For example, if a matrix has a value of +1.0 on the $x$-axis, this would mean that it gives full weight to one of the two dimensions concerned and ignores the other, while a value of 0.0 would mean that both dimensions are given average weights. It appears that the Statement matrix sets greater store by the second dimension ('fall vs rise') than by the first ('routine'), whereas the opposite holds for the Ques- 
tion matrix (cf the horizontal axis in Figure 6). The Statement matrix also emphasises the 'fall vs rise' dimension relative to the 'fall-rise vs other' dimension, while for the Nonsense sentence the opposite is true (cf the vertical axis in Figure 6). The behaviour of the Statement data relative to the other matrices is probably due to the fact that a greater difference in communicative effect is achieved by substituting a rise for a fall in non-interrogative sentences than in other sentence types, and listeners are therefore inclined to perceive the difference between these tones as greater. In order to compare the results of the 'semantic' experiment with those obtained in the experiment in which phoneticians rated the stimuli for phonetic similarity, a non-metric three-dimensional scaling analysis (ALSCAL) was performed on the matrix obtained in the latter experiment. The derived configuration closely resembled the one given in Figure 5. The (Pearson) correlation coefficient between the 36 inter-stimulus distances in the two configurations was .91 ( $p<.01)$. Although this high coefficient already indicated that asking naive subjects to rate the tones on partly meaningful and partly non-meaningful carrier sentences for semantic similarity, and asking non-naive subjects to rate the same tones on non-meaningful carrier sentences for phonetic similarity amounted to doing the same thing, the inter-stimulus distances of both configurations were correlated with the theorical distances in our model, to see if the 'semantic' configuration resembled the model better than did the 'phonetic' configuration. To this end, the distance of one modification was assumed to be 1 , while the distance between two tones with the same modification was assumed to be 1.3 . This latter figure was arrived at by dividing the mean raw score for a difference between two tones with the same modification by the mean raw score for a difference of one modification, which ratio was taken to be a rough estimate of the relative perceptual distances concerned. The distance of two modifications was then 2 , while a distance of a tone plus one modification was taken to be the hypothenuse of a triangle with sides 1 and 1.3 , and the distance of a tone plus two modifications that of a triangle with sides 2 and 1.3, i.e. 1.64 and 2.39 respectively. The correlation coefficient between the 36 inter-stimulus distances in the 'semantic' configuration and the model distances was $.54\left(p^{<} .01\right)$ and that between the 'phonetic' distances and the model distances $.57(p<.01)$, which coefficients are not significantly different.

\subsection{DIsCUSSION}

The experiment described above was undertaken to lend plausibility to a proposal for the structure of the English nuclear tone paradigm. It was clearly ve- 
ry successful where the six tones in the categories 'fall' and 'fall-rise' are concerned. Of the 36 inequalities predicted by the model for these tone categories only one had the wrong sign $(1,5-1,6)$, and 26 of them were significant $(p<.05)$. The three tones in the category 'rise' did not pattern in the derived configuration in the way we expected: the positions of the delayed rise and the unmodified rise are reversed, while the stylised rise is uncomfortably far removed from the other two rise variants. These two deviations could be attributed to (1) the fact that the stylised rise, a level tone, was perceived as rather different from both the delayed and the unmodified rise, instead of being perceived as closer to the latter than to the former, and (2) the fact that the delayed rise was attracted by the stylised fall-rise.

Clearly, these deviations have a phonetic explanation. The delayed rise and the stylised fall-rise both involve a plateau and a rising movement late in the final syllable, and the stylised rise, as a level tone, is very different from tones with rising movements. When collecting proximity judgements from phoneticians, our hope was to be able to underscore the finding that emerged from our analysis of the dimension weight indices (see Figure 6), i.e. that the naive subjects had responded in a non-phonetic fashion and had given functional, semantic ratings to our stimuli. This hope was vain: the two groups of subjects did not respond differently to the stimull, in spite of the different instructions. This was clear from the good correlation between the inter-stimulus distances in the two derived configurations, as well as from the fact that there was no difference in correlation between these two sets of distances on the one hand and the hypothetical distances in our model on the other. This result does not, strictly speaking, demonstrate that the naive subjects based their judgements on phonetic considerations. The only thing we can say is that the experiments did not reveal that semantic differences between English tones differ from phonetic differences between them.

The fact that the correlation between our derived 'semantic' stimulus configuration and the hypothetical configuration is low $(r=.54)$ should not be interpreted to mean that there is a poor resemblance between model and observations. The correlation coefficient was only meant to be seen in relief against the coefficient between the model and the 'phonetic' configuration. A simple visual inspection of Figures 2 and 5 is, we would suggest, a better way of assessing the similarity between the two configurations. It should also be observed that our model distances were inordinately restrictive. There is, for example, no reason why the distance between 'delay' and 'unmodified' should equal the distance between 
'unmodified' and 'stylisation'. Or indeed, that these distances should be the same when measured between variants in different tone categories. Stylisation is, for instance, further removed from 'unmodified' in the case of the fall than in the case of the fall-rise: although the structure postulated in Figure 1 does not imply equality here, these distances were made equal in the model in Figure 2. To make a comparison, the subjective semantic difference between He killed her and She died may well be greater than that between He tripped her and She

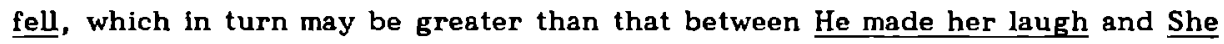
laughed, in spite of the fact that in all three cases the same semantic difference of 'causation' is involved.

A comparison of the dimension weight indices for the three matrices that were entered into the INDSCAL analysis suggests that the declarative carrier sentences elicited relatively large difference judgments between rises and falls. This was interpreted as an artefact of the extra communicative effect created by the interchange of these tones. For the assessment of semantic attributes of tones it would therefore seem to be appropriate to use syntactic questions as carrier sentences, which are impervious to such shifts from 'question' to 'statement' as a result from the substitution of a fall for a rise.

If, to end on a speculative note, the number of tones had been increased at the expense of the number of carrier sentences, and the modification 'half-completion' had been included in our material to produce three further tones, we might have ended up with a more orderly arrangement of the tones in the category 'rise'. The modification 'half-completion' produces tone variants that would intuitively seem to be positioned between 'unmodified' and 'stylised' (Gussenhoven, 1983). The half-completed rise has a brisk rise to mid level in or immediately after the nuclear syllable and a mid level post-nuclear stretch, and could thus be regarded as a phonetic hybrid of the unmodified rise and the stylised rise. As such, it might have had a corrective effect on the positions of the rise variants. 
Notes

1. I thank Ellen Bard for her contribution in the design stage of this experiment, Margo van Eyck for helping with the processing of the results, Toni Rietveld and Carel van Dijk for their discussion of statistical matters, and Leo Noordman for his comments on an earlier version of this report.

2. The literal text of their instruction was: 'What you are about to hear are 90 pairs of intonation patterns. Your task will be to compare the intonation patterns in each pair, and to decide whether they express very nearly the same meaning, or very different meanings. For each pair, there is a set of five boxes on your answer sheet. If you think that the two intonation patterns have very similar meanings, you tick the first box; if you think they have very different meanings, you tick the fifth box. Boxes 2,3 and 4 can be used for intermediate contrasts. Only put one tick per pair of intonation patterns, and only put your ticks inside the boxes. (Follow illustrations and trial pairs).'

3. I refrain from giving significance levels for comparisons about which Figure 1 makes no predictions. For anyone interested in estimates for other comparisons, a rough rule-of-thumb would appear to be that if the summed differences between scores in the Question and Statement matrices exceeds 33, there is a fair chance that the difference would reach a significance level of .05 , two-tailed.

\section{References}

Brazil, D. (1975). Discourse intonation I, Birmingham: English Language Research, Birmingham University.

Crystal, D. (1969). Prosodic systems and intonation in English. Cambridge: Cambridge University Press.

Gold, B. \& L Rabiner (1969). 'Parallel processing techniques for estimating pitch periods of speech in the time domain'. JASA 46, 442-8.

Gunter, R. (1982). Review of D.R. Ladd, The structure of intonational meaning: Evidence from English. (Bloomington: Indiana. 1980). Language in Society $11,297-307$.

Gussenhoven, C. (1983). A semantic analysis of the nuclear tones of English. Bloomington (Indiana): IULC (Also this volume).

Halliday, M.A.K. (1967). Intonation and grammar in British English. The Hague: Mouton. (Incorporating a revision of 'The tones of English', Archivum Linguisticum 15, 1-28. 1963.)

Holmes, J.N., I.G. Mattingly \& J.N. Shearme (1964). 'Speech synthesis by rule'. Language and Speech 7, 127-39.

Young, F.W. \& R. Lewyckyj (1979). ALSCAL-4 user's guide. 2nd edition. Chapel Hill: Psychometric Laboratory, University of North Carolina.

Ladd, D.R. (1978). 'Stylized intonation'. Language 54, 517-40.

O'Connor, J.D. \& G.F. Arnold (1973). Intonation of colloquial English (2nd edition, first published 1963). London: Longman. 
Owen, E. (1980). 'Intonation and meaning'. Journal of Psycholinguistic Research 9, 23-39.

Pierrehumbert, J.B. (1980). The phonology and phonetics of English intonation. MIT dissertation.

Uldall, E. (1972). 'Dimensions of meaning in intonation'. In D. Bolinger (ed) Intonation. Harmondsworth: Penguin Books. 250-59. 


\section{APPENDIX}

Wilcoxon matched pairs signed-rank tests are listed for all inequalities predicted by the model, for Questions, Statements and summed data for Questions and Statements separately. The first column lists(absolute) $z$-scores, the second gives information about the sign of the difference and the significance level. In this column, blanks indicate that the difference between total scores has the wrong sign, while exclamation marks indicate that such a difference is significant at $p^{>} .05$, two-tailed. Where the sign is right, significance levels are specified if these reach at least $p=.05$, one-tailed, ' $n s^{\prime}$ indicating that this level is not resched.

\begin{tabular}{|c|c|c|c|c|c|c|}
\hline & Ques & ions & State & ents & Total & \\
\hline $1,3>1,2$ & 3.25 & .000 & 2.70 & .004 & 3.6 & .000 \\
\hline $1,3>2,3$ & 1.00 & ns & 0.58 & ns & 1.02 & ns \\
\hline $4,6>4,5$ & 0.28 & & 2.36 & .009 & 1.62 & .05 \\
\hline $4,6>5,6$ & 1.5 & ns & 2.05 & .002 & 2.72 & .004 \\
\hline $7,9>7,8$ & 4.5 & .000 & 2.89 & .002 & 4.85 & .000 \\
\hline $7,9>8,9$ & 1.6 & .05 & 2.50 & $!$ & 0.95 & \\
\hline
\end{tabular}

\begin{tabular}{|c|c|c|c|c|c|c|}
\hline \multirow[b]{2}{*}{$1,5>1,4$} & \multicolumn{2}{|c|}{ Questions } & \multicolumn{2}{|c|}{ Statements } & \multicolumn{2}{|l|}{ Total } \\
\hline & 4.76 & .000 & 3.9 & .000 & 5.57 & 1.000 \\
\hline $4,2>1,4$ & 4.68 & .000 & 4.14 & 1.000 & 5.3 & 1.000 \\
\hline $1,8>1,7$ & 2.7 & $!$ & 0.55 & ns & 1.84 & \\
\hline $7,2>1,7$ & 1.67 & .05 & 1.83 & .04 & 2.45 & 1.007 \\
\hline $7,5>7,4$ & 0.86 & & 2.17 & .02 & 0.88 & ns \\
\hline $8,4>7,4$ & 1.53 & ns & 3.25 & 1.000 & 3.35 & .000 \\
\hline $\mid 9,5>9,6$ & 1.14 & & 1.94 & 1.03 & 0.95 & ns \\
\hline $\mid 8,6>9,6$ & 0.3 & & 2.1 & 1.02 & 1.83 & .03 \\
\hline $\mid 6,2>6,3$ & 2.59 & $\mid .004$ & 2.45 & 1.07 & 3.36 & .000 \\
\hline $5,3>6,3$ & 3.6 & .000 & 1.9 & .03 & 4.02 & .000 \\
\hline $8,3>9,3$ & 4.19 & .000 & 3.4 & .000 & 4.54 & .000 \\
\hline $9,2>9,3$ & 1.33 & ns & 1.08 & ns & 1.8 & .04 \\
\hline $6,2>5,2$ & 2.97 & 1.002 & 2.5 & .006 & 3.9 & .000 \\
\hline $\mid 5,1>5,2$ & 3.89 & $\mid .000$ & 2.6 & 1.005 & 4.7 & .000 \\
\hline $\mid 5,3>5,2$ & 0.86 & ns & 0.4 & & 0.7 & ns \\
\hline $4,2>5,2$ & 3.6 & .000 & 3.4 & .000 & 4.42 & .000 \\
\hline $8,1>8,2$ & 2.31 & .01 & 2.12 & .02 & 3.11 & .001 \\
\hline $8,3>8,2$ & 4.74 & .000 & 2.54 & .006 & 4.76 & .000 \\
\hline $9,2>B, 2$ & 0.6 & ns & 2.3 & $!$ & 1.5 & \\
\hline $7,2>8,2$ & 1.74 & .04 & 0.74 & & 0.8 & ns \\
\hline $8,4>8,5$ & 1.6 & & 0.3 & ns & 0.56 & ns \\
\hline $8,6>8,5$ & 0.14 & ns & 2.02 & .02 & 1.65 & .05 \\
\hline $7,5>8,5$ & 3.9 & $!$ & 0.78 & & 3.3 & $!$ \\
\hline $9,5>8,5$ & 0.59 & & 1.73 & .04 & 0.88 & $\mathrm{~ns}$ \\
\hline
\end{tabular}




\begin{tabular}{|c|c|c|c|c|c|c|}
\hline \multirow[b]{2}{*}{$\mid 1,5>1,2$} & \multicolumn{2}{|c|}{ Questions } & \multicolumn{2}{|c|}{ Statements } & \multicolumn{2}{|l|}{ Total } \\
\hline & 3.73 & .000 & 2.81 & 1.003 & 4.19 & .000 \\
\hline $2,4>1,2$ & 3.64 & 1.000 & 3.65 & .000 & 4.47 & 1.000 \\
\hline $1,8>1,2$ & 0.67 & ns & 2.94 & .002 & 2.47 & .006 \\
\hline $2,7>1,2$ & 4.04 & 1.000 & 4.12 & .000 & 4.6 & .000 \\
\hline $2,6>2,3$ & 0.27 & ns & 0.9 & ns & 0.82 & ns \\
\hline $3,5>2,3$ & 1.8 & 1.04 & 0.5 & ns & 1.75 & .04 \\
\hline $2,9>2,3$ & 0.8 & ns & 0.87 & ns & 1.16 & ns \\
\hline $3,8>2,3$ & 3.9 & .000 & 3.13 & .001 & 4.46 & .000 \\
\hline $4,2>4,5$ & 1.26 & ns & 3.68 & .000 & 3.6 & .000 \\
\hline $5,1>4,5$ & 2.17 & .02 & 2.77 & .003 & 3.07 & .001 \\
\hline $5,7>4,5$ & 2.5 & $!$ & 1.51 & ns & 0.78 & \\
\hline $4,8>4,5$ & 0.18 & ns & 2.5 & 1.006 & 1.87 & .04 \\
\hline $6,2>5,6$ & 2.53 & 1.006 & 2.8 & 1.003 & 3.66 & .000 \\
\hline $5,3>5,6$ & 3.44 & 1.000 & 2.12 & 1.02 & 3.77 & .000 \\
\hline $6,8>5,6$ & 3.26 & 1.000 & 3.56 & 1.000 & 4.14 & .000 \\
\hline $5,9>5,6$ & 2.52 & 1.006 & 3.76 & .000 & 4.03 & .000 \\
\hline $7,2>7,8$ & 4.68 & 1.000 & 4.38 & 1.000 & 5.21 & .000 \\
\hline $8,1>7,8$ & 2.34 & .01 & 3.68 & 1.000 & 4.41 & 1.000 \\
\hline $7,5>7,8$ & 1.56 & ns & 2.84 & .003 & 3.15 & 1.000 \\
\hline $8,4>7,8$ & 3.22 & 1.000 & 3.57 & 1.000 & 4.3 & .000 \\
\hline $8,3>8,9$ & 3.76 & .000 & 0.43 & ns & 3.37 & 1.000 \\
\hline $9,2>8,9$ & 0.85 & ns & 2.25 & $!$ & 0.71 & \\
\hline $9,5>8,9$ & 0.58 & ns & 0.76 & & 0.12 & \\
\hline $\mid 8,6>8,9$ & 0.23 & ns & 0.48 & & 0.45 & ns \\
\hline
\end{tabular}

\begin{tabular}{|c|c|c|c|c|c|c|}
\hline \multicolumn{7}{|c|}{ a tone +2 modifications $>$ a tone +1 modification } \\
\hline & \multicolumn{2}{|c|}{ Questions } & \multicolumn{2}{|c|}{ Statements } & \multicolumn{2}{|l|}{ Total } \\
\hline $1,6>1,5$ & 1.77 & & 0.8 & ns & 0.48 & \\
\hline $1,6>2,6$ & 0.1 & ns & 1.2 & & 0.72 & ns \\
\hline $1,9>1,8$ & 3.6 & .000 & 0.19 & & 2.31 & .01 \\
\hline $1,9>2,9$ & 1.2 & ns & 0.53 & ns & 1.24 & ns \\
\hline $3,4>3,5$ & 0.84 & ns & 0.07 & & 0.61 & ns \\
\hline $3,4>2,4$ & 1.99 & .02 & 1.49 & & 0.15 & ns \\
\hline $44,9>4,8$ & 2.35 & .01 & 1.04 & ns & 3.03 & .001 \\
\hline $4,9>5,9$ & 2.02 & .02 & 0.82 & & 0.64 & ns \\
\hline $\mid 6,7>6,8$ & 0.75 & & 2.93 & 1 & 3.03 & 1 \\
\hline $6,7>5,7$ & 3.39 & .000 & 0.88 & & 1.91 & .03 \\
\hline $3,7>3,8$ & 1.5 & & 1.43 & & 1.96 & ! \\
\hline $3,7>2,7$ & 0.93 & ns & 0.62 & & 0.38 & ns \\
\hline
\end{tabular}




\begin{tabular}{|l|ll|l|l|l|l|}
\hline \multicolumn{2}{|c|}{ a tone +1 modification $>1$ modification } \\
\hline & Questions & \multicolumn{2}{|c|}{ Statements } & Total \\
\hline $1,6>1,2$ & 2.99 & .002 & 3.53 & .000 & 3.79 & .000 \\
$1,9>1,2$ & 4.24 & .000 & 3.26 & .000 & 4.5 & .000 \\
$3,4>2,3$ & 3.0 & .002 & 0.4 & $\mathrm{~ns}$ & 2.41 & .08 \\
$3,7>2,3$ & 2.8 & .003 & 2.33 & .01 & 3.5 & .000 \\
$4,3>4,5$ & 3.12 & .001 & 2.12 & .02 & 3.18 & .000 \\
$4,9>4,5$ & 2.3 & .01 & 3.3 & .000 & 3.93 & .000 \\
$1,6>5,6$ & 2.44 & .008 & 3.34 & .000 & 3.74 & .000 \\
$7,6>5,6$ & 2.29 & .01 & 0.55 & $\mathrm{~ns}$ & 1.91 & .03 \\
$7,3>7,8$ & 5.08 & .000 & 4.26 & .000 & 5.36 & .000 \\
$7,6>7,8$ & 4.21 & .000 & 1.8 & .03 & 3.84 & .000 \\
$1,9>8,9$ & 2.1 & .02 & 1.94 & & 0.53 & $\mathrm{~ns}$ \\
$4,9>8,9$ & 2.03 & .02 & 1.9 & & 1.0 & $\mathrm{~ns}$ \\
\hline
\end{tabular}

\begin{tabular}{|c|c|c|c|c|c|c|}
\hline & \multicolumn{2}{|c|}{ Questions } & \multicolumn{2}{|c|}{ Statements } & \multicolumn{2}{|c|}{ Totals } \\
\hline $1,6>1,4$ & 4.1 & .000 & 4.07 & .000 & 4.94 & .000 \\
\hline $3,4>1,4$ & 5.1 & .000 & 3.17 & .001 & 5.0 & .000 \\
\hline $7,3>1,7$ & 2.2 & .02 & 1.46 & ns & 2.32 & .01 \\
\hline $7,9>1,9$ & 1.3 & ns & 0.5 & ns & 1.06 & ns \\
\hline $6,7>4,7$ & 2.4 & .007 & 1.42 & ns & 2.83 & .003 \\
\hline $4,9>4,7$ & 3.76 & .000 & 4.12 & $.00 \mathrm{~J}$ & 4.91 & .000 \\
\hline $7,3>9,3$ & 3.5 & .000 & 2.24 & .03 & 3.87 & .000 \\
\hline $9,1>9,3$ & 2.3 & .008 & 1.31 & ns & 2.53 & .006 \\
\hline $6,1>6,3$ & 2.4 & .007 & 3.23 & .000 & 3.84 & .000 \\
\hline $4,3>6,3$ & 4.8 & .000 & 1.72 & .04 & 4.21 & .000 \\
\hline $4,9>6,9$ & 1.2 & ns & 1.32 & ns & 1.74 & .04 \\
\hline $6,7>6,9$ & 1.2 & & 1.2 & & 1.78 & \\
\hline
\end{tabular}

\begin{tabular}{|c|c|c|c|c|c|c|}
\hline \multirow[b]{2}{*}{$1,6>1,3$} & \multicolumn{2}{|c|}{ Questions } & \multicolumn{2}{|c|}{ Statements } & \multicolumn{2}{|l|}{ Total } \\
\hline & 0.94 & & 1.24 & ns & 0.27 & ns \\
\hline $4,3>1,3$ & 1.83 & .04 & 0.03 & & 1.32 & ns \\
\hline $\mid 1,9>1,3$ & 1.12 & ns & 0.55 & ns & 1.07 & ns \\
\hline $7,3>1,3$ & 2.25 & .01 & 1.62 & .05 & 2.39 & .01 \\
\hline $4,3>4,6$ & 3.26 & .000 & 0.11 & & 2.38 & .01 \\
\hline $\mid 6,1>4,6$ & 0.65 & ns & 1.11 & ns & 1.48 & ns \\
\hline $4,9>4,6$ & 2.69 & .004 & 0.9 & ns & 2.91 & .002 \\
\hline $7,6>4,6$ & 0.77 & ns & 1.78 & & 0.72 & \\
\hline $7,3>7,9$ & 2.08 & .02 & 1.52 & ns & 2.46 & .007 \\
\hline $\mid 1,9>7,9$ & 1.04 & ns & 0.39 & ns & 1.21 & ns \\
\hline $7,6>7,9$ & 1.39 & & 1.57 & & 2.06 & $!$ \\
\hline $4,9>7,9$ & 1.03 & ns & 1.07 & ns & 1.76 & .04 \\
\hline
\end{tabular}




\title{
8. Stress shift and the nucleus
}

\begin{abstract}
This article investigates the phonological relevance of the nucleus of the intonation contour. It does so primarily by reviewing the conditions under which stress shift occurs in English and Dutch, to see if such rules are in any way sensitive to the feature [nuclear]. One Dutch rhythm rule is identified which needs to refer to the feature. An attempt is made to relate the findings to the distinction claimed to exist in British English between a simple (mononuclear) fall-rise and a compound (binuclear) fall-plus-rise. It will be argued that no such distinction exists in either English or Dutch. It is pointed out that the existence of phonological rules that refer to the final sentence accent of a tone group does not imply that non-final sentence accents are distinct from the final one in a semantic sense.
\end{abstract}

\subsection{INTRODUCTION}

Consider the following British English contours for Your father won't be eble to help me.

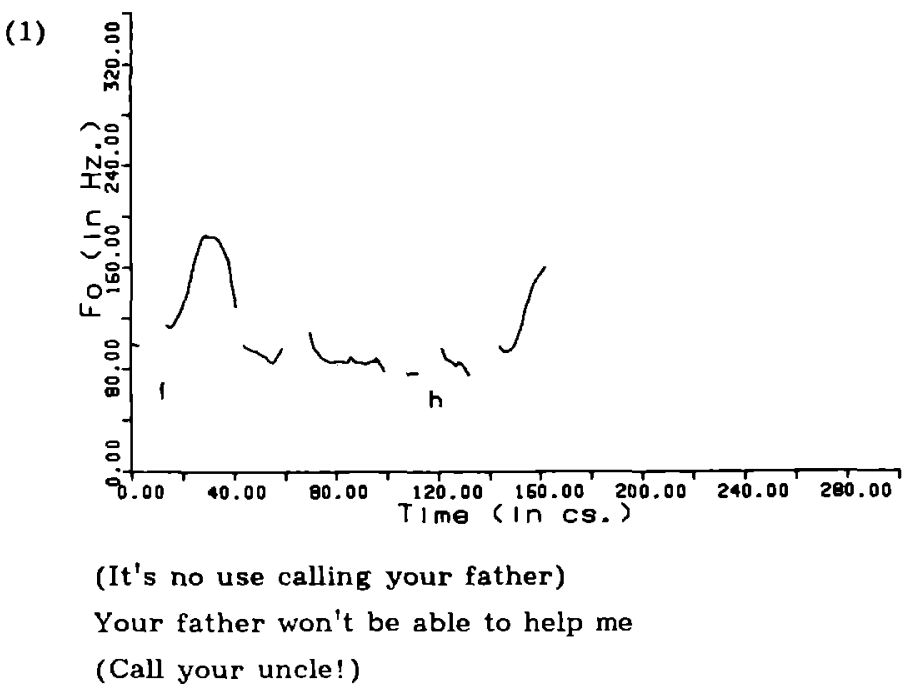


(2)

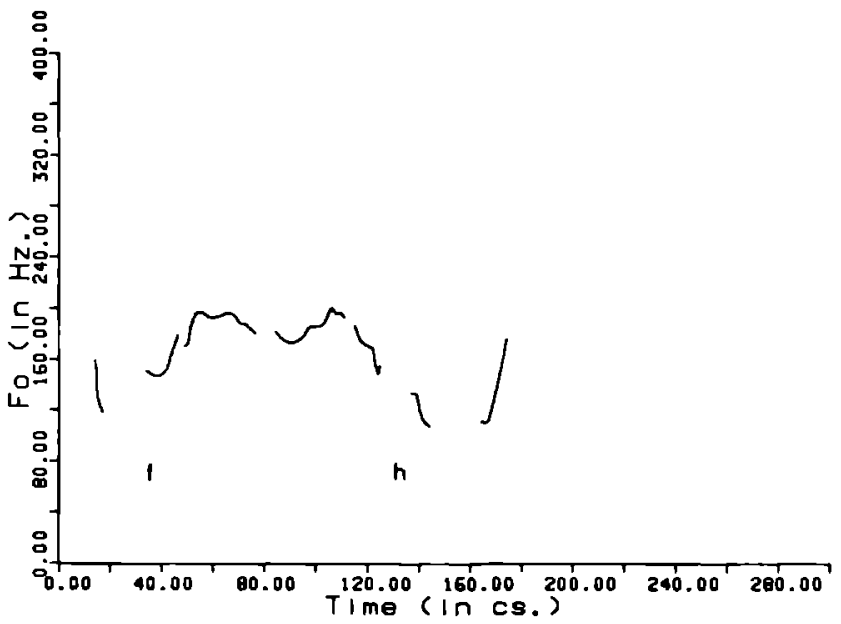

\section{( What's that you said?)}

Your father won't be able to help me?

(That I do not believe)

(3)

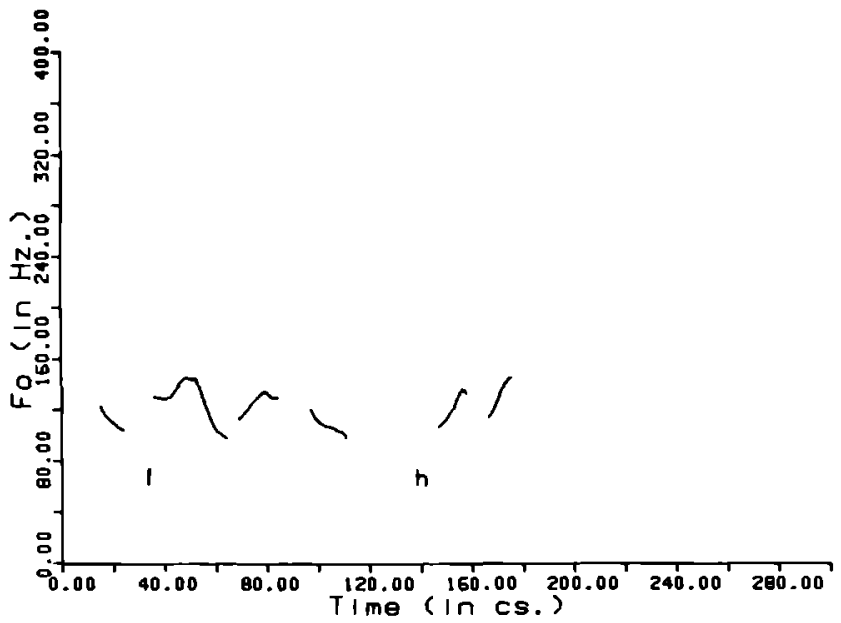

(Forget about it, you silly1)

Your father won't be able to help me

(Although he may be able to waste a lot of my time....) 
In each of (1), (2) and (3) there would seem to be at least two syllables, /fa:/ and $/$ help/, that somehow stand out as the result of pitch features. ${ }^{2}$ Also, in each case, the first syllable of father seems to be prominent because of a step-up in pitch relative to Your, while help seems prominent at least partly because of the higher pitch on me, in addition to whatever its pitch is relative to to. These are what we might call the phonetic facts, and few linguists would dispute them. This, however, is probably the extent to which linguists can be made to agree when it comes to either the semantic function of these prominence peaks, or the phonological structure that underlies their presence. Are the peaks interdependent in that a speaker must use the first pitch feature in combination with the other, or can he choose the one indepently of the other?

On the basis of their finding that listeners - who could be characterised as non-naive in one case and as phonetically trained in another - frequently hear two 'tonics' in utterances like these, Brown et al. (1980) would argue that the two characteristics that are traditionally attributed to the 'tonic', viz. that of marking new or significant information, and that of falling on the last lexical item in tone group-like stretches of speech representing 'unmarked' utterances (Halliday 1967), should properly be seen as resulting from two separate systems: one marking the salient information peaks and another marking the final boundary of the tone group. ${ }^{2}$

By contrast, Liberman \& Sag (1974) would claim that the structure of their 'contradiction contour', here reproduced as (4), is a holistic unit. They base this on their observation that listeners are able to interpret the meaning 'contradiction' even when the contour is hummed or played on a musical instrument. That is, when divorced from its lexical underpinning, the essential meaning of the contour is not lost, provided the general context remains intact. Their canonical example is

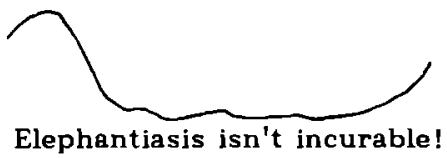

(For a critique of this analysis, see Cutler (1977), Ladd (1980:15-6)). I found it difficult to elicit this contour from British informants, who tended to come up with (3). 
There is a third view, particularly associated with the British tradition of intonation description (e g Palmer 1922, Kingdon 1958, Halliday 1970, Crystal 1969, O'Connor \& Arnold 1973), which maintains that intonationally prominent syllables are either of two types 'nuclear' or 'non-nuclear' Nuclear prominence owes its distinctive status to the fact that it is found on the first syllable of the stretch of speech associated with one of the 'nuclear tones' of an intonational tone-system (fall, rise, fall-rise, rise-fall, etc ), whlle non-nuclear prominence is found on the first syllable of the stretch of speech associated with a contour from a different system, that of 'head contours' (falling, rising, high level, low level, etc ) Any well-formed intonation contour must have a nuclear syllable, or 'nucleus', which may be preceded by a non-nuclear syllable marked by the head contour 3 In view of the extensive literature written in this tradition it is not difficult to analyse the contours (1) to (4) in terms of the British model

Utterance (1) would be said to have a fall-rise nuclear tone on father, which is spread over the stretch extending from father (the fall-element) to me, with the rise element starting after help Post-nuclear stretches are known as 'tals' There is some latitude in how the prominence on help should be characterised Crystal, for instance, distinguishes between complex and compound tones a fall-rise as in (1) would not mark a single nucleus, in his terms, but be an instance of a 'binuclear' (compound) tone, with both father and help being nuclear (1969 218) Simlarly, Halliday might call the movement away from help a 'minor tonic', 1 e one always co-occurring with 'a major tonic', while O'Connor \& Arnold speak of a 'sumple' fall-rise as opposed to a 'compound' fall-rise It is not fully clear from their description which one (1) should be assigned to (1973 30) In the most extensive corpus of spoken English analysed in terms of the British approach (Svartvik \& Quirk 1980), tone groups of this sort are normally marked with two nuclear syllables Note that irrespective of whether analysts Include the concept of compound tones in their system, in the case of (1) we are dealing with a single choice from the system of 'nuclear tones', there being no head contour in the utterance

Utterance (2) would be said to consist of a high head, beginning at father, and a (high) rising nuclear tone, beginning at help, a combination that $O^{\prime}$ Connor \& Arnold call a 'High Bounce' (1973 44)

Utterance (3) is a fairly common pattern a falling head - more properly a sliding head because of the pitch-prominent won't - starting at father, and a 
fall-rise nuclear tone beginning at help. O'Connor \& Arnold would consider the contour a 'switchback', like (1) in one interpretation."

Finally, Ladd analyses the American English (4) as a combination of a falling head (beginning at elephantiasis) and a low rise nuclear tone (beginning at -cur-) (1980: 15).

The question that comes to mind, of course, is why the British tradition should prefer this analysis to many others that are possible. Why could one not postulate, say, a 'dipping head' contour followed by a low rise nuclear tone in (1), or a fall-plus-rise tone for the pattern in (4) (as Liberman \& Sag would like to do)? Phrased concisely: what is the distinction between nuclear prominence and non-nuclear prominence ultimately based on, if not on some ill-defined notion of descriptive convenience?

There are a number of conceivable ways open to anyone who would like to defend the analytic framework. One is to characterise the nuclear tones such that they can be unambiguously identified. In a sense, this is of course what the standard descriptions of British English have done (see in particular Crystal 1969: 221-2). It would appear, however, that in practice that characterisation has either not been accepted, or has proved unworkable in the context of live data. Another approach would be to give a semantic characterisation of the nuclear tones that can be shown to be consistent over different utterances, such that a contour can be analysed on the basis of its meaning. In view of the difficulty of establishing intonational meaning (see Cruttenden (1981) for a short survey), this approach seems fraught with difficulties.

There may, however, be a third approach. Clearly, the most important evidence for the phonological reality of hypothesised phonological elements is their participation in phonological rules. To make an analogy, there is no firmer motivation for assigning separate statuses to final fortis and lenis obstruents in English than the fact that the rule governing the duration of the preceding post-onset voiced segments (consisting of [+syll] $([+$ son])([+son])), cannot be written without reference to some feature that distinguishes between the two classes of consonant in the structural description of that rule (cf the durations of /i/ in niece and / $\mathrm{i} /$ in knees, or of /ain/ in pint and /ain/ in pined). Observe, too, that it may be difficult to distinguish final fortis obstruents from flnal lenis obstruents on the basis of their phonetic characteristics alone and that their identification is to a large extent dependent on the non-local feature of the 
duration of the preceding voiced segments. Are there perhaps non-segmental phonological rules in intonation languages that will have to refer to the feature [nuclear] in their structural description?

In section 2, the rhythm rules of English and Dutch are vetted to see if any of them need to refer to [ \pm nuclear]. Before this is done, let us consider what theoretical significance would have to be attributed to finding such a rule. One of the (arguably putative) implications of the British descriptions is that there is only one major pitch-prominent syllable in the sentence, or tone group. There is now abundant evidence, both empirical (Brown et al. 1980) and theoretical (e.g. Gussenhoven 1983), that this is not the case. Also, 't Hart \& Collier's description of Dutch (1975), which is based on the free occurrence of any number of sentence accents, would have to be enriched with patently counter-intultive notions if it were made to conform to the above implication. Of course, inasmuch as the British descriptions admit the occurrence of 'pretonics' or 'head accents', It could be argued that the inference of 'one major accent per tone group' need not be made. But, as is clear from Bolinger (1956), also the notion that pre-final accents should be treated as belonging to a different paradigm is controversial. The only thing we can reasonably be concerned with here, therefore, is to establish whether it is necessary for any phonological rule to 'know' which is the last sentence accent in a tone group. If wo can establish this, then the feature [nuclear] will have been shown to be necessary only in this sense.

There may be practical significance, too. If an independent criterion for establishing which is the last sentence accent in the tone group is found, then it may provide a means of solving controversies which exist within the British tradition, such as whether sentences like (1) contain one or two sentence accents. This question is addressed in section 3 .

\subsection{RHYTHM RULES}

A potential candidate for an independently motivated rule that is sensitive to the feature [nuclear] may be found in the class of rhythm rules. Such rules shift prominences in utterances about to suit a more nearly alternating pattern. They have been reported for a number of languages (e.g. Liberman \& Prince 
1977, Prince 1983 for English, Schultink 1979 for Dutch). As a result of the application of a rhythm rule, the stress on some syllable is shifted on to some other syllable that is further removed from a third stressed syllable. This results in the removal of a non-peripheral prominence peak in some domain and the creatIon of a peripheral prominence peak in that domain, as in the English phrase fif'teen 'men $\rightarrow$ ' fifteen 'men, or in the German noun 'Vor,mittag $\rightarrow$ 'Vormit,tag. If we call the stress to be shifted the shiftable (stress) before the application of the rule and the shifted (stress) after it, and call the stress that causes the shift to take place the fulcrum, ${ }^{5}$ then what we ideally need is a rhythm rule which applies if and only if the fulcrum is [+nuclear]. It would be desirable, moreover, if that rule was obligatory rather than variable, because if it were, the status of the feature [nuclear] would more clearly be brought out as an 'all-or-none' feature, rather than simply as an additional prominence-lending feature that would increase the likelihood of the rule applying. Thus, in the ideal case, the rhythm rule should be insensitive to the pitch height, the 'emphasis' or general prominence of the fulcrum, and insensitive to the number of syllables that separate the shiftable from the fulcrum, or to the speaker's style or speed of utterance. Weaker cases are imaginable, of course. It could, for instance, be the case that the rule is obligatory if the fulcrum is nuclear and variable if it is not. Against this background of desiderata, then, let us look into the conditioning factors of the rhythm rules of two languages, English and Dutch.

\subsection{AN ENGLISH RHYTHM RULE}

The subject of 'rhythmical variation' or 'stress clash' has long lain dormant in linguistics. This also goes for the English rhythm rule, informally known as the 'thirteen men rule'. It has of course been part of English language teaching programmes at least since the beginning of this century (e.g. Rippmenn, 1913: 82 [1906], Ward, 1945: 167 [1929]) and has been mentioned in the linguistic literature (e.g. Kjparsky 1975:595), but it was only in 1977 that it recelved formal treatment in a theoretical framework in the Liberman \& Prince article on metrical stress assigment. Until Prince (1983), not much appears to have been done with the descriptive device put forward there to deal with the phenomenon of stress clash: the 'metrical grid'. Thompson (1980) is to be credited with a further specification of just when a clash occurs, and has incorporated the device in his 'footmaker', a set of rules generating Abercrombian foot-boundaries, and Giegerich (1983) argues that a more economical solution can be arrived at without in- 
voking the concept of metrical grid at all. By contrast, Prince (1983) claims that the grid can do everything the tree can do, and proposes that tree-structure be dispensed with. Very briefly, and ignoring problems and implications: Liberman \& Prince's metrical grid is an alignment of columns over syllables, whose heights are determined by the metrical tree structure assigned to the utterance on the basis of [ \pm stress]-markings of the syllables. The feature [stress] is a segmental feature, which would seem to correspond with Gimson's 'strong' and 'weak' vowels $(1980: 226)$. Its values are assigned by SPE-type stress rules (Chornsky \& Halle 1968), whose operation is seen to be related to the tree-building procedure, and apply together with this procedure in iterations. The trees are binary-branching and are built up from right to left, assigning $s$ (strong) and $w$ (weak) to the descending branches at each node, according to three principles (cf Liberman \& Prince 1977: 264-8):

1. No s dominates a [-stress] syllable;

2. Tree-building proceeds from the right, with maximum ('highest') structures being erected at every [+stress] encountered;

3. The right-hand branch of any node is assigned $s$ if it itself branches (assuming we are dealing with word-level phonology ${ }^{6}$ ).

On the basis of the tree, a metrical grid is erected via the Relative Prominence Projection Rule (RPPR). This grid should be seen as the representation of the hierarchy of relative prominences in the word. If, with Liberman \& Prince, we call the strongest terminal node corresponding to each node in the tree its Designated Terminal Element (DTE), then the RPPR requires that for each node the DTE of 'its strong subconstituent is metrically stronger than the DTE of its weak subconstituent'. If strength is symbolised as column-height, the metrical grid for association is therefore as given in (5). If 'element' is used to refer to any point where columns and levels cross (i.e. the asterisks in (5) ff), the rhythm rule proposed by Liberman \& Prince for English amounts to identifying a pressure for Iambic Reversal, i.e. a change from [w $s]$ to $\left[\begin{array}{ll}s & w\end{array}\right]$ in the tree, if any two adjacent elements are positioned over elements that are also adjacent, on the next level down. Such elements are called 'clashing'. (Note that the left-hand clashing element corresponds to the $s$ before the operation of Iambic Reversal.) If we may take a Phrase Stress Rule assigning the 'strong' to the rightmost constituents in (6) for granted, then the circled elements are clashing, and Iambic Reversal may take place, as indicated by the double arrow. Af- 
ter the switch, the RPPR erects a new grid (which in this case is identical to the old, except that the left-hand circled element will in effect have 'moved' to the column over the first syllable).

(5)

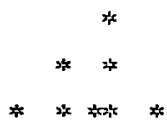

association

(6)

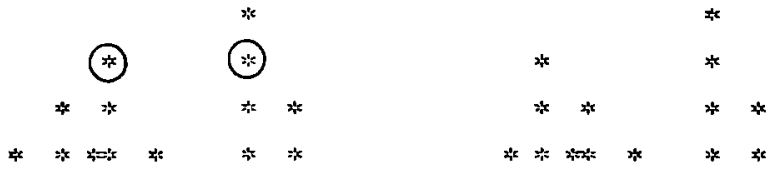

Association Football $\quad \rightarrow \quad$ Association Football

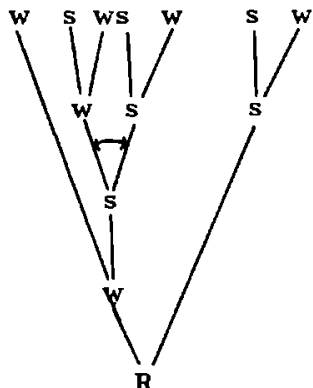

Liberman \& Prince put the following condition on Iambic Reversal: 'The strong should not be the DTE of an intonational phrase.' They point out that Iambic Reversal should not apply to Chi'nese ,expert ('an expert on Chinese') to rule out 'Chinese, expert. It would at first sight appear as if we here have a rule that is sensitive to the feature [nuclear]. Unfortunately, the constraint given by Liberman \& Prince appears to be too strong. The blocking of Iambic Reversal is not restricted to situations where the 'strong' is the DTE of an intonational phrase. In (7), the application of the rule is, for most speakers, equally unacceptable as it is for the phrase in isolation, although the DTE here is - vice, not - nese. 


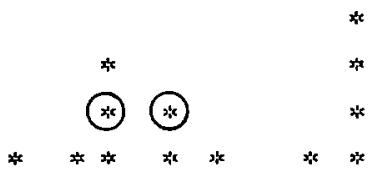

a Chinese expert's advice

The problem with the constraint is that it suggests that the potentially clashing elements are situated in the columns over - $\underline{\text { nese }}$ and $\underline{e x}-$, rather than over -nese and some following, stronger syllable, like -vice in (7). And of course, if Iambic Reversal does take place in (7), it is because -vice is a fulcrum, not ex-. In fact, because they define 'clashing' the way they do and constrain the rule the way they do, they predict pressure for change in many situations where there is none, as in (8).

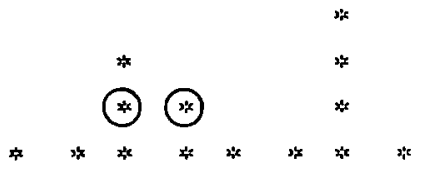

A Chinese expert is useless

If the general descriptive framework is to be maintained, the definition of 'clashing' should be revised. This could be done by including a provision that the right-hand column be not lower than the left-hand column, or, alternatively, that the left-hand element be positioned at the top of its column. Prince (1983), whose description does not have the above flaw, in effect introduces the second constraint. In his tree-less description it says 'Move the clashing element', and since in (B) this operation would leave a hole in a column, it is ruled out by the general well-formedness condition that columns have elements at all levels.

In summary, then, there is no employment for a feature [nuclear] in the English rhythm rule, because if we say that the shiftable must be [-nuclear], it could be objected that it should simply not be the main stress in the syntactic phrase, irrespective of its position in the intonational phrase. Neither can we say that the fulcrum must be [+nuclear], as it will be objected that [-nuclear] stresses, too, cause stress shift. As there are no other rhythm rules on a level beyond the word in English, we will now turn to the rhythm rules of Dutch. 


\subsection{RHYTHM RULES IN DUTCH}

Rhythm rules exist in many forms. While Iambic Reversal would appear to be the only phenomenon of its kind in English, it would not be reasonable to regard stress shift in Dutch as a unitary process, although, of course, it may be true that general principles or rhythmic patterning are at the basis of all stress shift phenomena.

It will be argued that Dutch has four separate rhythm rules that operate on the level of the phrase or beyond.

\subsubsection{Iambic reversal}

The phenomena in Dutch that most closely resemble English iambic reversal should properly be seen as resulting from two separate rules. In general, rhythmic restructuring would seem to be sensltive to the following three factors:

1. Rhythmic template of the word in which the shiftable stress occurs. Thus, tum-tum (if followed by an accented word) is less likely to undergo Iambic Reversal, all else being equal, than tum-ti-tum, while tum-tum-ti may occupy an intermediate position: unique may never undergo it, fantastic might undergo it, while picturesque is more likely to undergo it than either of these. Similarly, increasing the number of unaccented syllables between shiftable and fulcrum, will decrease the likelihood of stress shift, and tum-tum-ti will thus be less resistant than tum-tum-ti-ti: bi-polar magnet is more vulnerable than bi-lateral talks. It will be clear that Liberman \& Prince's metrical grid and their statement of Iambic Reversal do not capture these differences in any way (cf also Bolinger 1981). In addition, it may be the case that the position of the fulcrum in its word may be of influence, as the number of unaccented syllables preceding it in the word may be related to the pressure it can exert on the shiftable. Without controlled observation, however, it is difficult to establish just how important these factors are. Moreover, it will be necessary, for the purposes of a more detailed description, to decide on an operational definition of stress shift in order to deal with cases where the shiftable and shifted positions are sufficiently far removed for both syllables to be perceived as 'stressed', as in the case of 'hetero'sexual 'tendencies. 
2 The presence of a semantically active boundary between the shiftable and shifted positions Liberman \& Prince explicitly mention this factor, and propose that in order to make their Iambic Reversal Rule sensitive to such boundaries, lexical entries should have a guaranteed metrical strength of two levels, even if it is monosyllabic This requirement blocks Iambic Reversal in Montana cowboy, but it allows it in good-looking soldier ((9))

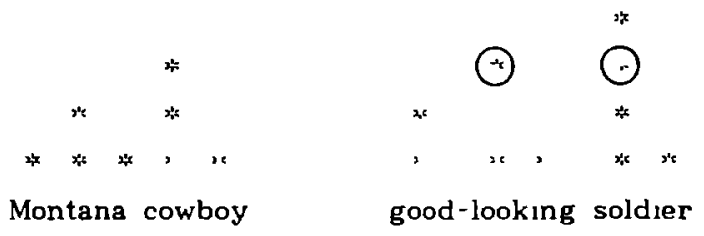

3 Famliarity of the concept denoted by the phrase concerned, possibly measurable as its frequency of occurrence Thus, if in a talk on brain functions the concept of a photographic memory is introduced for the first time, it may well not have Iambic Reversal applied to it, but subsequent mention wلl make this increasingly likely It is suggested that this factor may, on occasion, be exploited by speakers stylistically, to suggest that they 'know what they are talking about' This may also be the reason why evaluative adjectives like pıcturesque, fantastic and unique are so much less likely to undergo Iambic Reversal than more 'objective' adjectives like Romanesque, Norwegian and antique ( $\mathrm{Cf}$ also Bolinger's comments on the influence of word-meaning, 198140 )

Whlle all three factors would seem to have an influence (however they are 'weighted') on the same rule in English, in Dutch, factor 2 sharply distinguishes between what I wll call Stress Retraction and Rhetorical Retraction

Stress Retraction is virtually obligatory in certain adjectives and adverbs Schultink (1979) characterises this group as follows

1 in compounds dood'ziek ('very ll'), donker'blauw ('dark blue'),

2 in compounded derivatives drie'stemmig ('for three singers'), onder'gronds ('underground', - $\underline{\mathbf{s}}$ is a suffix), 
3. adjectives like aan'staande, jongst'leden, laatst'leden (before days of the week: 'next', 'last'(2x));

4. formations with on-: on'juist ('incorrect'), onbe'leefd ('impolite').

If the items under 3 . are listed as exceptions, the generalisation seems to be that shiftable and shifted positions should be separated by a (productive) morpheme boundary. In fact, Van den Berg (1970) noted that in words beginning with on-, retraction seemed to be sensitive to whether on- could be replaced with the free morpheme niet ('not'). If it is true that the nature of the boundary provides the explanation, then how should it be defined? Items that fail to undergo Stress Retraction, but do have a boundary of some sort, form a more varied group than may appear at first sight. Schultink observes that derived compounds (e.g. eer'zuchtig < 'eerzucht, lit. 'crave for honour', i.e. 'ambition' or (my example) grond'wettelijk < 'grondwet, lit. 'ground law', i.e. 'constitution') are exempt from the rule. One could add most adjectives consisting of Noun+Verb+present participle suffix, like zorg'wekkend 'worrying', tijd'rovend 'time-comsuming', angstaan'jagend 'fear inducing' (but not Frans-'sprekend 'French-speaking') and almost all words that like eer'zuchtig have the pattern ........ ig (whether derived compounds or not), such as licht'vaardig 'rash', recht'lijnig 'blinkered', zee'waardig 'sea-worthy', zwart'gallig 'very pessimistic', etc.. Also formations with - vriendelijk are exempt, like gebruikers-'vriendelijk 'user-friendly' and items like gelijk'vloers 'on the same floor', Franco'foon 'Francophone'. Thus, there are such contrasts as een 'baby-zacht 'huidje ('a baby-soft skin') and een baby-'vriendelijke 'luier ('a baby-friendly nappy'). Intuitively, it would seem as if adjectives that are subject to the rule contain $a$ higher-order boundary, say \# (or, if this is preferred, span a higher-order domain). In order to see that this intuition is not based on the facts of Stress Retraction themselves, observe that shifting adjectives cannot serve as constituents of compounds, but that non-shifting ones can. Thus, while a formation like "ultra-baby-zacht is not only non-existent, but also ill-formed, the formation hyper-gebruikers-vriendelijk is clumsy, but well-formed. Similarly, "on-bovengronds, "pseudo-doodziek, "hyper-keihard, "ultra-Frans-sprekend are bad, but ongelijkvloers, pseudo-zeewaardig, hyper-eerzuchtig and ultra-Francofoon (e.g. ' $\sim$ Walloons') are fine. It is apparently this \#-boundary, of which a compound may contain only one, that Stress Retraction is sensitive to. 
Rhetorical Retraction applies to adjectives and adverbs irrespective of a boundary (provided of course the usual phonological conditions are met). Both the absence of any discussion in the literature of this rule and the occasional complaints against its effects in the letters-to-the-editor sections of general periodicals suggest that the rule is an innovation. As its name implies, style, or more generally the rhetorical or propagandist content of the text, would appear to be an important variable accounting for its application. Its effects can frequently be observed in the speech of politicians, participants in meetings, and radio and television announcers, as in examples (10), (11) and (12) respectively.

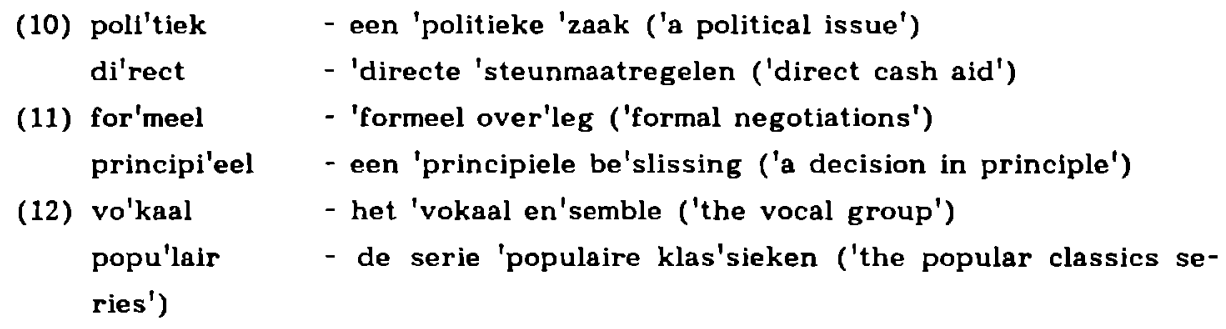

It should therefore be possible to find a minimal pair of adjectives that differ only in the presence of a morpheme boundary. An example is onver'mijdelijk in the sense of 'inevitable; always there' (no boundary) and onver'mijdelijk in the sense of 'unavoidable; which could not be avoided' (with boundary). In (13) onvermijdelijke can only mean 'always there', while in (14) we could have either 'the error (fout) that could not be avoided', with Stress Retraction, or the same meaning as in (13), with Rhetorical Retraction.'

(13) de onver'mljdelijke 'fout

(14) de 'onvermijdelijke 'fout

While it may be established that a description of stress retraction is certainly not complete when we have only Liberman \& Prince's metrical grid and Iambic Reversal Rule at our disposal, and that much more careful research is needed for both English and Dutch to establish just what the relevant favouring factors are and how they are weighted, we cannot detect any contribution on the part of the feature [nuclear] in the structural description of either Stress Retraction or Rhetorical Retraction in Dutch. Our attention should therefore be directed to a third rhythm rule in this language. 


\subsubsection{Trochaic Reversal}

The rhythm rules discussed above involve stress shifts to the left. Liberman \& Prince cite some of Kiparsky's examples of the reverse phenomenon in German (Kiparsky 1966), in which language we not only get halb'tot versus der 'halbtote 'Man, but also 'anziehen versus den 'Rock an, shift, which I will refer to as Trochaic Reversal, also exists in Dutch. Kiparsky gives two situations in which it may occur. First, it may occur in compounds

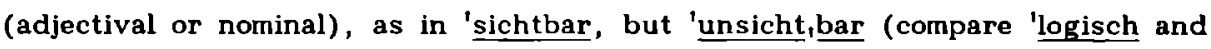
'un,logisch) and in 'Althoch,deutsch, 'Nachmit,tag. 'Urgross,vater, 'Vorur,teil, 'Luftab,wehr, etc. In these situations, a word (simple or compound) with the primary accent on the first syllable is embedded in a larger structure requiring the primary accent on the syllable preceding $i t$, which syllable acts as a fulcrum shifting the embedded primary, now secondary, stress on to a later syllable, which, in Liberman \& Prince's terms, must of course be [+stress]. Phonetically, Trochaic Reversal amounts to a durational restructuring of the post-accentual syllables and does not involve shifts of pitch peaks, as do the iambic rules discussed elsewhere in this article. In Dutch, this Trochaic Reversal is common in nominal compounds, provided the embedded item is not itself compound and the shifted syllable contains a short (or [-tense]) vowel. Examples are 'tandpas, ta ('toothpaste'), 'bloedli,chaampjes ('corpuscles'), 'jeugdher,berg ('youth hostel'), plant'soenar, beider ('municipal gardener'), 'kleurpot,lood ('colour crayon'), but not 'dans,leraar ('dancing master'), 'reis, schema ('itinerary'), 'post,giro ('Postal Giro'), which have a long (or I+ tense]) vowel in shiftable position.

Second, it occcurs in prefixed verbs that have the accent on the (separable) prefix, as in German 'mitnehmen versus das 'Buch mit, nehmen. Similarly, Dutch has 'opbreken versus de 'weg op breken ('to break up the road') or 'opmaken versus de 'kas op,maken ('to count/make up the cash'). The restriction to verbal prefixes would certainly seem sensible for Dutch, because 'opmaken in the sense of 'to finish, to deplete', where of is more properly an adverb, would not as readily be so treated. Thus, although 'opmaken in isolation is ambiguous, it is not in post-primary position: 'to (completely) spend the cash' would be de 'kas iomaken. Note that this generalisation not only captures the fact that 'opmaken ('to count, make up') is a single lexical entry, but also that Trochaic Reversal does not operate across a boundary within a nominal compound. As was said above, if the embedded element is itself a compound, no stress shift 
takes place 'spekıpannekoek ('bacon-pancake'), 'padvinders,zakmes ('scoutpen-knife'), 'oven, handschoen ('oven-mitt)

The question we need to consider here is whether Trochaic Reversal is in any way sensitive to the feature [nuclear] Examples (15) and (16) demonstrate that it is not In (15) the nuclear syllable would be noolt ('never'), while in (16) it is geld ('money')

Geld oppotten-doe 1k frodt

money hoard do I never

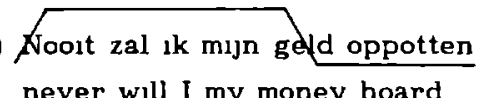

In either case, the prominence on geld is the fulcrum, and in either case -potis the most promment syllable of oppotten (in isolation 'oppotten) That is, given the right lexical input, Trochaic Reversal is operative irrespective of the value of the feature [nuclear] for geld It is of course true that op may not be nuclear, but as in the case of Iambic Reversal, this does not compel us to include it in the structural description or add it as a constraint We are again dealing with an if-condition, not an iff-condition the requirement is sumply that the fulcrum be metrically stronger than the shiftable

\subsubsection{Non-nuclear Retraction}

We have now come to the last of the four Dutch rhythm rules Compare (17), in which the adjective compound licht-blauw ('light-blue') occurs in sentence-initial position, with (18), in which the adverb meestal ('as a rule') occurs in the same position Note that both licht-blauw and meestal have the word accent on the final syllable in isolation

(17) a Licht-'blauw is de kleur van haar 'ogen

b ' 'Licht-blauw is de kleur van haar 'ogen light-blue is the colour of her eyes

(18) a '-Vees'tal gaan ballonnen naar 'boven

b 'Meestal gaan ballonnen naar 'boven as-a-rule go balloons (to) upwards 
Utterances (17) and (18) have the same rhythmical pattern, except for the first two syllables: stress shift does not apply to licht-blauw, but does apply to meestal. The reason why licht-blauw does not undergo it is that for the purposes of Stress Retraction there is no fulcrum nearby, and certainly not in the same phrase. The stress shift for meestal is obligatory: a pronunciation with the word-accent on the second syllable would be deviant, given the intonation contour. Clearly, we are dealing with a different rule altogether. Its distinguishing characteristics can be stated as follows:

1. While Rhetorical Retraction, and to a lesser extent Stress Retraction, are variable, this rule is obligatory. Both non-application in the right context and application in the wrong context are felt to be deviant by native speakers.

2. Give or take a word-boundary, the stress shift rules we have seen so far apply to certain rhythmic configurations or metrical grids, rather than to particular morphemes or words. The present rule applies to a finite set of quantifiers and adverbs, provided their phonemic make-up includes at least two [+stress] vowels and the word accent falls on the last of them.

3. In the description of the stress shift rules discussed so far we needed to refer to constituent boundaries and the syntactic bond or distance between fulcrum and shiftable. The present rule is applicable with the fulcrum following at whatever remove and with whatever boundaries occurring between it and the shiftable, provided it follows in the same tone group: this fulcrum is the nucleus.

The following items are subject to the rule, which we will refer to as Non-nuclear Retraction:

(19) Quantifiers

$$
\begin{aligned}
& \text { allebei ('both') } \\
& \text { allemaal ('all') } \\
& \text { allerlei ('all sorts') } \\
& \text { iedereen ('everybody') } \\
& \text { menigeen ('many people') }
\end{aligned}
$$

Adverbs

$$
\begin{aligned}
& \text { altijd ('always') } \\
& \text { allesbehalve ('anything but') } \\
& \text { enigszins ('somewhat') } \\
& \text { helemaal ('entirely') } \\
& \text { meestal ('as a rule') } \\
& \text { niettemin ('nevertheless') } \\
& \text { ruimschoots ('amply') }
\end{aligned}
$$


Adverbs (contd)

overal ('everywhere')

onlangs ('the other day')

(tot) dusver ('thus far')

The input to the rule is lexically determined. It is not the case that all words in these classes are subject to it. There are a few that have the accent on the lest, but do not shift, like alleen ('only, alone'), althans ('at least'), inderdaad ('in fact'), uberhaupt ('at all'). Interestingly, however, the words bijna ('almost') and onderling ('among one another') have a 'dictionary' pronunciation with the accent on the first syllable, but are frequently pronounced with the accent on the last when they occur as one-word sentences (and as such carry the nucleus). If these 'linguistic' pronunciations come to replace the 'dictionary' pronuciations, which does not seem unlikely, we would have two instances of accentual backformation. The active status of the rule is also lllustrated by the fact that beginning Dutch learners of English often pronounce words like always, also, beforehand, nowadays with the accent on the last syllable when they occur in nuclear position. Finally, it may be noted that al ('already') which derives from earlier alreeds, alrede, cannot be given the nucleus, the reason for which is possibly that it has lost the syllable that is to carry it. (The equivalent of English I've done that alREADy is Dat HEB ik al gedaan.) It cannot occur as a one word sentence either, it being obligatorily accompanied by nu ('now') or toen ('then') to carry the nucleus. Similarly, wel eens ('occasionally') is excluded from nuclear position, eens being a fossilised 'weak form' with reduced schwa, although the pressure of Non-nuclear Retraction frequently brings some speakers to put the nucleus on that syllable when wel eens occurs in a one-word sentence."

It should be stressed that the rule is sensitive to the feature [nuclear] only. The degree of emphasis that is applied to altijd in $(20)$ is entirely irrelevant: provided the nuclear tone follows (on zeggen) the word accent comes on al-. Similarly, no amount of muffling of the prominence on the word altijd in (21) will cause it to have the accent on al-, provided the word has the nuclear tone, in this case a fall. That is, both (20) and (21) have a high falling 'head accent' on the first prominence peak, and a low fall on the second: 
(20)

/Altijd heeft hij wat te zeggen

He's always got to say something

(21)

Ka'pot kan het al'tijy nog!

Broken it can always (i.e. stop fiddling about with it)

Neither is the rule sensitive to whether the word comes early or late in the tone group. When we have an early nucleus in (22), for instance, the word accent is on the second syllable:

(22) (A: When has he got to say something?)

$B:$ Al'thij heeft hij wat te zeggen!

What we are dealing with is, in other words, the strongest possible case of a rhythm rule sensitive to the feature [nuclear]: (a) it is obligatory, and (b) it applies if the fulcrum is nuclear (and, by necessity, the shiftable is not). Obviously, it would be interesting to see what this rule can tell us about the intonational structure of the utterances that we began this article with. Utterances (1), (2) and (3) in fact translate quite naturally into Dutch, without their contours being affected in any important way ((23)-(28) were elicited from a Dutch female informant who was asked to pronounce the Dutch sentences concerned with the intonation patterns of the English utterances (1), (2) and (3). Note that Dutch $/ \mathrm{h} /$ is voiced.)

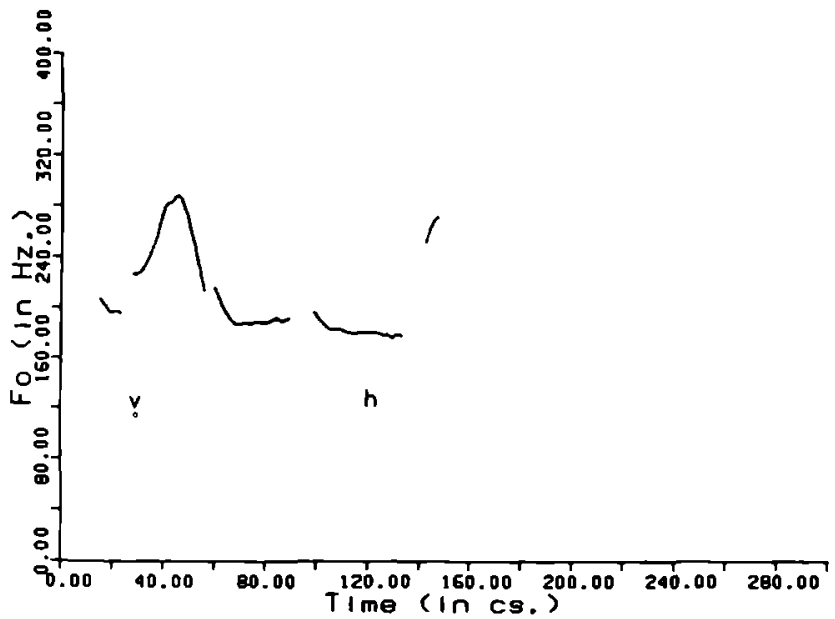

Je vader zal me njet kunnen helpen 
(24)

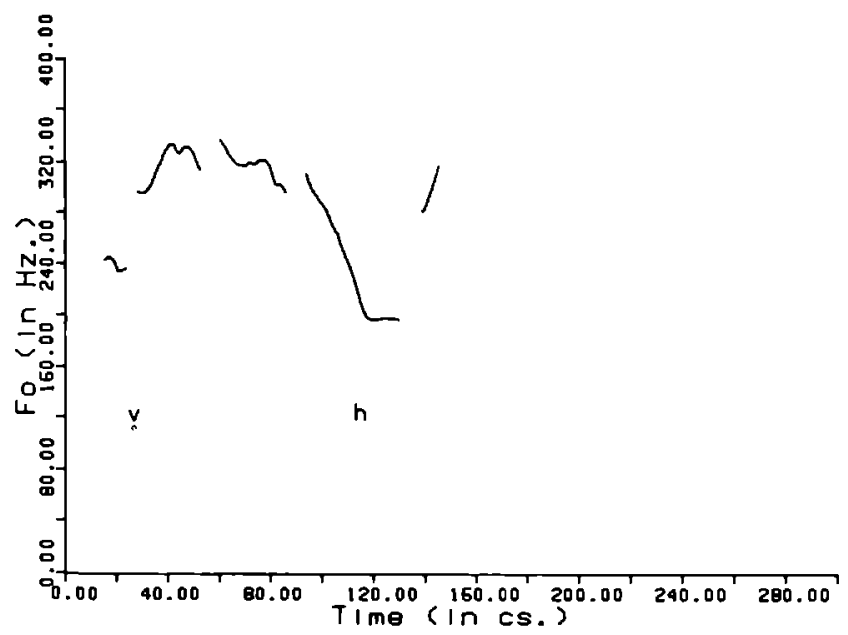

Je vader zal me niet kunnen helpen

(25)

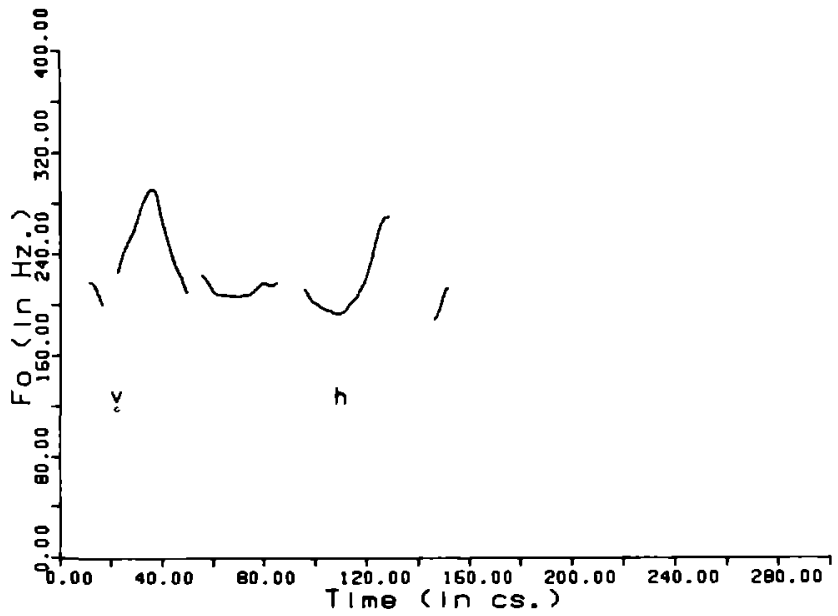

Je vader zal me niet kunnen helpen 
When we substitute iedereen (subject to Non-nuclear Retraction) for je vader we get :

(26)

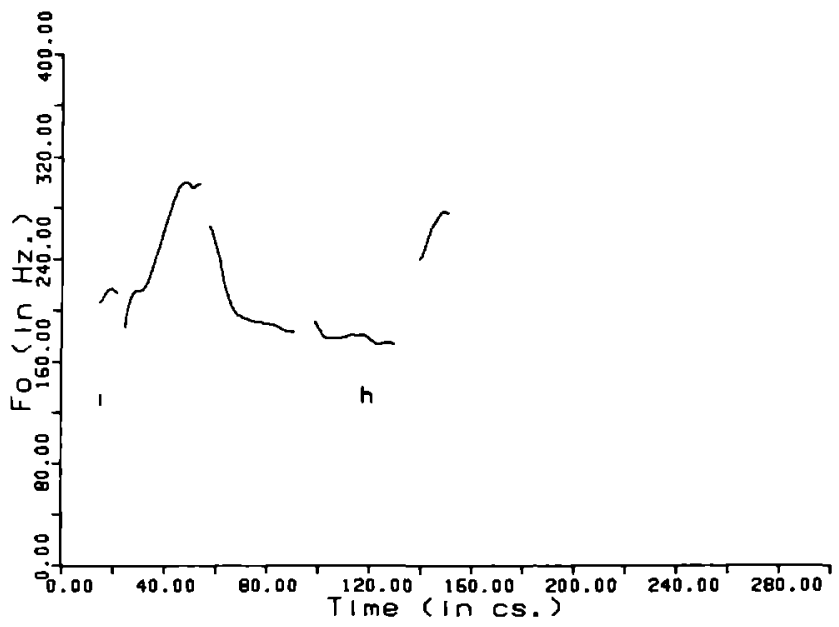

ledereen zal me niet kunnen helpen

(27)

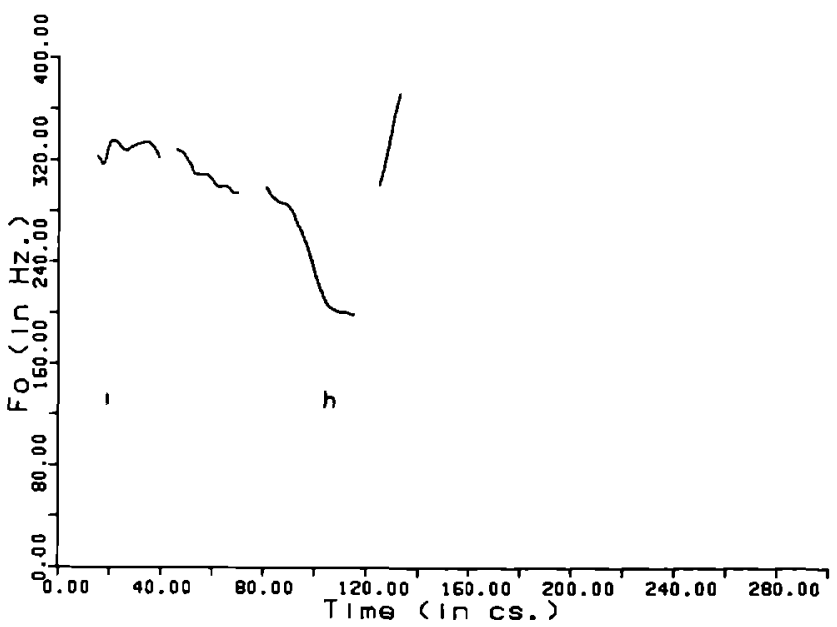

Iedereen zal me niet kunnen helpen 
(28)

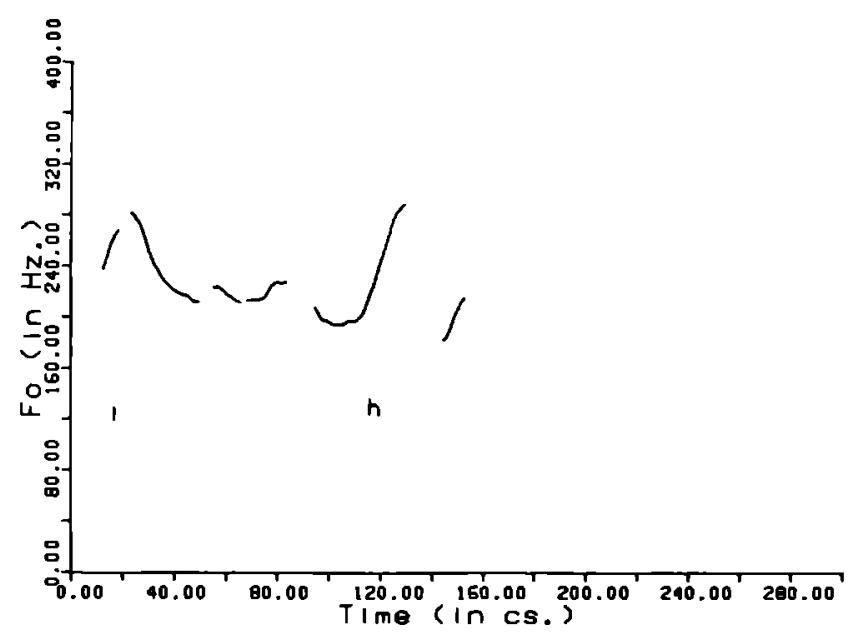

Iedereen zal me nlet kunnen helpen

When we compare (26) with (27) and (28), it will be clear that stress shift has occurred in (27) and (28), but not in (26). Clearly, helpen is post-nuclear in (26) - and by consequence in (23) - and the rising pitch movement does not mark a sentence accent there. In (24), (25), (27) and (28), however, helpen is marked by an accent-lending rise, as is evident form the fact that Non-nuclear Retraction has occurred in (27) and (28).

Unfortunately, Non-nuclear Retraction is a rule of Dutch, not of English, and the intonation of Dutch is not the same as the intonation of English. Willems (1982) demonstrates that both English and Dutch listeners can fairly successfully tell a Dutch contour from a corresponding English one, and Gussenhoven (1983) gives illustrations of how the languages may differ even with regard to the location of the nucleus. Yet, I would like to suggest that at the level we are dealing with here, that of the phonological status of major accents in the tone group, the two languages do not differ, and that it is therefore not unreasonable to see Non-nuclear Retraction as reflecting the phonological relevance of 
the nucleus in a shared system. There are, to be sure, other nucleus-governed phenomena that the languages have in common. One, pointed out to me by Bob Ladd (pc), is downstep, a term borrowed from analyses of tone languages, to describe what $O^{\prime}$ Connor \& Arnold (1973: 37) call the 'stepping head': a series of descending terraces, the beginning of each one of which marks an accented syllable (Pierrehumbert 1980). 't Hart \& Collier describe the same phenomenon in Dutch as a sequence of $E$ falls (1975). Observe that while the domain for downstap can be - and often is - smaller than that of the tone group, it cannot be terminated in the middle of an NP or VP: its termination must coincide with a major category boundary. Thus, in (29), downstep cannot end after damn:

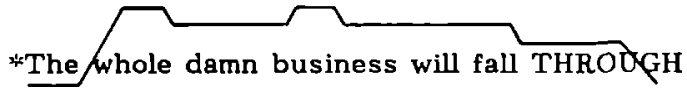

However, the nucleus always provides a possible point at which downstep may terminate. Although fall through is a single lexical item, through may fall outside the domain of downstep in (30) because it is the nucleus:

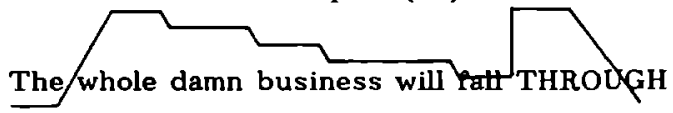

When we add another word to carry the nucleus, it can no longer terminate downstep in the same way, as is illustrated by

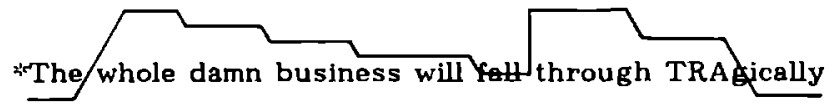

The same regularity can be observed in Dutch: while it is possible to leave toestanden out of the downstep domain in De hele familie van der Meer had van die moeilijke TOEstanden ('The whole van der Meer-family had these difficult problems'), downstep cannot be broken off at the same point in De hele familie van der Meer had van die moeilijke toestanden geNOEG('.... was fed up with these difficult problems'). 


\subsection{THE DIVIDED FALL-RISE: ONE OR TWO NUCLEI?}

The question we can now try to address is whether Dutch Non-nuclear Retraction can tell us anything about post nuclear prominence, more in particular whether a case can be made in Dutch for the existence of a simple fall-rise by the side of a compound one, which is the 'sumple vs compound' opposition most frequently postulated for English (the only one, for instance, to be included in O'Connor \& Arnold's description) To take O'Connor \& Arnold's examples as the basis for our discussion, let us see whether the putative distinction in (32) and (33) (1973 29) can be shown to have a counterpart in Dutch

(32) My `mother was born in Sheffield (but not my father)

(33) My 'mother was born in sheffield (Isn't that interesting?)

They point out that although the resultant contours are 'very sumlar indeed', 'they are nevertheless very different in meaning' and that it is therefore necessary to keep them separate Again, both utterances translate faıly literally into Dutch and retain their intuitively different meanings And, barring low level phonetic detal with respect to pitch span (W山lems 1982), also their contours remain intact, with the fall and the rise taking off from corresponding elements In the notation of 't Hart \& Collier (1975) the pattern for both would be 9

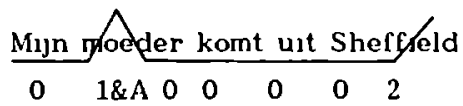

( 0 =level, $1=$ prominence lending rise, $A=$ prominence lending fall, $2=$ non-prominent rise )

If we now move one of the words that is subject to Non-nuclear Retraction into the position of Sheffield, by replacing the lexico-syntactic structure with, say, Mijn moeder kent ze allemaal ('My mother knows all of them'), then the version corresponding to (32), in which only mother is claumed to be nuclear, ought to show the rise taking off from the first syllable of allemaal if it, too, is [-nuclear] in Dutch, whereas in the equivalent of (33), in which both mother and Sheffield are claumed to be nuclear, we ought to see a rise taking place on the last syllable of alemaal, if indeed it is nuclear Both versions, however, are identical 
Mijn moeder kent ze allemfal (either 'but not my father'

$\begin{array}{lllllllll}0 & 1 \& A & 0 & 0 & 0 & 0 & 0 & 2 & \text { or 'Isn't that interesting?') }\end{array}$

and have the rise on the final syllable.

Moreover, this final rise is not a nuclear tone, but a boundary tone, as is apparent when we add a further unaccented word like nog ('still') or natuurlijk ('of course') to this sentence. Such a contour (cf (36)) is distinct from one which has a nuclear rise on allemaal (cf Liberman \& Sag's contradiction contour'):

$$
\begin{aligned}
& \text { Mijn noeder kent ze allofnaal nog!? } \\
& 0 \quad 1 \& A \begin{array}{llllll}
0 & 0 & 0 & 0 & 0 & 1
\end{array} \quad(\text { (or } 2) \\
& (\theta=\text { high reference line) }
\end{aligned}
$$

(37) Mijn moeder kent ze allemaal nofs?

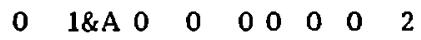

For Dutch, in other words, it would appear that no case can be made for a distinction between a smple and a compound fall-rise. The fall-element is treated as nuclear, and the risc-element as non-nuclear in either case.

It should again be stressed that this conclusion concerns a fact of Dutch, not of English. In spite of the close resemblance of the intonational systems of the two languages, one cannot use the absence of an option in one language as evidence that its claimed presence in another is spurious. Yet, the fact that the English pair (32)-(33) has phonetically very similar - and semantically equivalent counterparts in Dutch which appear to be identical, should make one suspicious. The problem is, too, that in at least some discussions about the opposition between the fall-rise and the fall-plus-rise in English, the case for it is artificially strengthened by the tacit inclusion of contours that consist of a pre-nuclear accent (a falling head) followed by a nuclear rise (cf also Note 10). Sharp (1958), who offers a large number of examples of the opposition, would on occasion seem to smuggle in such examples with nuclear rises. Examples of 'true' oppositions he gives are (38) and (39).

(38) ${ }^{\top} \mathrm{He}$ 's the plumber ( $=$ the other man isn't)

'He's the /plumber ( = ask him to mend the tap) 
(39)

$\checkmark$ I can (= even though you can't)

'I can (as an unenthousiastic reply to 'Who plays bridge?')

But (40) should be treated with caution

(40) 'What shall I tell hum? (= I really can't think of anything)

which is probably 'What shall I 'TELL him' This is certainly true for 'All ,right, which is - normally speaking - impossible with the nucleus on all Observe that there 15 , of course, a real distinction between (not Sharp's examples)

(41) “TWELVE men (= not eleven men)

(42) 'Twelve, MEN (= don't you mean eleven women')

as can readily be seen if we replace twelve with thirteen

(43) Thur $`$ TEEN men $(=(41))$

(44) Thirteen , MEN $(=(42))$

But how are we to split up (43) into two phonologically different patterns? Of course, it is possible to give somewhat different contexts in which (43) would be appropriate One context is given in (41) Another would be created if we assume it to be spoken in a surprised or tut-tutting fashion by someone who recelves a photograph of her friend's wedding ceremony, in which she appears before a clerical official with thirteen bridegrooms What would appear to constitute the difference here is the pragmatic basis for the choice of a non-focus status for men in the first example, men was already present in the discourse, in the second it was not Rather, it was avalable for non-focus reference in view of the background of the wedding, as her friend was expected to marry a man It does not follow, however, that the two structures are also phonologically distinct

There is a further problem that the Dutch contour in (34) raises Standard descriptions of British intonation have it that the rise-element of the fall-rise takes off from the last 'secondary accent' in the tal, rather than on the last syllable of the tone group Thus, Gimson (1980 268) says it is 'initiated on the syllable carrying the secondary accent', and O'Connor \& Arnold (1973 13) state that it takes place on or from the last stressed syllable of the word group' 
Crystal (1969: 220) speaks of 'distribution (of the elements) over lexical items', implying association of the rise-element with words rather than syllables. (Inc1dentally, Crystal's distinction between 'complex' and 'compound' fall-rises is easier to Interpret: the former are confined to the syllable (1969: 217), the latter are spread over more words, and both (32) and (33) exemplify compound tones in his terms. Crystal's concern is to separate compound tones from sequences of tone groups). Thus, the situation in British English would seem to be different from that found in Dutch, but also from that found in American English. Pike (1945) associates the rise element $\left('-3^{\prime}\right)$ with the last syllable of the tone group, irrespective of word-accent:

(45) Help, Catherine!

$1-4-/-4--3 /$

Similarly, Liberman (1975) and Pierrehumbert (1980) explicitly state that their high boundary tone, one function of which is to provide the rise-element of the fall-rise, can only be associated with boundaries of the intonation contour.

In order to demonstrate that we are dealing with a real difference between British English on the one hand and American English and Dutch on the other in the manner in which the final rise is associated, we need examples in which the 'secondary accent' is at least two syllables removed from the end of the tail, since the fact that the word accentual patterns of, for instance, Glasgow and Dundee are preserved in (46) and (47) could be due to the preservation of the durational structure, accented syllables being longer than unaccented ones, all else being equal. That is, we may hear the 'accent' on dee in (47) as a result of the greater durational latitude this syllable gives to the final rise, as opposed to the shorter gow, which may cause the rise to take the shape of a step-up from Glas- in (46).

(46) My "mother was born in Glasgow

(47) My mother was born in Dundee

In an utterance like (48), however, where the secondarlly accented syllable cow- is more than two syllables removed from the end, we would have, crudely, pattern (a) according to the standard British description, but pattern (b) according to an alternative description which associates the second element of a fall-rise with the last syllable: 
b That's what I call cowardlupess'

Informal observation suggests that informants accept both patterns as well-formed, and find it difficult to hear any difference between them In four cases out of five, moreover, informants confidently responded with pattern $\underline{b}$ when offered a for imitation It is suggested, therefore, that the difference is of a low-level phonetic kınd, and that structurally the two utterances in (48) are identical as far as nuclear tone choice and location is concerned Certainly, I have found no clams that this difference should be associated with a difference between sumple and compound fall-rises 10

There is, moreover, language-internal evidence in English for a unitary analysis of a (divided) fall-rise that is at least suggestive Echoed statements, in the words of O'Connor \& Arnold (1973 75) may have the 'effect of questions in most cases, as in so many other European languages '[and are used] to elicit a repetition by the listener of something he has sald' This type of utterance requires a high rise as the nuclear tone Note that for (1) that nuclear tone would have to go to father rather than help, and for both (32) and (34) to mother rather than to Sheffield, as in (49) and (50) Simularly, an unpatient repetition, an utterance type not dealt with by $O^{\prime}$ Connor \& Arnold, requires a (high) fall on the nuclear syllable Note again, that if (1), (32) and (33) were repeated by a speaker who wished to register his impatience at not having been understood the first time, this fall would likewise be placed on father and mother respectively, as in (51) and (52)

(49) Your 'father won't be able to help you?

(50) Your 'mother was born in Sheffield?

(51) Your 'father won't be able to help you'

(52) My 'mother was born in Sheffield'

It could of course be argued that in the case of double nuclei the first element rather than the second element is selected for these non-complex tones because, as Halliday and $O^{\prime}$ Connor \& Arnold claum, it is the more umportant of the two This approach leads to obvious problems, however Note that anyone who claums that the tones in (32) and (33) are different on the basis of the semantic difference between the utterances, would also have to argue that their impatient 
counterparts or their echoed counterparts really contain different tones, as the semantic differences between them remain unaffected Again, it would appear that we are here dealing with the straightforward substitution of one term for another from the same paradigm The tests also suggest that part of Crystal's discussion of the compound fall-plus-rise may be based on tone groups consisting of a falling head followed by a rising nuclear tone, as in / ROUND the 'CORner/ (1969 268), although, of course, given out of context as they are, it is not really possible to pronounce on their structure In any event, this would provide an explanation for his statement that the second element of a fall-plus-rise is functionally more important than the first (1969 219)

There does, however, remain a problem even for an analyst who wishes to see a divided fall-rise as a single accent, in particular when there is a further hypothesis lurking round the corner one that would claim that tones have meanIng Somewhere a boundary must be drawn beween a sequence of two tone groups, one with a fall and one with a rise, and a single tone group with a (divided) fall-rise what, for example, is the structure of (53) to (60)?

(53) I'd 'do it if I were, you

(54) You're not a Jehovah's 'witness are you?

(55) I can give you a 'rise if that's what you, mean

(56) That's what I've always 'wanted a chuld

(57) They never do what you 'want them to do, these, chuldren

(5B) I said 'no', damn 1 t

(59) 'NN', he said

(60) He 'falled, the numskull

How can we tell whether we are dealing with a single tone group or a sequence of two? The question, of course, is of interest also when we do not harbour a conviction that tones are semantic units (cf Crystal, 1975 29, who points out that they are not necessarly invested with independent meaning, but considers the question phonologically relevant) But if they are, there is the more reason to believe that the answer to the question is non-arbitrary and absolute, and not just one of descriptive elegance It would, under that assumption, be unexpected for the opposition to be 'neutralised' in utterances like (53) to (60), unless we were to assume that the combination of the meanings of two terms (the fall and the rise) wll somehow equal the meaning of a third (the fall-rise) There is perhaps an indicative test that can be applied to these utterances If we pronounce them with a 'dip' just before the putative 'rise' 

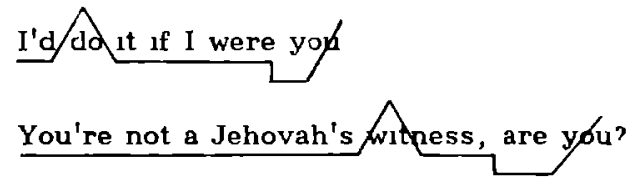

it wll appear that such dipping is odd in (53), (55), (57), and (59), but are perfectly acceptable in (54), (56), (58) and (60) By this test, the former four would have to be classified as single tone groups with a fall-rise in nuclear position, whle the latter four would be sequences of two tone groups, one with a fall and another with a rise

To return briefly to the $O^{\prime}$ Connor \& Arnold examples we gave at the beginning of this section, it may be observed that although (32) and (33) are identical from the point of view of nuclear tone choice and location, they need not be identical as far as their focus distribution is concerned It has been observed In many places (e g Schmerling 1976 82, Chafe 1970 225, Pierrehumbert 1980 73) that verbs often remain unaccented even though they are 'comment' or 'focus', 1 e unpredictable from the context Arguably, (32) has just my mother in focus, but (33) my mother was born This difference in focus need not be reflected in a difference in nucleus assigment

It should be observed that an interpretation of the fall-rise as a unitary choice from a paradigm of tones does not make it umpossible to regard the rise element as a boundary tone (cf Brown et al 1980 117, Pierrehumbert 1980 16), provided the following points are made

1 The boundary tone is not an independent choice from a system comprising a boundary fall (or 'low tone') and a boundary rise, but an obligatory movement determined by the nuclear tone option employed for the preceding nucleus,

2 It is not necessarily associated with the last lexical item or any 'secondary stress' in the tal, but - frequently - with the last syllable of the tal

The double-focus hypothesis concerning the fall-rise has vitiated a lot of research in English intonation An interpretation of the rise-element of the fall-rise as 'nuclear' and therefore 'focus', forces analysts to look for semantıc or pragmatic reasons why the item it is found on is singled out to carry it $A$ quotation from André (1973-4 115) wlll llustrate the point 
you / see the ' difference $N$ 'is that\#

As regards the second focus item [ $\left.\begin{array}{lll}1 & \mathrm{e} & 1 \mathrm{~s}\end{array}\right]$, it can be interpreted as a normally non-focal item, being marked when major focal in such a case "be", if the only element in the verb phrase, has contrastive implications in terms of tense and polarity

The reason for the rise on is lies of course in its being final in the tone group concerned Likewise, Lindstrom (1978 102), taking a simlar view of the divided fall-rise, is forced to conclude that vocatives may or may not be nuclear (cf 'Thank you Mr Smith vs 'Thank you Mr ,Smith), thereby missing the generallsation that vocatives are appended to tone groups as tals (e g Crystal 1975 25) The same comment applies to Tregidgo (1981), who speaks of 'focus' (for the fall-element) and 'counter-focus' (for the rise-element) to refer to nucleus + tal combinations marked with a fall-rise, and to Fox (1982) who analyses they're all the 'same, these polı,ticians as having major focus on the part before the comma when same has a fall, but as having major focus followed by a minor focus when same has a fall-rise, again, missing the generalusation that postposed non-focus elements like these politicians are appended as tals (Note the difference between this type of utterance and (57) on the one hand and (56) on the other ) In 1914, Coleman, at the conclusion of an article written well ahead of its time, asked if any of his readers could tell him why it is that yesterday is given prominence in (63), but not in (64)(Coleman used scalar numbers, from 1 to indicate low pitch, to 9 indicating very high pitch)

(63) $1 \quad 3 \quad 3 \quad 4-1 \quad 1 \quad 1 \quad 3 \quad 3$

I went to Malvern yesterday

$\begin{array}{lllllllll}1 & 3 & 3 & 3 & 4-1 & 1 & 1 & 1 & 1\end{array}$

(64) So you went to Malvern yesterday

Then and now, Coleman's query should receive this answer The difference in percelved prominence is the result of a difference in choice of 'tone' associated with Malvern in (63) a fall-rise is used and in (64) a fall The real question, therefore, is why in the one utterance one tone is used and in the other anoth$e r$, the difference in prominence on yesterday being Incidental to that cholce, and not independently of significance 


\subsection{FINDING THE NUCLEUS}

The approach taken in this article to establish the identity and the relevance of the nucleus of the intonation contour differs significantly from earlier attempts to give the concept of the nucleus a more clearly defined status by experimental means In a series of experiments, Currie $(1980,1981)$ found that listeners identify tonics in isolated utterances on the basis of a number of criteria, among which are the phonetic cues maximum $F \emptyset$ height, maximum $F \emptyset$ movement and maxumum intensity Cumulation of these cues generally led to fairly uniform identification of the tonic by (non-naive) listeners, but when these cues were in different locations in the utterance, judges tended to identify several syllables as 'tonic' In utterances that had a clear 'given/new' structure, either because of clefting or because the information focus was on a (non-final) contrasted element contradicting a previous element, judgements tended to be more uniform, and when such utterances are presented together with their context in written form, near-uniformity results (The term 'tonic' as used by Curre is equivalent to our term 'nucleus', and is based on Halliday $(1963,1970)$, whose terms for prenuclear and nuclear accents are 'pre-tonic' and 'tonic' respectively .) It is difficult to see what theoretical conclusions can be drawn from experinents like these Some of the conclusions that Currie (1981) in fact draws in a final discussion of the results may well in themselves represent true propositions, but it is arguable whether they can validly be based on her results In order to accommodate the various 'tonıcs' that are ıdentified in utterances with a neutral, or perhaps ambiguous 'glven/new' structure (the new element occurring as the rightmost lexical item), Currie proposes that a tone group may consist of more than one tone unit, each of which may have a stressed syllable It is clear that a tone group may contain more than one assigned accent, but whle I am not sure if the method applied by Currie would reveal even these accents (Gussenhoven 1982), it is unlikely to ledd to a better understanding of what the nucleus is It is not unreasonable to see her results as reflecting the unfortunate confusion with which the concept of the tonic is surrounded, in which case they would tell us no more than what we already knew Since the nucleus is commonly seen - or even described - as 'the most prominent syllable in the tone group', it is not surprising to find that what is essentially a phonological feature is interpreted as an aggiegate of (largely) phonetic features (cf Ladd 1982) It would not be difficult to present listeners with well-formed utterances, in which the nucleus is considerably less promment than one or more pre-nuclear accents, and so elicit an overwhelming majority of 'tonic' judgements on the 
pre-nuclear accent(s). What this illustrates is that - at least for the time span within which judges are required to give their responses - this task overtaxes the introspective powers of the judges to a considerable extent.

\begin{tabular}{|c|c|c|}
\hline 1. & $\begin{array}{lc}.91 & .09 \\
\text { Nooit zal hij TOEgeven } \\
\text { Never will he give in (always) }\end{array}$ & $\begin{array}{l}9 \quad 1 \\
\text { altijd }\end{array}$ \\
\hline 2. & $\begin{array}{l}\qquad .21 \\
\text { De kapitein is echt op heel veel plaatsen geWEEST } \\
\text { The captain is really in very many places been } \\
\text { (everywhere) }\end{array}$ & $\begin{array}{l}10 \\
\text { overal }\end{array}$ \\
\hline 3. & $\begin{array}{l}.10 \\
\text { Dat WEET ik niet. Hij at er in elk geval NOOIT } \\
\text { That I know not. He ate there in any case never } \\
\text { (always) }\end{array}$ & $\begin{array}{r}10 \\
\text { altijd }\end{array}$ \\
\hline 4. & $\begin{array}{l}1.0 \\
\text { Problemen waren er NOOIT } \\
\text { Problems were there never (everywhere) }\end{array}$ & $\begin{array}{c}10 \\
\text { overal }\end{array}$ \\
\hline 5. & $\begin{array}{l}.91 \quad .09 \\
\text { Ik heb er dikwijls MOEITE mee gehad } \\
\text { I have there of ten trouble with had (always) }\end{array}$ & $\begin{array}{l}9 \quad 1 \\
\text { altijd }\end{array}$ \\
\hline 6. & $\begin{array}{l}.83 \\
\text { Dat heb je } \frac{.17}{\text { VAAK in de uitverkoop }} \\
\text { That get you often in the sales (occasionally) }\end{array}$ & (see text) \\
\hline 7. & $\begin{array}{l}.09 \\
\text { Ga je geregeld naar een DOKter? } \\
\text { Go you regularly to a doctor? (occasionally) }\end{array}$ & $\begin{array}{ll}8 & 2 \\
\text { wel eens }\end{array}$ \\
\hline
\end{tabular}

Table 1. Nucleus judgements as a function of $F \emptyset$ height, and the effect of non-nuclear retraction in adverbs substituted in nuclear and non-nuclear positions. 

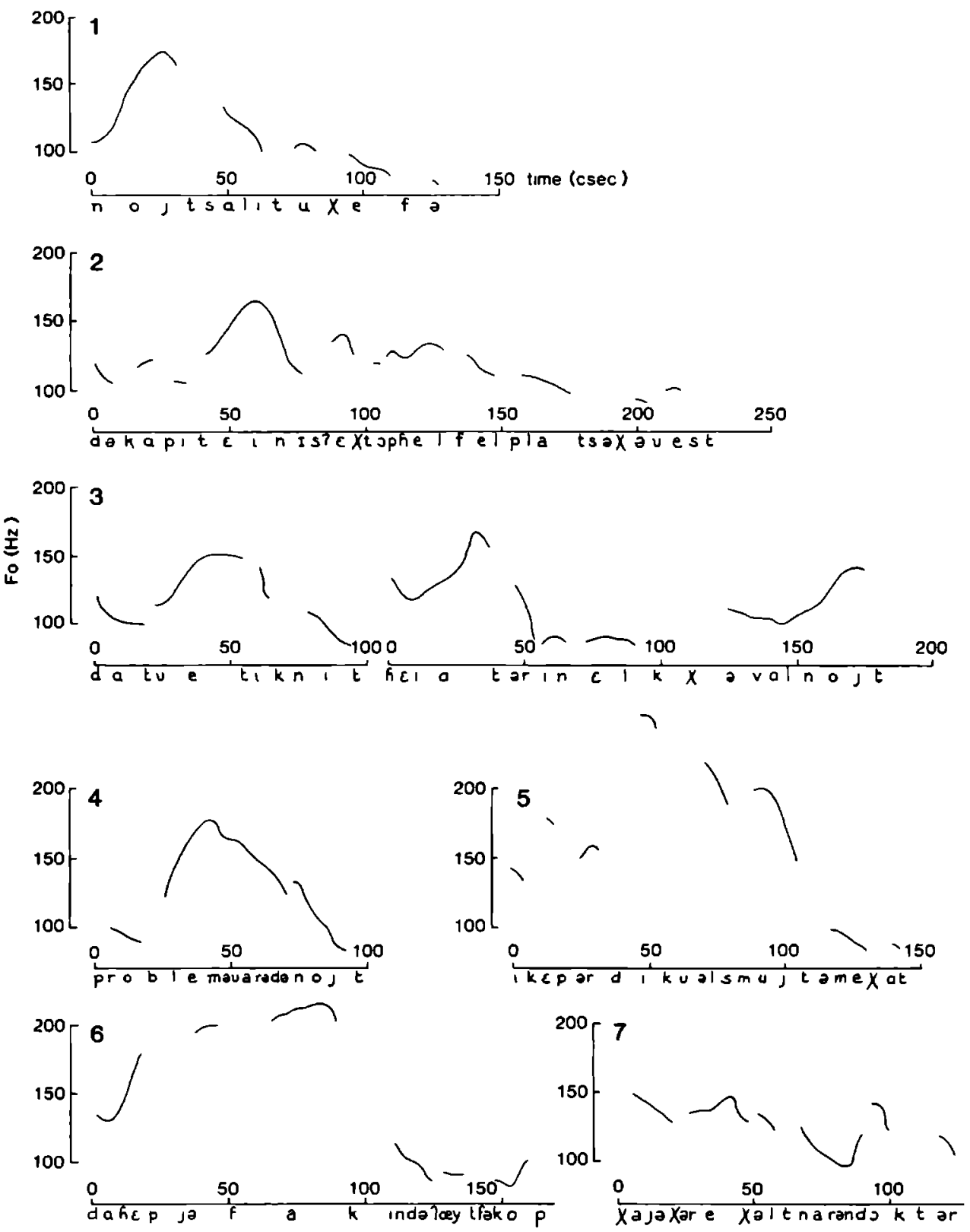

Figure 1. Contours and transcriptions of the utterances in Table 1. 
The pointlessness of asking linguistically naive or even linguistically non-naive listeners to determine within the time span of a second or two what the nucleus is in an aurally presented utterance is clearly brought out by the results of an experiment with ten native speakers of Dutch. These subjects, who were second-year university students of English, could be assumed to be familiar with the concept of the nucleus from their first-year grammar and phonetics classes. They were given the following two tasks.

1. The Nucleus Test (NT). The subjects were presented with seven utterances which had been produced and recorded on tape by the author. Table 1 lists these utterances, and Figure 1 gives their transcripions and $F$ The utterances were selected with the aim of eliciting a large number of incorrect nucleus markings. To this end, five of them had a wide-range pre-nuclear accent, followed by a low-range nuclear fall (nos. 1, 2, 3, 4, 5 ). (Note that the accent on nooit in $\mathrm{nr} 4$ is virtually embedded in the slope coming from the pre-nuclear -blem-; note also that without the accent on nooit the contour would have steeply shot down to the baseline around wa-.) No. 6 had a divided fall-rise, with the fall (marking the nuclear syllable) on a less 'important' word (vaak 'often'), and the rise (marking the last syllable of the tail) on an 'important' word (uitverkoop 'sales', which word has the word accent on the first syllable (!)). No. 7 had a fairly strong pre-nuclear accent, followed by a nuclear accent marked by a half-completed fall - also called a 'suspended' fall (Crystal 1969). (A similar incomplete fall occurs in No. 3. Observe that this fall from high to mid is partially masked by the voiceless / $t$ / of nooit. This pattern should not be confused with the relaxation reversal commonly seen at the ends of rises and falls on fully voiced segments.) Before the NT was given, a number of obvious examples of nucleus placements were discussed, to see if all subjects realised what the test was about. The order of the stimull in the test was different from that in Table 1 , and three further utterances were included to serve as distractors.

2. The Intonation Imitation Task (IIT). In this task the same ten subjects were presented with the ten utterances used in the NT. This time their task was to imitate these utteraces as faithfully as they could, but not before they had replaced a particular word in each utterance with a word taken from the set of words that is subject to Non-nuclear Retraction. On their test sheets the word to be replaced was underlined in the sentence concerned, and the word they had to substitute for it was glven in brackets (cf Table 1). The 
same three distractors were used. The prediction was that subjects would apply stress shift to the inserted word if that word did not carry the nucleus, i.e. in nos. $1,2,5$, and 7 . Their imitations were scored by three non-naive judges, who were asked to determine which syllable of the seven relevant words was the most accented in that word. (In no. 7 they were asked to mark the most accented syllable of the utterance, see below.) The judges were entirely unanimous, if we ignore the fact that, between them, two of them marked a pre-final syllable as accented in addition to the final one in three cases.

The results are given in Table 1 . The nucleus judgements are given as proportions of total number of judgements given in that utterance (no. 3 was counted as two utterances). The real nucleus has been capitalised. The scores for the IIT are given in the last column, with the number of times the word accent came on either the first or last syllable given over that syllable.

Both predictions were borne out. In the NT, judges were overwhelmingly misled by the wide-range pre-nuclear accents, and clesignated it as the nucleus. Yet, from their behaviour in the IIT it is equally clear that they knew - at a tacit level - that another sentence accent came after it: they applied Non-nuclear Retraction (see in particular nos. 1, 2, and 5). An exception is no. 6. Here, the item wel eens had to be slotted into nuclear position. As was observed in section 2.2 .3 , this adverb cannot have the nucleus, and the task predictably caused havoc in the subjects' responses. Only three subjects responded with the nucleus on heb (the only well-formed response), three put it on wel, and four on eens, which latter pronunciation would of course have been the correct pronunciation if wel eens had not been an exceptional item. It may be observed, incidentally, that the agreement between stimulus and imitation with respect nucleus location is very high (cf Quirk 1968).

\subsection{SUMMARY}

In summary, it can be said that the concept of the nucleus is not simply a descriptive expediency that has enabled analysts to break down intonation contours into manageable chunks, to be laid aside when other contour-chunks turn out to produce a more elegant analysis, but a phonological reality that is rele- 
vant outside the area of pitch contours proper. In order to find evidence for such relevance, the structural descriptions of five rhythm rules were investigated. The English rhythm rule discussed by Liberman \& Prince (1977) was found not to be sensitive to the distinction nuclear-non-nuclear, in spite of their claim that it is. Of four Dutch rhythm rules investigated, one turned out to be crucially dependent on whether the fulcrum is nuclear, and its structural description therefore cannot be given without reference to it. It is emphasised that this finding does not support the notion of 'head contours' as a separate paradigm, but only that phonological rules may have to 'know' whether a sentence-accent is final.

No evidence was found in Dutch for the existence of a 'simple' fall-rise by the side of a 'compound' one, and it was suggested that this distinction has no foundation in English either. It was also suggested that standard descriptions of British English should be amended to include the possibility of associating the rise-element of the fall-rise tone with the last syllable of the tone group. 
Notes

1. I should like to thank Ton Broeders, Gill Brown, Heinz Giegerich, Bob Ladd, Henry Thompson, Brian Wenk and an anonymous reviewer for Linguistics for their comments on an earlier, and somewhat different draft of this article. The contours reported here were produced with the help of standard ILS programs, or a program based on Gold \& Rabiner (1969) written by Steve Hiller (Figure 1). I thank the staff of the phonetics laboratories of Edinburgh University and Nijmegen University for their help.

2. It should be observed that the research reported in Brown et al. (1980) was done on Edinburgh Scottish English, which dialect of English does not appear to display the rich variety of intonational patterns that standard descriptlons of Educated British intonation claim exists in the latter dialect.

3. There is considerable terminological variation among different authors. In addition to the survey in Ladd (1980: 16, 208-9), note Brazil's (1978) term tonic for 'head plus nuclear syllable', preceding and following stretches being called 'proclitic' and 'enclitic' respectively. The analytic frameworks shows considerable simllarity, however.

4. It should be stressed that $O^{\prime}$ Connor \& Arnold's practice of taking combinations of head contours and nuclear tones as their basis for a semantic treatment of British English intonation should be seen to reflect the difficulty of assigning meaning to individual tones, head or nuclear, and does not imply that they consider the resulting contours phonologically holistic. Their description, inspired by Palmer (1933), has a pedagogical orientation, which, in general, may make it desirable to present larger linguistic structures as learnable units, despite their being made up of elements from different linguistic paradigms.

5. The term 'fulcrum' was suggested to me by Bob Ladd.

6. This is not in fact a restriction Liberman \& Prince make. We assume it here for the purpose of discussion, in order to avoid running into problems that are unrelated to either stress shift or the nucleus.

7. The difference between bimorphemic and monomorphemic onvermijdelijk is perhaps better brought out by the example that the Anglist R.C.J. Born once used to illustrate the difference between unavoidable and inevitable: Hij was onvermijdelijk te laat: 'He was unavoidably late' and 'He was inevitably late'. Written evidence for Rhetorical Retraction appeared in Onze Taal 50, no. 12 (1981), where it said 'Een spontaan applausje voor deze dichters!' ('A spontaneous (little) applause for these poets!') in the column 't Rijmschap, p. 129. Spontaan is monomorphemic and has the word accent on the second syllable.

8. The case of wel eens was brought to my attention by Ton Broeders.

9. I here ignore the interesting complication that the more literal - and longer - translation Mijn moeder is in Sheffield geboren has a different word order from the English, and that this word order is greatly preferred to ... is geboren in Sheffield if this stretch is unaccented, but that the latter word order is quite natural if Sheffield is accented. This fact in itself is evidence that in Dutch Sheffield is non-nuclear in either meaning of (34).

10. Lee (1956) comes close to making this distinction. After cataloguing the widely different interpretations of fall-rise patterns in the (British English) 
literature, he proposes a distinction between a fall-rise tone and a fall-rise sequence. In the tone, so he says, the rise-element generally begins immediately after the fall, while in the sequence the rise occurs on a later word, with the intervening syllables generally remaining low in pitch, or rising just a little. The semantic distinctions noted between the two patterns are either similar to that claimed by O'Connor \& Arnold for the examples here given as (32) and (33) (e.g. She doesn't speak to `anybody she meets along the road, i.e. 'only to certain people' versus She doesn't speak to 'anybody she meets along the, road, i.e. 'she is generally silent when travelling'), or would seem to refer to differences between fall-rise nuclei and tone groups having a falling head followed by a rising nuclear tone. This latter point was also made by Schubiger (1956). Note that in neither the tone nor the sequence is the rise associated by Lee with the last syllable. Also Schubiger (1956) says that in the sequence, the rise 'often quite slight (comes) on the weightiest word (in the tail).' The descriptive bias towards pattern a may have a historical explanation. Often, tone groups with a fall-rise nuclear tone followed by a tail that is separated from the preceding material by a comma in writing, are characterised as sequences of tone groups ( $\mathrm{cf}$ most of the examples in Palmer 1922:91-2 and at least some in Armstrong \& Ward 1931: 35). Evidently, in such an analysis, the second tone would have to be associated with a word rather than a syllable. In Kingdon, the two tones have become a 'divided Tone III', a fall-rise spread over two words: 'The rising part (comes on a later word) which is included in the feeling conveyed by Tone III, but to which only partial emphasis need be given' (1958: 20). In addition, it could be the case that pattern a should be interpreted dialectally, such that it was either more common earlier this century, or is more strictly part of a narrowly defined RP. Jones (1962: 303) even says: 'When there is no stressed or semi-stressed syllable after the emphatic word the terminal rise begins at the syllable following the emphatic word', which description squares with the representation given in Palmer (1922:10).

\section{References}

André, E. (1973-4). Studies in the correspondence between English intonation and the noun-phrase in English grammar, with special reference to the tone-unit. Liniversité de Liège Dissertation.

Armstrong, L.E. \& Ward, I.C. (1931). A handbook of English intonation. 2nd ed. Cambridge: Heffer.

Berg, B. van den (1970). 'Het woordaccent van afleidingen met het prefix on-'. Nieuwe Taalgids, Van Haeringennummer. 1-15.

Bolinger, D.L. (1958). 'A theory of pitch accent in English'. Word 14, 109-49. Reprinted in D.L. Bolinger, Forms of English: Accent, morpheme, order, Ed I. Abe \& T. Kanekiyo (1965). Tokyo: Hokuou.

Bolinger, D.L. (1981). Two kinds of vowels, two kinds of rhythm. Bloomington, Indiana: Indiana University Linguistics Club.

Brazil, D. (1978). Discourse intonation II. English Language Research, Birmingham University.

Brown, G., Currie, K.L. \& Kenworthy, J. (1980). Questions of intonation. London: Croom Helm. 
Chafe, W.L. (1970). Meaning and the structure of language. Chicago: University of Chicago Press.

Chomsky, N. \& Halle, M. (1968). The Sound Pattern of English. New York: Harper \& Row.

Coleman, H. O. (1941). 'Intonation and emphasis'. Miscellanea Phonetica I. 6-26.

Cruttenden, A. (1981). 'Falls and rises: meanings and universals'. Journal of Linguistics 17. 77-91.

Crystal, D. (1969). Prosodic systems and intonation in English. Cambridge: Cambridge University Press.

Crystal, D. (1975). The English tone of voice. London: Arnold.

Currie, K.L. (1980). 'An initial "search for tonics"'. Language \& Speech 23. 329-50.

Currie, K.L. (1981). 'Further experiments in the "search for tonics"'. Language \& Speech 24. 1-28.

Cutler, A. (1977). 'The context-dependence of "intonational meanings"'. Papers from the thirteenth regional meeting of the Chicago Linguistic Society. 104-15.

Fox, A. (1982). 'Remarks on intonation and "Ausrahmung" in German'. Journal of Linguistics 18. 89-106.

Giegerich, H.J. (1983). 'On English sentence stress and the nature of metrical structure'. Journal of Linguistics $19,1-28$.

Gimson, A.C. (1980). An introduction to the pronunciation of English. 3rd ed. London: Arnold.

Gold, B. \& Rabiner, L. (1969). 'Parallel Processing Techniques for estimating pitch periods of speech in the time domain'. JASA 46. 442-8.

Gussenhoven, C. (1982). 'Stresses: are they there when you hear them?'. Work in Progress 15. Edinburgh University Department of Linguistics.

Gussenhoven, C. (1983). 'Focus, mode and the nucleus'. Journal of Linguistics $19,377-417$ (Also this volume).

Halliday, M.A.K. (1963). 'The tones of English'. Archivum Linguisticum 15. 1-28.

Halliday, M.A.K. (1967). 'Notes on transitivity and theme in English, Part 2'. Journal of Linguistics 3. 199-244.

Halliday, M.A.K. (1970). A course in spoken English: Intonation. Oxford: Oxford University Press.

Hart, J. 't \& R. Collier (1975). 'Integrating different levels of intonation analysis'. Journal of Phonetics 3, 235-55.

Jones, D. (1962). Outline of English phonetics. 9th ed. Cambridge: Cambridge University Press. 
Kingdon, R. (1958). The groundwork of English intonation. London: Longman.

Kiparsky, P. (1966). 'Ueber den deutschen Akzent'. Studia Grammatica 7. (Berlin: Akademie-Verlag) 69-98.

Kiparsky, p. (1975). 'Stress, syntax and meter'. Language 51. 576-616.

Ladd, D.R. (1980). The structure of intonational meaning: Evidence from English. Bloomington \& London: Indiana University Press.

Ladd, D.R. (1982). Review of Brown et al. (1980). Language 58, 204-8

Lee, W.R. (1956). 'Fall-rise intonations in English'. English Studies 37. 62-72.

Liberman, M. (1975). The intonational system of English. MIT dissertation. IULC version 1978.

Liberman, M. \& Prince, A. (1977). 'On stress and linguistic rhythm'. Linguistic Inquiry 8. 249-336.

Liberman, M. \& Sag, I. (1974). 'Prosodic form and discourse function'. Papers from the tenth regional meeting of the Chicago Linguistic Society. 416-27.

Lindström, O. (1978). Aspects of English intonation. Gothenburg: Acta Universitatis Gothoburgensis.

O'Connor, J.D. \& Arnold, G.F. (1973). Intonation of colloquial English. 2nd ed. London: Longman.

Palmer, H.E. (1922). English intonation with systematic exercises. Cambridge: Heffer.

Palmer, H.E. (1933). A new classification of English tones. Tokyo: Kaitakusha.

Pierrehumbert, J.B. (1980). The phonology and phonetics of English intonation. MIT Dissertation.

Pike, K.L. (1945). The intonation of American English. Ann Arbor: University of Michigan Press.

Prince, A.S. (1983). 'Relating to the grid'. Linguistic Inquiry 14, 19-100.

Quirk, R. (1968). 'On scales of contrast in connected English speech'. In Essays on the English Language: medieval and modern. London: Longman. $136-147$.

Rjppmann, W. (1913 [1906]). The sounds of spoken English. 5th ed. London: Dent.

Schmerling, S.F. (1976). Aspects of English sentence stress. Austin: Univers1ty of Texas Press.

Schubiger, M. (1956). 'Again: fall-rise intonations in English'. English Studies 37. $157-60$.

Schultink, H. (1979). 'Reacties op "stress clash"'. Spektator 8. 195-208.

Sharp, A.E. (1958). 'Falling-rising intonation patterns in English'. Phonetica 2. $127-52$. 
Svartvik, J. \& Quirk, R. (eds) (1980). A corpus of English conversation. Lund: Gleerup.

Thompson, H.S. (1980). Stress and salience in English: theory and practice. Palo Alto, Calif: Xerox Palo Alto Research Center.

Tregidgo, P.S. (1981). 'Focus and counter-focus'. IATEFL Newsletter 70. 46-52.

Ward, I.C. (1945 [1929]). The phonetics of English. 4th ed. Cambridge: Heffer.

Willems, N.J. (1982). English intonation from a Dutch point of view. Dordrecht: Foris. 


\section{Stress shift in Dutch as a rhetorical device}

\subsection{INTRODUCTION}

The term stress shift refers to the phenomenon observable in an English phrase like 'fifteen 'men, where the word fif'teen has undergone a change in the promlnence relation holding between its syllables as a result of the proximity of the accent on men. " Where this stress shift is to the left (as a result of another accent on the right) the phenomenon is referred to as Iambic Reversal (cf Liberman \& Prince 1977, who use the term to refer to their rule governing stress shift in English).

In Dutch, the following two types of Iambic Reversal occur:

1. Stress Retraction ( $S R$ ). The rule applies to accented compound adjectives and adverbs that have the main accent on the rightmost constituent in isolation. If some other accented word follows the compound, it is the leftmost constituent that appears to carry the main accent in the compound. Thus, jjs'koud ('ice-cold', adj.) will be pronounced 'ijskoud in 'ijskoud 'bier ('ice-cold beer'). Similarly, hard'op ('out loud', adv.) will be pronounced as indicated when it is used in a one-word sentence, but as 'hardop in iets 'hardop 'voorlezen ('to read something out loud'). To all intents and purposes, $S R$ is obligatory. If It is assumed that the rightmost constituent has the word accent in isolation, we should say that the rule applies so as to shift the stress onto the accentable syllable of the leftmost constituent. Alternatively, If we assume both constituents of the compound to have a word accent in isolation, the rule applies so as to delete the accent on the rightmost constituent.

2. Rhetorical Retraction (RR). The rule applies to accented non-compounded as well as compound adjectives and adverbs that have the word accent on a non-initial syllable. If some other accented word follows, RR may apply so as to shift the accent onto the leftmost syllable, excluding (reduced) pre- 
fixes like ge-, be- and ver-. Examples are commerci'eel $\rightarrow$ een 'commerciele 'aanpak ('a commercial approach'), poli'tiek - een 'politieke 'zaak ('a political issue'), or gegaran'deerd (with ge-) $\rightarrow$ ge'garandeerd 'veilig ('guaranteed [to be] safe'). There would otherwise seem to be no restrictions on the nature of the first syllable, which may contain schwa. Thus, le'gaal /la'xa.1/ + 'legaal 'ingeschreven ('legally registered'), where after the application of RR the first syllable of legaal may have /e./ or, more rarely, /a/. The rule is probably an innovation, and is rarely mentioned in the literature (but see Gussenhoven \& Broeders 1981: 124, Gussenhoven 1983). $\mathrm{RR}$ is clearly a variable rule. One of the more important factors determining its application would appear to be speech style: it seems particularly frequent in propagandist speech, as used for instance In commercials, political speeches and at meetings. As an indication of its variable nature, it may be observed that on Dutch radio and television, application seems rare in national news bulletins, but frequent in the more informal, corporation-produced news shows.

In view of what was said above, it appears that $R R$ and $S R$ can both apply to such compounds as eco'nomisch-ver'antwoord ('economically sound'), which with SR becomes eco'nomisch-verantwoord (be'leid), and with RR applying in addition 'economisch-verantwoord (be'leid). Of course, there could be application of just RR, as in (Dit beleid is) 'economisch-ver'antwoord. In the case of compounds in which the accentable syllable of the leftmost constituent is also the leftmost syllable (e.g. ㅆjs'koud) RR can only apply vacuously, SR being an obligatory rule.

The experiment described below was carried out to test the hypothesis that, while $S R$ is a (virtually) obligatory rule of Dutch, $R R$ is a variable rule, in which rhetoricity is an important variable.

\subsection{MATERIALS}

Two reading tests were prepared. One, referred to as POL, dealt with a fictitious political issue, the introduction of a radio/TV Reform Bill, and was written in the style of a political speech. The other, referred to as $A D$, dealt with the introduction of a fictitious brand of toothpaste, and was written in the style of a 
commercial filmscript. In view of their subject matter, both texts are likely to elicit the application of RR.

In POL there were 11 words that satisfied the conditions for SR and 48 that satisfied those for $\mathrm{RR}$. In $\mathrm{AD}$, these figures were 12 and 44 , respectively. Appendix I gives sample paragraphs of both texts with English translations. For either text, four reading assignments were prepared, which were intended to elicit increasing degrees of rhetoricity on the part of the reader. The four reading assignments for POL are given below, in translation. The reading assignments for AD were comparable to the ones used for POL.

\section{Reading assignments for POL:}

\section{Rhetoricity level 1}

Imagine that a machine has been developed which is capable of 'translating' normally spoken language into a written text. Such a machine would falthfully type out what you speak into it, without requiring the speaker to speak at dictation speed.

Your assignment: Read this text in your most ordinary style, such that the machine produces a correct text. If you 'fluff' a sentence, please start it again. (Note that the machine will type out everything you say, so don't add instructions like 'Colon', 'In capitals' or anything of the kind.)

\section{Rhetoricity level 2}

Imagine you are in charge of the PR bureau of a national political party. The Party, which is not in power, is opposed to a Radio/TV Reform Bill which the Government intends to introduce. The Party is about to hold its annual congress. At this congress, an appeal must be made to party members to attend a national protest ralley against the Bill. The $P R$ team are responsible for the text of this appeal, which is to be read out by a prominent party member. At a campaign meeting you want to discuss the various proposals for this text with your team members. The appended text is one such proposal.

Your assignment: You don't think the proposal is particularly good, but you also think that you should read it out in full so that everybody can form their own opinion. Read the text at the meeting. If you 'fluff' a sentence, please start it again. 


\section{Rhetoricity level 3}

As rhetoricity level 2

Your assignment Read the text at the meeting so that everybody can take it in, and can infer from the way you read it that you yourself think the proposal reasonably successful If you 'fluff' a sentence, just start it again

\section{Rhetoricity level 4}

Imagine you are an opposition party front bencher and media specialist of a big political party The national party executive has asked you to appeal to the party members at the Annual Party Congress to attend a national protest ralley against a new Radio/TV Reform Bll which the Government intends to introduce The Party PR team has provided you with the text for this appeal

Your assignment Read the text from the rostrum at the Annual Party Congress, such that the point of view presented in it carries the right kind of conviction If you 'fluff' a sentence, just start it again

Clearly, the design of this experunent is talored to the need to have at our disposal language data that differ only in the rhetoricity of the style with which they are produced Thls advantage was considered to outweigh the drawback of possible artefacts produced by the experimental situation (reading a text in a language laboratory in what was obviously a test situation) Collecting naturally produced language data would have involved coping with the difficulty of finding an independent measure for the rhetorical content of fairly lengthy passages of speech (which it might have been too tedious for judges to rate, even if some suitable instruction could have been formulated) On the other hand, the method we did use presupposed that the tendency to increase the application of RR with the rhetoricity of the style is sufficiently strong in the language for untrained speakers to subconsciously adjust their pronunciation in an acting situation This methodology brings an important caveat in its wake what style-dependent variabulty we may observe is, so to speak, second-hand Is is a reflection of our subjects' subconscious tendency to transfer real-life features, in our case rhetoricity-dependent variation in $R R$, to their performance as elicited by the experimental task In other words, our concern is to demonstrate the existence of this variation, not its extent

Twenty-four native speakers of Dutch, ten male and 14 female, were recruited from the student population of the University of Nijmegen To discourage obviously poor readers from taking part, the sign-up list stipulated that subjects should be competent readers and should possess some acting ablity The ten 
male and the 14 female subjects were evenly, but otherwise randomly assigned to $P O L$ and $A D$. Each of the 12 subjects assigned to $P O L$ and each of the 12 subjects assigned to $A D$ was given an instruction sheet, four numbered, closed envelopes containing the reading assignments, a reading text ( $P O L$ or $A D$ ) and a cassette tape. The subjects were seated in a language laboratory, and instructed to study their text and work through their four reading assignments. They were not permitted to inspect a later reading assignment before recording an earlier one. The order of the assignments was controlled for by arranging Rhetoricity level and serial order as a (partial) Latin square: each Rhetoricity level occurred three times in each serial position. Subjects were paid a small fee.

Three non-naive judges, who were native speakers of Dutch, were recruited to rate the experimental words for stress. They did this independently, and were instructed to use the following five scoring categories:

1. The first (unreduced) syllable of the adjective or adverb, or the first constituent of a compound adjective or adverb, carried the word stress ( $~ \nabla-V^{\prime}$ in Table 1).

2. The word carries the stress on the syllable that has the stress when the word is said in isolation ( $V-\nabla$ ' in Table 1 ).

3. Both syllables meant under 1 and 2 were stressed ( $\nabla-\nabla \cdot$ in Table 1$)$.

4. Neither of the syllables meant under 1 and 2 was stressed (' $V-V^{\prime}$ In Table 1).

5. No judgement is possible.

The fifth scoring category Included instances where the subject had skipped the text concerned, had read a different word, or placed the last sentence accent on the experimental word, leaving the following major class word unaccented. This last situation was included in this category because the accentual configuration concerned obviously does not satisfy the conditions for stress shift. SR-words to which also RR had been applied (e.g. 'biologisch-chemisch for bio'logisch-' 'chemisch), of which they were some ten instances, were only counted as instances of SR. While the judges appeared vaguely aware of what the 
test was about, they were not of course informed of its purpose. The readings were presented to them in random order.

\subsection{RESULTS AND DISCUSSION}

The three judges were unanimous in their judgements in $82 \%$ of the 2832 tokens in POL and in $83 \%$ of the 2640 tokens in $A D$. Instances of disagreement were subsequently included in scoring category 5 , i.e. merged with instances where judges agreed that no judgement was possible. A breakdown of these raw data obtained for the RR-words over Rhetoricity level is given for POL and AD separately in Table 1. Note that the RR-scores for $\nabla-V$ gradually increase, and those for $V-\nabla$ gradually decrease with rhetoricity level; note also the marked difference between the scores in the category $V-\bar{V}$ for $R R$ and $S R$.

\subsection{A RETRACTION-INDEX}

The data made it possible to calculate a retraction-index. A retraction-index can be seen as a measure of the extent to which, in some category, iambic reversal had taken place. This index was defined as the number of times the first syllable was judged to be stressed plus half the number of times both syllables were judged to be stressed, divided by the total number of judgments, or

$$
\text { RET-index }=\left(f_{\text {flrst }}+0.5\left(f_{\text {both }}\right)\right) /\left(f_{\text {first }}+f_{\text {last }}+f_{\text {both }}+f_{\text {neither }}\right)
$$

The inclusion of one half of the 'both'-judgements in the numerator is an expression of the fact that a pronunciation like een 'commerci'ele 'instelling is a step from een commerci'ele 'instelling towards een 'commerciele 'instelling. The inclusion of all judgements in the divisor ensures the expression of the number of opportunities the speakers had to apply iambic reversal in the RET-index. As will be clear, the potential range of the RET-index is from 0.0 to 1.0. Appendex II lists RET-indices for all items in both POL and $A D$, in the order from lowest to highest. RR-words and $S R$-words are listed separately. 
Table 1. Breakdown of raw scores for RR-words and SR-words over Rhetoricity level for POL and AD. The column 'Total' excludes category 5 'no score').

\begin{tabular}{|c|c|c|c|c|c|c|}
\hline POL - RR-words & & & & & & \\
\hline Scoring cat. & $\nabla-V$ & $V-\bar{v}$ & $\nabla-\nabla$ & $V-V$ & Total & No score \\
\hline \multicolumn{7}{|l|}{ Rhet. level } \\
\hline 1 & 234 & 196 & 6 & 2 & 438 & 138 \\
\hline 2 & 239 & 188 & 6 & 6 & 439 & 137 \\
\hline 3 & 259 & 184 & 9 & 6 & 458 & 118 \\
\hline 4 & 269 & 180 & 14 & 1 & 464 & 112 \\
\hline Total & 1001 & 748 & 35 & 15 & 1799 & 505 \\
\hline \multicolumn{7}{|l|}{ POL - SR-words } \\
\hline 1 & 107 & 1 & 6 & 0 & 114 & 18 \\
\hline 2 & 105 & 1 & 2 & 0 & 108 & 24 \\
\hline 3 & 106 & 2 & 3 & 0 & 111 & 21 \\
\hline 4 & 109 & 0 & 2 & 0 & 111 & 21 \\
\hline \multirow[t]{2}{*}{ Total } & 427 & 4 & 13 & 0 & 444 & 84 \\
\hline & \multicolumn{5}{|c|}{ General total POL } & 2832 \\
\hline
\end{tabular}

\begin{tabular}{|c|c|c|c|c|c|c|}
\hline$A D-R R$-words & & & & & & \\
\hline Scoring cat. & $\nabla-V$ & $V-\nabla$ & $\nabla-\nabla$ & $V-V$ & Total & No score \\
\hline \multicolumn{7}{|l|}{ Rhet. level } \\
\hline 1 & 217 & 189 & 1 & 0 & 417 & 99 \\
\hline 2 & 197 & 171 & 9 & 1 & 378 & 138 \\
\hline 3 & 236 & 166 & 10 & 1 & 413 & 103 \\
\hline 4 & 242 & 170 & 8 & 2 & 422 & 94 \\
\hline Total & 892 & 696 & 38 & 4 & 1630 & 434 \\
\hline \multicolumn{7}{|l|}{$A D$ - SR-words } \\
\hline 1 & 85 & 0 & 15 & 0 & 100 & 44 \\
\hline 2 & 100 & 0 & 10 & 0 & 110 & 32 \\
\hline 3 & 105 & 1 & 10 & 0 & 116 & 29 \\
\hline 4 & 99 & 2 & 11 & 0 & 112 & 32 \\
\hline \multirow[t]{2}{*}{ Total } & 389 & 3 & 46 & 0 & 438 & 138 \\
\hline & \multicolumn{5}{|c|}{ General total AD } & 2640 \\
\hline
\end{tabular}




\subsection{ITEM-ANALYSIS}

Since the number of RR-words was relatively large, and since some of these words were either hardly ever retracted (e.g. religieuze (POL)) or almost always (e.g. strukturele (both $\mathrm{POL}$ and $\mathrm{AD}$ )), it was decided to evaluate the measuring instrument by means of an item analysis. Item scores were taken to be the numerator-values for the RET-index, i.e. $\nabla-v=1, \nabla-\nabla=0.5$, other $=$ 0.0. Item-total correlation coefficients $\left(r^{\prime} s\right)$ over the (12 subjects $\times 4$ readings or) 48 readings of both $\mathrm{POL}$ and $\mathrm{AD}$ were calculated. The column headed ' $\mathrm{I} / \mathrm{T}^{\prime}$ in Appendix II lists the correlation coefficients. A correlation coefficient of .30 was chosen as a convenient threshold value: RR-words whose scores did not show an item-total correlation of $r>.30$ are marked - . These items were not subjected to further analysis. This procedure left us with $33 \mathrm{RR}$-words in POL and $32 \mathrm{RR}$-words in AD. There does not seem to be a ready explanation of why the scores of certain items failed to vary in unison with the total scores.

\subsection{RR-WORDS VS SR-WORDS}

As predicted, there appeared to be a clear difference between RET-indices for RR-words and those for SR-words. Table 2 gives the 10th, 50th and 90th centiles. The difference in distribution of the RET-indices between SR-words and RR-words is obvious. If we take .90 as an abitrary value, and perform a $x^{2}$-test on the distribution of the words above and below this value, the difference is significant at $p^{<.01}$. These results clearly suggest that the two groups of words were drawn from different populations. In fact, the variation in the SR-words is so small that no further statistical tests will be applied to them: the rule of Stress Retraction is, to all intents and purposes, obligatory. The explanation for the fact that four SR-words in AD had a RET-index of less than .90 (which we might see as a convenient operational definition of 'obligatory') would appear to be that these were either unusual words or nonce-words, and were consequently pronounced somewhat carefully by our subjects, with stresses on both constituents ( $c$ the column 'both' for the SR-words in AD, and Appendix II). 
Table 2. Mean RET-indices and 10th, 50th and 90th Centiles for RR-words and $\mathrm{SR}$-words in POL and AD combined.

\begin{tabular}{|l|l|l|}
\cline { 2 - 3 } \multicolumn{1}{c|}{} & RR $(n=65)$ & SR $(n=23)$ \\
\hline Mean & .55 & .95 \\
\hline 10th centile & .17 & .84 \\
50th centile & .55 & .98 \\
90th centile & .83 & 1.00 \\
\hline
\end{tabular}

\subsection{RHETORICITY LEVEL}

As our hypothesis predicted, the RET-indices for the different readings increased with the Rhetoricity level, even though differences between one level and the next appeared small. Table 3 gives mean RET-indices and standard deviations per Rhetoricity level for POL and AD separately.

Table 3. Mean RET-indices (and standard deviations) for four Rhetoricity levels in POL and $A D$.

\begin{tabular}{|l|l|l|l|l|}
\cline { 2 - 5 } \multicolumn{1}{c|}{} & Level 1 & Level 2 & Level 3 & Level 4 \\
\hline POL & $.54(.20)$ & $.56(.20)$ & $.59(.22)$ & $.60(.20)$ \\
$\mathrm{AD}$ & $.46(.28)$ & $.48(.25)$ & $.55(.27)$ & $.55(.22)$ \\
\hline Tot & .50 & .52 & .57 & .58 \\
\hline
\end{tabular}

Although our Rhetoricity levels should strictly speaking be taken as ordinal values, there are, in view of the robustness of the test, no reasons to suppose that taking Rhetoricity level as a metric variable constitutes a drastic violation of the assumptions underlying an analysis of covariance. Therefore, it was decided to perform an anlysis of covariance on the data in both POL and $A D$, with RET-index as the dependent variable, subjects as a factor and Rhetoricity level as a covariate, and to test for the siginificance of the covariate by means of a one-sided test. Subjects were included in the analysis because of the great varlation between subjects: we observed a a standard deviation of .18 with a mean of .57 in POL, and a standard deviation of .23 with a mean of .52 in $A D$, which suggested that the variation between subjects should be controlled for before the effect of the covariate was measured. The results of the analyses of covariance showed that in $A D$ the effect of the covariate was significant $(p=.03)$, while in POL a weakly significant effect was observed $(p=.08)$. 


\subsection{OTHER EFFECTS}

While the purpose of the experment was to demonstrate that the Dutch rule of Rhetorical Retraction is sensitive to the rhetoricity of the speech style, the data also lend themselves to testing other hypotheses that have been expressed in the literature (e g Bolinger 1981, Gussenhoven 1983, Hayes forthcoming ${ }^{2}$ ) Among these are the following

1 Repetition of the phrase makes retraction more probable

2 The greater the number of syllables between the syllable whose stress is to be shifted and the syllable onto which the stress is to be shifted, the more probable retraction Thus, retraction might be expected to be more likely in effec'tief be'leid than in mo'reel be'leid

3 The greater the number of syllables between the syllable whose stress is to be shifted and the following accent responsible for the shift, the less prob able retraction The following example for English is taken from Hayes (forthcoming) 'Cornel 'hockey vs Cor'nell ath'letics

Testing for other effects. The first hypothesis of this section can be interpreted in two ways We can assume that retraction is more probable as the speaker utters the phrase more frequently within a given tume-span, or we can assume that retraction is a function of the frequency of occurrence of the adjective or adverb in the language Both interpretations can be tested in our data The first can be tested by repeating the analysis of covariance with order of piesentation, which was carefully controlled for, rather than Rhetoricity level as the covariate The prediction here would be that the RET-index will increase with the number of times subjects had read the text It appears that the effect of serial position of the reading assignment is in fact significant in $A D(p<01)$, but not in POL Table 4 gives mean RET-indices and standard deviations for POL and $\mathrm{AD}$ for the four readings

Table 4 Mean RET-ındices (and standard deviatıons) for four consecutive readings of POL and $A D$

\begin{tabular}{|l|l|l|l|l|}
\cline { 2 - 5 } \multicolumn{1}{c|}{} & 1st & 2nd & 3rd & 4 th \\
\hline POL & $54(22)$ & $60(19)$ & $57(20)$ & $58(20)$ \\
AD & $44(25)$ & $47(23)$ & $55(24)$ & $58(27)$ \\
\hline
\end{tabular}


The other interpretation can be evaluated with the help of Uit den Boogaart (1975), who gives word frequencies for spoken and written language separately. We used the figures for written language, partly because the sort of speech style we are concerned with is often based on written, or at least prepared texts, and partly because too many of our words have zero frequency in the spoken corpus. Column 'WF' in Appendix II lists the word frequencies (WFs) in a 600,000 word corpus. The words were divided into two halves, a low-frequency half with $W F<15$ and a high-frequency half with $W F \geq 15$. We observed virtually the same RET-index in the lower half and the higher half (.56 and .54 respectively), and frequency of occurrence must therefore be rejected as an explanatory factor.

Hypotheses 2 and 3 of this section can be tested by merging the data In POL and $A D$ as listed in Appendix II (excluding the ones that failed the item-analysis), adding the data concerning the intervening unaccented stretches, and performing an analysis of variance with the number of syllables between shifted and shiftable positions (First Stretch) and the number of syllables between shifted position and the position of the accent responsible for the shift (Second Stretch) as factors. In both cases three levels were assumed: zero syllables, one syllable, and more than one syllable intervening, the number of three-syllable stretches being very small. These data are included in Appendix II in columns ' $1 \mathrm{st}$ ' and '2nd'. There appears to be a significant effect only for the number of syllables between shiftable and shifted positions (First Stretch). The second stretch falls far short of a significant level. The RET-indices for the three levels in the first stretch are: .36 for zero syllables intervening; .65 for one syllable intervening, and .58 for two or more syllables intervening. According to a post-hoc Scheffe test it is the differences between 'zero intervening syllables' and each of the other two that are significant $(p<.01)$, the difference between 'one syllable intervening' and 'two or more syllables intervening' not reaching a significant level. No interaction effect between 'First Stretch' and 'Second Stretch' was observed. 


\subsection{CONCLUSION}

Although in one of the two texts the effect of Rhetoricity level was only weakly significant, the experiment has successfully demonstrated that the rhetoricity level of a reading assignment can influence the extent to which speakers are inchned to apply iambic reversal in monomorphemic words the more forcefully we demanded our subjects to read their text so as to convince their (magined) audience of the quality of its content, the more frequently iambic reversal was applied Thus, the postulation the rule of Rhetorical Retraction, which was shown to behave differently from Stress Retraction, has been justified

The results were virtually identical for two groups of speakers reading different texts, and this is of course a point in favour of the reliablity of the results it should be stressed that both texts were deliberately constructed so as to elicit liberal application of $\mathrm{RR}$ Texts of a less propagandist nature would almost certainly have elicited lower indices The test situation itself, too, may have introduced an element of formality into the speech situation of the sort that might contribute to the application of RR The fact the the mean RET-index is 55 should therefore not be interpreted to mean that RR is applied in about $55 \%$ of the cases in Dutch generally

It was found that the number of syllables between potential stress positions in an adjective or adverb will influence the likelihood with which RR is applied a stretch of one or more intervening syllables favours application of the rule No effect was observed for the number of syllables between the stress responsible for the shift and the stress to be shifted It is noted, however, that our materials were not especially designed to answer these questions No effect was found for word frequency As for repetition of the phrase by the same speaker, only in one text did we find a small, but significant effect for the number of tumes subjects had read the text We will consider this evidence inconclusive 


\section{Notes}

1. I am indebted to Dr M.A. van 't Hof for his guidance in the statistical processing of the results. I thank him, Flor Aarts, Phil Hyams, Toni Rietveld and Felix Vieregge and two anonymous readers for Linguistics for their comments on an earlier version of this article.

2. Hayes proposes a more explicit hypothesis, which clains - among other things - that rhythmic organisation favours tetrasyllabic feet (one accented syllable followed by three unaccented ones), with stress shift operating so as to inhibit destruction and induce formation of such feet. Our data are not suited to test this more complex hypothesis.

\section{References}

Bolinger, D. (1981). Two kind of vowels, two kinds of rhythm. Bloomington (Indiana): IULC.

Gussenhoven, C. (forthcoming). 'Stress shift and the nucleus'. Linguistics 21 (Also this volume).

Gussenhoven, C. \& A. Broeders (1981). English pronunciation for student teachers. Groningen: Wolters-Noordhoff-Longman.

Hayes, B. (forthcoming). 'The phonology of stress shift'. Linguistic Inquiry.

Liberman, M. \& A. Prince (1977). 'On stress and linguistic rhythm'. Linguistic Inquiry 8, 249-336.

Uit den Boogaart, P.C. (ed) (1975). Woordfrequenties in geschreven en gesproken Nederlands. Utrecht: Oosthoek, Scheltema \& Holkema. 


\section{APPENDIX I}

Two sample paragraphs from POL and AD are given below, with English translations Experimental words are underlined (RR) or given in bold type (SR)

Het nieuwbakken plan om het nationale omroepbestel los te koppelen van levensbeschouwing en maatschappijvisie betekent een $d_{1}$ rekte aanslag op een zwaar-bevochten verworvenheid van onze demokratie De regering heeft het bij monde van zijn pasbenoemde minister van WVC bestaan om haar plan demokratisch te noemen Deze ministeriele gotspe verdient slechts een holle hoonlach Kennelijk is de opvatting van de minister er louter een van het getal Dit, zo stellen wij, is een numerieke dwaalleer' Is het in een demokratie net juist van essentieel belang dat alle groepen in de samenleving, van bijstandtrekkende BOM-moeder tot rechts-luberale burger, een stem in het kapittel krijgen? Was de veelgeprezen sociaal-demokratie nou juist niet bedoeld on de zwakke te beschermen tegen de sterke?

Graag brengen wij U hierbil op de hoogte van een revolutionaire vinding op het gebled van de gebitsverzorging Deze vinding luidt een waarlijk sensationele ontwikkeling in en betekent een totale afrekening met de traditionele tandpasta's Het betreft het middel SESAL SESAL is zonder meer een geniale vinding, die op eenvoudige, maar radikale wijze een einde maakt aan wat de medische professie tot op heden als een strukturele volksziekte heeft moeten beschouwen tandbederf'
The new-fangled plan to make the national broadcasting system independent of religious and political affliation poses a direct threat to a hard-won achievement of our democracy Through its newly-appointed Minister of Cultural Affairs the Government has had the temerity to call its plan democratic This ministerial chutspe only deserves loud and scornful laughter Apparently, the Minister's concept (of democracy) is formulated purely in terms of numbers This, we put it to you, is a numerical fallacy Is it not of essential importance precisely in a democracy that all social groups, from the unmarried-mother-onthe-dole to the right-of-centre, conservatıve householder, are given a chance to say therr piece? And was not our much-prased welfare state intended precisely to protect the weak against the strong?

We are pleased to inform you of a revolutionary discovery in the area of dental care This discovery heralds a truly sensational development and will show up traditional toothpastes for what they are worth We are referring to the compound SESAL SESAL is nothing less than a brilliant discovery, which in a sumple, but radical manner puts a stop to what the medical profession has so far had to consider an endemic disease tooth decay' 


\section{APPENDIX II}

Below are listed all the SR-word and RR-words in POL and AD seperately, ordered according to RET undex For the RR words, analysis-data are given, as follows 'I/T' stands for 'Item total correlation' (Pearson correlations, see text), WF for 'Word Frequency' (in a written corpus of 600,000 words), '1st' for the number of unaccented syllables between shiftable and shifted positions, and '2nd' ditto between the shiftable syllable and the accented syllable responsible for the shift

Item Index I/T WF 1st 2nd

POL - RR-words

SR-words

$\begin{array}{lrrrrr}\text { religieuze } & 04 & - & & \\ \text { artistieke } & 10 & 39 & 22 & 1 & 1 \\ \text { ministeriele } & 11 & - & & & \\ \text { sociaal } & 12 & 46 & 164 & 0 & 2 \\ \text { morele } & 15 & 43 & 23 & 0 & 1 \\ \text { publiek } & 17 & 31 & 28 & 0 & 1 \\ \text { exorbitante } & 21 & - & & & \\ \text { acute } & 25 & - & & & \\ \text { catastrofale } & 28 & - & & & \\ \text { demonstratieve } & 31 & 42 & - & 2 & 2 \\ \text { commerciele } & 34 & 67 & 18 & 1 & 1 \\ \text { politieke } & 35 & 31 & 216 & 1 & 1 \\ \text { massaal } & 35 & 32 & 19 & 0 & 1 \\ \text { aktief } & 40 & - & & & \\ \text { loyale } & 43 & 51 & 4 & 0 & 2 \\ \text { direkte } & 44 & 30 & 6 & 0 & 1 \\ \text { populaire } & 44 & 45 & 35 & 1 & 1 \\ \text { externe } & 47 & 35 & \mathbf{B} & 1 & 2 \\ \text { edukatieve } & 50 & - & & & \\ \text { frontale } & 50 & 44 & 5 & 0 & 1 \\ \text { sentimentele } & 53 & 48 & 5 & 2 & 2 \\ \text { materiele } & 55 & 56 & 23 & 2 & 1 \\ \text { controversiele } & 59 & 45 & - & 2 & 2 \\ \text { lnferieure } & 60 & - & & & \\ \text { ordinaire } & 62 & 34 & 1 & 1 & 1 \\ \text { essentieel } & 63 & 33 & 18 & 1 & 1 \\ \text { collektief } & 63 & 33 & 10 & 1 & 1 \\ \text { dubieuze } & 63 & - & & & \\ \text { legitieme } & 63 & 59 & 2 & 1 & 1 \\ \text { solidaire } & 64 & 56 & 6 & 1 & 1 \\ \text { alternatief } & 64 & - & & & \\ \text { cumulatieve } & 68 & - & & \\ \text { prinaire } & 70 & 39 & 14 & 0 & 1 \\ \text { cruciaal } & 73 & 46 & - & 0 & 1 \\ \text { visuele } & 73 & - & & & \\ \text { radikaal } & 73 & 30 & 16 & 1 & 2 \\ \text { numerieke } & 74 & 37 & - & 1 & 1 \\ \text { definitief } & 76 & 32 & 32 & 2 & 1 \\ \text { cultureel } & 76 & 50 & 47 & 1 & 1 \\ \text { lntegrale } & 82 & 55 & 9 & 1 & 2 \\ \text { lucratieve } & 84 & 63 & - & 1 & 1 \\ \text { permanent } & 84 & - & & & \\ \text { objektieve } & 85 & 42 & 10 & 1 & 1 \\ \text { agressieve } & 86 & - & & & \\ \text { nationale } & 89 & 32 & 57 & 1 & 1 \\ \text { constant } & 91 & 34 & 19 & 0 & 0 \\ \text { horizontale } & 95 & 41 & 6 & 2 & 1 \\ \text { strukturele } & 98 & - & & & \end{array}$

nleuwbakken 93

overduidelijke 95

Rooms-liberale 95

pasbenoemde 97

bljstandtrekkende $\quad 98$

keihard 99

onhanteerbaar 99

zwaarbevochten 99

onverdeelde 100

rechtsliberale $\quad 100$

veelgeprezen 100

strukturele 
$A D$ - RR-words

\begin{tabular}{|c|c|c|c|c|}
\hline royaal & 07 & 30 & - & 0 \\
\hline totale & 09 & - & & \\
\hline fatale & 15 & 31 & 11 & 0 \\
\hline re-eel & 16 & - & & \\
\hline neutrale & 18 & 36 & 16 & 0 \\
\hline unieke & 20 & 45 & 25 & 0 \\
\hline formeel & 20 & 44 & 31 & 0 \\
\hline gegarandeerd & 21 & 30 & 3 & 1 \\
\hline minıscule & 29 & 30 & - & 1 \\
\hline experimenteel & 30 & 31 & 18 & 3 \\
\hline direkte & 33 & - & & \\
\hline catastrofale & 38 & 65 & - & 2 \\
\hline intern & 39 & 41 & 17 & 0 \\
\hline aktieve & 40 & 56 & 41 & 0 \\
\hline decoratieve & 44 & 45 & 3 & 2 \\
\hline professioneel & 45 & 70 & 6 & 2 \\
\hline sensationele & 47 & 61 & 7 & 2 \\
\hline intensief & 48 & 34 & 22 & 1 \\
\hline originele & 49 & 40 & 21 & 2 \\
\hline resoluut & 52 & 76 & 8 & 1 \\
\hline traditionele & 56 & 72 & 41 & 2 \\
\hline revolutionaire & 57 & 64 & 22 & 3 \\
\hline fenomenale & 61 & 73 & - & 2 \\
\hline radıkale & 62 & 46 & 16 & 1 \\
\hline ideale & 62 & - & & \\
\hline objektief & 69 & 54 & 10 & 1 \\
\hline individuele & 71 & 60 & 10 & 3 \\
\hline additionele & 72 & 58 & - & 2 \\
\hline effektieve & 73 & 57 & 16 & 1 \\
\hline spektakulaire & 76 & 51 & 16 & 2 \\
\hline exclusieve & 79 & 48 & 3 & 1 \\
\hline constante & 80 & - & & \\
\hline geniale & 81 & 46 & 9 & 1 \\
\hline potentiele & 84 & 37 & 6 & 1 \\
\hline positieve & 84 & 49 & 49 & 1 \\
\hline essentieel & 84 & - & & \\
\hline kwantıtatieve & 86 & 35 & 1 & 2 \\
\hline nationale & 88 & - & & \\
\hline strukturele & 91 & - & & \\
\hline absoluut & 93 & - & & \\
\hline primair & 96 & - & & \\
\hline ktuele & 98 & 41 & 12 & 1 \\
\hline optumale & 98 & - & & \\
\hline
\end{tabular}

SR-words

biologisch-chemische 72 niets-ontziende 80 macro-moleculaire $\quad 87$ medisch-fysisch 88 Frans-Britse 94 groen-gele 96 zelf-verricht 98 twee-voudige 98 fijn-mazig 98 welbekende 99 bovengenoemde 100 vakbekwame 


\section{Author index}

Abe, I.: 220.

Allerton, D.J.: 14, 34, 44, 89, 115 .

Andre, E.: 320.

Armstrong, L.E.: 329.

Arnold, G.F.: 19, 93, 118-9, 125, $130,194,195,202,218,220$, $226,228,230-1,238-9,242-5$, $255,267,294-5,313-4,316,318$, $320,328-9$.

Ashby, M.G.: 128.

B. : 205 .

Bald, W.D. : 121-2.

Bauer, L.: 115, 130.

Berman, A.: 12, 20-1.

Berg, B. van den: 303 .

Bing, J.M.: 5, 57, 71, 88, 98, 101, $109,113,115-7,120,122-3$, $124-6,128-9,132-7,146,155$, $231,237,248,251-2$.

Blom, J.G.: 162 .

Bloomfield, L. : 14.

Bolinger, D.: 1, 13, 30, 35, 37, 40, $47,49,63-4,183,188,194$, $199-200,202,212,216,222,236$, $249,256-7,259,296,301-2,342$.

Born, R.C.J.: 328.

Brazil, D.: 20, 57, 98, 129-30, 160, $195,202,220,226,228,248$, $252-4,261,267,278,328$.

Bresnan, J.: 12, 20, 63.

Broeders, A. : 57-8, 328, 334.
Brown, G.: 57, 65, 110, 113, 146, $161,170,196,200,261,293$, $296,320,328$.

Brown, M.D. : 163.

Bruce, G.: 260 .

Buuren, L. van: 261.

Chafe, W.L.: $12,14,65,155,320$.

Chomsky, N.: 11-12, 14, 23, 63, $155,158,169,298$.

Clark, E. V. : 58.

Clark, H.H.: 58.

Cohen, A.: 238, 243.

Coleman, H.O.: 321.

Colin, A.J.T.: 145.

Collier, R.: 7, 64, 72, 77, 186-7, $196,237,239,260,296,313-4$.

Cook, T.L.: 46.

Coulthard, M.: 20, 57, 98, 129-30, $160,195,220,252-3$.

Cruttenden, A.: $20,34,35,44$, $115,199,248,295$.

Crystal, D.: 6, 11, 57, 98-101, $107-8,111-2,115-7,120,122-3$, $124,129-31,146,185,195,218$, $220,222,238-9,248,267,294-5$, $317,319,321,325$.

Currie, K.L.: 8, 161, 170, 196, $293,296,320,322$.

Cutler, A.: 1, 197-8, 207, 254, $257,293$.

Davy, D.: 98-100, 116-7, 129, 145, 185.

Deakin, G. : 248. 
Dienhart, J.H.: 115, 130.

Dik, S.: 14, 45, 47.

Dixon, W.J.: 163.

Doodkorte, A.C.J.: 8, 177, 179, $182,190$.

Duckworth, A.P.: 145 .

Edwards, E.A.: 25.

Enkvist, N.E. : 154.

Firbas, J.: 5, 37, 101, 113, 115-6, $123-4,128,130,142$.

Fox, A.: 321 .

Fries, C.C.: 145.

Fuchs, A.: 29, 30, 44, 73, 82 .

Gandour, J.T.: 260.

Gârding, E. : 260.

Geffen, C.P.: van 190.

Gibbon, D.: 98, 220, 222.

Giegerich, H.J.: 297.

Gimson, A.C.: 130, 134, 218, 221, $298,316$.

Glenn, M.G. : 194, 248.

Gold, B. : 276.

Goldsmith, J.: 197, 213, 260.

Greenbaum, S.: $14,30,57,103$, $112,115,118,120,145,183-6$.

Grundt, A.W.: 260 .

Gunter, R.: 207, 260, 271, 278.

Gussenhoven, C.: 27, 45, 73, 88, $104,110,131,151,162,168$, $171,177,182,195,222,232$, $237,268,285,296,312,322$, 334,342 .
Halle, M.: 11, 63, 158, 169, 213, 298.

Halliday, M.A.K. : 11-2, 14, 23, 36, $42,65,102,118,120,130,139$, $151,154,170,195,197,200$, $220,252,267,294,322$.

Hart, J.'t: 7, 64, 72, 77, 186-7, $196,237-9,243,260,294,296$, 313-4.

Hartvigson, H.H.: 115, 130.

Hayes, B.: 342, 345.

Höhle, T.N.: 23.

Huckin, T.N.: 122.

Isard, S.D.: 1.

Jackendoff, R.S.: 14, 16, 54, $248-9,251$.

Johns, C.: 20, 57, 98, 129-30, 160, $195,220,252-3$.

Jones, Daniel: 134, 258, 329 .

Jones, V. : 145.

Jong, J. de: 46 .

Keijsper, C.E.: 66.

Kenworthy, J.: 161, 170, 196, 293, 296,320 .

Kingdon, R.: 130-1, 178, 195, 294, 329.

Kiparsky, P.: 297, 305.

Kraak, A.: 14, 32 .

Krijgsman, K.J. : 190.

Kruyt, T.: 64, 89.

Kvistgaard Jacobsen, L. : 115, 130. 
Ladd, D.R.: 6, 12, 14, 18, 23-4, $57-59,71,89,94,98,111,122$, $197,199,213,216,220-1,228$, $231,248,251,255,257,259-60$, $268,293,295,313,322,328$.

Lakoff, G. : 12,63 .

Leben, W.R.: 213, 217, 222, 224, 260.

Lee, W.R.: 116, 145, 328.

Leech, G.: 14, 30, 57, 103, 112, $115,118,120,145,183-6$.

Leek, F.C. van der: 58.

Lewyckyj, R.: 278.

Liberman, M.: 6, 11, 18, 58, 128 , $132,135-6,158,169,194,199$, $208,213,220,231,242,248$, $254-6,293,295-8,301-2,304-5$, $315,317,327-8,333$.

Lindström, O.: 321.

Local, J. : 145.

Lodewyckx, A.: 39.

Lyons, J.: 55.

Malmberg, B.: 260.

Mattingly, I.G.: 272 .

Nespor, M.: 169.

Nieuwint, P.: 58, 89.

Nooteboom, S.G.: 64 .

Oakeshott-Taylor, J.: 32-3, 177, 183.

O'Connor, J.D.: 19, 93, 118-9, $125,130,194-5,202,218,220$, $226,228,230-1,238-9,242-5$, $255,267,294-5,313-4,316,318$, $320,328-9$.

Osselton, N.E.: 8, 182.
Owen, E.: 269.

Paardekooper, P.C. : 43, 187.

Pakosz, M.: 247-8.

Palmer, H.E.: 93, 118, 128, 154, $195,294,328-9$.

Palmer, L.R.: 258.

Pellowe, J.: 145.

Pierrehumbert, J.B.: 116, 128, $133,136,213-4,217,221,222$, $228,234,248,259-60,267-8$, $313,317,320$.

Pike, K.L. : 6, 98, 194, 317.

Postal, P.M.: 145-6, 154.

Posthumus, J.: 178, 190.

Prince, A.: 11, 255, 296-8, 300-2, $304-5,327-8,333$.

Prince, E.F.: 14, 35, 158, 169.

Purcell, E.T.: 260.

Quirk, R.: 14, 30, 57, 98, 103, $108,112,115,118-22,129,145$, $146,183-6,294,326$.

Rabiner, L.: 276.

Rando, E.: 120.

Rijpma, E.: 78, 87.

Rippmann, W.: 297.

Rusiecki, J.P.L. : 145.

Sag, I. : 194, 199, 208, 231, 242, $246,248,254-256,293,295,315$.

Schils, E.D.J.: 3.

Schmerling, S.F.: 2, 11-15, 24 , $26-7,32,34,44,63,66,71,82$, 145,320 . 
Schubiger, M.: 115, 120, 130-1, $177,185,187,190,195,237$, 329.

Schuringa, F.G.: 78,87 .

Schultink, H. : 297, 302-3.

Searle, J.R.: 57, 194 .

Selkirk, E.O.: 5, 158, 169-70.

Sharpe, A.E. : 315-6.

Shearme, J.N.: 272 .

Siertsema, B.: 120.

Smith, H.L.: 128, 194, 259.

Sфrensen, K. : 177.

Svartvik, J.: 14, 30, 57, 98, 103, $112,115,118,120-2,129,145$, $183-6,294$.

Szamosi, M.: 12, 20, 21.

Taglicht, J.: 47.

Terken, J.M.B.: 64, 89.

Thompson, H.S.: 297.
Tibbitts, E.L.: 251.

Toorn, M.C. van der: 186 .

Trager, G.L.: 128, 194, 259.

Tregidgo, P.G.: 321.

Uit den Boogaart, P.C.: 343.

Uldal, E. : 220, 222,269, 271.

Vergnaud, J.R.: 213.

Verhagen, A.: 89.

Vogel, I. : 169.

Ward, I.C. : 297, 329.

Watters, J.R.: 45, 58.

Wells, R.S.: 194.

Weijnen, A.: 190.

Willems, N.: 220, $312,314$.

Williams, B.: 260.

Young, F.W.: 278.

Zandvoort, R.W.: 8, 177, 179, 182, 184,190 . 


\section{Samenvatting}

\section{Over de positie en de betekenis van het zinsaccent}

Dit proefschrift is een bundeling van negen artikelen die handelen over drie aspekten van het zinsaccent.

Wanneer wij spreken, leggen we op bepaalde woorden een accent. De vraag die in de eerste vijf artikelen centraal staat is hoe het komt dat die accenten op bepaalde woorden terecht komen, en niet op andere. Een oninteressant antwoord op die vraag is dit: de accenten liggen op die woorden ondat de spreker die woorden wil benadrukken, en dat wil hij omdat hij ze in de gegeven situatie voor de hoorder belangrijker vindt dan de woorden die hij niet accentueert. De moeilijkheid met dit antwoord is dat het nu lijkt alsof de taalkunde de vraag wil beantwoorden waarom mensen bepaalde dingen willen zeggen, en niet de vraag volgens welke regels de uitingen waarmee ze dat doen worden opgebouwd. Dit laatste is echter waar de taalkunde in geïnteresseerd is. In de artikelen wordt dan ook geprobeerd de zinsaccenten en betekeniscategorieën in de taal (waarvan die spreker gebruik moet maken om zijn bedoelingen over te brengen) aan elkaar te relateren door middel van regels, die het gebruik van de betekeniscategorieën vertalen in accenten op bepaalde woorden. Uit de beschrijving blijkt dat het bovengenoemde antwoord niet alleen oninteressant is, maar ook onjuist: vaak liggen de accenten op woorden die de spreker beslist niet het belangrijkst vindt.

De zinsaccenten kunnen op verschillende manieren worden uitgesproken, of, anders gezegd, voor elk zinsaccent kunnen we een aantal verschillende 'tonen' gebruiken. In het zesde en zevende artikel wordt geprobeerd de tonen van het Engels in te delen, zodanig dat een classificatiesysteem ontstaat warmee elke toon kan worden benoemd. Het classificatiesysteem geeft tegelljk de betekenisaspecten van de tonen aan. Als we weten hoe een toon geclassificeerd wordt, kunnen we ook de betekenis ervan afleiden. Die betekenissen blijken nogal vaag: het algemene betekeniseffect dat een bepaalde toon in een bepaalde uiting teweegbrengt komt in hoge mate tot stand in samenwerking met de betekenis van de woorden in de uiting en met de veronderstellingen die we als hoorder hebben over waarom de spreker juist deze woorden met deze toon in deze situatie gebruikt. In dit laatste verschilt de betekenis van intonatie overigens niet principieel van de betekenis van woorden (inclusief grammaticale aspecten als vormen van het werkwoord).

Het derde aspect, behandeld in de laatste twee artikelen, betreft de verschuiving van accenten in woorden, zoals dat bijvoorbeeld voorkomt in keihard, onjuist enz., welke woorden in combinatie met een volgend woord een accentverschuiving ondergaan van het eerste naar het tweede woorddeel (bijv. van -hard naar kei- in een keihard argument). Er worden voor het Nederlands vier van zulke regels gejdentificeerd. Een ervan wordt aan een nader onderzoek onderworpen. Le regel betreft de verschuiving in enkelvoudige woorden als politiek, vocaal, professioneel. Er wordt aangetcond dat de verschuiving hier vaker optreedt naarmate de spreker zich wervender opstelt, d.w.z. een retorischer stijl hanteert. Hiermee wordt geülustreerd dat variatie in intonatiekenmerken net zo goed als variatie in andere uitspraakaspecten kan worden gebruikt om meer informatie te geven dan uit de woorden alleen is op te maken. 



\section{Curriculum vitae}

Carlos Gussenhoven was born in Amsterdam on 19 July 1946, where he attended the St Ignatius College (Gymnasium $\alpha$ ) He studied English Langusge and Literature at the University of Amsterdam from 1964 to 1971 , spending the academic year $1967 / 8$ at the University of Edinburgh He has been teaching at the Instituut Engels-Amerikaans of the University of Nijmegen since 1971 From 1981 to 1983 he was engaged in research at the Un1versity of Edinburgh and the University of Nijmegen, of which this thesis is the result He has published in the field of phonetics and phonology and co-authored two books on the pronunciation of English 

'Compound tones' bestaan niet. (Dit proefschrift)

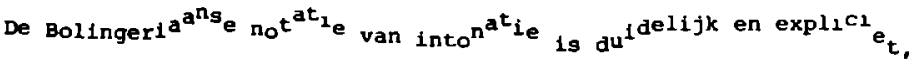
mear

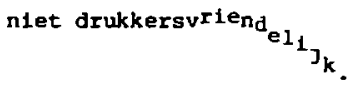

Voor de beantwoording van de vraag of de intonatie van een citaat dezelfde is of moet zijn als die van het oorspronkelijke taalprodukt (bIjv. Partee 1973:411) is het van belang te weten of het citaat de rapportage van het gebruik van een ulting betreft of de rapportage van het begtaan van een zin. Alleen in het tweede geval zal de hoorder de spreker van het cltaat verantwoordelijk kunnen achten voor de betekenıs van de intonatıe van de oorspronkelıjke $\mathrm{z}$.

Partee, B. Hall (1973) 'The syntax and semantics of quotations'. In S.R. Anderson \& P. Kiparsky (edd) Festschrift for Morris Halle. New York.

IV

Hoewel de notie 'accentverlenende toonhoogtebeweging' natuurlijk geinterpreteerd moet worden binnen het kader van de door 't Hart a Collier (1975) opgestelde grammatica van de intonatie van het Nederlands, blifft hij lets ongemakkelijks houden in het licht van van Katw1 jks bevinding dat 'there are cases where a listener has to assign intonation structure to an utterance before he can decide on the accent structure' (1974:99).

Hart, J. 't \& R. Collıer (1975) 'Integratıng different levels of intonation analysis'. Journal of Phonetics 3, 235-55.

Katw1jk, A. van (1974) Accentuation in Dutch: An experimental 1inguistic study. Proefschrift Utrecht.

v

Ook aan de schrijfwljze niet, nú, hóe kan men zien dat sprekers van het Nederlands de fonetisch korte klinkers / $1, Y, u /$ indelen bij de fonologisch lange: vergelijk dit, mèt, gùn, off, wàt met méé, léuk, voooór. dáár. 

Het feit dat anders dan men op grond van andere onderzoekingen zou verwachten en anders dan het geval blijkt bij Nederlandse fricatieven in andere posities, mannen een hogere waardering hebben dan vrouwen voor het voorkomen van de standaardvarlant van frlcatieven in consonantclusters yan het type frlcatief + stemhebbende plosief (bijv. [z] in plaats van [s] In asbak), kan worden uitgelegd als bevestiging van de stelling van slis (1984) dat de varıatle in stemhebbendheid in deze Nederlandse clusters voornavelijk fysiologisch bepaald is.

S1is, I.H. (1984) 'Assimllation of volce in Dutch'. Proceedings of the Xth International Congress of Phonetic Sciences. Dordrecht.

VI I

Stellingen in proefschriften zijn meestal definitionele zinnen, zoals stelling I hlerboven, of eventualiteitszinnen, zoals stelling II hierboven, zelden eventleve zinnen, zoals de volgende stelling.

VIII

Als na talloze en langdurige vergaderingen over toekenning, organisatıe en begelelding van onderzoek het werk gedaan moet worden, is er qeen terminal vrij, of is de connecttijd op.

Stellingen behorende biJ het proefschrift 'On the grammar and semantics of sentence accents' door C.H.M. Gussenhoven. 




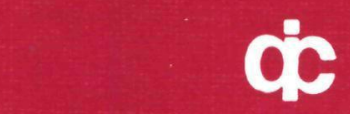

Printed by ICG Printing, Dordrecht 